Towards Deciphering Metamorphic Reaction Kinetics through Porphyroblastic Textural Analysis in the Bugaboo Contact Aureole (South Eastern British Columbia, Canada)

by

\title{
Arianne Petley-Ragan
}

A thesis submitted to the Faculty of Graduate and Postdoctoral Affairs in partial fulfillment of the requirement for the degree of

\section{Master of Science}

in

\section{Earth Science}

\author{
Carleton University \\ Ottawa, Ontario \\ (C) 2015 \\ Arianne Petley-Ragan
}




\section{$\underline{\text { Abstract }}$}

The relative rate of intergranular diffusion and interfacial attachment of chemical species during low-pressure metamorphic reactions is determined through analyzing the texture of porphyroblastic phases in the Bugaboo contact aureole. The observed mineral assemblages are predicted to be in equilibrium from $500-590^{\circ} \mathrm{C}$ at $1.60 \mathrm{kbar}$ with graphite and a $\mathrm{COH}$-bearing fluid. Porphyroblasts of $\mathrm{Bt}$ + And $+\mathrm{Crd} \pm \mathrm{Pl}$ within the outer aureole display syn-kinematic growth textures while the inner aureole consists of pre-kinematic Bt + And $+\mathrm{Crd}+\mathrm{Kfs}$ porphyroblasts. Chemical homogeneity of Bt + Crd across the aureole, along with similar chemistries for prograde and retrograde Chl, indicate chemical equilibration during retrograde metamorphism. Mineral chemistries therefore do not provide reliable P-T estimates for incipient porphyroblast crystallization, peak metamorphism nor the relative rate between reaction processes. The threedimensional spatial distribution of Bt + Crd porphyroblast centers and sizes from the outer aureole is obtained using XR- $\mu \mathrm{CT}$ to study the effects of metamorphic reaction processes on resultant porphyroblastic texture. Mineral texture is shown to be more reliable over mineral chemistry when deciphering the kinetics of metamorphic processes. 


\section{$\underline{\text { Acknowledgements }}$}

This project would not have been completed without the assistance of my superiors, co-workers, friends and family. My supervisor, Dr. Fred Gaidies, has provided support and encouragement since the $2^{\text {nd }}$ year of my undergraduate degree and continues to challenge my knowledge everyday. This project would not have been possible were it not for Fred's fascination in my results and his constant belief in my success. To Dave Pattison, Brett Hamilton and Rajeev Nair for accompanying us to the Bugaboos and helping to collect hard-to-reach samples. Special thanks again to Dave Pattison and Chris DeBuhr for providing the majority of samples that were the focus of this thesis. Without my visit to the University of Texas at Austin I would not have met Richard Ketcham, Romy Hanna and Matthew Colbert, who I would like to thank endlessly for suggesting the unique method of segmentation that I used. An additional thanks goes to Peter Jones for taking the time to chemically analyse inclusion-free cordierite spots in order to achieve reliable results.

My office mates, Carolyn Dziawa and Freya George, were the best of company during the past year, offering a different perspective on complex metamorphic theories. Thanks to all the graduate students in Earth Science who were there when I was in need of a break, as well as the undergraduate students whose constant questioning would not have kept my mind sharp and I would not have realized my passion for teaching. Finally, I would like to thank my parents, sister, extended family and best friends for accepting my passion for "looking at rocks"! 


\section{$\underline{\text { Table of Contents }}$}

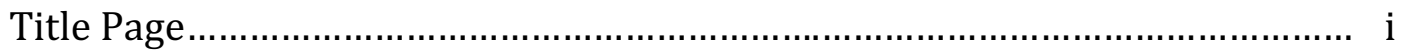

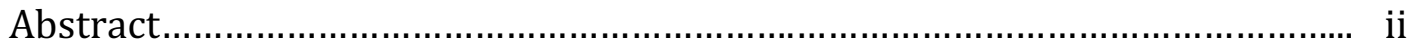

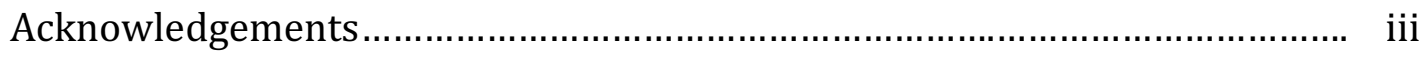

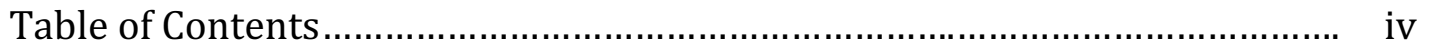

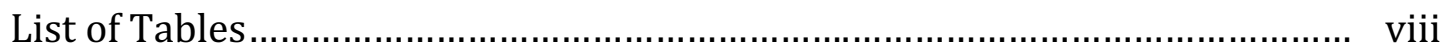

List of Illustrations................................................................................ viii

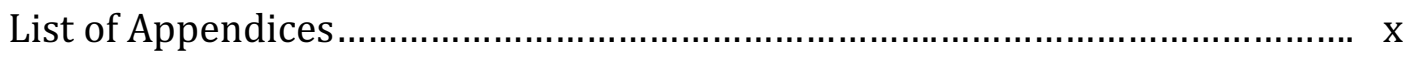

Chapter 1: Textural Analysis as a Means of Interpreting Metamorphic

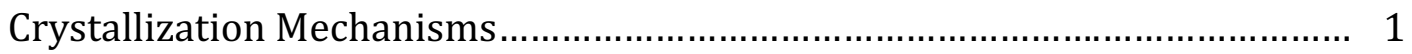

1.0 Purpose of Thesis ............................................................... 1

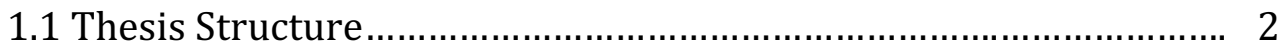

1.2 Background Information ................................................. 3

Chapter 2: Petrography, Phase Equilibria and X-Ray Attenuation of Mineral Assemblages in the Bugaboo Contact Aureole ................................................. 8

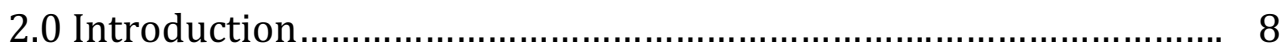

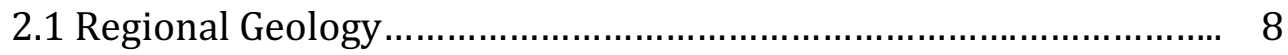

2.1.1 The Bugaboo Batholith ......................................... 10

2.1.2 Cobalt Lake Field Locality ....................................... 13

2.2 Previous Work on the Bugaboo Contact Aureole........................ 15

2.2.1 Metamorphic Zones at Cobalt Lake.............................. 15 
2.2.2 Bulk Rock and Mineral Chemistry ................................... 18

2.2.3 The Reaction: $\mathrm{Ms}+\mathrm{Crd}=\mathrm{Bt}+\mathrm{And}+\mathrm{Qtz}+\mathrm{H} 2 \mathrm{O} \ldots \ldots \ldots \ldots \ldots . .21$

2.3 Methods.............................................................................. 22

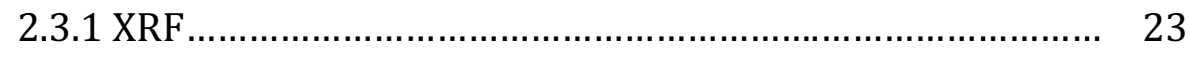

2.3.2 Phase Equilibria.......................................................... 23

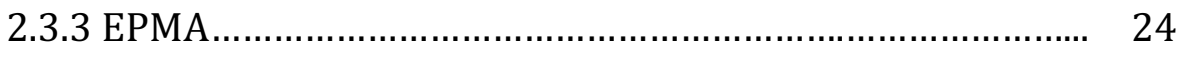

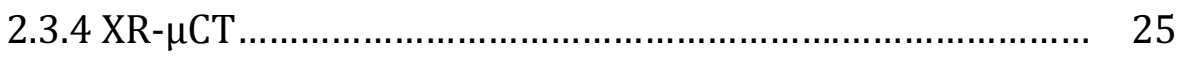

2.3.5 Segmentation ........................................................ 30

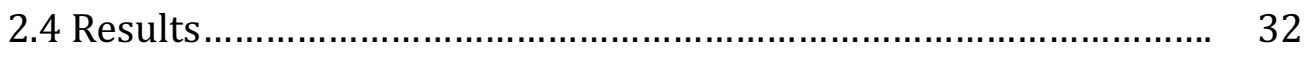

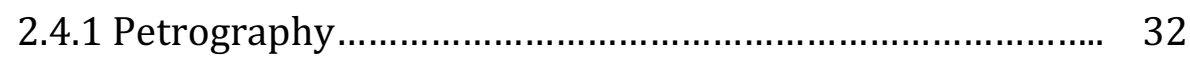

Outer aureole........................................................... 36

(1) And-Chl.................................................. 36

(2) Bt-And-Crd-Chl....................................... 36

Middle aureole ....................................................... 38

(3A) Bt-And-Crd porphyroblasts........................ 38

(3B) Bt-foliated matrix....................................... 39

(3C) Pre-kinematic And-Crd............................ 40

Inner aureole ........................................................ 41

(4) Kfs-Bt-And-Crd ......................................... 41

2.4.2 Cordierite and Chlorite Chemistry .................................... 42

2.4.3 Phase Equilibria................................................................. 44

Effects of a C-O-H Fluid............................................... 44

Predicted Equilibrium Assemblages ................................. 47 
Cordierite and Biotite Isopleths ..................................... 51

2.4.4 Computed Tomography ………………………….......... 55

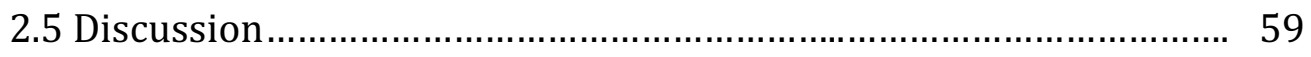

2.5.1 Prograde Metamorphic Mineral Growth........................... 59

2.5.2 Retrograde Metamorphism............................................. 62

2.5.3 Structural Relationships and Aureole Kinematics............ 64

2.5.4 Determining a P-T Path.................................................... 65

2.5.5 The Mg\# of Cordierite and Biotite........................................ 68

2.5.6 Visibility of Porphyroblasts in CT .................................... 69

Cordierite in CT_009................................................ 70

Cordierite in CT_033 and CT_041…………………..... 71

Andalusite in CT_044 and CT_045 ................................. 72

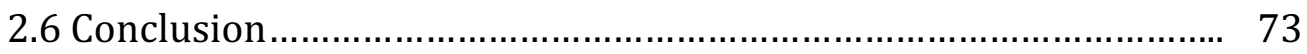

Chapter 3: A Statistical Analysis on the Distribution of Cordierite and Biotite from the Bugaboo Contact Aureole: Implications for Metamorphic Nucleation and Crystal Growth of Porphyroblasts....................................................................... 75

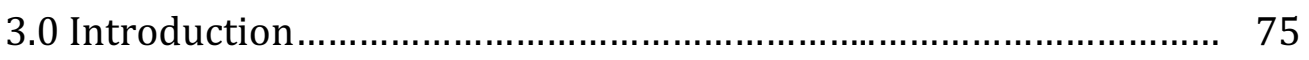

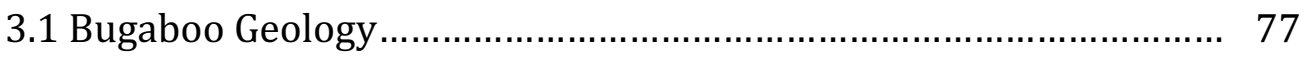

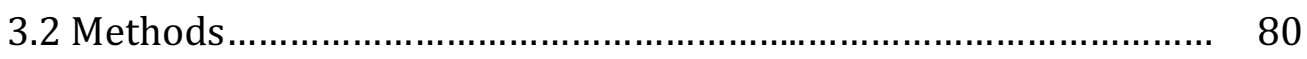

3.2.1 XRF and Theriak/Domino ............................................... 80

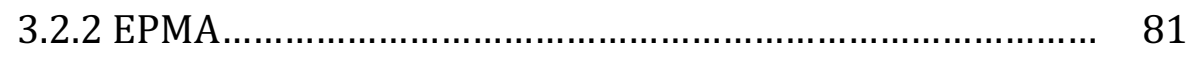

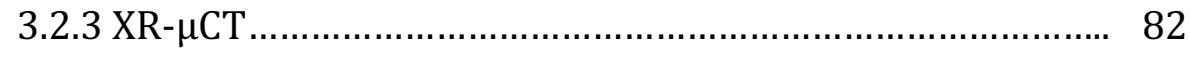




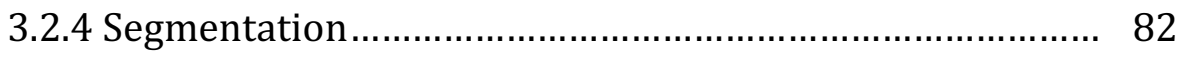

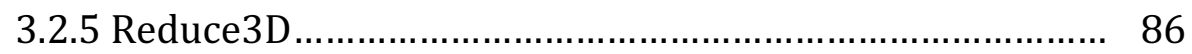

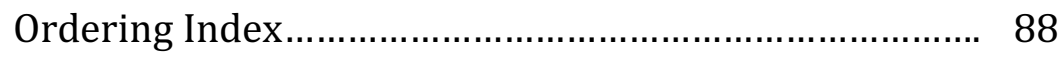

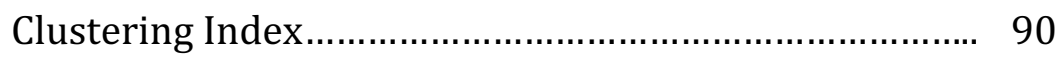

Impingement Index ............................................... 90

Isolation Index...................................................... 91

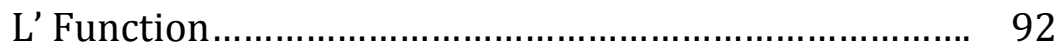

Pair Correlation Function........................................... 92

Mark Covariance Function......................................... 93

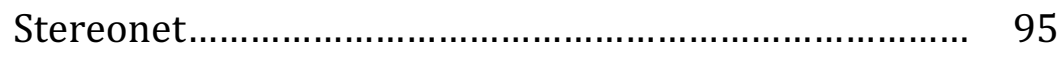

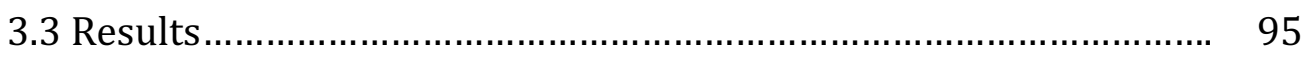

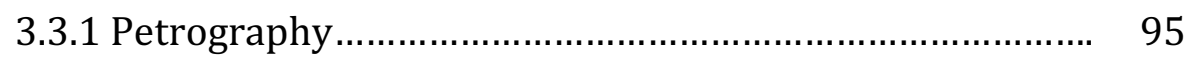

3.3.2 Phase Equilibria......................................................... $\quad 97$

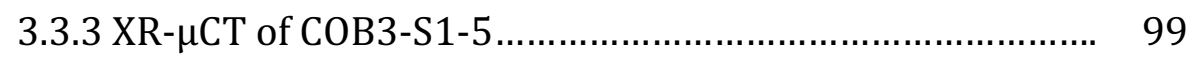

3.3.4 Mineral Chemistry ........................................................ 103

3.3.5 Quantification of Cordierite and Biotite......................... 105

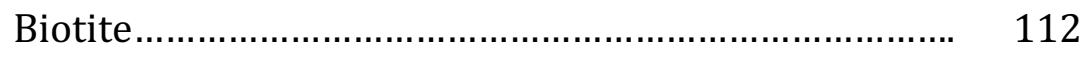

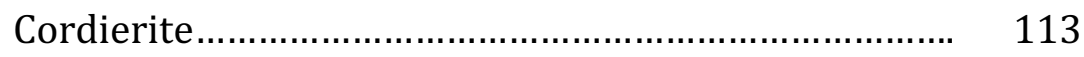

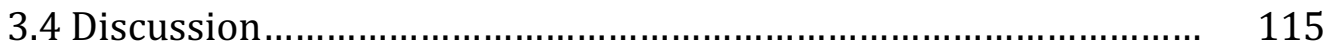

3.4.1 Clustering of Porphyroblast Centers.............................. 117

3.4.2 Ordering of Porphyroblasts........................................... 120

3.4.3 Considering Elongation of Porphyroblasts..................... 122

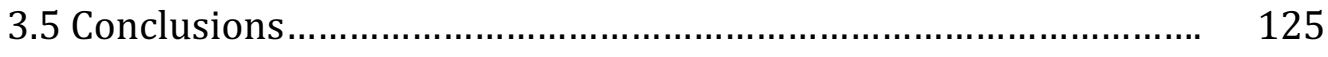


Chapter 4: Concluding Thesis Remarks..................................................... 127

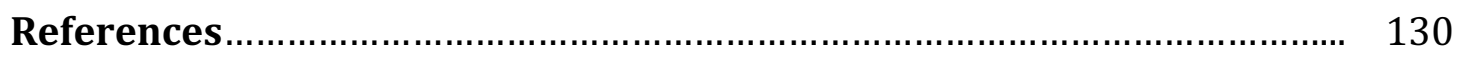

List of Tables

2-1 Metamorphic zones found at Cobalt Lake 17

2-2 Bulk rock compositions of Bugaboo samples (mol. \%) 20

2-3 CT scan settings for each sample 27

2-4 Average cordierite chemical analyses from Zone 2 (Mg\#) 43

2-5 Chlorite chemical analyses from COB3-S1-5 (cation number) 44

2-6 Predicted P-T conditions for Bugaboo samples 48

3-1 Bulk rock composition of COB3-S1-5 (mol. \%) 81

3-2 Error calculations for orthogonal slice segmentation 86

3-3 Chemical analyses of Crd, Bt and Chl (cation number) 103

3-4 Reduce3D data for cordierite 106

3-5 Reduce3D data for biotite 106

\section{List of Illustrations}

2-1 Location of the Bugaboo batholith in south eastern British Columbia 9

2-2 Morphology of the Bugaboo batholith and contact aureole 11

2-3 Metamorphic zones of the Bugaboo contact aureole at Cobalt Lake 14

2-4 AFM and ACF plots of the Bugaboo bulk rock compositions 19

2-5 Mg\# values for Crd, Bt and Chl throughout the Bugaboo aureole $\quad 21$

2-6 Petrography photographs of representative samples from each zone 33-35 
2-7 Phase equilibria illustrating the effect of a $\mathrm{COH}-$ fluid 46

2-8 Phase equilibria for representative samples from each zone 49

2-9 Mg\# isopleths for Crd and Bt within Zone 2 52

2-10 Mg\#-T and V-T graphs for Crd, Bt and Chl within Zone 2

2-11 CT slice images of samples with visible porphryoblasts 57

2-12 Linear X-ray attenuation of mineral phases in COB3-S1-5 58

3-1 Location of the Bugaboo contact aureole in south eastern British Columbia $\begin{array}{ll}\text { and sample locality of COB3-S1-5 at Cobalt Lake } & 78\end{array}$

3-2 CT image of COB3-S1-5 produced by NRecon 83

3-3 Blob3D images showing orthogonal slice segmentation 85

3-4 Reduce3D scale-dependent statistics illustration 89

3-5 Petrography photographs of COB3-S1-5 96

3-6 Phase equilibrium diagram for COB3-S1-5 98

3-7 Linear X-ray attenuation of phases in COB3-S1-5 100

3-8 CT image and corresponding thin section of COB3-S1-5 102

3-9 Chemical profiles analyses across Crd in COB3-S1-5 104

3-10 Cordierite quantification using volume and aspect ratio 107

3-11 Biotite quantification using volume and aspect ratio 108

3-12 Reduce3D statistical results for cordierite 109

3-13 Reduce3D statistical results for biotite 110

3-14 Stereonet plots for cordierite and biotite 111

3-15 Linear X-ray attenuation of Crd chemistries and densities 116 
List of Appendices

Appendix I: Thermodynamic Database (tcdb55c2_COH_prltbi2) 136

Appendix II: Chemical Profiles of Cordierite from Zone 2

COB3-S1-5 147

COB3-S1-7 153

COB-6 157

Appendix III: Rock Specific Phase Equilibria 160

COB-14 161

COB3-S1-1 162

COB3-S1-2 163

COB3-S1-5 164

COB3-S1-7 165

COB3-S1-8 166

COB3-S1-10 167

COB3-S1-12 168

COB3-S1-15 169

COB-6 170

COB-9 171

COB-10 172

COB-12 173

COB-25 174

COB-27 175

COB-29 176

COB-31 177

COB2-S2-1 178

COB2-S2-2 179

COB2-S2-4 180

COB2-S2-6 181

COB2-S2-7 182

COB2-S2-9 183 


\section{CHAPTER 1}

Textural Analysis as a Means of Interpreting

Metamorphic Crystallization Mechanisms

\subsection{Purpose of Thesis}

The aim of this research is to quantify the texture of porphyroblasts from a suite of contact metamorphic rocks by using computational techniques that aid in unraveling their formation history. The Bugaboo contact aureole in south-eastern British Columbia, Canada, was chosen because the rocks are well exposed and previous work has shown that these rocks contain intriguing features for studying metamorphism (DeBuhr, 1999; Pattison et al., 2002; Pattison et al., 2011; Pattison and DeBuhr, 2015). The study of low pressure metamorphic settings of relatively isobaric pressure-temperature (P-T) paths allows for the isolation and study of the effects of temperature on porphyroblast nucleation and crystal growth.

The dominant aureole porphyroblasts (biotite and cordierite) are observed to not change chemically from low to high grade, which is not expected through equilibrium thermodynamic modelling. This observation has been interpreted to represent slow Fe-Mg ion exchange between the phases and chemical disequilibrium upon crystallization (Pattison et al., 2002; 2011). Rapid heating in an isobaric metamorphic setting may have resulted in a significant degree of overstep (departure from equilibrium) for the biotite- and cordierite-producing reactions. This may have resulted in mineral chemistries that signify a lower $\mathrm{T}$ equilibrium than what was actually experienced due to slow chemical diffusion that cannot 
sustain the rapid $\mathrm{T}$ increase. If a significant amount of overstepping occurred, the relative rate of metamorphic reaction processes may be reflected in the spatial and size distribution of the resultant porphyroblasts. When modelling rock systems and crystal growth the relative rates between sequential atomic scale mechanisms (e.g.; diffusion and interface processes) are not considered, and it is the slowest step that will control overstepping, the rate of crystallization and the porphyroblasts' distribution. Understanding the true rate-controlling step will provide more information on the metamorphic environment in which the rock formed.

Furthermore, cordierite is a mineral that has never been texturally examined through computed tomography (CT). Combining the analysis of cordierite with that of biotite porphyroblasts in the same rock adds valuable information that has only been conducted once before with garnet and biotite (Hirsch and Carlson, 2006). Therefore, this thesis not only presents a new method of extracting CT data but also greatly contributes to the growing field of quantitative metamorphic texture analysis.

\subsection{Thesis Structure}

The thesis is structured into two main chapters; Chapter 2 describes the petrography, phase equilibria and CT data for all the collected samples from the Bugaboo contact aureole, while Chapter 3 goes into detail on a select sample from the outer aureole that was used to quantify the texture of biotite and cordierite porphyroblasts. Chapter 2 is written in a thesis format while Chapter 3 is written in paper format. Important background information on metamorphic reaction 
mechanisms will be presented in the remainder of this chapter and conclusions for the entire thesis are drawn together in Chapter 4.

\subsection{Background Information}

The term texture is used here to define the spatial and size distribution of minerals whereas in other works it may encompass whole rock fabric and microstructure. The research of metamorphic nucleation and crystallization mechanisms through mineral texture analysis has been ongoing since the 1960's (Galwey and Jones, 1963; Kretz, 1966; 1969), although a quantitative understanding of the processes that take place during the transformation and recrystallization of rocks is still scarce. We know the basics of metamorphism; a mineral becomes energetically unstable at certain conditions and reacts to produce a new energetically more favourable mineral, but what are the sub-reaction processes that control the position of the product mineral in the rock space? What factors determine its shape, orientation and relationship to other minerals? What allows some minerals to grow larger than others? All of these factors make up the texture of a metamorphic rock and there are underlying reasons for their development. Deciphering texture is important for sedimentary and igneous rocks as well, shedding light on the depositional environment of sediments and the volcanic or plutonic settings of solidified magma, and so the examination and interpretation of rock texture is crucial across many geological fields. Here, a brief review of what we already know about the formation of metamorphic textures in relation to mineral nucleation and growth will be presented. 
When a mineral leaves the thermodynamically stable phase assemblage, a number of processes must occur prior to the complete crystallization of a new phase; (1) the dissolution of the reactant phase and (2) the nucleus formation of the product phase, with (3) diffusion of elements away from the reactant, through the rock towards the product nucleus where (4) the elements are attached to the growing crystal structure (Kretz, 1974; Fisher, 1978; Carlson, 1989). Once the nucleus has reached a critical size crystal growth takes over until the reaction goes to completion. These processes occur simultaneously with nucleation ongoing as long as the product phase assemblage reduces the Gibbs free energy of the entire system. However, product phases will not begin to nucleate until there is a substantial amount of energy to form their surfaces. This amount of energy is a function of interfacial energy (Gaidies et al., 2011) and reaction affinity or driving force (Pattison et al., 2011) and will not accumulate unless a departure from equilibrium, called overstepping, is experienced.

The rates of nucleation and crystal growth in a rock are controlled by the slowest atomic-scale process, either diffusion through the rock matrix or attachment at the crystal surface, since both dominate processes (1) through (4). If attachment at the crystal interface is faster than diffusion, the reaction is diffusioncontrolled and a chemical potential gradient around growing nuclei and crystals is expected (Carlson, 1989; 1991). The formation of a chemically depleted halo surrounding a product phase reduces the probability of the nucleation of another product phase. This is because the halo has a low chemical affinity as a result of its deficiency in chemical nutrients. If nucleation of a second crystal were to occur 
within the proximity of an already growing crystal, their depletion haloes may impinge and crystal growth would slow down since they are both attempting to draw nutrients from the same region. This leads to an ordered distribution where the largest crystals are more isolated and the smallest are closely spaced, creating a positive correlation between size and distance at the scale of neighbouring crystals.

On the other hand, if diffusion through the rock is fast and the attachment of elements to the growing crystal surface is the rate-limiting step, then a chemical potential gradient at the crystal surface is expected (Kretz, 1974; Lasaga, 1998; Gaidies et al., 2011). This is known as an interface-controlled reaction rate and would allow neighbouring crystals to grow to their full extent with little competition for nutrients, leading to a random distribution of crystal size and no correlation between size and distance. Of course, the expectation that diffusion-control leads to an ordered texture and that interface-control leads to a random texture is based on the assumption that the probability for nucleation is everywhere the same, creating a random distribution of nucleation sites or crystal centers. If this assumption is not true, crystals may display a clustered texture, possibly representing a heterogeneous distribution of chemical nutrients in the protolith.

Another suggested rate-controlling step is the rate of energy input into the rock that drives the reaction, such as heating (Fisher, 1978; Carlson, 1989). This is theorized to produce a random distribution of nucleation sites (Carlson, 1989), but since both chemical diffusion and attachment are thermally activated mechanisms, the relative rate between them will remain the determining factor in what controls the kinetics of crystal growth (Daniel and Spear, 1999). 
Distinguishing between ordering, clustering and random textures requires measuring the spacing between all crystals, the abundance of crystals spaced at specific distances and the size of crystals spaced at specific distances. This type of analysis was first conducted in the field of biology for studying the distribution of trees in a forest (Clark and Evans, 1954). Although this is limited to two-dimensions (2D), there are similarities between the consumption of nutrients by growing trees and the consumption of chemical elements by growing crystals. Soon enough, the statistical analysis of 2D point distributions was applied to crystalline rocks (Galwey and Jones, 1963; Kretz, 1966; 1969; Fisher, 1978; Carlson, 1989; 1991; Jerram et al., 1996; Rudge et al., 2008; Jerram and Cheadle, 2000).

The collection of three-dimensional (3D) data; $x-y-z$ coordinates of crystal centers, crystal volume and crystal orientation, is possible with high resolution CT scanners (Denison et al., 1997a) and has allowed for the statistical analysis of textures in 3D. Software has been created that allows for the extraction of minerals from CT data and their quantification, such as Blob3D (Ketcham, 2005). Reduce3D (Hirsch, 2000) measures crystal spacing and correlates this with crystal size before comparing the results to a null hypothesis of what would be obtained if the same crystal population had a perfect random distribution of interface-controlled growth. The deviation from random may be towards clustering, when crystals are more closely spaced at a specific distance, or ordering, where crystals are more spaced apart and there is a correlation between size and distance. The scale-dependence of the statistics calculated with Reduce3D allows for the specific scale of a porphyroblastic texture to be determined and has shown that more than one 
texture can dominate the texture of a porphyroblast population. Textural analysis of metamorphic mineral populations provides a substantial amount of new information for the interpretation of reaction mechanisms and has opened many doors to the understanding of porphyroblast nucleation and crystal growth that will eventually lead to better predictions and models of dynamic rock transformations. 


\section{CHAPTER 2}

Petrography, Phase Equilibria and X-Ray Attenuation of Mineral Assemblages in the Bugaboo Contact Aureole

\subsection{Introduction to Chapter}

This chapter gives a detailed description of the geology of the region surrounding the Bugaboo batholith and its contact aureole with an in depth investigation of the petrographic textures and kinematics of the aureole rocks. Equilibrium phase diagrams are presented that provide P-T constraints for the different metamorphic zones and mineral assemblages of the aureole which led to an approximate position of the metamorphic path experienced by the rocks. A number of samples displayed porphyroblasts through XR- $\mu \mathrm{CT}$ and a possible explanation for their visibility is discussed.

\subsection{Regional Geology}

The Bugaboo contact aureole is located in the Purcell Mountains of southeastern British Columbia (Fig. 2-1A). The Purcell Mountains consist of Proterozoic meta-sedimentary rocks part of the western-most sliver of the Foreland Fold and Thrust Belt that is pressed against the accreted terranes of the Omineca Crystalline Belt further west. The meta-sedimentary rocks make up the Purcell and Windermere Supergroups that were originally deposited along the western margin of the North American craton prior to Cordillera construction. During orogenesis the Purcell and Windermere Supergroups deformed into the Purcell anticlinorium, a 


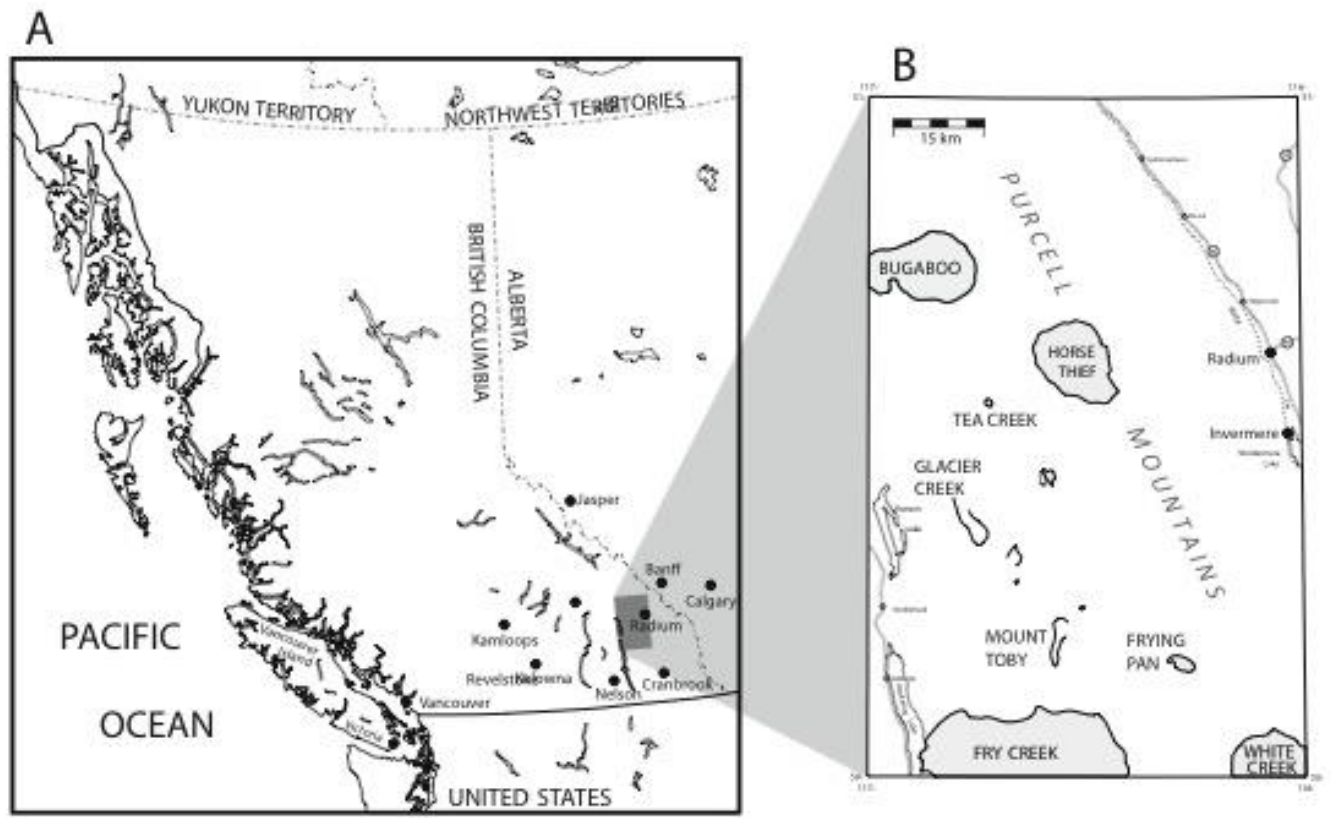

Figure 2-1. (A) Location of the Purcell Mountains in south-eastern British Columbia, Canada and (B) the position of the Bugaboo batholith and contact aureole. The Bugaboo batholith is part of a suite of granitoid intrusions west of Radium. Edited after DeBuhr (1999).

400-km-long series of NE-SW-trending anticlines (Cook and Van der Velden, 1995). The sediments underwent regional metamorphism with increasing grade towards the SW, transitioning from lower greenschist to lower amphibolite facies (Reesor, 1973).

The Purcell Supergroup is a sequence of interlayered slate, argillite, quartzite and limestone with meta-diorite sills cross-cutting the entire succession. The Windermere Supergroup unconformably overlies the Purcell Supergroup and can be subdivided into the Toby Formation of dominantly quartzite, and the Horsethief Creek Group of which the majority is metapelite (Reesor, 1973; DeBuhr, 1999).

Granitoid bodies are scattered within the Purcell and Windermere Supergroups as syn- to post-kinematic intrusions that have superimposed contact 
aureoles on the regional metamorphic features (Fig. 2-1B). Late syn-kinematic intrusions, such as the Mount Toby, Glacier Creek, Tea Creek and Frying Pan stocks, trend parallel to the Purcell anticlinorium and are locally gneissic along their margins (Reesor, 1973). Further west of Figure 2-1B lies the Nelson and Kuskanax batholiths, which together with the stock intrusions occurred during a mid-Jurassic magmatic episode 175-162 Ma (Brandon and Lambert, 1993). The Bugaboo, Fry Creek, Horsethief Creek and White Creek batholiths are mid-Cretaceous intrusions of 115-106 Ma that overprint the pre-existing structures of the Purcell anticlinorium (Reesor, 1973; Archibald et al., 1983; Brandon and Lambert, 1993). This younger magmatic period resulted in dominantly granodiorite to granite bodies and has been proposed to be the product of crustal anatexis from overthickening of the crust (Brandon and Lambert, 1993).

\subsubsection{The Bugaboo Batholith}

The Bugaboo batholith is a steeply dipping composite granitic intrusion that covers approximately $130 \mathrm{~km}^{2}$ (Fig. 2-2). The batholith is comprised of hornblendebiotite granodiorite to the west (Reesor, 1973) and biotite granite to the east (Brandon and Lambert, 1993; DeBuhr, 1999). The biotite granite is porphyritic with phenocrysts of potassium feldspar and a matrix of 5 vol. \% biotite, 25 vol. \% quartz and 35 vol. \% each of potassium feldspar and plagioclase (Reesor, 1973; DeBuhr, 1999). Altered plagioclase encloses randomly oriented secondary muscovite crystals while biotite is being replaced by both muscovite and chlorite (Brandon and Lambert, 1993). The hornblende-biotite granodiorite is aphanitic to phaneritic with 
approximately 5 vol. \% hornblende, 10 vol. \% biotite, 15 vol. \% potassium feldspar, 20 vol. \% quartz and 50 vol. \% plagioclase (Reesor, 1973). The Fry Creek, Horsethief Creek and White Creek batholiths consist of biotite granite that is similar to what is found in the Bugaboo batholith (Reesor, 1973; Brandon and Lambert, 1993). A thorough petrographic investigation of the batholith rocks was not done for this thesis.

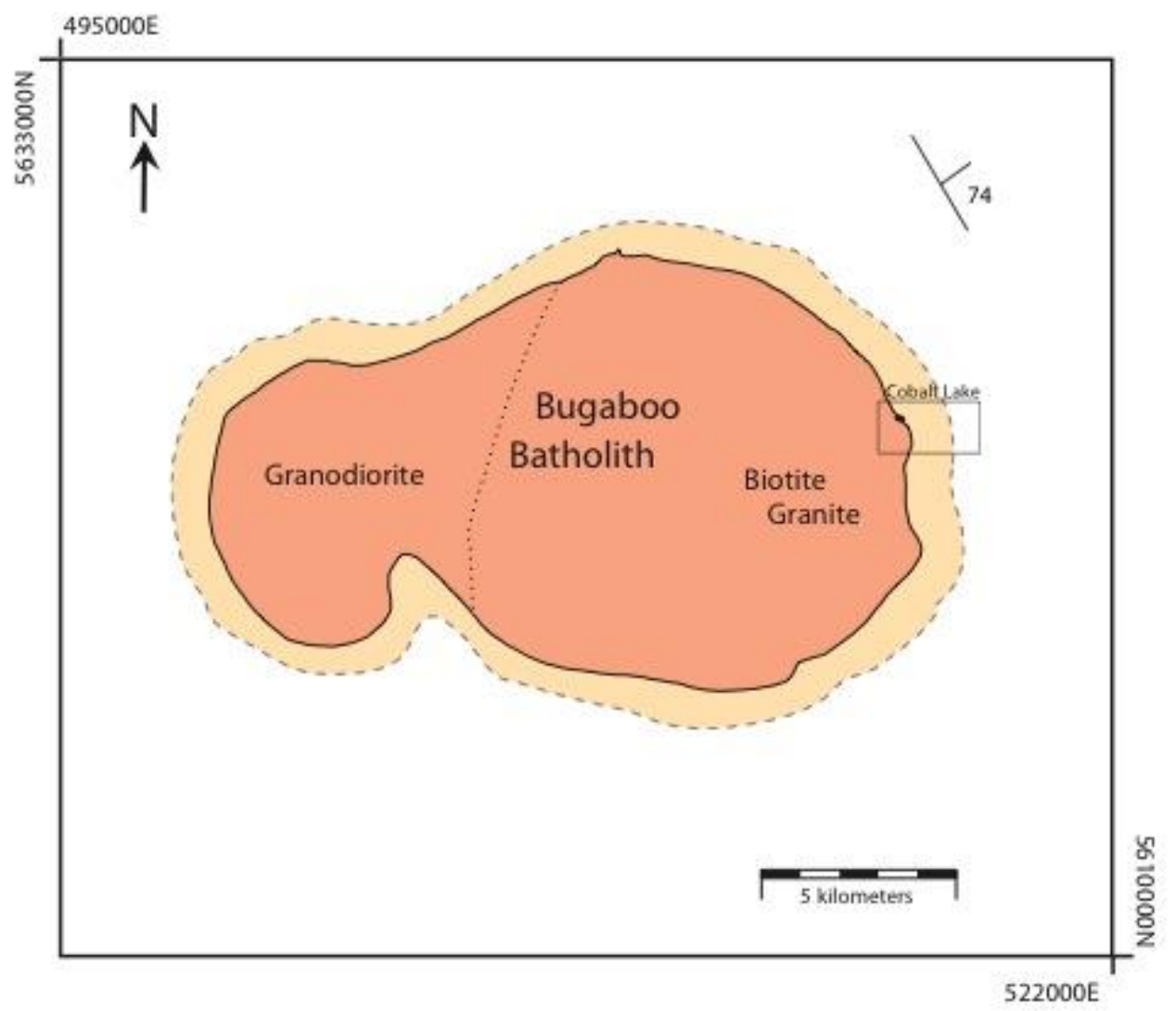

Figure 2-2. Morphology of the Bugaboo batholith and the approximate location of its $1 \mathrm{~km}$ wide contact aureole. Cobalt Lake is located along the eastern margin of the batholith where the contact is relatively parallel to the regional metamorphic foliation of $336 / 74 \mathrm{NE}$. The batholith is comprised of granodiorite and biotite granite. Edited after DeBuhr (1999).

Inclusions of the hornblende-biotite granodiorite within the biotite granite were noted by Reesor (1973), suggesting the eastern portion of the batholith followed emplacement of the western portion. Conclusively, the intrusion may have 
occurred as two successive magmatic events. Geochronology based on Rb-Sr of whole rock apatite provides an age of $107 \pm 5$ Ma for the biotite granite (Brandon and Lambert, 1992), whereas K-Ar ages of biotite are $93.5 \pm 1.5$ Ma for the biotite granite and $89.1 \pm 1.9$ Ma for the hornblende-biotite granodiorite (Archibald et al., 1984). These younger ages contradict field relationships observed by Reesor (1973) and may instead represent final cystallization ages upon cooling (Pattison and DeBuhr, 2015). Post-kinematic plutons further south (Fry Creek and White Creek in Fig. 2-1B) give younger biotite $\mathrm{K}-\mathrm{Ar}$ ages of 65-55 Ma which have been interpreted by Archibald et al. (1984) to indicate late thrusting within the Purcell anticlinorium. This late deformation phase may have also been weakly experienced by the Bugaboo batholith and its contact aureole. Xenoliths of Horsethief Creek Group metapelite and Precambrian basement are also present in the eastern portion of the batholith (Brandon and Lambert, 1993).

Previous observations on the mineralogy of the contact aureole surrounding the Bugaboo batholith, and its neighbouring intrusions, have suggested a depth of 7$11 \mathrm{~km}$ for initial emplacement. This corresponds to approximately 2.3-3.8 kbar (Archibald et al., 1983; Brandon and Lambert, 1993). Recent work has confined pressure estimates to 3.0-3.3 kbar based on thermodynamic modeling of mineral assemblages and comparison to the reaction sequence within the aureole (Pattison and DeBuhr, 2015). The current study will also provide new P-T estimates based on thermodynamic phase equilibria. 


\subsubsection{Cobalt Lake Field Locality}

Out of four visited and studied localities of the Bugaboo contact aureole, Cobalt Lake was preferred due to its continuous exposure from the outer aureole to the batholith contact (DeBuhr, 1999). Fieldwork was conducted by DeBuhr (1999) through 3 seasons from 1994-1996 during which traverses were done and the majority of samples were collected, and structural and lithological relationships were mapped. A field season in 2013 was done by the author and additional samples were collected. Figure 2-3 is a geological map of the Cobalt Lake region displaying sample localities that were studied and used to distinguish between the different metamorphic zones of the contact aureole. Mineralogical zone boundaries for the current study match those defined by DeBuhr (1999) with new textural boundaries defined by the author.

Horsethief Creek Group phyllitic protoliths are located $\sim 1 \mathrm{~km}$ away from the Bugaboo batholith and are lower greenschist facies. Porphyroblasts of chlorite and locally chloritoid are present in a foliated matrix of muscovite, chlorite, quartz, plagioclase and ilmenite (DeBuhr, 1999). Paragonite was identified by Pattison and DeBuhr (2015) in the regional phyllites.

A structural aureole was noted by Reesor (1973) as the presence of a contact-parallel foliation and crenulation cleavage that strengthens towards the batholith. Up to $5 \mathrm{~km}$ from the contact, these structural indications of the Bugaboo emplacement were identified (Reesor, 1973). Unfortunately, where regional metamorphic structures run parallel to the Bugaboo contact it is difficult to distinguish any structural reestablishment, specifically the formation of crenulation 


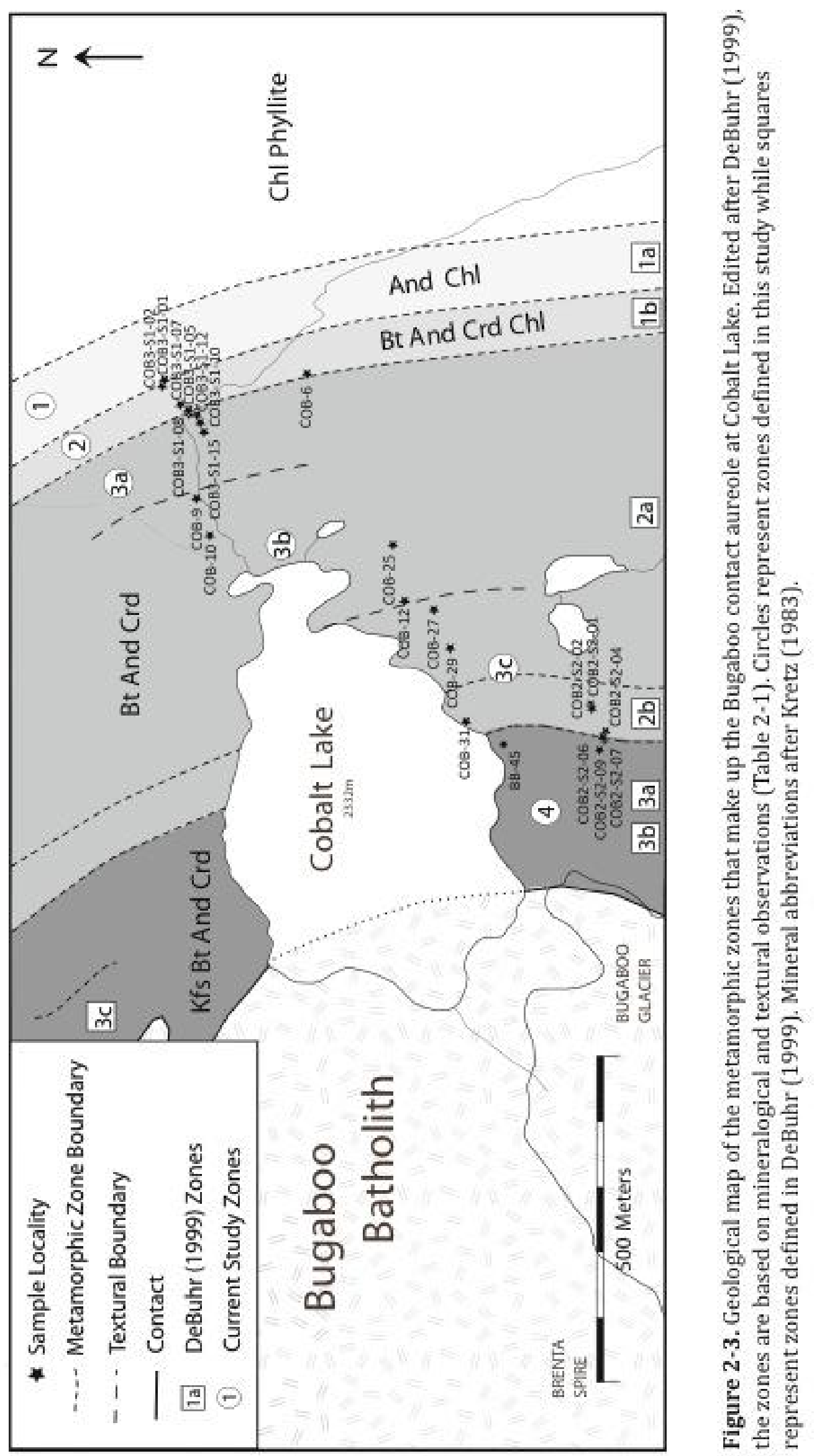


cleavages which require a regional protolith foliation that is perpendicular to the intrusion. At Cobalt Lake, the regional metamorphic structure runs relatively parallel to the Bugaboo batholith contact (Fig. 2-2), therefore the structural aureole is only identified as the constriction of pre-existing foliations and folds (DeBuhr, 1999; Pattison and DeBuhr, 2015).

\subsection{Previous Work on the Bugaboo Contact Aureole}

The contact aureole at Cobalt Lake was studied in great detail in a $\mathrm{PhD}$ thesis by DeBuhr (1999) and in a thorough petrographic investigation by Pattison and DeBuhr (2015). Three other field localities were also studied; Iceberg Lake, Bugaboo Glacier and Kickoff Meadows. The continuous reaction Ms $+\mathrm{Crd}=\mathrm{And}+\mathrm{Bt}+\mathrm{Qtz}+$ $\mathrm{H}_{2} \mathrm{O}$ is predicted to occur within the middle aureole and was investigated by Pattison et al. (2002) and briefly discussed by Pattison et al. (2011). The following is a short summary of the observations, results and interpretations of previous studies that are of importance for this thesis.

\subsubsection{Metamorphic Zones at Cobalt Lake}

Dominated by metapelitic hornfelses and schists, the Bugaboo contact aureole is characterized by porphyroblasts of biotite, andalusite and cordierite in a fine foliated muscovite, ilmenite, quartz and plagioclase matrix. Three metamorphic zones were defined by DeBuhr (1999), and Pattison and DeBuhr (2015) based on mineral assemblages (Table 2-1 and Fig. 2-3). The outer aureole, Zone 1, is split into spotted phyllites with andalusite and altered cordierite (1a), and the first 
appearance of biotite porphyroblasts with andalusite and cordierite (1b) in matrices containing primary chlorite. Zone 2 makes up the largest portion of the contact aureole, consisting of large biotite, andalusite and cordierite porphyroblasts (2a) with the addition of sparse sillimanite fibers at highest grades (2b; Fig. $4 \mathrm{H}$ in Pattison and DeBuhr, 2015). Sillimanite aggregates make up $<0.1$ vol. $\%$ of the rocks in which it was identified. Film-like andalusite present between cordierite interfaces has also been observed (Fig. 5E in Pattison et al., 2002). The inner aureole consists of a K-feldspar zone with muscovite (3a), a K-feldspar zone with no muscovite (3b) and a migmatite zone (3c). The migmatites do not dominate Zone $3 \mathrm{c}$ and were not studied in this thesis. They are located north of Cobalt Lake (Fig. 2-3) and consist of leucosomes, segregations rich in quartz and feldspars, and biotite-rich regions.

The modal amount of each mineral phase was plotted against distance in Figure 6 of Pattison and DeBuhr (2015). Overall, an increase in porphyroblast volume (Bt, And, Crd and $\mathrm{Kfs}$ ) is seen from low to high grade, with matrix phases chlorite and muscovite decreasing in abundance. A drastic increase in porphyroblast volume and reduction in chlorite occurs between Zone 1a and 1b. Zone 2a contains the same modal volume percent of each phase throughout until approaching the beginning of Zone $2 \mathrm{~b}$ at which andalusite and biotite become more abundant than cordierite. This coincides with the breakdown of muscovite, after which the modal volume of cordierite rises again with the decrease of biotite. 
Table 2-1. Summary of the metamorphic zones of the Bugaboo contact aureole at Cobalt Lake defined in this study and by DeBuhr (1999). The zones are defined by mineral assemblages while sub-zones distinguish textural variations such as the kinematic relationships between porphyroblasts and the matrix structure. Mineral abbreviations after Kretz (1983).

\begin{tabular}{|c|c|c|c|c|c|c|}
\hline Zone & $\begin{array}{c}\text { Zones } \\
\text { based } \\
\text { on } \\
\text { DeBuhr } \\
\text { (1999) }\end{array}$ & Samples & $\begin{array}{c}\text { Distance } \\
\text { from } \\
\text { Contact } \\
\text { (m) }\end{array}$ & $\begin{array}{l}\text { Matrix } \\
\text { Phases }\end{array}$ & $\begin{array}{l}\text { Porphyroblasts } \\
\text { (kinematics) }\end{array}$ & $\begin{array}{c}\text { Retrograde } \\
\text { Phases }\end{array}$ \\
\hline 1 & $1 \mathrm{a}$ & $\begin{array}{c}\text { COB3-S1- } \\
1\end{array}$ & $880-900$ & $\begin{array}{l}\text { Qtz Pl } \\
\text { Ms Ilm } \\
\text { Chl }\end{array}$ & And (syn) & Chl \\
\hline 2 & $1 b$ & $\begin{array}{c}\text { COB3-S1- } \\
2,5,7 \\
\text { COB-6 }\end{array}$ & $830-880$ & $\begin{array}{c}\text { Qtz Pl } \\
\text { Ms Ilm } \\
\text { Chl }\end{array}$ & $\begin{array}{c}\text { Bt And Crd } \pm \mathrm{Pl} \\
\text { (syn) }\end{array}$ & Chl \\
\hline 3A & $2 \mathrm{a}$ & $\begin{array}{c}\text { COB3-S1- } \\
8,10,12, \\
15, \text { COB- } \\
25\end{array}$ & $540-830$ & $\begin{array}{l}\text { Qtz Pl } \\
\text { Ms Ilm }\end{array}$ & $\begin{array}{c}\text { Bt And Crd } \pm \mathrm{Pl} \\
\text { (syn) }\end{array}$ & Chl \\
\hline 3B & $2 \mathrm{a}$ & $\begin{array}{l}\text { COB-9, } \\
10,12\end{array}$ & $460-700$ & $\begin{array}{l}\text { Qtz Pl } \\
\text { Ms Ilm } \\
\text { Bt }\end{array}$ & And Crd (syn) & Chl Ms \\
\hline $3 C$ & $2 a, 2 b$ & $\begin{array}{c}\text { COB-27, } \\
29,31, \\
\text { COB2-S2- } \\
1,2,4\end{array}$ & $240-540$ & $\begin{array}{l}\text { Qtz Pl } \\
\text { Ms Ilm } \\
\text { Bt }\end{array}$ & And Crd (pre) & Ms \\
\hline 4 & $\begin{array}{c}3 \mathrm{a}, 3 \mathrm{~b}, \\
3 \mathrm{c}\end{array}$ & $\begin{array}{c}\text { COB2-S2- } \\
6,7,9\end{array}$ & $215-240$ & $\begin{array}{c}\text { Qtz Pl } \\
\text { Ms Ilm } \\
\pm \mathrm{Bt} \pm \mathrm{Kfs}\end{array}$ & $\begin{array}{l}\text { Kfs And Crd } \pm \mathrm{Bt} \\
\text { (pre) }\end{array}$ & Ms \\
\hline
\end{tabular}




\subsubsection{Bulk Rock and Mineral Chemistry}

The bulk rock compositions for Bugaboo samples obtained by DeBuhr (1999) are plotted in AFM and ACF diagrams in Figure 2-4 with the average metapelite composition after Symmes and Ferry (1991) and Mahar et al. (1997). The samples are labeled according to their metamorphic zone defined in this thesis (Table 2-1). The mol. \% of each element is listed in Table 2-2 and was used for thermodynamic modeling. No chemical trends are observed from low to high grade in the aureole, although the protolith composition plots at a relatively lower A value than samples within the aureole. All the rocks have $\sim 25 \mathrm{~mol} . \% \mathrm{Mg}$ and $<10 \mathrm{~mol} . \% \mathrm{Ca}$, and differ more significantly in terms of their A and F values. Samples from Zone 2 of Pattison and DeBuhr (2015; Zone 3 in current study) show the greatest variation in chemical content than all other zones most likely because this zone covers the greatest distance. In relation to other major bulk oxide compositions, no outstanding chemical trends were observed that can be related to position in the aureole.

The $\mathrm{Mg} \#=\mathrm{Mg} /(\mathrm{Mg}+\mathrm{Fe})$ of cordierite, biotite and chlorite are plotted against distance from the contact in Figure 2-5. There is a weak decrease in Mg\# for cordierite and biotite as metamorphic grade increases however the values do not change by more than a value of 0.06 . Other mineral chemistries have been plotted throughout the aureole by DeBuhr (1999) and Pattison \& DeBuhr (2015) with trends observed in the $\mathrm{K} /(\mathrm{K}+\mathrm{Na})$ of muscovite and the Ti content of biotite, both increasing as one moves closer to the contact (see Fig. 10 in Pattison and DeBuhr, 2015). 

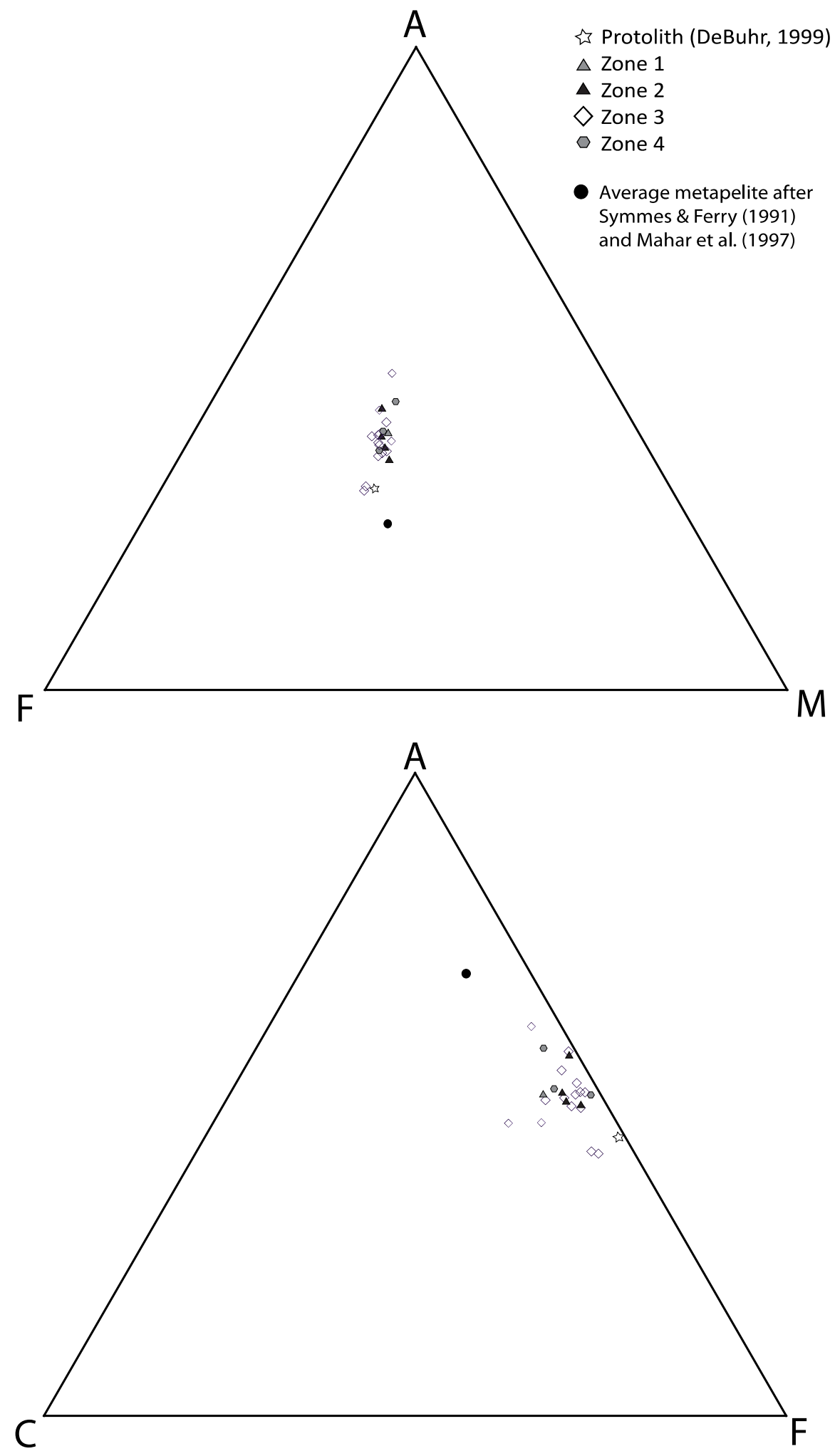

Figure 2-4. AFM and ACF plots of the bulk rock compositions of samples studied at Cobalt Lake (Fig. 2-3). Data was obtained by DeBuhr (1999). 
Table 2-2. Bulk rock composition obtained by XRF by DeBuhr (1999) and calculated into mol. \% element for the Bugaboo samples at Cobalt Lake (Fig. 2-3). These compositions were used with Theriak/Domino (de Capitani and Petrakakis, 2010) for thermodynamic modeling of phase equilibria for this study. The value used for $\mathrm{H}_{2} \mathrm{O}$ is $100 \mathrm{~mol} . \%$ and $\mathrm{C}$ is $50 \mathrm{~mol}$ \% for each sample.

\begin{tabular}{|l|c|c|c|c|c|c|c|c|c|l|}
\hline $\begin{array}{c}\text { Mol. } \% \\
\text { Element }\end{array}$ & $\mathbf{S i}$ & $\mathbf{T i}$ & $\mathbf{A l}$ & $\mathbf{F e}^{2+}$ & $\mathbf{M n}^{2+}$ & $\mathbf{M g}$ & $\mathbf{C a}$ & $\mathbf{N a}$ & $\mathbf{K}$ & Total \\
\hline COB3-S1-1 & 55.03 & 0.68 & 25.71 & 5.72 & 0.10 & 4.43 & 1.05 & 3.23 & 4.07 & 100 \\
\hline COB3-S1-2 & 56.27 & 0.65 & 25.69 & 5.81 & 0.06 & 4.64 & 0.43 & 1.77 & 4.68 & 100 \\
\hline COB3-S1-5 & 50.34 & 0.60 & 31.21 & 5.55 & 0.06 & 4.00 & 0.15 & 2.59 & 5.50 & 100 \\
\hline COB3-S1-7 & 51.07 & 0.67 & 27.45 & 7.52 & 0.16 & 5.73 & 0.86 & 2.72 & 3.83 & 100 \\
\hline COB3-S1-8 & 53.06 & 0.63 & 28.91 & 5.20 & 0.07 & 3.73 & 0.38 & 2.08 & 5.94 & 100 \\
\hline $\begin{array}{l}\text { COB3-S1- } \\
10\end{array}$ & 53.37 & 0.61 & 28.84 & 5.55 & 0.05 & 3.92 & 0.15 & 2.75 & 4.76 & 100 \\
\hline $\begin{array}{l}\text { COB3-S1- } \\
12\end{array}$ & 53.96 & 0.60 & 27.70 & 6.09 & 0.05 & 4.34 & 0.32 & 2.27 & 4.67 & 100 \\
\hline $\begin{array}{l}\text { COB3-S1- } \\
\text { 15 }\end{array}$ & 52.49 & 0.68 & 28.40 & 6.54 & 0.13 & 4.98 & 0.52 & 2.25 & 4.00 & 100 \\
\hline COB-6 & 53.88 & 0.67 & 27.17 & 6.30 & 0.11 & 4.57 & 0.72 & 2.24 & 4.43 & 100 \\
\hline COB-9 & 56.84 & 0.69 & 23.72 & 5.67 & 0.06 & 4.57 & 2.10 & 2.75 & 3.60 & 100 \\
\hline COB-10 & 55.39 & 0.68 & 26.49 & 5.93 & 0.06 & 4.28 & 1.09 & 1.75 & 4.33 & 100 \\
\hline COB-12 & 56.52 & 0.70 & 24.96 & 5.95 & 0.10 & 4.44 & 0.62 & 2.42 & 4.28 & 100 \\
\hline COB-14 & 52.59 & 0.88 & 26.94 & 7.31 & 0.03 & 5.25 & 0.06 & 1.80 & 5.14 & 100 \\
\hline COB-25 & 52.73 & 0.65 & 28.36 & 6.14 & 0.06 & 4.77 & 0.26 & 1.89 & 5.15 & 100 \\
\hline COB-27 & 54.71 & 0.70 & 25.71 & 7.01 & 0.07 & 4.95 & 0.56 & 2.32 & 3.96 & 100 \\
\hline COB-29 & 41.99 & 0.86 & 35.60 & 7.07 & 0.11 & 5.38 & 0.82 & 4.37 & 3.81 & 100 \\
\hline COB-31 & 55.08 & 0.67 & 26.10 & 6.43 & 0.10 & 4.26 & 0.58 & 1.30 & 5.49 & 100 \\
\hline COB2-S2-1 & 54.22 & 0.74 & 27.82 & 6.33 & 0.08 & 4.26 & 0.73 & 1.17 & 4.67 & 100 \\
\hline COB2-S2-2 & 56.74 & 0.73 & 24.10 & 7.19 & 0.08 & 4.82 & 0.77 & 1.23 & 4.33 & 100 \\
\hline COB2-S2-4 & 53.99 & 0.71 & 27.85 & 5.94 & 0.06 & 4.29 & 0.33 & 1.78 & 5.05 & 100 \\
\hline COB2-S2-6 & 51.69 & 0.65 & 28.61 & 6.44 & 0.08 & 4.78 & 0.87 & 2.37 & 4.50 & 100 \\
\hline COB2-S2-7 & 56.15 & 0.52 & 28.35 & 3.31 & 0.06 & 2.72 & 0.35 & 2.37 & 6.18 & 100 \\
\hline COB2-S2-9 & 53.38 & 0.66 & 28.17 & 6.38 & 0.06 & 4.63 & 0.18 & 1.51 & 5.03 & 100 \\
\hline
\end{tabular}




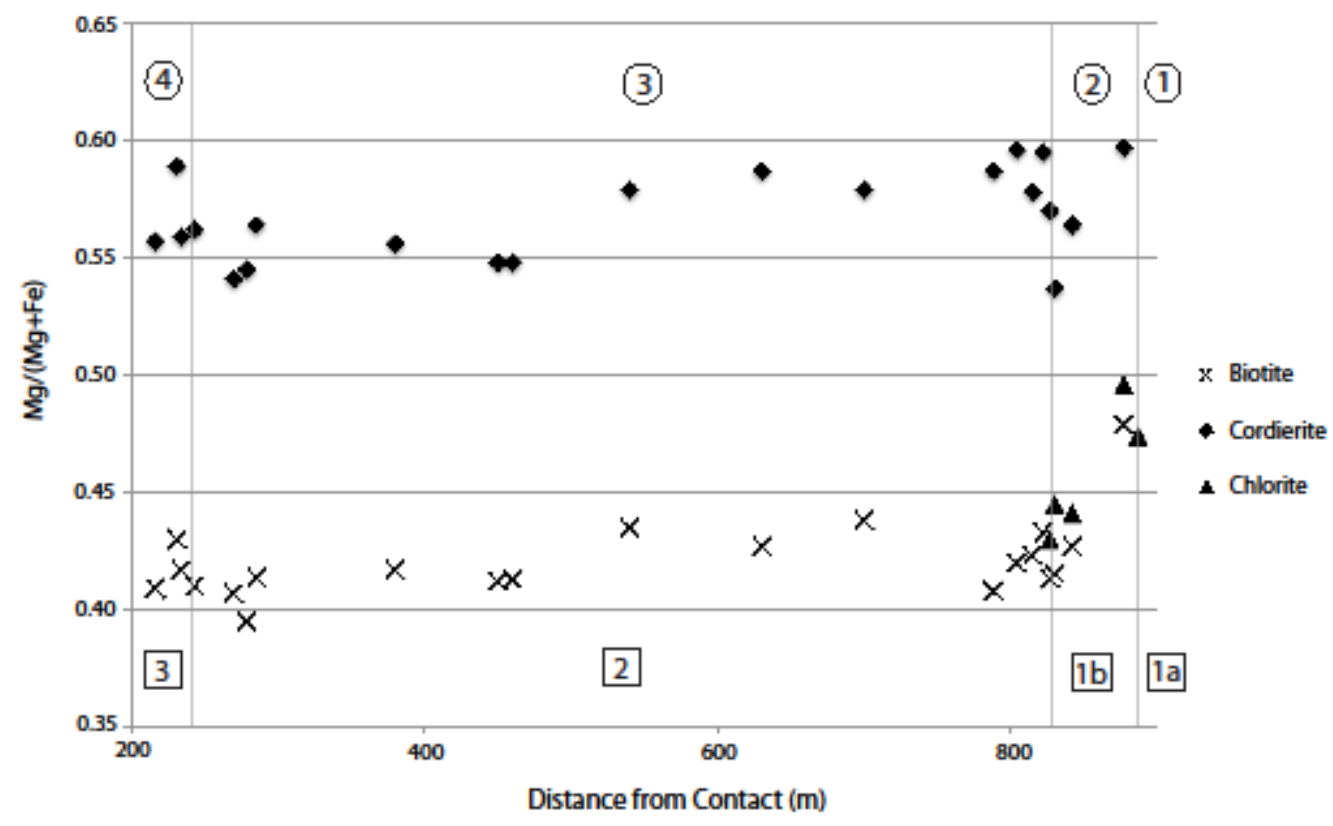

Figure 2-5. $\mathrm{Mg} /(\mathrm{Mg}+\mathrm{Fe})$ values for biotite, cordierite and chlorite throughout the Bugaboo contact aureole. Data obtained by DeBuhr (1999). Circles represent zones defined in the current study while squares represent zones defined by DeBuhr (1999).

2.2.3 The Reaction: $\mathrm{Ms}+\mathrm{Crd}=\mathrm{And}+\mathrm{Bt}+\mathrm{Qtz}+\mathrm{H}_{2} \mathrm{O}$

The continuous reaction between cordierite and muscovite, and andalusite, biotite and quartz is predicted to occur throughout Zone 2 of Pattison and DeBuhr (2015; Zone 3 in current study; Table 2-1 and Fig. 2-3). The slope of this reaction is predicted by thermodynamics to have an impact on the Fe-Mg content of biotite and cordierite with increasing grade. A positive slope, where cordierite and muscovite are being produced, predicts Fe-enrichment in biotite and cordierite, while a negative slope and the consumption of cordierite and muscovite predict Mgenrichment (Fig. 3 from Pattison et al., 2002). The observation of film-like andalusite growing along cordierite interfaces (Fig. 5E from Pattison et al., 2002) and the decrease in cordierite modal volume at the upper limit of Zone 2 (Fig. 6 from Pattison and DeBuhr, 2015) suggests cordierite consumption and a negative 
slope for this reaction. These textural observations should indicate Mg-enrichment for biotite and cordierite with increasing grade. However, the homogeneous Fe-Mg content observed throughout the aureole, with perhaps slight Fe-enrichment, indicates otherwise (Fig. 2-5). This reaction has been interpreted to have a low reaction affinity, which indicates that there is minimal difference between the Gibbs free energy of the reactants and products (Pattison et al., 2011). This may have resulted in a large amount of overstep since the reaction required more energy input at greater temperatures to proceed. If these chemistries are preserved from peak prograde metamorphism, then the question arises as to whether a textural analysis on rocks from the middle aureole will also reveal a significant amount of overstep.

\subsection{Methods}

A combination of techniques was used to analyze the samples from the Bugaboo contact aureole. A thorough petrographic description of every sample was completed to understand the kinematic relationship between porphyroblasts and matrix structures. Bulk rock compositions obtained by DeBuhr (1999) were used to predict equilibrium phase assemblages at varying $\mathrm{P}-\mathrm{T}$ conditions. Mineral chemistries from specific samples were obtained by the author to compare with predicted equilibrium compositions of biotite and cordierite as well as to study chemical zoning within cordierite porphyroblasts. The rock samples were scanned with a high resolution X-ray computed tomography (XR- $\mu \mathrm{CT}$ ) scanner to obtain three-dimensional (3D) images of their mineral constituents and textural interiors. 


\subsubsection{XRF}

Bulk rock chemical compositions were obtained by X-ray fluorescence (XRF) at the Geochemical Laboratories of Earth \& Planetary Sciences at McGill University (DeBuhr, 1999). A jaw crusher and tungsten carbide ring mill at the University of Calgary were used to prepare the powders and various steps to minimize contamination were done. The analyses were done on a Philips PW2400 3kW automated XRF spectrometer with a rhodium X-ray tube of $60 \mathrm{kV}$. Readers are referred to DeBuhr (1999) for a more detailed description of this method.

\subsubsection{Phase Equilibria}

A thermodynamic database after Holland and Powell (1998), with slight adjustments (Appendix I), was used to predict the P-T conditions of all obtained bulk rock compositions (Table 2-2). Phase diagrams were calculated using TheriakDomino modeling software (de Capitani and Petrakakis, 2010) considering a chemical system of $\mathrm{MnO}, \mathrm{Na}_{2} \mathrm{O}, \mathrm{CaO}, \mathrm{K}_{2} \mathrm{O}, \mathrm{FeO}, \mathrm{MgO}, \mathrm{Al}_{2} \mathrm{O}_{3}, \mathrm{SiO}_{2}, \mathrm{TiO}_{2}, \mathrm{H}_{2} \mathrm{O}$ and $\mathrm{CO}_{2}$. The molar amount of oxygen was calculated for each bulk rock composition with 100 moles of hydrogen and 50 moles of carbon and a hydrogen to oxygen ratio of 2:1. This results in a modal $\mathrm{COH}$-fluid in equilibrium with graphite. An additional phase diagram was produced assuming a pure $\mathrm{H}_{2} \mathrm{O}$ fluid to observe the effects of excluding graphite within the assemblage and $\mathrm{CO}_{2}, \mathrm{CO}$ and $\mathrm{CH}_{4}$ within the fluid. Isopleths of the Mg\# for cordierite and biotite were predicted within the same P-T range for select samples. 
The database used is tcdb55c2_COH_prltbi2 (Appendix I) with the following solution models; plagioclase after Holland and Powell (2003), ideal ilmenite after Tinkham and Ghent (2005), chlorite from Holland and Powell (1998) extended to include $\mathrm{Mn}-\mathrm{Chl}, \mathrm{Al}$-free $\mathrm{Chl}$ is negligible and excluded, white mica after Coggon and Holland (2002) including pyrophyllite, margarite is considered a pure phase, biotite from White et al. (2005) including Ti-biotite, and cordierite is considered an ideal solution with Fe, Mn and Mg-cordierite after Holland and Powell (1998). Hydrous cordierite is considered as the $\mathrm{Mg}$ end member. $\mathrm{CO}_{2}, \mathrm{CO}, \mathrm{CH}_{4}, \mathrm{H}_{2} \mathrm{O}$ and $\mathrm{O}_{2}$ are considered components of the fluid from Holland and Powell (1998).

\subsubsection{EPMA}

Mineral spot analyses from DeBuhr (1999) were done at the University of Alberta on a JEOL JXA 8900 electron probe microanalyzer (EPMA). A beam current of $15 \mathrm{nA}$ was accelerated to $15 \mathrm{kV}$ to obtain all analyses with a peak counting time of 20 seconds (DeBuhr, 1999). A ZAF matrix correction was then used to convert the raw data to weight percent.

Chemical profiles of cordierite porphyroblasts of COB3-S1-5, COB3-S1-7 and COB-6 were done with an automated Cameca Camebax MBX electron probe at Carleton University under an accelerating voltage of $20 \mathrm{kV}$ and a beam current of 20 nA. Spots were spaced at $20 \mu \mathrm{m}$ intervals with peak counting times between 15-30 seconds to achieve 40,000 accumulated counts for each element. The Cameca PAP matrix correction program was used. Weight percent was converted to cation numbers, from which the mole percentages of $\mathrm{Na}, \mathrm{Fe}, \mathrm{Mg}$ and $\mathrm{Mn}$ were obtained. At 
first, many analyses across the cordierites were removed due to their inclusion-rich nature. A second approach was used where every $5^{\text {th }}$ spot (every $100 \mu \mathrm{m}$ ) was manually readjusted $\sim 10-15 \mu \mathrm{m}$ away from the original spot to analyze an inclusion-free region of cordierite.

\subsubsection{XR- $\mu C T$}

Computed tomography (CT) allows for the interior of solid materials to be viewed in a non-destructive manner. By capturing the variation in X-ray attenuation within a geo-material, which is a function of mineral density and chemistry, and reconstructing the data into a sequence of two-dimensional (2D) images that can be stacked and viewed with computer software, CT provides the opportunity to visualize rocks in 3D. Additional software is able to isolate the regions of interest (Avizo), such as porphyroblasts, measure their properties (Blob3D; Ketcham, 2005) and quantify the texture of the population (Reduce3D; Hirsch, 2000 and Stereonet software).

A SkyScan 1173 X-ray micro-computed tomography (XR- $\mu$ CT) scanner at Carleton University was used to scan $2.5 \mathrm{~cm}$ diameter rock cores from the Bugaboo contact aureole. Samples were scanned at a resolution of 12.08 microns per pixel, $130 \mathrm{keV}, 61 \mu \mathrm{A}$ and 1325-50 ms exposure time (see Table 2-3 for sample specific settings). A brass $0.25 \mathrm{~mm}$ filter was used to pre-harden the X-ray beam and diminish the effects of beam hardening (discussed below). The samples rotated $360^{\circ}$ during the scan with steps between $0.2-0.3^{\circ}$ (Table 2-3). A frame averaging of 8-20 was applied and no random movement was used. The X-ray signal was calibrated by 
obtaining detector readings when the X-rays are on and off, this is called white (Xrays on) and black (X-rays off) flat field correction and was done before every scan.

The XR- $\mu$ CT scanner is set up with the rotating sample between the X-ray source and the detector. As X-ray photons pass through a rock they interact with atomic particles either by fully or partially transferring energy to an electron. Photoelectric absorption is when an X-ray photon transfers all of its energy to an inner shell electron, which is then ejected and consequently detected by the CT camera. Attenuation is dominated by photoelectric absorption up to $100 \mathrm{keV}$, relatively low X-ray energies. Compton scattering occurs when X-ray photons have higher energies, up to $5 \mathrm{MeV}$, and only a portion of the energy is transferred between an incoming X-ray photon and an outer shell electron, after which both are scattered and detected. The degree of attenuation depends on the atomic number of the absorbing atom, $\mathrm{Z}$; photoelectric absorption is proportional to $\mathrm{Z}^{4-5}$ while Compton scattering is proportional to Z (Ketcham and Carlson, 2001). The X-ray energy used to scan the Bugaboo samples did not exceed $130 \mathrm{keV}$, therefore photoelectric absorption and Compton scattering were causing the X-ray signal detected at the X-ray camera. The X-ray energy setting, $130 \mathrm{keV}$, represents only the maximum energy emitted, with the entire spectrum of energies below it, down to 40 $\mathrm{keV}$, also being passed through the sample.

Table 2-3. Sample names of rocks collected form the Bugaboo contact aureole with corresponding CT names and settings used for each scan. An electron voltage of 130 $\mathrm{keV}$ and a beam current of $61 \mu \mathrm{A}$ were used for each scan.

\begin{tabular}{|l|c|c|c|c|c|} 
Sample & CT Name & Resolution & Rotation & Frame & Exposure \\
\hline
\end{tabular}




\begin{tabular}{|c|c|c|c|c|c|}
\hline Name & & $(\boldsymbol{\mu m})$ & Step ( $\left.^{\circ}\right)$ & Averaging & time (ms) \\
\hline COB3-S1-5 & CT_009 & 12.08 & 0.21 & 20 & 1300 \\
\hline $\begin{array}{c}\text { COB3-S1- } \\
15\end{array}$ & $\begin{array}{c}\text { CT-014, 15, } \\
16\end{array}$ & 12.08 & $\begin{array}{c}0.21, \\
0.225\end{array}$ & 20 & 1300,800 \\
\hline $\begin{array}{c}\text { COB3-S1- } \\
10\end{array}$ & CT_027 & 12.08 & 0.30 & 20 & 1350 \\
\hline COB3-S1-7 & CT_031,33 & 12.08 & 0.30 & 20 & 1350 \\
\hline COB-12 & CT_034 & 12.08 & 0.30 & 15 & 1350 \\
\hline COB3-S1-8 & CT_036 & 12.08 & 0.30 & 15 & 1350 \\
\hline COB3-S1-1 & CT_037 & 12.08 & 0.30 & 15 & 1350 \\
\hline COB3-S1-2 & CT-039 & 12.08 & 0.30 & 12 & 1350 \\
\hline COB-6 & CT_040,41 & 12.08 & 0.30 & 12 & 1350 \\
\hline COB3-S1- & CT_042 & 12.08 & 0.30 & 20 & 1350 \\
\hline 12 & CT_043 & 12.08 & 0.25 & 20 & 1325 \\
\hline COB2-S2-7 & CT_044 & 12.08 & 0.25 & 20 & 1350 \\
\hline COB2-S2-1 & CT_045 & 12.08 & 0.25 & 20 & 1350 \\
\hline COB2-S2-2 & CT_071 & 12.08 & 0.20 & 10 & 1325 \\
\hline COB-25 & CT-071 & 8 & 1325 \\
\hline COB-27 & CT_072 & 12.08 & 0.20 & 8 & 1350 \\
\hline COB2-S2-6 & CT_073 & 12.08 & 0.20 & 8 & 1350 \\
\hline COB2-S2-9 & CT_074 & 12.08 & 0.20 & 8 & 1325 \\
\hline BB-45 & CT_081 & 12.08 & 0.20 & 8 & \\
\hline
\end{tabular}

The immediate raw data are called sinograms; visual representations of detector readings for each rotation step view (Ketcham and Carlson, 2001). In order to convert the sinograms into 2D slices that can be stacked, the raw CT data was input into a program called NRecon. The X-ray attenuation data of every 12.08 microns is displayed as a pixel with a greyscale value, ranging between $0-256$, where greater X-ray attenuations, thus greater densities, appear with a greater greyscale value (there is the option to reverse this feature). Next, the slices are corrected for beam hardening and ring artifacts that arise during the scan and can 
be problematic when segmenting and finally quantifying areas of interest in the CT data.

As the X-ray beam travels through the rock core it preferentially loses low energy (soft) X-rays that are easily absorbed by the material and is left with high energy (hard) X-rays as it exits. Therefore, the beam's energy increases (hardens) as it travels through the sample and the number of X-rays in the beam decreases. Rock material that is intersected by a long ray path, closer to the center of the rock core, will appear to have a lower X-ray attenuation due to the lower amount of X-rays that reach it. This artifact is known as beam hardening and can be seen in the reconstructed CT slices as an increase of greyscale value towards the outer edge of the rock core. Beam hardening is already corrected for before the scan by introducing a filter (brass $0.25 \mathrm{~mm}$ ) through which the X-ray beam passes and low energy X-rays are filtered out before reaching the sample. However, this does not fully diminish the effects and NRecon is able to correct for beam hardening after the scan by normalizing the CT values by $0-20 \%$ across each slice to acquire a satisfactory image.

Circular features centered on the axis of rotation of the rock core are present in the CT data and are spatially related to oxide minerals that create starburst artifacts. Ring artifacts are a result of anomalous X-ray values caused by defects or shifts in the tomography scanner's camera. Defects, such as broken pixels, or movement of the detector, caused by temperature changes, will project anomalous $\mathrm{X}$-ray values onto the CT data and this is carried out across the rotating sample, creating rings. A setting called random movement can be chosen for a scan to move 
the sample about randomly and can help in reducing ring artifacts in the data. NRecon is also able to correct for ring artifacts by introducing new rings that overlay the old ones. Therefore, ring artifacts can easily be over-corrected for when too many new rings are introduced. The correction value was limited to a range between 5-15. Starburst artifacts caused by the presence of high density minerals, such as oxide, can enhance the appearance of rings and make ring corrections difficult (Ketcham and Carlson, 2001).

Due to the limitation of X-ray CT resolution, material features that are $<12.08$ $\mu \mathrm{m}$ are difficult to visualize because they are represented by a CT value that is an average of all the values in their neighborhood. This is known as the partial volume effect. Features such as crystal interfaces or small inclusions will appear blurred and may have an effect on the final calculated volume of segmented areas. This effect will be mentioned throughout the segmentation section of this chapter.

In order to predict the relative greyscale values of various phases, the linear X-ray attenuations with incoherent scattering was calculated based on the chemical data obtained for COB3-S1-5. This was done on the National Institute of Standards and Technology (NIST) website: http://physics.nist.gov/PhysRefData/Xcom/html /xcom1.html which provide the X-ray attenuation values for elements, compounds and mixtures at a range of electron voltages. The exact chemical compositions of minerals were taken from DeBuhr (1999) as well as analyses done by the author. The linear attenuations were then multiplied by the mineral density as predicted by Theriak/Domino at $510^{\circ} \mathrm{C}$ and 1.6 kbar (chosen based on phase equilibria, Section 
2.5.4). Since cordierite and chlorite are not predicted to exist in thermodynamic equilibrium, the density of chlorite was therefore predicted at $500^{\circ} \mathrm{C}$ and $1.6 \mathrm{kbar}$.

\subsubsection{Segmentation}

The reconstructed slices were halved and every second slice was used so that the pixel size and interslice spacing is double that of the initial scan $(24.16 \mu \mathrm{m}$ if scan resolution was $12.08 \mu \mathrm{m}$ ). Avizo software was used to visualize the rock core in 3D and ultimately obtain areas of interest within the CT data. The isolation of specific areas of the CT data is called segmentation. A favorable method of segmentation is to define the grey-scale values that correspond to areas of interest and automatically separate them from the rest of the rock by creating a threshold. Thresholds are commonly successful when segmenting minerals of a much higher or lower X-ray attenuation than other phases. Threshold segmentation can also be done with Blob3D software (Ketcham, 2005) which additionally displays each selected region, or 'blob', in 3D and the user can choose to accept or reject it. Blob3D provides an output file of all the properties of the accepted blobs; $x-y-z$ coordinates of their center of mass, volume based on number of pixels, surface area, etc. Blob3D is automatically prompted to fit a best-fit ellipsoid onto the object using the leastsquares method to provide the long and short axis lengths, aspect ratio and the ellipsoid's orientation.

When minerals exhibit similar X-ray attenuations to other phases in the rock, or the attenuation varies within a single crystal, segmentation may be difficult or impossible. This was the case for cordierite in sample COB3-S1-5 (CT_009). 
Therefore, instead of manually selecting cordierite regions in every slice, which is not time effective, three perpendicular slices were selected that intersect the center of every crystal, and the region corresponding to the centered crystal was manually segmented in Avizo. This method was chosen with the intention of using Blob3D to fit a primitive ellipsoid onto the orthogonal segments, allowing for an approximation of the volume of all cordierite porphyroblasts. Primitive fitting differs from the best fit ellipsoid mentioned previously and is explained in detail by Ketcham (2005). It involves finding a sphere or ellipsoid that closely matches the crystal's surface. Because the ellipsoids were being fit onto orthogonal segments, which do not fully represent the crystal surface, the Surface merit function in Blob3D was chosen as it does not remove any surface pixels, which the Impinged and Incomplete Surface functions do (Ketcham, 2005).

The cordierite from COB3-S1-5 was segmented using orthogonal slices, including porphyroblasts that intersected the boundary of the sample in order to obtain an accurate volume fraction. Biotite porphyroblasts from the same sample were segmented using a threshold in Blob3D.

\subsection{Results}

\subsubsection{Petrography}


Select photos representative of each metamorphic zone are presented in Figure 2-6 with mineral abbreviations after Kretz (1983). Samples collected by DeBuhr (1999) from Cobalt Lake and studied by Pattison and DeBuhr (2015) are the focus of this thesis. The contact aureole was divided into 4 main zones based on porphyroblast and matrix assemblages, with subdivisions created to define any textural differences (Fig. 2-3). There are many similarities in how the aureole was subdivided to previous work (DeBuhr, 1999; Pattison and DeBuhr, 2015) and a few differences arise mainly due to the contrast in sample density (Table 2-1).

The outer aureole consists of 2 zones, here labeled Zone 1 and 2 . These zones enclose the first appearance of contact metamorphic minerals to the disappearance of prograde chlorite. Zone 3 is the largest zone making up the middle aureole and comprises three textures: the largest cordierite, andalusite and biotite (3A), a decrease in biotite size as it joins the foliated matrix (3B) and andalusite and cordierite exhibiting inclusion textures sub-parallel to the matrix foliation (3C). Closest to the contact, Zone 4 consists of infrequent potassium feldspar porphyroblasts and the transition towards a muscovite-free matrix. 


\section{Zone 1 (And-Crd-Chl)}
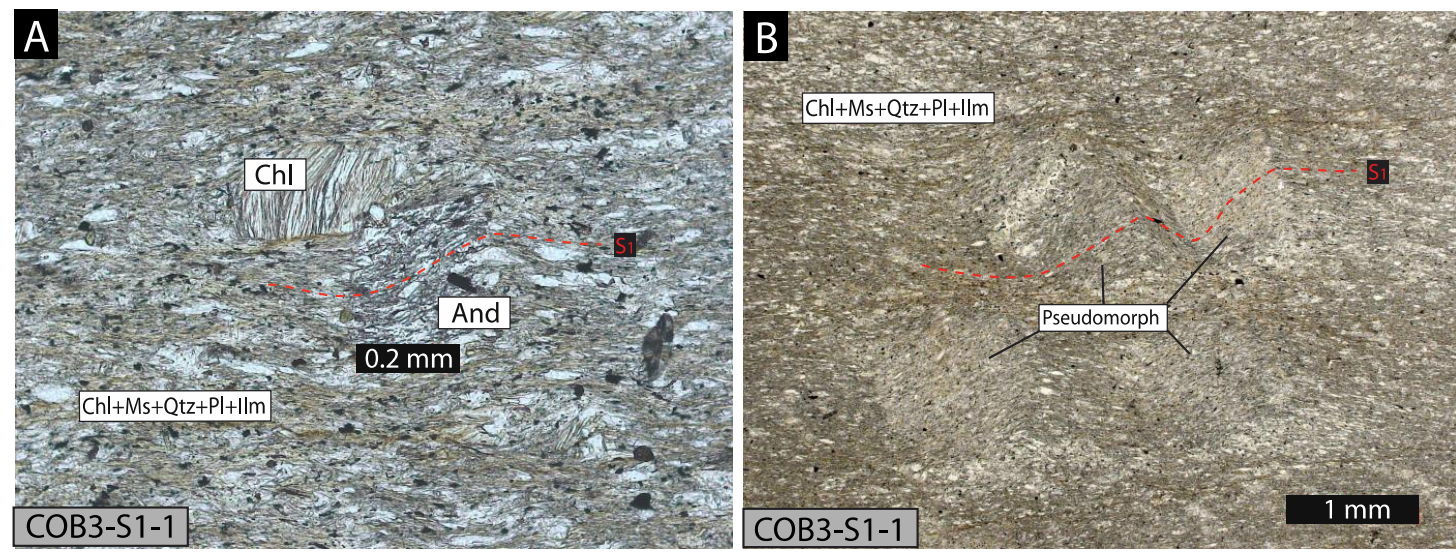

\section{Zone 2 (Bt-And-Crd-Chl)}
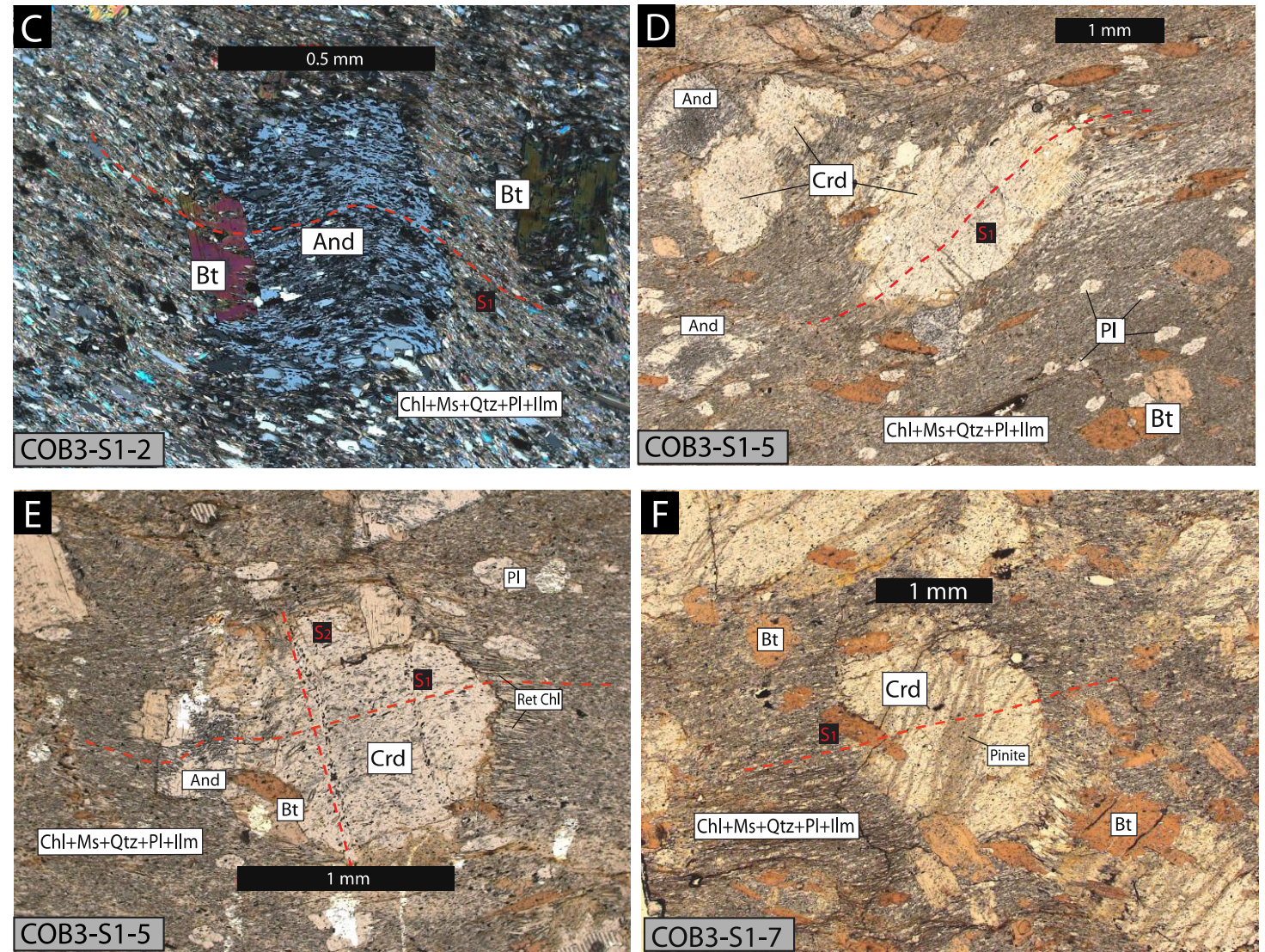

Figure 2-6. Petrography photographs representing Zone 1 and 2 of the Bugaboo contact aureole. (A) Chl porphyroclasts and And porphyroblasts showing syn-kinematic texture. (B) Mica pseudomorphs showing preserved syn-kinematic growth textures. (C) Bt inclusions within the rim of And with rotated inclusion trails. (D) Aligned $\mathrm{Pl}+\mathrm{Bt}+\mathrm{And}+\mathrm{Crd}$ porphyroblasts parallel to the matrix foliation. (E) Inclusion relationships between porphyroblasts within Zone 2 and Ret Chl rim texture surrounding Crd. (F) Pinite alteration within fractured Crd cross-cuts the matrix foliation S1. 
Zone 3A (Bt-And-Crd)
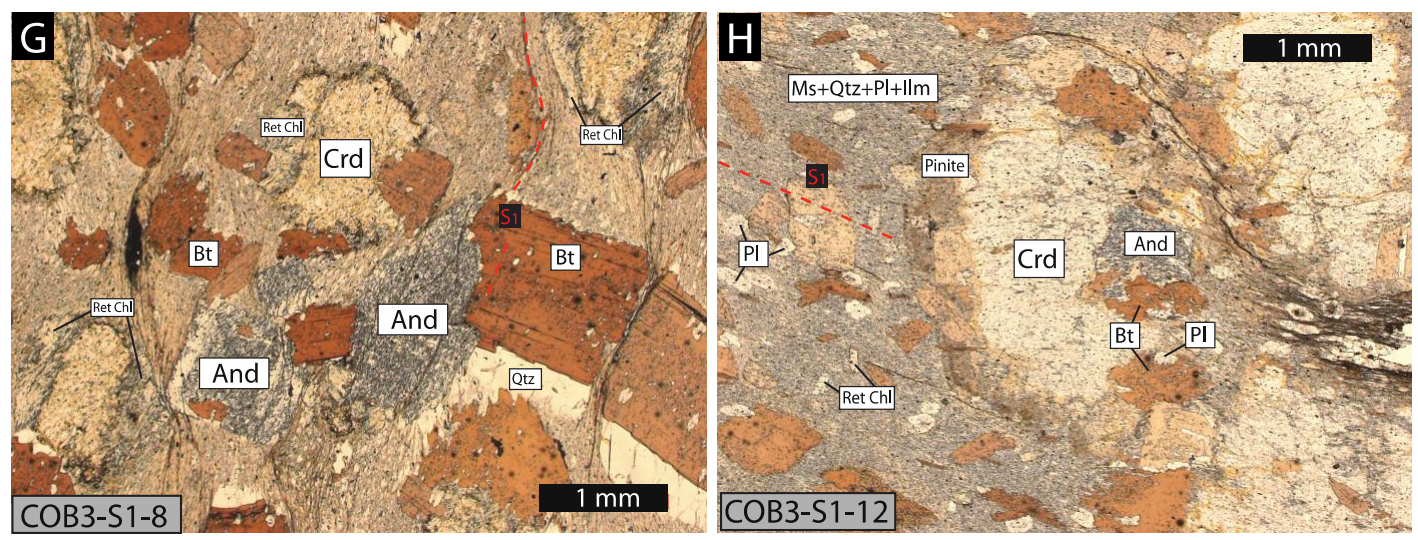

\section{Zone 3B (Foliated Bt)}
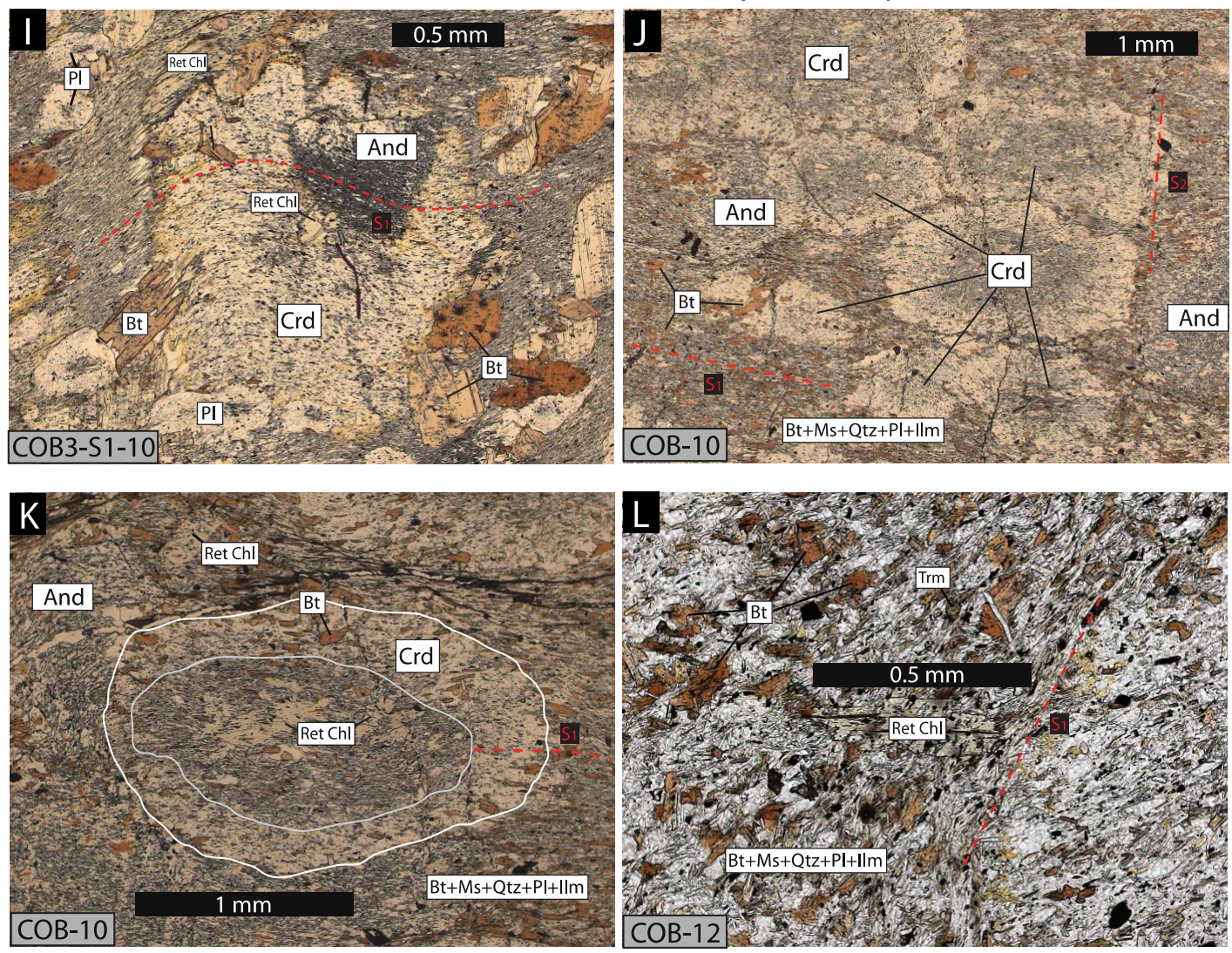

Figure 2-6. Petrography photos representative of Zones 3A and 3B. (G) Porphyroblasts increase in size, equant $\mathrm{Bt}$ shows hourglass inclusion texture and Crd displays replacement by Ret $\mathrm{Chl}$. $(\mathrm{H}) \mathrm{Pl}+\mathrm{Bt}+\mathrm{And}$ are included in Crd which contains rims of pinite alteration. (I) Syn-kinematic porphyroblasts texturally display the dominant growth of Crd over the other phases. (J) And+Crd porphyroblasts within a fine foliated Bt-rich matrix with cross-cutting S2 Bt-Ilm fractures. (K) Ret Chl growth within the core of Crd. (L) Ret Chl cross-cutting the matrix foliation S1. 
Zone 3C (Pre-kinematic And-Crd)
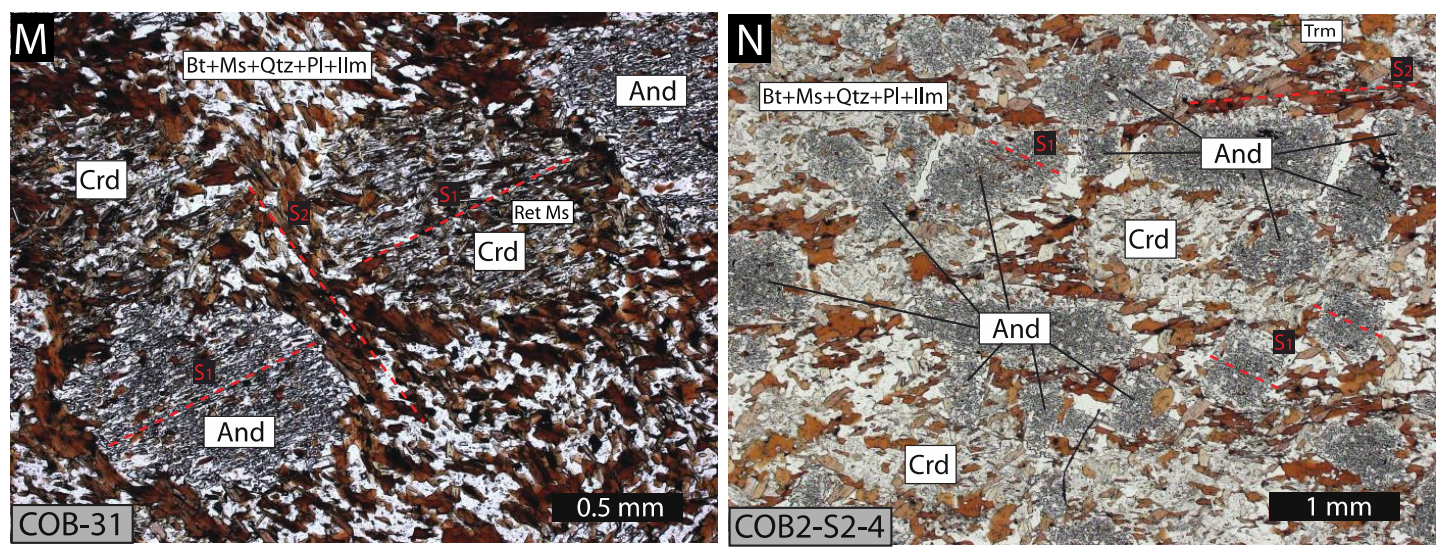

\section{Zone 4 (Kfs-Bt-And-Crd)}
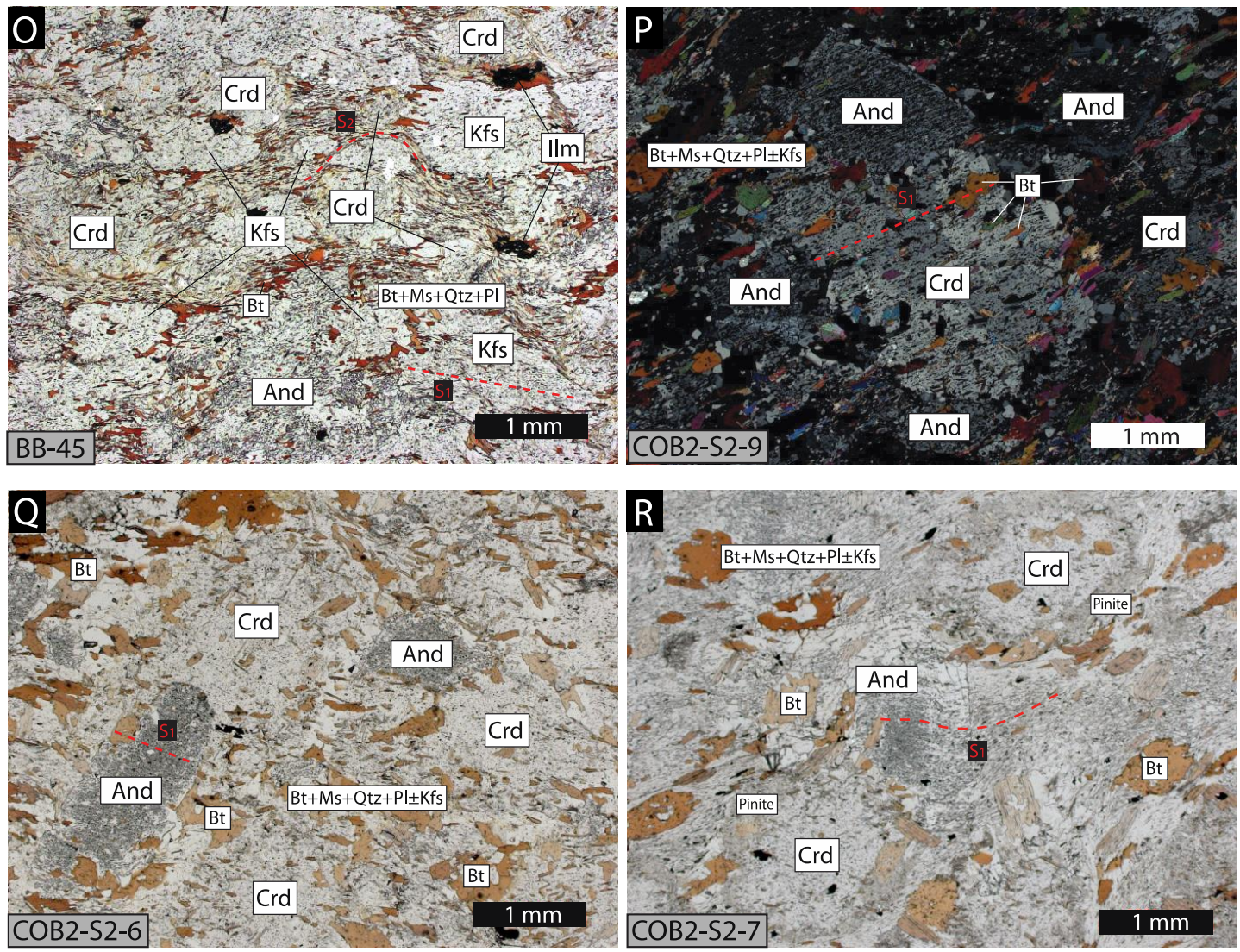

Figure 2-6. Petrography photos representative of Zones 3C and 4. (M) And+Crd show sub-parallel inclusion trails S1 to the Bt-rich matrix foliation S2. (N) Poikiloblastic porphyroblasts in a poorly foliated matrix. (O) Kfs+And+Crd porphyroblasts are wrapped by a Bt-rich matrix foliation S2. (P) And+Crd porphyroblasts show straight inclusion trails parallel to a matrix of minor Kfs and elongate biotite. (Q) Bt begins to coarsen but remains elongated parallel to the matrix deformation. (R) And shows syn-kinematic inclusion trails and Crd contains a rim of pinite alteration. 
The Outer Aureole

(1) And-Chl: COB3-S1-1, 02-COB-13

Chlorite porphyroclasts of 200-300 $\mu \mathrm{m}$ are remnants from regional metamorphism and are wrapped by a chlorite-muscovite-ilmenite foliation $\left(\mathrm{S}_{1}\right)$ that dominates the matrix along with quartz and plagioclase (Fig. 2-6A). The matrix makes up approximately $90 \%$ of the rock volume. Equant andalusite porphyroblasts of 0.2-1.0 mm contain rotated inclusion trails and are locally replaced by muscovite. Full muscovite-chlorite pseudomorphs are 0.5-1.0 $\mathrm{mm}$ showing relict inclusion trails that are at an angle to the present matrix foliation but rotate to merge at the rims (Fig. 2-6B). The following reaction in NFASH is responsible for the occurrence of andalusite porphyroblasts without biotite and cordierite in Zone 1:

$$
\mathrm{Qtz}+\mathrm{Pg}=\mathrm{And}+\mathrm{Ab}+\mathrm{H}_{2} \mathrm{O}
$$

\section{(2) Bt-And-Crd-Chl: COB3-S1-2, 5, 7 and COB-6}

Zone 2 begins with the co-existance of $100-400 \mu \mathrm{m}$ biotite porphyroblasts with chlorite porphyroclasts in COB3-S1-2. The matrix makes up approximately $70-80 \%$ of the rock volume and is foliated by chlorite, muscovite and ilmenite $\left(\mathrm{S}_{1}\right)$ accompanied by quartz and plagioclase. Poikiloblastic $0.5 \mathrm{~mm}$ andalusite and 0.5 $2.0 \mathrm{~mm}$ altered cordierite porphyroblasts share crystal interfaces with biotite and often contain inclusions of biotite within their rims (Fig. 2-6C). Andalusite and cordierite rarely share interfaces and contain rotated merging inclusion trails. 
Alteration of cordierite to yellow pinite (fine grained micas) is concentrated along its rims and occasionally within its cores.

Moving further into Zone 2 the porphyroblasts begin to coarsen; $0.1-1.0 \mathrm{~mm}$ biotite, $0.8-1.2 \mathrm{~mm}$ andalusite and $0.5-3.0 \mathrm{~mm}$ cordierite, and the matrix makes up an estimated $60 \%$ of the rock volume. Plagioclase porphyroblasts of $100-500 \mu \mathrm{m}$ are observed in COB3-S1-5 with inclusion-rich cores (Fig. 2-6D, E). All porphyroblasts are elongated parallel to the matrix foliation $\left(S_{1}\right)$ and enclose rotated merging inclusion trails with hourglass inclusion patterns in biotite and andalusite (Fig. 26D). Plagioclase inclusions are present in all other porphyroblasts, biotite inclusions are common in andalusite and cordierite, and andalusite is occasionally found as inclusions in cordierite (Fig. 2-6E). Andalusite is equant and has inclusion-free rims. Cordierite is ovoid to sub-idiomorphic and exhibits cyclic twinning. Yellow alteration to pinite is present along the rims of cordierite and within fractures (Fig. 2-6F). Foliated retrograde chlorite has locally replaced the outer $100-200 \mu \mathrm{m}$ of cordierite and ilmenite-rich crenulation cleavages $\left(S_{2}\right)$ that run perpendicular to the matrix foliation also appear in cordierite (Fig. 2-6E).

The growth of biotite, andalusite, cordierite and occasionally plagioclase within Zone 2 occurs at the expense of chlorite by the following KFMASH reaction:

$$
\mathrm{Chl}+\mathrm{Ms}+\mathrm{Qtz}=\mathrm{Bt}+\mathrm{And}+\mathrm{Crd} \pm \mathrm{Pl}+\mathrm{H}_{2} \mathrm{O}
$$

The presence of both reactants and products in this zone suggests it to be a "reaction zone" (DeBuhr, 1999) in which a decrease in matrix chlorite and an 
increase in porphyroblast volume are observed towards the beginning of Zone 3 . The presence of inclusion-free andalusite rims suggests reaction (II) followed primary andalusite growth of reaction (I).

The Middle Aureole

\section{(3) Bt-And-Crd:}

The absence of foliated matrix chlorite defines Zone 3, however, a change in texture divides this zone into three; Zone 3A: porphyroblasts of biotite, andalusite and cordierite with merging inclusion trails, Zone 3B: andalusite and cordierite with inclusion trails merging into a biotite-foliated matrix, and Zone 3C: andalusite and cordierite with inclusion trails non-parallel to the matrix biotite foliation. The matrix of Zone 3 makes up $40-50 \%$ of the rock volume. Completion of reaction (II) is responsible for the initial growth of phases observed.

(3A) Bt-And-Crd porphyroblasts: COB3-S1-8, 10, 12, 15, COB-25

Porphyroblasts of biotite $(0.3-1.5 \mathrm{~mm})$, andalusite $(0.8-3 \mathrm{~mm})$ and cordierite (0.5-8 $\mathrm{mm})$ are present in all samples with plagioclase porphyroblasts (200-500 $\mu \mathrm{m})$ observed in COB3-S1-10 and 12. The matrix is dominated by a muscoviteilmenite foliation $\left(\mathrm{S}_{1}\right)$ in addition to quartz and plagioclase. Ovoids of plagioclcase porphyroblasts are elongated parallel to $S_{1}$ and contain inclusion-rich cores with no particular orientation. Biotite is idiomorphic with hourglass inclusion trails that run parallel to $S_{1}$ (Fig. 2-6G), or creates sub-idiomorphic mica fish with an elongation parallel to $\mathrm{S}_{1}$ (Fig. 2-6H). The largest andalusite and cordierite porphyroblasts are 
found in COB3-S1-12 and 15. Sub-idiomorphic andalusite is rich in rotated inclusion trails and occasionally displays inclusion-free rims. Cordierite is sub-idiomorphic hexagonal to elongated ovoids with a homogeneous distribution of inclusions displaying weak rotation (Fig. 2-6I). Cordierite contains inclusions of all other porphyroblasts, andalusite contains inclusions of biotite and plagioclase, and biotite occasionally contains inclusions of plagioclase within its rim (Fig. 2-6I). Retrograde replacement of cordierite by pinite and chlorite varies in this zone. Where retrograde chlorite does not replace cordierite rims it appears as $<100 \mu \mathrm{m}$ lathes cross-cutting the matrix foliation and a $\sim 200 \mu \mathrm{m}$ thick pinite rim surrounds cordierite instead (Fig. 2-6H). Replacement by retrograde chlorite, when present, commonly occurs along cordierite interfaces that are parallel to the matrix foliation (Fig. 2-6G) as well as within cordierite cores (Fig. 2-6I). Fractures running perpendicular to $S_{1}$ are not common, although a foliation that strongly wraps porphyroblasts creating quartz pressure shadows was observed in COB3-S1-8 (Fig. 2-6G). Frequent inclusions of andalusite within cordierite may indicate minor cordierite growth at the expense of andalusite simultaneous with reaction (II) by the following KFMASH reaction:

$$
\text { And }+\mathrm{Chl}+\mathrm{Qtz}=\mathrm{Crd}+\mathrm{H}_{2} \mathrm{O}
$$

(3B) Bt-foliated matrix: COB-9, 10, 12

The matrix phases of quartz, plagioclase and muscovite coarsen up to $100 \mu \mathrm{m}$ and the foliation is dominated by biotite and muscovite $\left(\mathrm{S}_{1}\right)$. Tourmaline joins the 
assemblage as a trace matrix mineral. Biotite lathes reach sizes no greater than 300 $\mu \mathrm{m}$ and are abundant as inclusions in andalusite and cordierite. Plagioclase porphyroblasts were not observed. Poikiloblasts of andalusite $(0.3-1.0 \mathrm{~mm})$ and cordierite $(0.5-1.5 \mathrm{~mm})$ contain weakly merging parallel inclusion trails and are elongated parallel to $S_{1}$ (Fig. 2-6J, K). Andalusite is rarely idiomorphic, and contains a homogeneous distribution of inclusions, it is also observed as $<0.5 \mathrm{~mm}$ inclusions in cordierite. Ovoid cordierite frequently contains inclusion-rich cores where retrograde chlorite grows and a rim less abundant in inclusions with little to no pinite alteration (Fig. 2-6K). Retrograde chlorite is also present as $0.5 \mathrm{~mm}$ lathes cross-cutting the matrix foliation (Fig. 2-6L). Ilmenite-rich fractures are present as $S_{2}$ perpendicular to $S_{1}$ in the matrix and through the porphyroblasts (Fig. 2-6J). Cordierite containing inclusion-poor rims possibly provides evidence for the sequence of reaction (II) to (III).

(3C) Pre-kinematic And-Crd in Bt-foliated matrix: COB-27, 29, 31, COB2-S2-1, 2, 4

Muscovite is less abundant in the matrix of rocks where andalusite and cordierite contain poor inclusions trails $\left(\mathrm{S}_{1}\right)$ that are at an angle to the matrix foliation $\left(\mathrm{S}_{2}\right)$. The matrix is dominated by a biotite foliation that weakly wraps the porphyroblasts (Fig. 2-6M). Other matrix phases include muscovite, quartz, plagioclase, ilmenite and tourmaline. Both cordierite and andalusite are homogeneously poikiloblastic (Fig. $2-6 \mathrm{~N}$ ). Andalusite is $0.3-1.2 \mathrm{~mm}$ sub-equant with an elongation sub-parallel to $S_{2}$. Cordierite ovoids are $<1.0 \mathrm{~mm}$ and show no replacement by retrograde chlorite and little alteration to pinite, however 
muscovite lathes appear within the porphyroblasts and are not parallel to $S_{1}$, suggesting secondary muscovite growth at the expense of cordierite. Biotite is frequently included in cordierite and andalusite, while andalusite is occasionally observed as large inclusions in cordierite, reiterating reaction (II) sequentially followed by (III).

\section{The Inner Aureole}

(4) Kfs-Bt-And-Crd: COB2-S2-6, 7, 9, BB-45

Potassium feldspar appears as $0.5-1.0 \mathrm{~mm}$ porphyroblasts or as infrequent $<0.5$ $\mathrm{mm}$ crystals as part of the matrix. The matrix makes up approximately $40 \mathrm{vol} . \%$ and consists of quartz and plagioclase with foliated biotite and minor muscovite $\left(\mathrm{S}_{2}\right)$. Ilmenite coarsens up to $0.5 \mathrm{~mm}$ porphyroblasts (Fig. 2-60). Biotite is either part of the matrix foliation (Fig. 2-60) or forms $0.2-1.0 \mathrm{~mm}$ sub-idiomorphic porphyroblasts that are elongated parallel to the deformed matrix (Fig. 2-6P, Q, R). As a major phase, K-feldspar creates ovoids with few inclusions of quartz, ilmenite and biotite (Fig. 2-60). Cordierite occurs as $0.5-1.5 \mathrm{~mm}$ ovoids with inclusions of biotite and ilmenite, and alteration to pinite along its rims. Poikiloblastic andalusite is $0.5-1.5 \mathrm{~mm}$, sub-idiomorphic and contains inclusion-free rims. Weak inclusion trails $\left(\mathrm{S}_{1}\right)$ within porphyroblasts are sub-parallel (Fig. 2-60), parallel (Fig. 2-6P, Q) or rotated (Fig.2-6R) in relation to the matrix foliation, which locally wraps them.

Growth of K-feldspar porphyroblasts with abundant andalusite is defined by the KFMASH reaction of muscovite in muscovite-poor matrices. The presence of 
infrequent K-feldspar crystals in muscovite-rich matrices with abundant cordierite can be explained by the KFMASH reaction of biotite and andalusite:

$$
\begin{aligned}
& \mathrm{Ms}+\mathrm{Qtz}=\mathrm{And}+\mathrm{Kfs}+\mathrm{H}_{2} \mathrm{O} \\
& \mathrm{Bt}+\mathrm{And}+\mathrm{Qtz}=\mathrm{Crd}+\mathrm{Kfs}+\mathrm{H}_{2} \mathrm{O}
\end{aligned}
$$

\subsubsection{Cordierite and Chlorite Chemistry}

Chemical profiles across cordierite porphyroblasts from Zone 2 (COB3-S1-5, COB3-S1-7 and COB-6) with mol. \% of $\mathrm{Na}, \mathrm{Fe}, \mathrm{Mg}$ and Mn can be found in Appendix II. Overall, the porphyroblasts are chemically homogeneous with respect to Mn and show weak variation in $\mathrm{Na}, \mathrm{Fe}$ and $\mathrm{Mg}$, however no clear trends are observed from core to rim consistently for every crystal. A few cordierites that were analyzed show an increase in mol. \% Fe and a decrease in mol. \% Mg from core to rim (e.g.; Crd1 and 3 from COB3-S1-5), but this is a weak chemical zonation that does not adjust by more than 0.04 mol. \%. The modal amounts of each element are the same for the cordierite in the three samples, with the greatest variation in $\mathrm{Na}$ from $0.15 \mathrm{~mol} . \%$ in COB3-S1-5 to 0.10 mol. \% in COB3-S1-7 and 0.08 mol. \% in COB-6. Mn rests around 0.01-0.02 mol. \% in all cordierites while Fe and Mg hover around 0.37-0.40 mol. \% and $0.46-0.50 \mathrm{~mol} . \%$, respectively. The average $\mathrm{Mg \#}$ from each analyzed cordierite is listed in Table 2-4 and is 0.54-0.55 in CT_009 (the CT scan of COB3-S1-5), COB3S1-7 and COB-6. The average Mg\# value for cordierite in sample COB3-S1-5 approaches 0.56 . 
Chlorite analyses from DeBuhr (1999) of the protolith sample (COB-14) and samples containing prograde chlorite (Zones 1 and 2) are displayed in Table 2-5 alongside analyses of retrograde chlorite in COB3-S1-5. There is no difference between the chemistry of prograde chlorite and the two types of retrograde chlorite in COB3-S1-5.

Table 2-4. Average cordierite $\mathrm{Mg} \#=\mathrm{Mg} /(\mathrm{Mg}+\mathrm{Fe})$ based on chemical profile analyses across cordierite porphyroblasts in rock samples from Zone 2 (Appendix II). CT_009 is a thin section of the scanned rock core of COB3-S1-5.

\begin{tabular}{|c|c|c|c|c|}
\hline & COB3-S1-5 & CT_009 & COB3-S1-7 & COB-6 \\
\hline Crd1 & 0.556 & 0.541 & 0.545 & 0.547 \\
\hline Crd2 & 0.561 & 0.547 & 0.545 & 0.543 \\
\hline Crd3 & 0.559 & 0.544 & 0.541 & 0.543 \\
\hline Crd4 & 0.555 & & 0.540 & \\
\hline Crd5 & 0.552 & & & \\
\hline Crd6 & 0.555 & & & \\
\hline Average & $\mathbf{0 . 5 5 7}$ & $\mathbf{0 . 5 4 4}$ & $\mathbf{0 . 5 4 3}$ & $\mathbf{0 . 5 4 4}$ \\
\hline
\end{tabular}


Table 2-5. Chlorite analyses in number of cations from protolith chlorite and prograde chlorite analysed by DeBuhr (1999) and of retrograde chlorite from the rim and core of cordierite in COB3-S1-5 analyzed in this study.

\begin{tabular}{|c|c|c|c|c|c|c|c|}
\hline Chl Type & Sample & $\mathbf{S i}$ & $\mathbf{T i}$ & $\mathbf{A l}$ & $\mathbf{F e}^{2+}$ & $\mathbf{M n}^{2+}$ & $\mathbf{M g}$ \\
\hline \multirow{3}{*}{ Protolith Chl } & COB-14 & 2.612 & 0.003 & 2.941 & 2.248 & 0.006 & 2.083 \\
\hline \multirow{4}{*}{ Prograde Chl } & COB3-S1-1 & 2.611 & 0.006 & 2.888 & 2.312 & 0.029 & 2.081 \\
\cline { 2 - 8 } & COB3-S1-2 & 2.621 & 0.006 & 2.887 & 2.203 & 0.019 & 2.169 \\
\cline { 2 - 8 } & COB3-S1-5 & 2.702 & 0.006 & 2.917 & 2.282 & 0.017 & 1.803 \\
\cline { 2 - 8 } & COB3-S1-7 & 2.584 & 0.007 & 2.930 & 2.505 & 0.022 & 1.887 \\
\cline { 2 - 8 } & COB-6 & 2.594 & 0.006 & 3.029 & 2.330 & 0.022 & 1.873 \\
\hline Retrograde (Crd rim) & COB3-S1-5 & 2.578 & 0.008 & 2.950 & 2.467 & 0.015 & 1.915 \\
\hline Retrograde (Crd core) & COB3-S1-5 & 2.579 & 0.007 & 2.945 & 2.483 & 0.017 & 1.906 \\
\hline
\end{tabular}

\subsubsection{Phase Equilibria}

The bulk rock chemistries obtained by DeBuhr (1999; Table 2-2) were used to predict equilibrium phase diagrams and $\mathrm{Mg \#}$ isopleths of cordierite and biotite using the database tcdb55c2_COH_prltbi2 (Appendix I).

\section{Effect of a COH-Fluid}

Figure 2-7 displays two phase diagrams produced by Theriak-Domino for the bulk composition of COB3-S1-5 using the thermodynamic database of Holland and Powell (1998); tcdb55c2_COH_prltbi2 (Appendix I). Figure 2-7A does not use a 
solution model for the fluid phase and considers the fluid to be $100 \%$ water or $\mathrm{X}_{\mathrm{H} 20}$ $=1$. Figure 2-7B considers a $\mathrm{COH}$-fluid in equilibrium with graphite according to Connolly and Cesare (1993), causing $\mathrm{X}_{\mathrm{H} 2 \mathrm{O}}<1$. The addition of carbon to the thermodynamic system is shown to have a major impact on the stability of most phase assemblages, especially those which contain water-bearing phases The production of $\mathrm{CO}_{2}$, $\mathrm{CO}$ and $\mathrm{CH}_{4}$, along with $\mathrm{H}_{2} \mathrm{O}$ creates a more dynamic fluid system that causes the stability of assemblages with $\mathrm{H}_{2} \mathrm{O}$-bearing phases (e.g.; $\mathrm{Chl}$, Ms, $\mathrm{Bt}$ and $\mathrm{Crd}$ ) to shrink. In addition, phases that grow at the expense of these minerals are affected (e.g.; Grt) allowing them to grow at lower P and T. It has been shown that as temperature increases, $\mathrm{C}+\mathrm{H}_{2} \mathrm{O}$ react to produce $\mathrm{CO}_{2}+\mathrm{CH}_{4}$, resulting in a decrease in $\mathrm{X}_{\mathrm{H} 20}$ with $\mathrm{T}$ (Ohmoto \& Kerrick, 1977). As the water content of the fluid decreases with rising $\mathrm{T}$, water-bearing phases become less stable allowing for the stability of their products.

When considering a $\mathrm{COH}$-fluid (Fig. 2-7B), the stability field of the dominant Crd-bearing assemblage within the Bugaboo aureole (labelled Ms-Pl-Bt-And-Crd) shrinks by $\sim 1$ kbar, a significant amount when interpreting the depth of the batholith intrusion. The crystal structure of cordierite can hold water causing the stability of phase assemblages with cordierite to be sensitive to changes in fluid composition. Because it may be unrealistic to assume a fluid of pure $\mathrm{H}_{2} \mathrm{O}$ in a metapelite, and in order to consider the influence of the fluid composition on metamorphic phase equilibria, a database was chosen that included carbon within the chemical system. 

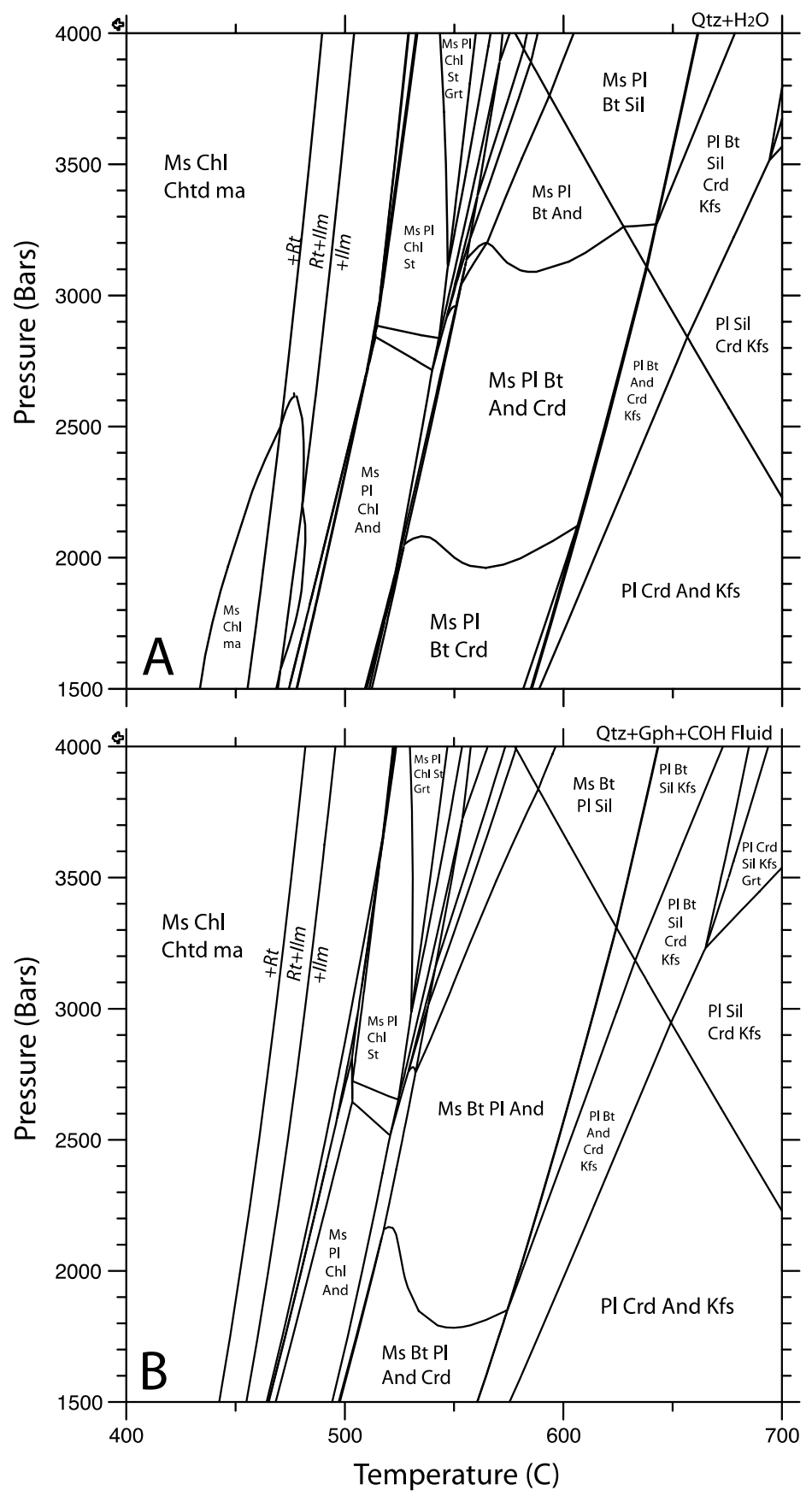

Figure 2-7. Phase equilibria for sample COB3-S1-5 (Zone 2) predicted by Theriak/Domino using the thermodynamic database enclosed in Appendix I. (A) Carbon is not considered part of the chemical system and (B) carbon is considered part of the system and graphite is predicted to equilibrate with a COH fluid according to Connolly and Cesare (1993). Mineral abbreviations after Kretz (1983). 


\section{Predicted Equilibrium Assemblages}

All the phase diagrams produced for each bulk rock composition can be found in Appendix III with mineral abbreviations after Kretz (1983). The prediction by Theriak/Domino of the P-T conditions of phase assemblages varies between rocks and is a direct result of the different bulk rock chemistries that were sampled. The P-T stability of the equilibrium assemblage Ms-Pl-Bt-And-Crd is of interest because it dominates the middle aureole mineralogy (Zone 3) and places a constraint on the maximum estimated $\mathrm{P}$ reached. The univariant line that bounds the upper $\mathrm{P}$ limit of this multi-variant assemblage fluctuates from 1.0-2.2 kbar between phase diagrams in Appendix III (also see Table 2-6). Within the $60^{\circ} \mathrm{C}$ that the assemblage is in equilibrium, this upper univariant line curves so that the field shrinks to lower P before growing again at higher T (Fig. 2-8). Assuming an isobaric heating path that crosses this univariant curve, such as the dotted lines in Figure 28, cordierite is predicted to possibly experience two growth episodes. First, cordierite is produced at the expense of chlorite, when the univariant curve is crossed the Crd-bearing assemblage goes out of equilibrium and one bearing all other phases becomes stable. A second crossing of the univariant curve by the isobaric P-T path results in the growth of cordierite once more, this time at the expense of muscovite and with the co-production of K-feldspar. An isobaric heating path at lower P that does not cross this curve, such as the solid lines in Figure 2-8, would experience only one cordierite-producing reaction, at low $\mathrm{T}$ by the expense of chlorite. Two bulk compositions, COB3-S1-8 and COB2-S2-7, predict a positive slope for this line instead of the curved line that is predicted for all other compositions. 
Table 2-6. Predicted $\mathrm{T}$ range for the mineral assemblage observed in each rock sample at the maximum P possible in Zone 3 assuming isobaric heating (see Fig. 2-8 for example P-T paths). The values are predicted by Theriak/Domino, as highlighted in Figure 2-8 and Appendix III.

\begin{tabular}{|c|c|c|c|}
\hline Sample & $\begin{array}{c}\text { Metamorphic } \\
\text { Zone }\end{array}$ & Temperature $\left({ }^{\circ} \mathrm{C}\right)$ & Pressure (kbar) \\
\hline COB-14 & Protolith & $450-485$ & 1.55 \\
\hline COB3-S1-1 & 1 & 505 & 1.80 \\
\hline COB3-S1-2 & \multirow{4}{*}{2} & 510 & 1.70 \\
\hline COB3-S1-5 & & 510 & 1.75 \\
\hline \multirow{2}{*}{$\begin{array}{c}\text { COB3-S1-7 } \\
\text { COB-6 }\end{array}$} & & 490 & 1.30 \\
\hline & & 505 & 1.75 \\
\hline \multirow{5}{*}{$\begin{array}{c}\text { COB3-S1-8 } \\
\text { COB3-S1-10 } \\
\text { COB3-S1-12 } \\
\text { COB3-S1-15 } \\
\text { COB-25 }\end{array}$} & \multirow{5}{*}{$3 \mathrm{~A}$} & $500-565$ & 1.65 \\
\hline & & $505-560$ & 1.65 \\
\hline & & $500-560$ & 1.55 \\
\hline & & 505-560 & 1.65 \\
\hline & & $510-575$ & 1.75 \\
\hline COB-9 & \multirow{3}{*}{ 3B } & - & - \\
\hline COB-10 & & $480-545$ & 1.10 \\
\hline COB-12 & & $510-575$ & 1.80 \\
\hline \multirow{6}{*}{$\begin{array}{c}\text { COB-27 } \\
\text { COB-29 } \\
\text { COB-31 } \\
\text { COB2-S2-1 } \\
\text { COB2-S2-2 } \\
\text { COB2-S2-4 }\end{array}$} & \multirow{6}{*}{$3 \mathrm{C}$} & $480-550$ & $<1.50$ \\
\hline & & $500-560$ & 1.35 \\
\hline & & $490-550$ & 1.25 \\
\hline & & $474-540$ & $<1.00$ \\
\hline & & - & - \\
\hline & & $500-560$ & 1.60 \\
\hline \multirow{3}{*}{$\begin{array}{l}\text { COB2-S2-6 } \\
\text { COB2-S2-7 } \\
\text { COB2-S2-9 }\end{array}$} & \multirow{3}{*}{4} & $560-580$ & 1.55 \\
\hline & & $575-595$ & 1.90 \\
\hline & & $570-590$ & 1.65 \\
\hline
\end{tabular}




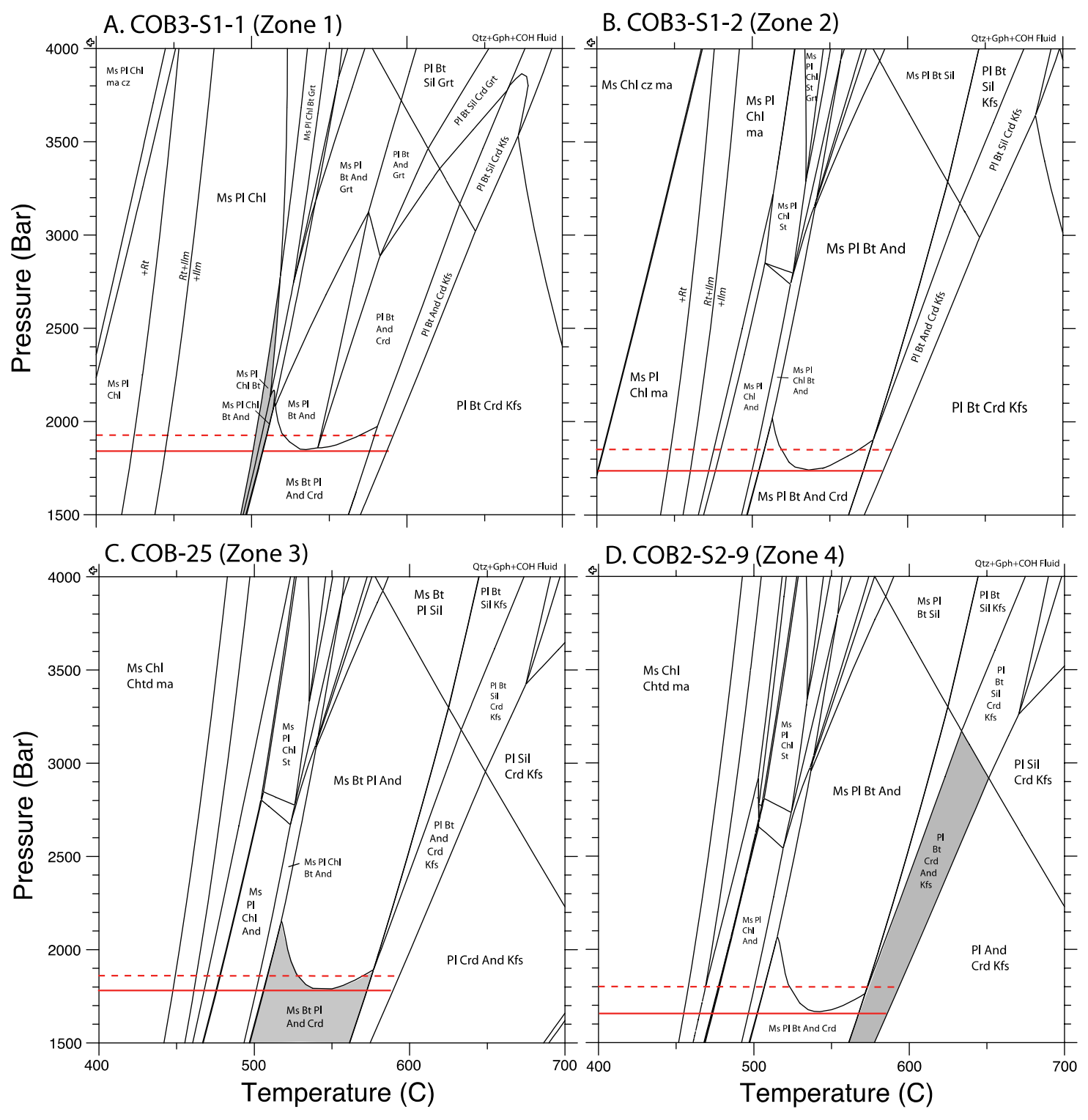

Figure 2-8. Phase equilibria predicted by Theriak/Domino using the thermodynamic database in Appendix I for a representative sample from each metamorphic zone of the Bugaboo contact aureole. Highlighted multi-variant fields and univariant line (for Zone 2) correspond to the observed mineral assemblage within that metamorphic zone. The dotted red lines illustrate a P-T path that crosses the Crd-consuming univariant line, resulting in two episodes of Crd growth. The solid red lines illustrate a P-T path that lies below the Crdconsuming univariant line, resulting in one low T production of Crd (see text for details). Mineral abbreviations after Kretz (1983). 
For all the phase diagrams, at $\mathrm{T}$ greater than the equilibrium of this Zone 3 assemblage, commonly when K-feldspar comes into equilibrium and muscovite goes out, assemblages with cordierite are predicted to be stable over a greater P range.

The prediction of a smaller stability field for Ms-bearing assemblages and a larger stability for Bt-bearing assemblages occur for respective Fe-Mg-rich rocks; COB3-S1-7, COB3-S1-15, COB-9, COB-27, COB-29 and COB2-S2-2. Additionally, these bulk rock compositions also predict a lower $\mathrm{T}$ stability for Crd-bearing assemblages. A similar arrangement is predicted for samples COB3-S1-1, COB-6 and COB2-S2-6, where muscovite is predicted to destabilize at intermediate $\mathrm{T}$ prior to the production of cordierite and K-feldspar. These samples also have a respectively higher Fe-Mg content than samples where muscovite consumption is predicted to parallel K-feldspar production.

Bulk rock compositions of relatively high $\mathrm{Mn}$ content are predicted to stabilize garnet at low $\mathrm{P}$, occasionally $<2$ kbar and coming in contact with the mineral assemblages that are observed in the Bugaboo contact aureole, although garnet was not observed. Samples COB-9 and COB2-S2-2 do not predict a field in which muscovite and cordierite are stable together, even below $1.5 \mathrm{kbar}$. These two issues may be indications of bulk rock compositions that are not representative of the rock and its observed mineral assemblage.

Each diagram has the univariant line or the multi-variant field shaded that corresponds to the rock's peak metamorphic mineral assemblage (Appendix III). The range of $T$ values for this shaded region is listed in Table 2-6 along with the maximum P possible for an isobaric heating path to remain within the multi-variant 
field of Zone 3 (Ms-Pl-Bt-And-Crd), as illustrated by the solid lines in Figure 2-8. The $\mathrm{T}$ values do not vary greatly between samples within the same metamorphic zone. The P estimates consistently remain $<1.90$ kbar with a few reaching below 1.0 kbar. Six samples predict a P < 1.50 kbar; COB3-S1-7, COB-10, COB-27, COB-29, COB-31 and COB2-S2-1 (Table 2-6).

A representative sample from each zone is displayed in Figure 2-8. Zone 1 corresponds to andalusite and possibly biotite porphyroblasts in a chlorite-rich matrix at peak conditions of $505^{\circ} \mathrm{C}$ and $1.83 \mathrm{kbar}$ (Fig. 2-8A). The reaction Zone 2 containing chlorite and cordierite is estimated to be stable at $510^{\circ} \mathrm{C}$ and $1.72 \mathrm{kbar}$ (Fig. 2-8B). The largest zone within the aureole, Zone 3, spans from $510-575^{\circ} \mathrm{C}$ at 1.78 kbar (Fig. 2-8C). It should be noted that the $\mathrm{P}$ estimates for this zone are different for each specific bulk rock composition, however the $\mathrm{T}$ range remains relatively consistent (Table 2-6). Approaching the contact, Zone 4 begins at $560^{\circ} \mathrm{C}$ at $1.65 \mathrm{kbar}$ and can reach up to $650^{\circ} \mathrm{C}$ if $\mathrm{P}$ increases to $2.9 \mathrm{kbar}$ (Fig. 2-8D). The upper $\mathrm{T}$ limit of this zone is defined by the stability of Bt-bearing assemblages while the maximum $P$ is defined by the stability of And-bearing assemblages.

\section{Cordierite and Biotite Isopleths}

The Mg\# $(\mathrm{Mg} / \mathrm{Mg}+\mathrm{Fe})$ of cordierite and biotite was predicted by Theriak/Domino to compare with chemical trends observed in the aureole. The isopleths for COB3-S1-5, COB3-S1-7 and COB-6 are displayed in Figure 2-9 and Mg\#$\mathrm{T}$ and $\mathrm{n}-\mathrm{T}$ graphs are shown in Figure 2-10. Throughout the multi-variant field MsPl-Bt-And-Crd (Zone 3) the Mg\# of both cordierite and biotite is relatively 

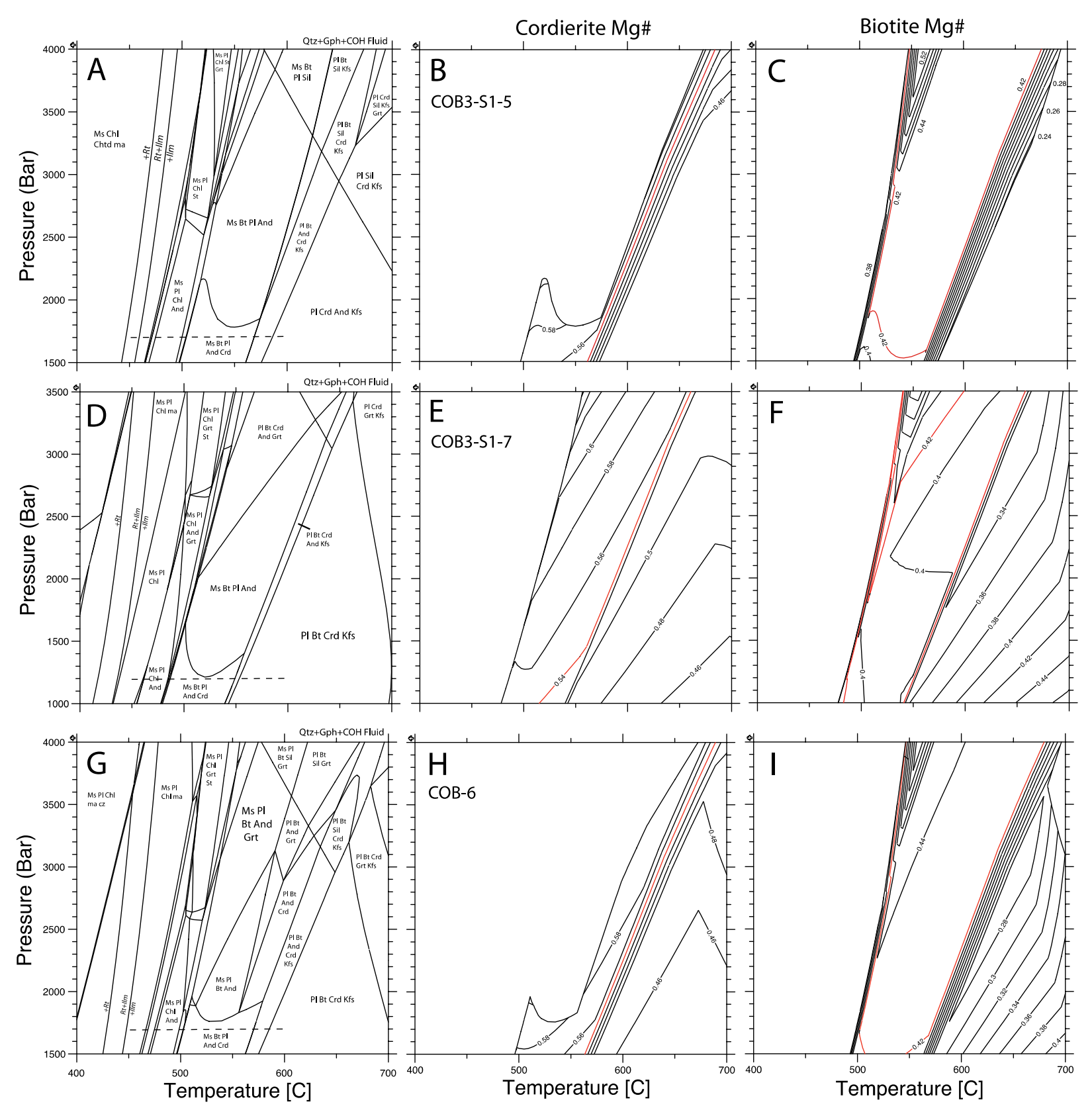

Figure 2-9. Mg\# isopleths calculated by Theriak/Domino using database in Appendix I for COB3-S1-5 (A,B,C), COB3-S1-7 (D,E,F) and COB-6 (G,H,I) in which the chemistry of cordierite was analyzed. See Appendix II for cordierite profiles. Highlighted isopleths represent the average observed Mg\# for each sample (Fig. 2-5 for Bt and Table 2-5 for Crd). Dotted lines on phase equilibrium diagrams represent the P-T path for Fig. 2-10. 

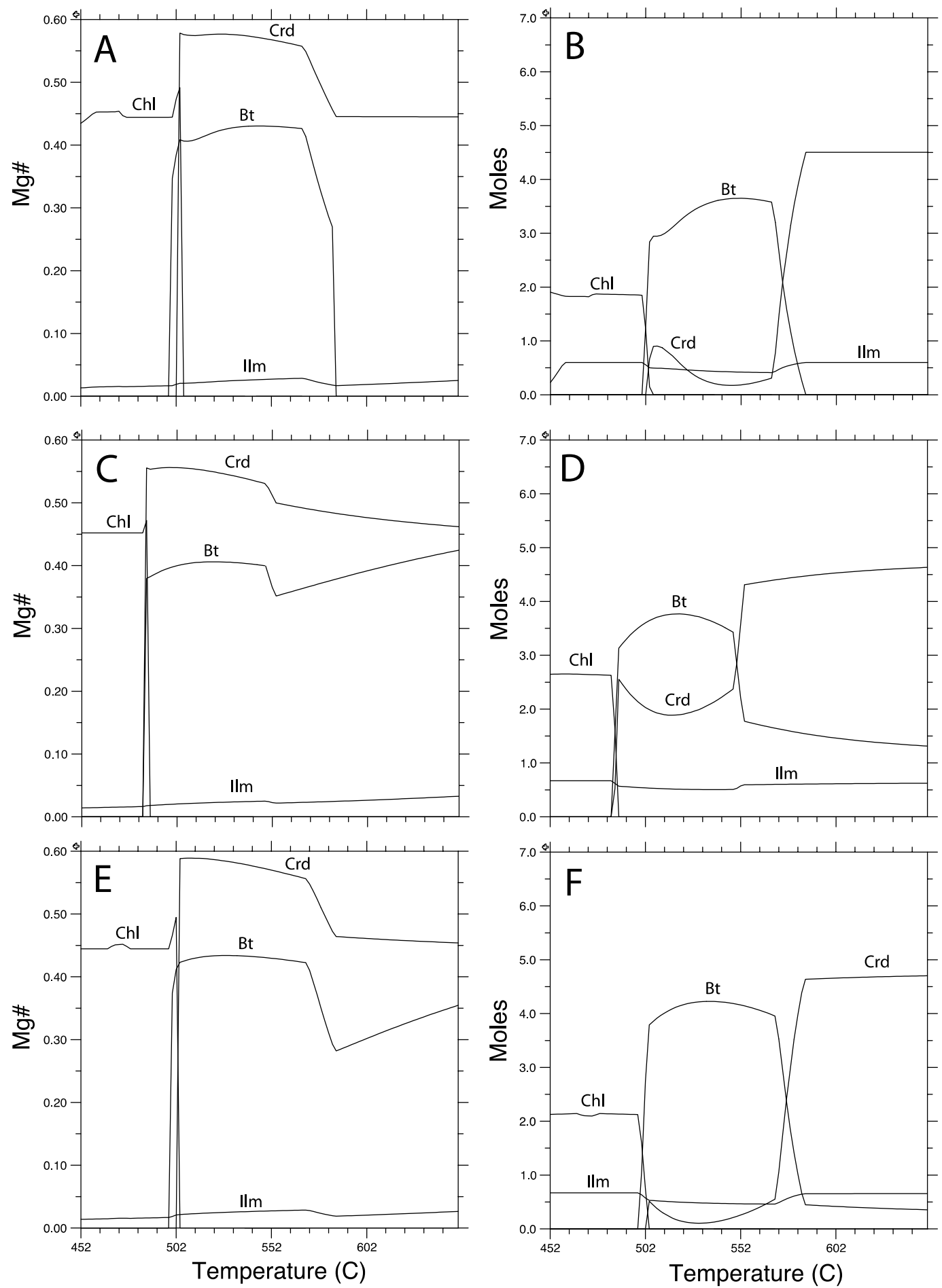

Figure 2-10. Mg\#-T and n- $\mathrm{T}$ plots for ilmenite, chlorite, biotite and cordierite in COB3-S1-5 at 1.7 kbar (A-B), COB3-S1-7 at 1.2 kbar (C-D) and COB-6 at 1.7 kbar (E-F) predicted by Theriak/Domino along the dotted lines of Figure 2-9A, D and G. The shaded regions represent the $T$ intervals of observed mineral assemblages at Cobalt Lake. Fe-enrichment in Crd and Bt within Zone 4 corresponds to molar changes in both phases (see text for discussion). 
homogeneous although their compositions are predicted to be strongly $\mathrm{T}$ dependent.

Overall, cordierite is estimated to decrease in $\mathrm{Mg \#}$ with rising $\mathrm{T}$ for the three bulk rock compositions (Fig. 2-9B, E, H). During the first $60^{\circ} \mathrm{C}$ of cordierite growth, its Mg\# decreases by no more than 0.04 from 0.60 for COB3-S1-5 and COB-6, and from 0.56 for COB3-S1-7. The beginning of Zone 4 coincides with a rapid decrease in cordierite Mg\# until either Bt- or And-bearing assemblages go out of equilibrium, after which the Mg content of cordierite gradually decreases (Fig. 2-10A, C, E). When garnet is predicted to join the stable mineral assemblage at higher T, the Mg\# of cordierite is predicted to gradually increase again (Fig. 2-9E, H).

Biotite is predicted to increase in $\mathrm{Mg \#}$ within the $\mathrm{T}$ range from which it initially equilibrates to when chlorite destabilizes, approximately $5^{\circ} \mathrm{C}$, after which it is predicted to remain around 0.40-0.42 (Fig. 2-9C, F, I). When the T for Zone 4 is reached, the Mg\# of biotite is estimated to decrease in COB3-S1-5 until it goes out of equilibrium. In COB3-S1-7 and COB-6, the Mg\# of biotite is estimated to decrease until the destabilization of andalusite, after which it increases again until biotite goes out of equilibrium. The biotite Mg\# isopleths become more T-dependent with the equilibrium of Grt-bearing mineral assemblages (Fig. 2-9F, I).

Assemblages bearing chlorite, K-feldspar, andalusite, staurolite and garnet have a significant effect on the chemistry of these two phases, in addition to the effect of each phase on one another. As Chl-bearing assemblages go out of equilibrium and Crd-bearing assemblages become stable, the Mg\# of biotite becomes less $\mathrm{T}$ dependent until K-feldspar is produced. At low $\mathrm{T}$, the Mg\# of 
cordierite is weakly dependent on T (Fig. 2-9E), but when it joins the equilibrium assemblage at higher P-T its Mg\# is strongly $\mathrm{T}$ dependent (Fig. 2-9B, H). The $\mathrm{T}$ dependency of the Mg-Fe content of cordierite and biotite increases for the P-T range that corresponds to Zone 4 where they are both predicted to become richer in Fe until the breakdown of biotite or andalusite (Fig. 2-10A, C, E). The consumption of biotite is predicted to be simultaneous with the leveling out of the Mg\# of cordierite. When Bt-bearing assemblages are stable at higher $\mathrm{T}$, the consumption of andalusite parallels the beginning of gradual Mg-enrichment in biotite (Fig. 2-9F, I) and Fe-enrichment in cordierite (Fig. 2-9E, H). Garnet is predicted to affect the composition of cordierite and biotite at high $\mathrm{T}$ by consuming Fe and causing Mgenrichment in both phases, at low $\mathrm{T}$ garnet does not affect the composition of cordierite (Fig. 2-9E) and only affects biotite when cordierite is not part of the mineral assemblage (Fig. 2-9F, I). St-bearing assemblages are predicted to enrich biotite in Mg content at high P conditions (Fig. 2-9C, F, I). The most intriguing feature of the predicted isopleths is the Fe-enrichment of cordierite and biotite between the $\mathrm{T}$ at which $\mathrm{K}$-feldspar joins the stable mineral assemblage to when biotite or andalusite destabilize, within Zone 4. This corresponds to a drastic change in the molar proportions of both phases (Fig. 2-10B, D, F), with biotite decreasing and cordierite increasing in abundance.

\subsubsection{Computed Tomography}

The majority of scanned samples do not display contrasts in X-ray attenuation between separate phases, thus making segmentation difficult or 
impossible. The samples that showed potential for cordierite segmentation are COB3-S1-5 (CT_009), COB3-S1-7 (CT_033) and COB-6 (CT_041), all from metamorphic Zone 2 (Fig. 11A-C). The X-ray attenuation of cordierite in these samples is lower than the remainder of the rock, with the exception of CT_009, which contains cordierite that displays a range of attenuation values (Fig. 2-11A). Samples COB2-S2-1 (CT_044) and COB2-S2-2 (CT_045) displays low attenuating equant andalusite porphyroblasts for possible segmentation (Fig. 2-11D-E). However, due to the high volume fraction of porphyroblasts, the interlocking of like porphyroblast phases and the small degree of contrast between visible phases and the matrix, segmentation remained difficult in this study.

CT_009 contains a relatively small volume fraction of spaced cordierite porphyroblasts that are visible for two reasons; they contain regions of low X-ray attenuation and are surrounded by a rim of higher attenuation material (Fig. 2-11A). These adjacent contrasts allowed cordierite to be manually segmented in Avizo with the orthogonal slice method (Section 2.3.5). Biotite porphyroblasts are clearly visible as highly attenuating areas dispersed throughout a lower attenuating matrix. The andalusite porphyroblasts are not visible due to their similar attenuations to the dominate rock phases quartz and muscovite. Plagioclase porphyroblasts absorb less X-rays than the matrix and can be seen upon close inspection, however their size introduces the volume effect, which makes them difficult to see and segment. A weak lineation is observable in the plagioclase porphyroblasts which runs parallel to the lineation of biotite porphyroblasts and at an angle to highly attenuating laminations present in the rock matrix (Fig. 2-11A). 


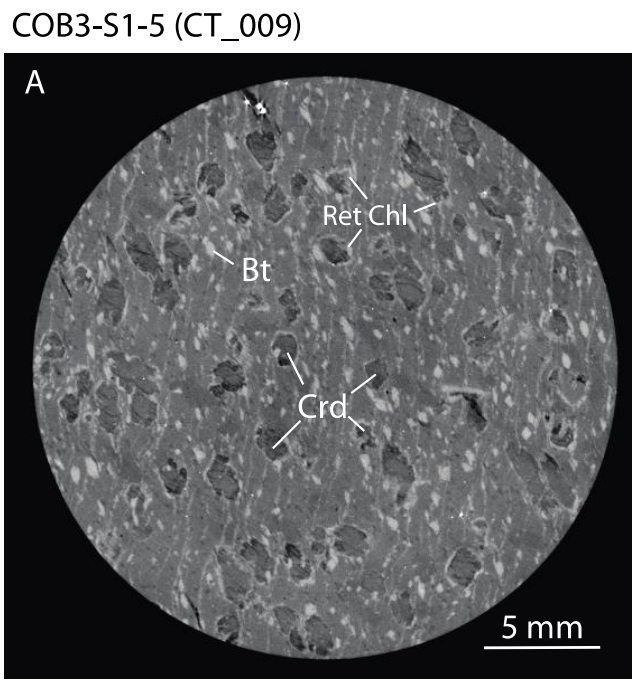

COB-6 (CT_041)

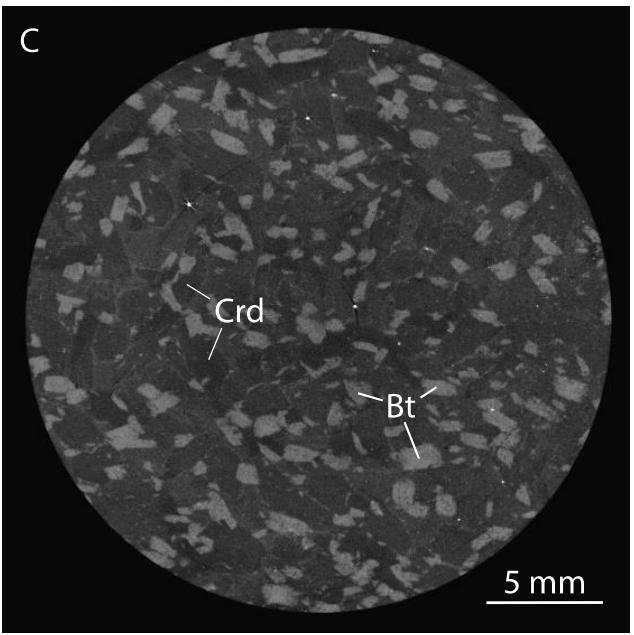

COB2-S2-2 (CT_045)

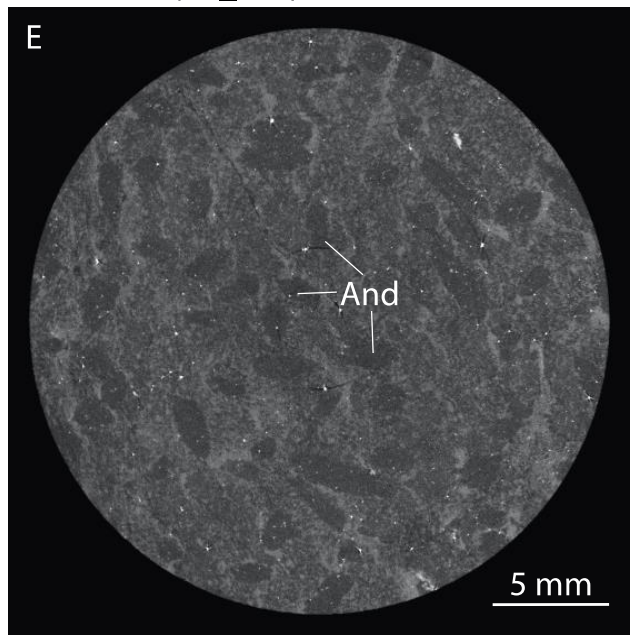

\section{COB3-S1-7 (CT_033)}

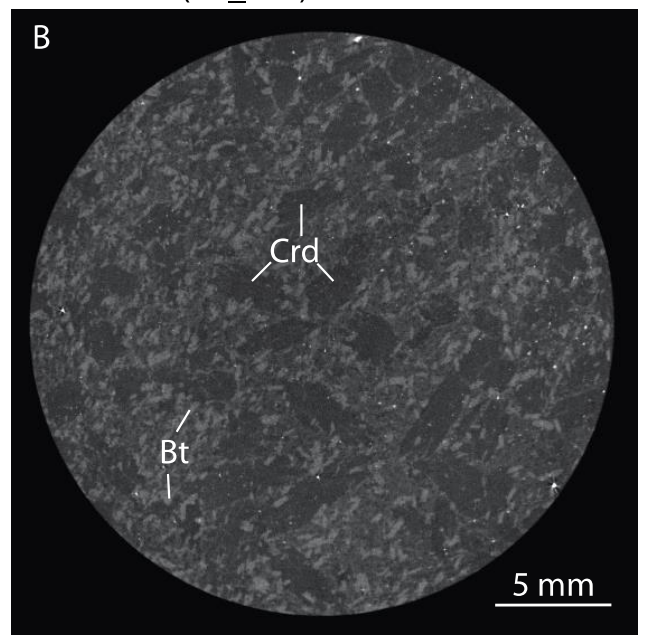

COB2-S2-1 (CT_044)

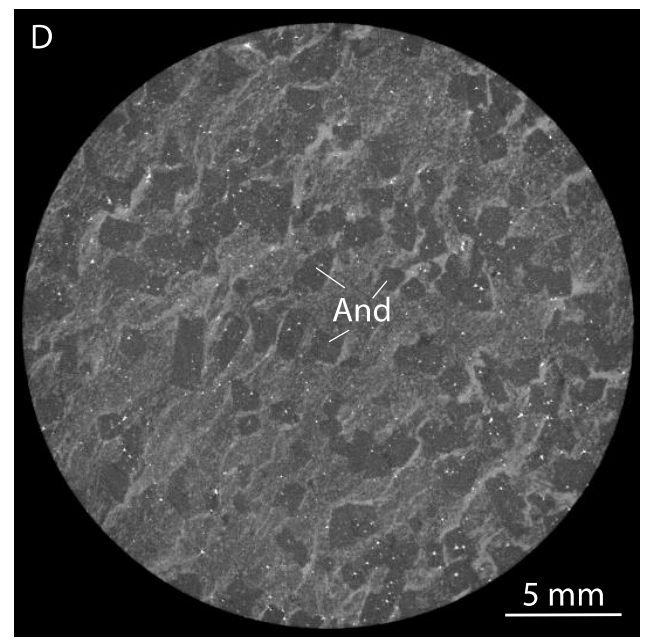

Figure 2-11. Computed tomography data for Bugaboo samples that show potential for Crd (A-C) and And (D-E) segmentation. (A) Crd from COB3-S1-5 shows a variation in Xray attenuation and is surrounded by a high $\mathrm{X}$-ray attenuating rim. Bt porphyroblasts are also visible. (B) Crd from COB3-S1-7 shows homogeneous X-ray attenuation and more abundant interlocking Bt porphyroblasts. (C) COB-6 contains large Bt porphyroblasts but weak contrast between Crd and the matrix phases. (D) Equant And is visible in COB2-S2-1 due to contrast with the highly attenuating Bt-rich matrix. (E) Equantly elongated And visible in COB2-S2-2. 
The specific chemistries of the mineral phases in CT_009 were used to calculate their corresponding X-ray attenuation on the NIST website. The resulting graph is shown in Figure 2-12 and displays an exponential decrease in X-ray absorption with increasing X-ray energy. The relative X-ray attenuation between different phases remains constant for the majority of the spectrum, with ilmenite as the highest, followed by biotite and chlorite, then cordierite, muscovite and the lowest attenuating phases andalusite, albite and quartz. The unique variation in Xray attenuation of cordierite in CT_009 (Fig. 2-11A), which is not a result of chemical heterogeneities according to Figure 2-12, allowed for its segmentation from the rock and the extraction of every porphyroblast's size, shape and position which will be discussed in greater detail in Chapter 3.

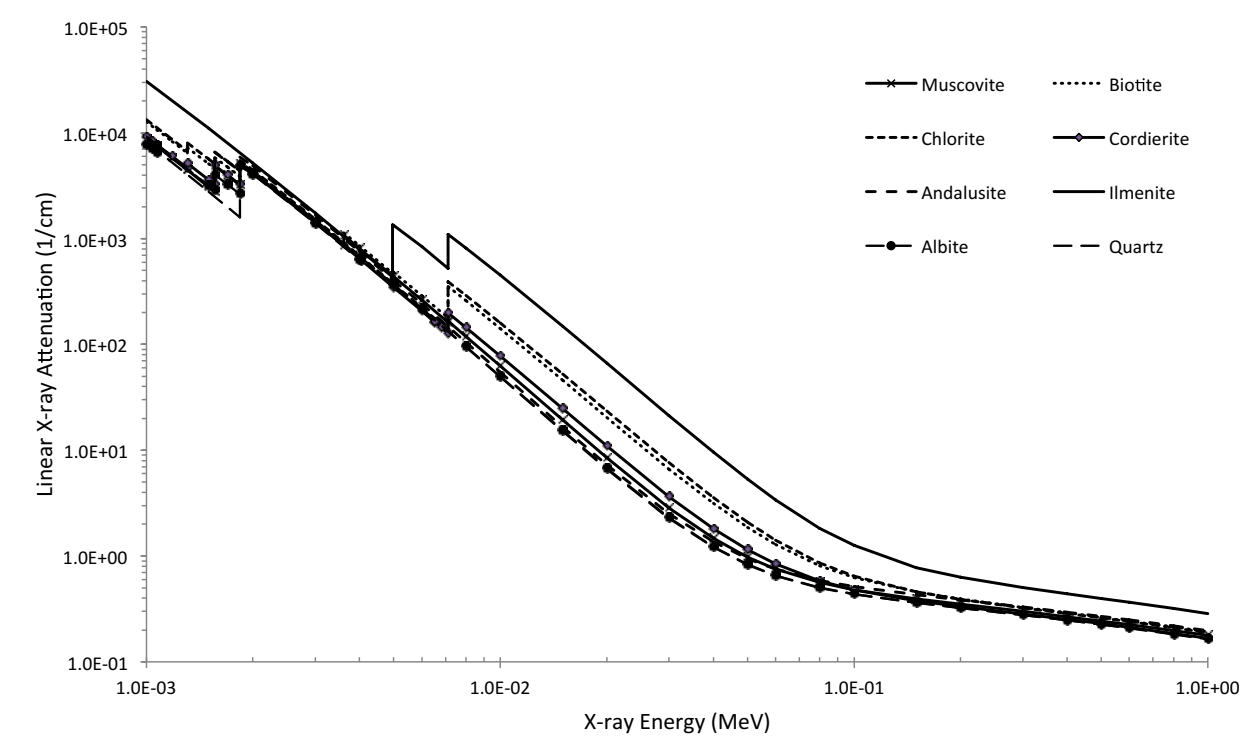

Figure 2-12. Linear X-ray attenuation coefficient of mineral phases in COB3-S1-5 (CT_009) calculated on the NIST website (Section 2.3.4). Mineral chemistries obtained by DeBuhr (1999) and the author were used with a density value predicted by Theriak/Domino for $510^{\circ} \mathrm{C}$ and $1.6 \mathrm{kbar}$. Samples were scanned at an X-ray energy spectrum of 40-130 keV (0.04-0.13 MeV). See Figure 2-11A for CT image. 


\subsection{Discussion}

Combining the observations from previous work on the Bugaboo contact aureole and results obtained in this study by the author the following discussion will work towards understanding the metamorphic history of the aureole as a whole. Furthermore, explanations for the visibility of certain porphyroblasts in CT will be discussed.

\subsubsection{Prograde Metamorphic Mineral Growth}

The sequence of porphyroblast growth was compared to the order of equilibrium reactions crossed during an isobaric increase in $\mathrm{T}$ for the phase diagrams enclosed in Appendix III. The kinematic growth of mineral phases in relation to $\mathrm{D}_{1}$ (deformation of the matrix in Zones 1,2 and $3 \mathrm{~A}$ ) and $\mathrm{D}_{2}$ (deformation of the matrix in Zones 3B, 3C and 4) is discussed.

Beginning in Zone 1, the presence of minor andalusite porphyroblasts matches phase equilibria as the first major porphyroblast to crystallize. The muscovite-chlorite pseudomorphs in COB3-S1-1 (Fig. 2-6B) were thought to be alteration of cordierite (DeBuhr, 1999; Pattison and DeBuhr, 2015), but the growth of cordierite prior to biotite is not predicted in phase equilibria (Fig. 2-8). Therefore, a more likely host to these pseudomorphs is biotite porphyroblasts. Upon inspection of the equant shape of the mica aggregates (Fig. 2-6B), this conclusion may be more reasonable suggesting progress of the $\mathrm{KFMASH}$ reaction $\mathrm{Ms}+\mathrm{Chl}=\mathrm{And}+\mathrm{Bt}+\mathrm{Qtz}+$ $\mathrm{H}_{2} \mathrm{O}$. If the pseudomorphs are after cordierite then either the bulk rock composition or thermodynamic database used in this study are not appropriate. The biotite 
pseudomorphs and andalusite porphyroblasts contain rotated merging inclusion trials indicating syn- $\mathrm{D}_{1}$ growth.

Inclusion relationships in thin sections for Zones 2 and $3 \mathrm{~A}$ clearly show cordierite as the final phase to complete crystallization, embedding previously grown phases (plagioclase, biotite, andalusite) as inclusions within its structure (Fig. 2-6E, F, H, I). These inclusions commonly appear within the outer rim of cordierite porphyroblasts, possibly suggesting that the two phases nucleated and grew together before the included phase ceased growing and cordierite continued growth around it. The presence of included phases in cordierite is an indication that cordierite did not require full consumption and destabilization of that phase in order to nucleate and grow, therefore plagioclase, biotite and andalusite are passive phases in relation to the Crd-producing reaction. All phase diagrams match these observations and predict cordierite to grow after plagioclase, biotite and andalusite (Fig. 2-8). The presence of biotite and plagioclase inclusions in andalusite (Fig. 2-6C, G, H) indicates the growth of andalusite simultaneously with and dominantly after its included phases. However, phase equilibria modeling predicts the Bt-producing reaction to occur after that of andalusite (Fig. 2-8), with the exception of COB3-S1-1, COB-9, COB-31 and COB2-S2-7 (Appendix III). Additionally, a few bulk rock compositions result in the prediction of the andalusite and biotite reaction occurring simultaneously (e.g.; COB-12). The position of these univariant lines is evidently sensitive to bulk rock chemical changes. With that being said, petrography observations remain significant, with biotite growth completing before andalusite growth finishes, and all porphyroblasts growing syn-kinematic to $\mathrm{D}_{1}$. 
The matrix assemblage of Zones 3B and 3C, composed of foliated biotite, proposes the crystallization and deformation of biotite prior to andalusite and cordierite growth. This is reinforced by the presence of aligned biotite inclusions in both porphyroblasts (Fig. 2-6J, K). The identification of sillimanite in the upper limits of Zone 3C by DeBuhr (1999) and Pattison and DeBuhr (2015), describes fibrous crystals $<100 \mu \mathrm{m}$ in the matrix taking up no more than 0.1 vol. \% of the rock. These rare crystals may have only nucleated in Al-rich or highly strained regions, and are therefore not as significant for P-T estimates as it is not one of the dominant rock phases. The formation of biotite is interpreted to be pre- $\mathrm{D}_{1}$ with deformation syn- $\mathrm{D}_{1}$ alongside the growth of andalusite and cordierite. There is no distinction as to whether andalusite or cordierite continued growth after the other.

Zone 4, with the presence of K-feldspar, does not show clear evidence of this phase's growth after the crystallization of cordierite and andalusite. However, the absence of any K-feldspar crystals included in both of these phases and vice versa, and the similarity in their matrix relationships suggests simultaneous growth pre- $\mathrm{D}_{2}$ (Fig. 2-60). The presence of small aligned biotite inclusions in K-feldspar is evidence that biotite grew and experienced deformation prior to K-feldspar growth, during $\mathrm{D}_{1}$. Phase equilibria modeling predicts K-feldspar growth $\sim 60^{\circ} \mathrm{C}$ after cordierite and $\sim 70^{\circ} \mathrm{C}$ after andalusite, yet is texturally similar.

The simultaneous nucleation and growth of phases that are predicted to take place at different $\mathrm{T}$ may be an indication that the reactions were overstepped resulting in 'cascading' (Waters and Lovegrove, 2002; Pattison et al., 2011) or Ostwald's step rule (Threlfall, 2003). Cascading may occur if multiple reactions 
involving the same reactant phases are overstepped leading to the progression of all the reactions simultaneously and seemingly overlapping of porphyroblast growth. The Ostwald step rule states that in order for a specific reaction to proceed, all previous reactions must take place in order of kinetic favorability. Both theories state that the overstepping of multiple reactions will result in the sequential production of all their products over a short $\mathrm{T}$ range. Within Zone 2 and 3 of the Bugaboo aureole, the syn-kinematic growth of all porphyroblasts is explained by concurrent matrix deformation with heating. Possible overstepping of the And-, Btand Crd-producing reactions may have resulted in the nucleation of andalusite and biotite first in Zone 2, which are kinetically favourable before cordierite nucleation. Crystallization of cordierite is preferred once andalusite and biotite are part of the stable mineral assemblage and continued growing after their growth was completed, enclosing them as inclusions. A similar scenario may also explain the observed simultaneous growth of the same porphyroblasts in Zone 3 and K-feldspar with andalusite and cordierite in Zone 4.

\subsubsection{Retrograde Metamorphism}

The re-equilibration of the mineral assemblage during a decrease in $\mathrm{P}$ and $\mathrm{T}$ is evident by the presence of retrograde chlorite, pinite and pseudomorphism. Partial chlorite or pinite pseudomorphs after cordierite are common throughout Zone 2 (Fig. 2-6E, G, H, K) while there is no replacement of any other phase. Retrograde chlorite is observed to preferentially grow along the rims of cordierite in some samples (Fig. 2-6E, G), seen in the tomography of CT_009 (Fig. 2-11), while in 
others it is seen to only replace its core (Fig. 2-6I, K). This is interesting because the chemical profiles across analyzed cordierite show no chemical difference between core and rim in relation to $\mathrm{Fe}, \mathrm{Mg}, \mathrm{Na}$ and $\mathrm{Mn}$ (Appendix II). A potential explanation for the growth of retrograde chlorite within cordierite cores may be the presence of fractures in cordierite that expose the mineral's internal structure as a preferable nucleation site. An issue with this interpretation is the absence of chlorite within observed cordierite fractures. Preserved inclusions of chlorite from prograde metamorphism may provide a more reasonable explanation for the growth of chlorite within cordierite upon retrogression, markedly since this feature occurs within lower grade rocks of the middle and outer aureole where chlorite inclusions may have had the opportunity to become secured within a cordierite porphyroblast.

In samples where cordierite is not being replaced by retrograde chlorite, small retrograde chlorite lathes that cross-cut the matrix foliation are abundant (Fig. 2-6H, L). The nucleation of chlorite in the matrix, and not along pre-existing grain boundaries, suggests sufficient availability of nutrients during retrograde metamorphism for these rock samples. The chemistry of retrograde chlorite, whether in the core of cordierite, along the rim of cordierite, or in the matrix, is the same as the chemistry of prograde chlorite (Table 2-4) suggesting chemical equilibrium across the rock during retrograde metamorphism. Closer to the batholith contact, replacement of cordierite is seen by the secondary growth of muscovite lathes that are not parallel to the matrix foliation (Fig. 2-6M), indicating retrogression in the absence of deformation. In conclusion, the entire aureole experienced a degree of re-equilibration during cooling after peak metamorphism, 
notably cordierite porphyroblasts, and according to chlorite chemistry, the rock acquired chemical equilibrium.

\subsubsection{Structural Relationships and Aureole Kinematics}

Metamorphic mineral growth is syn-kinematic to $\mathrm{D}_{1}$ in Zones 1,2 and $3 \mathrm{~A}$, as inclusion trails through all porphyroblasts are slightly rotated and merge with the exterior matrix $\mathrm{S}_{1}$ (Fig. 2-6A-I). All porphyroblasts create additional lineations that parallel the $S_{1}$ foliation as observed in thin section and tomography. Deformation occurred at the same time and after biotite growth in Zone 3B, forming a biotite dominated foliation $S_{1}$, which is preserved as merging inclusion trails through andalusite and cordierite. Therefore andalusite and cordierite are syn to postkinematic to the biotite deformation. Zones $3 \mathrm{C}$ and 4 contain pre-kinematic porphyroblasts wrapped by a biotite-rich foliation $S_{2}$ (Fig. 2-6M-R), indicating a dominant deformation event after primary mineral growth, $D_{2}$, preserving $S_{1}$ as inclusion trails. The preservation of biotite inclusion trails proposes the growth of andalusite and cordierite during or after a primary deformation event, $\mathrm{D}_{1}$. In general, two deformation events occurred, with $\mathrm{D}_{1}$ penetrating the entire aureole and strengthening towards the contact as the production of a biotite foliation in Zone $3 \mathrm{~B}$, and $\mathrm{D}_{2}$ taking place only within the inner aureole as tightening of the foliation and wrapping of porphyroblasts.

Biotite and ilmenite-rich crenulation cleavages run parallel to the dominant $S_{1}$ matrix foliation and inclusion trails (Fig. 2-6E, J). These are labeled $S_{2}$ in the rocks of the middle and outer aureole and may be related to the deformation event that 
created the biotite foliation $S_{2}$ in higher grade samples. The presence of ilmenite and biotite within these crenulations suggests heat and fluid involvement to allow diffusion and the crystallization of re-oriented phases. Therefore, this deformation event most likely occurred after growth of all primary mineral phases within the outer aureole but close to peak metamorphic conditions and possibly simultaneous with $\mathrm{D}_{2}$ in the inner aureole.

The foliation of retrograde chlorite along the interfaces of cordierite (Fig. 26E) and preferably along cordierite interfaces that are parallel to the matrix foliation (Fig. 2-6G) introduces the idea that retrogression occurred under stresses oriented in the same direction as the stress that produced the main foliation. Retrograde chlorite lathes in the matrix, however, do not align with $S_{1}$.

\subsubsection{Determining a P-T Path}

When predicting equilibrium assemblages through thermodynamic modeling, it is commonly assumed that the bulk rock composition used is a good representation of the rock throughout metamorphism. Therefore, it is assumed that the chemistry of the rock has not changed since peak conditions were reached, inferring the fact that no fluid infiltrated the system to alter its chemistry. Since there is no chemical trend from low to high grade seen in the bulk rock chemistry (Fig. 2-4) it is reasonable to accept the notion that no fluids were introduced into the aureole as a result of the batholith intrusion. There is still the possibility that fluids changed the chemistry of the rocks prior to metamorphism, but since this does not 
change the chemistry of the rocks from what they were at peak metamorphism, the bulk rock data is useable.

When interpreting a P-T path for contact metamorphism, a P was chosen that is reasonable in terms of intrusion depth yet within the P range predicted by the majority of phase diagrams. The wide variation in the position of the Ms-Pl-Bt-AndCrd multi-variant field of Zone 3 (Fig. 2-8 and Appendix III) may be a result of bulk rock compositions that are not true representations of the actual rocks. The absence of this field in a few phase diagrams whose rocks contained the assemblage is a strong suggestion that either the bulk rock composition is inaccurate or the thermodynamic database used is not suited for such low P conditions. A similar argument can be presented to explain the Mn-rich rock samples whose bulk composition predicted Grt-bearing assemblages overlapping the observed mineral assemblages of the aureole. No matter, the majority of bulk compositions accurately predict the stability of the main mineral assemblages observed.

An isobaric metamorphic path that does not cross the upper univariant line of the Ms-Pl-Bt-And-Crd multi-variant field is interpreted. This is due to petrographic observations in this study that reveal one main episode of cordierite growth and no andalusite growth at the expense of cordierite. Debuhr (1999) and Pattison and DeBuhr (2015) present the observation of film-like andalusite along cordierite interfaces which may suggest otherwise, however, these secondary andalusite aggregates do not make up a large portion of the rock volume and if an isobaric path were to cross this univariant curve, it would not be by a significant amount. Therefore, for simplification, a P-T path within the dominant multi-variant 
field of the contact aureole is interpreted. A metamorphic path at $1.6 \mathrm{kbar}$ and from $500-590^{\circ} \mathrm{C}$ throughout the aureole fits best for most of the bulk rock phase equilibrium diagrams.

If a non-isobaric metamorphic path is assumed instead, the range in $\mathrm{T}$ and the maximum $\mathrm{P}$ for Zone 3 would be equivalent to the above conditions. The $\mathrm{P}$ would begin to increase at the upper limit of Zone $3 \mathrm{C}$ and into Zone 4 but would not exceed the stability of Bt-bearing assemblages. Biotite is observed throughout the entire aureole, even within migmatites closest to the contact (DeBuhr, 1999; Pattison and DeBuhr, 2015). The strengthening of the matrix foliation towards the contact may indicate a weak P increase within Zone 4.

The $\mathrm{P}$ achieved for the Bugaboo aureole at Cobalt Lake in this study is significantly lower than the estimated 3.0 kbar obtained in the most recent study by Pattison and DeBuh (2015). This is dominantly a result of the use of a thermodynamic database that considers a $\mathrm{COH}$-bearing fluid in equilibrium with graphite, as well as the use of rock specific bulk compositions. The Nelson batholith, a neighboring intrusion in the Purcell Mountains (south of Fig. 2-1B), is surrounded by a contact aureole that has provided P estimates between 2.0-4.5 kbar (Pattison and Vogl, 2005). The mineral assemblage found here contains garnet porphyroblasts which may explain the slightly higher P results obtained. Similar porphyroblastic assemblages to the Bugaboo aureole have been observed in the 2.53.0 kbar South Mountain aureole in Halifax, Nova Scotia (Jamieson et al., 2012) and in the 1.5 kbar aureole surrounding the Land's End and Tregonning granites of Cornwall, UK (Pownall et al., 2012). Considering common uncertainties for P 
predictions by Theriak/Domino, the estimates achieved in this study are relatively close to P estimates obtained by other studies on contact aureoles of similar mineral assemblages.

\subsubsection{The Mg\# of Cordierite and Biotite}

The negligible variation in $\mathrm{Mg \#}$ across the aureole in cordierite and biotite (Fig. 2-5), with slight Fe-enrichment at highest grades, matches the thermodynamic prediction that their Mg\# remains generally constant within Zones 2 and 3 and decreases in Zone 4 (Fig. 2-10). However, the observed chemical values of cordierite in Zone 2 lie on isopleth near the end of Zone 3 and the beginning of Zone 4 (Fig. 29B, E, H). If we assume the chemistry of cordierite has not been altered since peak metamorphism and the thermodynamic model is accurate, then it may be possible that cordierite within the aureole grew at the location of the 0.54-0.55 Mg\# isopleth in the diagram, indicating a departure from equilibrium by approximately $50^{\circ} \mathrm{C}$. The observed chemistry of biotite is predicted to be in chemical equilibrium during prograde metamorphism throughout Zone 3 (Fig. 2-9C, F, I).

It is evident that once the thermodynamically stable mineral assemblage contains both cordierite and biotite, the phases compete for Fe and Mg resulting in mirrored molar proportions (Fig. 2-10B, D, F). The strong Fe-enrichment of cordierite and biotite after Kfs-bearing assemblages equilibrate and until Andbearing assemblages destabilize sparks attention because neither K-feldspar nor andalusite contain a significant amount of Fe or Mg (Pattison and DeBuhr, 2015). The molar decrease predicted for biotite would have released both Fe and Mg for 
cordierite, which increases in molar abundance over this $\mathrm{T}$ interval due to progress of Reaction V, creating more volumetric cordierite that incorporates more Fe than Mg.

The chemical homogeneity of Fe and Mg within cordierite porphyroblasts (Appendix II) and between separate porphyroblasts (Table 2-3) is an indication of chemical equilibrium across the entire rock volume. If this were a prograde metamorphic feature, one would assume that the transport of chemical nutrients throughout the rock was relatively fast and processes that occurred at the crystal surface controlled the rate of the Crd-producing reaction (Reaction II). Textural analysis in Chapter 3 should then lead to the conclusion of interface-controlled growth coupled with rapid chemical equilibration at peak metamorphism following overstepping of Reaction II. A second possible explanation for whole rock chemical equilibration would be during retrograde metamorphism, which was also interpreted with the similar chemistries of prograde and retrograde chlorite (Section 2.5.2).

\subsubsection{Visibility of Porphyroblasts in CT}

The occasional visibility of cordierite and andalusite in CT is questionable, mainly due to the fact that they display lower X-ray attenuation values than the rest of the rock (Fig. 2-11) when their chemistry is calculated to give slightly greater linear X-ray attenuation coefficients than the dominant matrix phases (Fig. 2-12). Cordierite is identified in CT by its elongate and sub-idiomorphic shape with rough crystal edges and the unique rim of highly attenuating retrograde chlorite (Fig. 2- 
11A-C). The identification of andalusite in Figure 2-11D and $\mathrm{E}$ was done by comparison to petrography. The low attenuating porphyroblasts show an idiomorphic crystal shape similar to andalusite in thin section. Individual biotite porphyroblasts are visible in samples from the outer aureole (Fig. 2-11A, C) but are not distinguishable as separate crystals once in Zone $3 \mathrm{C}$ where they dominate the foliated matrix (Fig. 2-11D, E). Even the abundance of touching biotite crystals in a few of the outer aureole rocks made segmentation difficult in this study (e.g.; Fig. 211B).

The specific X-ray attenuation values calculated in Figure 2-12 can be compared to what is observed in CT. In general, with greater energies, X-rays are able to penetrate material more effectively, but are less responsive to changes in material density (Ketcham and Carlson, 2001), however the relative sequence of lowest to highest absorbing phases remains relatively constant between 10-100 $\mathrm{keV}$. The peaks at energies $<10 \mathrm{keV}$ represent the shells from which electrons are ejected during photoelectric absorption. Above approximately $100 \mathrm{keV}$, the linear Xray attenuation of the mineral phases merge together (Fig. 2-12).

Cordierite in $C T_{-} 009$

The variation in X-ray attenuation across a single cordierite porphyroblast in CT_009 (Fig. 2-11A) is not due to chemical heterogeneities, which would have been found through EPMA analysis (Appendix II) and calculation of their X-ray attenuation (Fig. 2-12). Density is the other factor that contributes to how well a chemical structure can absorb X-rays, which may be the reason why cordierite is 
showing lower attenuations. Fractures were observed in thin section (Fig. 2-6D,E) that match the morphology of the dark regions in CT and may be lowering the density of cordierite in CT_009. Another feature of CT_009 is the contrast between cordierite porphyroblasts, whether fractured or not, and the high X-ray attenuation rim that surrounds them. All cordierite observed in thin section contains a rim of pinite alteration with many porphyroblasts additionally enclosed by retrograde chlorite (Fig. 2-6E). The X-ray attenuation of unaltered cordierite in CT_009 matches that of the matrix and without retrograde chlorite replacement along its rims, or fractures within its structure, cordierite may not have been visible in this sample.

\section{Cordierite in CT_033 and CT_041}

The abundance of cordierite porphyroblasts in these samples is greater than in CT_009 and their X-ray attenuation is much lower and homogeneous (Fig. 2-11B, C). The chemistry of cordierite is similar across all three cordierite-visible samples (Appendix II) and petrography shows no great dissimilarity in their textures. Pinite alteration may provide an explanation for lower X-ray attenuation of cordierite in these samples, as well as cordierite from CT_009. The fine grained aggregates of mica that replaced cordierite may have altered its chemistry and density causing less X-rays to be attenuated. Another possible explanation is the volumetric abundance of biotite in $\mathrm{CT}_{-} 033$ and CT_041 that may increase the visibility of cordierite due to the greater amount of contrast in the rock. A rock containing more biotite, a high attenuating phase, compared to a rock containing more muscovite and quartz, low attenuating phases, would create more contrast between the low X- 
ray attenuation phases. The interlocking closely spaced texture of cordierite in CT_033 and CT_041 made distinguishing grain boundaries difficult, whereas retrograde chlorite rims around cordierite in CT_009 defined the porphyroblasts' edges.

Andalusite in CT_044 and $C T_{-} 045$

The absence of visible cordierite in these higher grade samples, from Zone 3C, and the appearance of andalusite in the CT data was unexpected (Fig. 2-11D, E). The texture of andalusite in these samples is slightly different than andalusite in the samples described above. They are more inclusion-rich, with no inclusion-free rim, and take up more modal percent of porphyroblast volume in the rock. Containing many small inclusions, of quartz and albite, may decrease their overall X-ray attenuation because these are low attenuating minerals and their small size will cause the resulting CT pixel to be an average of the low attenuating inclusions in its area. This is a result of the volume effect. Additionally, the andalusite is present in a fine biotite foliated matrix, which wraps them, creating a higher X-ray attenuating matrix than in samples of lower grade. This increases the contrast between the matrix phases and the porphyroblasts, allowing for their visibility. Cordierite in these samples is not as abundant as andalusite and is being replaced by retrograde muscovite, a phase that also makes up a majority of the matrix, thereby causing cordierite to blend in with the matrix in the CT data. 


\subsection{Conclusion}

Chapter 2 has presented petrographic texture observations, P-T conditions and CT examinations of the samples collected across the Bugaboo contact aureole. Choosing a thermodynamic database that considers a $\mathrm{COH}$-bearing fluid is demonstrated to have a significant effect on the positioning of water-bearing phases, and most importantly for this study, the position of the stability field of Crdbearing assemblages. The presence of chiastolite within the Bugaboo hornfelses is a strong indication that graphite is present. Contact metamorphism is predicted to take place at approximately $1.6 \mathrm{kbar}$ and $500^{\circ} \mathrm{C}$ within the outer aureole up to $590^{\circ} \mathrm{C}$ within the inner aureole.

Through petrography and phase equilibria there is potential reasoning for overstepping of the Bt- and Crd-producing reactions by no more than $50^{\circ} \mathrm{C}$ at approximately $1.6 \mathrm{kbar}$ in Zone 2. This was deduced due to the relatively simultaneous nucleation and growth of all porphyroblasts when phase equilibria predicts otherwise, as well as the observed cordierite chemistry that is predicted to be in equilibrium at higher $\mathrm{T}$ than what is expected in Zone 2. Naturally, this conclusion is under the assumption that the thermodynamic model is accurate, the bulk rock compositions are representative and the observed cordierite chemistry is preserved from rapid equilibration at high $\mathrm{T}$ after overstepping. This last assumption explains the observation of cordierite equilibrium chemistry when a significant departure from equilibrium was experienced, although it does not explain the presence of prograde chlorite in the observed mineral assemblage. Retrograde chemical equilibration is a more reasonable explanation to justify the 
chemical homogeneity of cordierite, biotite and chlorite, erasing any prograde chemical trends. A textural analysis is therefore required to better understand the mechanisms in control of the prograde metamorphic reactions.

A new method of segmenting porphyroblasts in CT data that can not be manually segmented by Avizo or Blob3D software was introduced, along with explanations for the visibility of porphyroblasts in a select number of rocks. It has been shown that chemistry is not the only factor that plays a role in viewing minerals in CT, but density variations such as fracturing and alteration may also affect the final X-ray attenuation of a specific phase. Additionally, the relative contrasting X-ray attenuations between rock-sharing phases has an impact on their appearance and may be the determining factor that allows segmentation of a specific mineral of interest. Cordierite from CT_009 is visible due to the presence of density-reducing fractures as well as the presence of a retrograde chlorite rim that make the porphyroblasts stand out against the matrix. Segmentation of cordierite was done in CT_009 and their texture was quantified along with biotite's. The results and discussion for this detailed textural analysis is presented in Chapter 3. 


\section{$\underline{\text { CHAPTER } 3}$}

A statistical analysis of the distribution of cordierite and biotite from the Bugaboo contact aureole: Implications for metamorphic nucleation and crystal growth of porphyroblasts

This chapter provides a detailed description of the textural analysis of biotite and cordierite from sample COB3-S1-5 (CT_009) of Zone 2 within the Bugaboo contact aureole. As this chapter is written as a paper, a brief overview of the geological background and methods will be done with additional explanation of Reduce3D software (Hirsch, 2000) and the statistical methods involved in determining porphyroblastic textures.

\subsection{Introduction}

One approach to uncovering the micro-processes behind nucleation and crystal growth that take place during metamorphism is to analyze the resultant texture of porphyroblasts. The size, shape, orientation and location of a porphyroblast are a result of the unique environment under which it grew. Factors such as pressure $(\mathrm{P})$, temperature $(\mathrm{T})$, time $(\mathrm{t})$, and protolith chemistry and texture, play a role in defining the rock product of metamorphism. Textural analysis of metamorphic rocks in three-dimensions (3D) is a familiar technique to most metamorphic petrologists, however its application is limited due to the observability of only a hand full of minerals in computed tomography (CT) data. This has led to an abundance of textural studies on garnet (Denison and Carlson, 
1997; Daniel and Spear, 1999; Hirsch et al., 2000; Ketcham et al., 2005; Hirsch and Carlson, 2006; Hirsch, 2008; Gaidies et al., 2014) and several on other minerals such as biotite (Hirsch and Carlson, 2006) and periclase (Muller et al., 2009).

This study presents new textural data for cordierite and biotite porphyroblasts from a hornfelsic sample of the Bugaboo contact aureole in southeastern British Columbia. To the knowledge of the authors, this is the first quantitative textural analysis on cordierite. A different approach to extracting 3D data from CT will be presented and new insight will be provided into the nucleation and growth mechanisms that control mineral reaction rates during an isobaric heating event. Combining textural information from two different porphyroblast phases in the same rock allows to address the question as to whether their growths were controlled by the same process and if the sequential growth of the second phase had an impact on the texture of the first.

Metamorphic processes that impact porphyroblastic texture have been described in great detail (Kretz, 1974; Fisher, 1978; Carlson, 1989) and may be quantified through the interpretation of the spatial and size distribution of porphyroblasts. The rate of a mineral reaction is defined by the rate of the slowest sub-process, commonly argued to either be (1) the intergranular movement of chemical nutrients through the rock matrix towards a growing phase or (2) the attachment of chemical nutrients to the growing crystal structure. Two other processes must also occur; (3) the dissolution of the reactant mineral providing chemical nutrients for the product and (4) the formation of a nucleus on which crystal growth can advance. This study works towards distinguishing between (1) 
diffusion-controlled growth and (2) interface-controlled growth for biotite and cordierite porphyroblasts in a contact metamorphic setting. The porphyroblasts grow as a result of the KFMASH reactions (I) Ms $+\mathrm{Chl}=\mathrm{And}+\mathrm{Bt}+\mathrm{Qtz}+\mathrm{H}_{2} \mathrm{O}$ and (II) $\mathrm{Ms}+\mathrm{Chl}+\mathrm{Qtz}=\mathrm{And}+\mathrm{Bt}+\mathrm{Crd}+\mathrm{H}_{2} \mathrm{O}$ with both their primary growth dominantly occurring at the expense of muscovite and chlorite and with the coproduction of andalusite.

In order to differentiate between the rate-controlling processes, the spacing between porphyroblasts and the distribution of their sizes needs to be quantified. If crystals show a perfect random distribution and the size of porphyroblasts has no relation to their distance from each other, then diffusion through the rock is interpreted to be fast enough to allow crystal growth wherever preferred and the reaction may be interface-controlled. For the case of diffusion-controlled reaction, crystals compete for elements and their final size depends on how closely their nucleation sites are spaced resulting in an ordered distribution. In theory, a region depleted in nutrients should be present within the vicinity of diffusion-controlled growing crystals where no other crystal can nucleate due to the low chemical affinity (Carlson, 1989; 1991). This may be present as a reaction zone (ie; corona) or as a chemical potential gradient in the surrounding matrix.

\subsection{Bugaboo Geology}

The Bugaboo batholith of south eastern British Columbia (Fig. 3-1A) is part of a suite of granitoid bodies that intruded the Purcell Mountains post-Cordilleran deformation (Fig. 3-1B). Regionally metamorphosed greenschist facies pelites of the 

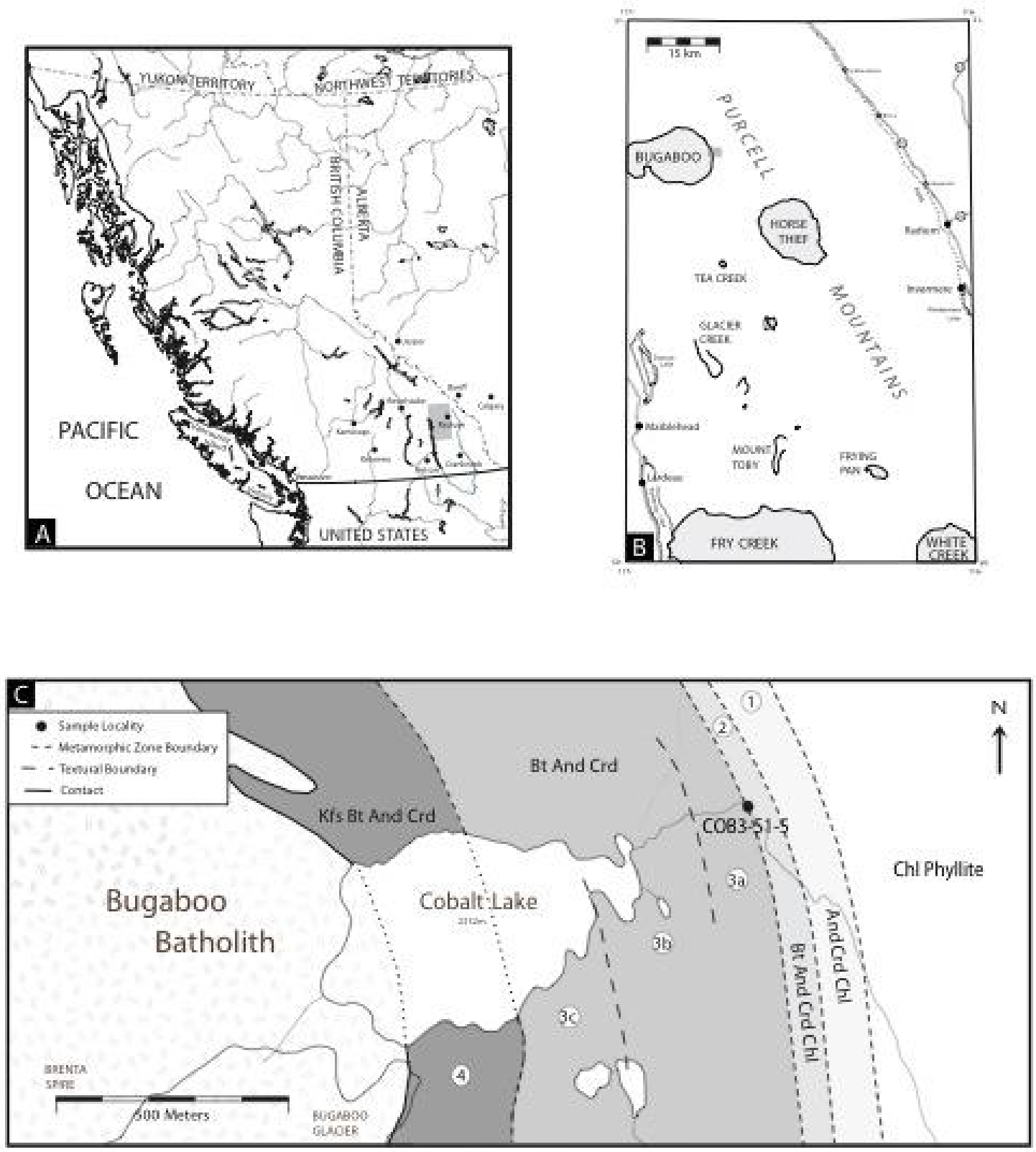

Figure 3-1. (A) Location of the Purcell Mountains in southeastern British Columbia, Canada. (B) The Bugaboo batholith is part of a suite of granitoid intrusions west of Radium in the Purcell Mountains. Cobalt Lake is located along the eastern margin of the batholith. (C) Geological map of the contact aureole and its metamorphic zones at Cobalt Lake with the location of COB3-S1-5 in Zone 2 of the outer aureole. Figures edited after DeBuhr (1999) and mineral abbreviations after Kretz (1983). 
Horsethief Creek Group surround the batholith. Originally deposited during the Proterozoic, these metasediments make up the western portion of the Foreland Fold and Thrust Belt of the Cordillera. The batholith intrusion ca. $107 \pm 5 \mathrm{Ma}$ (Brand and Lambert, 1992) resulted in contact metamorphism of the metapelites up to $1 \mathrm{~km}$ away from the contact. A portion of the contact aureole was studied by the authors at Cobalt Lake where there is continuous exposure from the outer aureole up to the batholith contact (Fig. 3-1C). The regional metamorphic structures (i.e.; foliation) run parallel to the contact at this locality.

The aureole is dominated by hornfelses containing porphyroblasts of biotite, andalusite and cordierite in a weakly foliated matrix of muscovite, albite, ilmenite and quartz. Figure 3-1C illustrates the separate metamorphic zones based on petrographic analysis done for this study. Chlorite and locally chloritoid porphyroblasts are observed in the Horsethief Creek Group protolith of greenschist facies regional metamorphism (Pattison and DeBuhr, 2015). The outer-most aureole, Zone 1, consists of chlorite porphyroclasts, andalusite porphyroblasts and pseudomorphic replacement of biotite by chlorite and muscovite, indicating prograde progress of Reaction I. The first appearance of cordierite by Reaction II is in Zone 2 with biotite and andalusite porphyroblasts in a chlorite-bearing matrix. The start of Zone 3A marks the break-down of chlorite and the volumetric increase of the main three porphyroblasts by completion of Reaction II. Zone 2 and Zone $3 \mathrm{~A}$ consist of syn-kinematic porphyroblast growth. Biotite dominates the foliated matrix in Zone 3B and the observation of pre-kinematic andalusite and cordierite porphyroblasts wrapped by a biotite-rich matrix defines Zone 3C. Fibrolite was 
identified in Zone 3C by Pattison and DeBuhr (2015) but was not observed in the samples studied here. The addition of sparse K-feldspar in the matrix and occasionally as pre-kinematic porphyroblasts marks Zone 4. A sporadic migmatite zone was identified by Pattison and DeBuhr (2015) to contain leucosomes with quartz, feldspars and biotite to the north of Cobalt Lake, closest to the batholith contact. Sample COB3-S1-5, from which the texture of cordierite and biotite porphyroblasts was quantified, is part of Zone 2 and will be described in detail petrographically.

\subsection{Methods}

\subsubsection{XRF and Theriak/Domino}

A representative sample of COB3-S1-5 was crushed for X-ray fluorescence (XRF) at the Geochemical Laboratories of Earth \& Planetary Sciences at McGill University (DeBuhr, 1999). A Philips PW2400 3kW automated XRF spectrometer was used to obtain the bulk rock composition listed in Table 3-1. The composition of COB3-S1-5 is used to predict the equilibrium P-T conditions of its observed mineral assemblage along with equilibrium isopleths of the Fe-Mg content of biotite and cordierite. Theriak/Domino modeling software (de Capitani and Petrakakis, 2010) was used to produce phase equilibrium diagrams along with the thermodynamic database after Holland and Powell (1998) with few adjustments (tcdb55c2_COH_prltbi2; Appendix I). A plagioclase solution model after Holland and Powell (2003) was used with ideal ilmenite after Tinkham and Ghent (2005), white mica including pyrophyllite after Coggon and Holland (2002) and biotite including 
its Ti end member after White et al. (2005). Hydrous cordierite is considered an ideal solution in this database. The metamorphic fluid is considered to be $\mathrm{COH}$ bearing and in equilibrium with graphite according to Connolly and Cesare (1993). The molar amount of oxygen was calculated assuming a 2:1 hydrogen-oxygen ratio.

Table 3-1. Bulk rock composition of COB3-S1-5 in mole percent (mol. \%) element input into Theriak/Domino software (de Capitani and Petrakakis, 2010). Data from DeBuhr (1999).

\begin{tabular}{|c|c|c|c|c|c|c|c|c|c|c|c|}
\hline $\mathbf{S i}$ & $\mathbf{T i}$ & $\mathbf{A l}$ & $\mathbf{F e}^{2+}$ & $\mathbf{M n}^{2+}$ & $\mathbf{M g}$ & $\mathbf{C a}$ & $\mathbf{N a}$ & $\mathbf{K}$ & $\mathbf{H}$ & $\mathbf{C}$ & $\mathbf{0}$ \\
\hline 50.34 & 0.60 & 31.21 & 5.55 & 0.06 & 4.00 & 0.15 & 2.59 & 5.50 & 100 & 50 & 212.49 \\
\hline
\end{tabular}

\subsubsection{EPMA}

A Cameca Camebax MBX electron probe micro-analyzer (EPMA) at Carleton University was used to study the chemistry across select cordierite porphyroblasts from COB3-S1-5. Spots were spaced at $20 \mu \mathrm{m}$ intervals under an accelerating voltage of $20 \mathrm{kV}$ and a current of $20 \mathrm{nA}$. In order to achieve 40, 000 counts for each element, the spots were analyzed for $15-30$ seconds. The most inclusion-free and unaltered cordierites of the sample were chosen, however due to their poikiloblastic nature an inclusion-free spot was manually chosen every $100 \mu \mathrm{m}$ to obtain a minimum amount of accurate analyses for each crystal. The Cameca PAP matrix correction program was used before the weight percent results were converted to cation numbers and final mole percentages (mol. \%) of $\mathrm{Fe}, \mathrm{Mg}$, $\mathrm{Na}$ and $\mathrm{Mn}$, since these elements were the most abundant in each cordierite porphyroblast. 


\subsubsection{XR- $\mu C T$}

A $2.5 \mathrm{~cm}$ wide rock core of COB3-S1-5 was scanned with a high resolution Xray computed tomography $(\mathrm{XR}-\mu \mathrm{CT})$ scanner at Carleton University, a SkyScan 1173 , to obtain the size and location of biotite and cordierite porphyroblasts. The resolution of the scan was $12.08 \mu \mathrm{m}$ with an X-ray energy spectrum of $40-130 \mathrm{keV}$, a beam current of $61 \mu \mathrm{A}$ and an exposure time of $1300 \mathrm{~ms}$ for each $0.21^{\circ}$ rotation step. Twenty scan frames were averaged to produce a single image. In order to remove low energy X-rays from the beam, a $0.25 \mathrm{~mm}$ brass filter was used to pre-harden the X-ray beam and reduce the effects of beam hardening. A black and white flat field correction was done before the scan to calibrate the detector signal in addition to black flat field corrections every 60 minutes during the scan. The CT data was converted into greyscale images that represent $12.08 \mu \mathrm{m}$ thick slices by NRecon software (Fig. 3-2). The National Institute of Standards and Technology website was used to calculate the linear X-ray attenuation coefficient of the mineral phases that make up COB3-S1-5 using the mineral chemical analyses obtained through EPMA. The values were multiplied by the density of the mineral phases as predicted by Theriak/Domino at $510^{\circ} \mathrm{C}$ and $1.60 \mathrm{kbar}$.

\subsubsection{Segmentation}

The scanned cylindrical rock core was reduced to a rectangular prism in Avizo in order to decrease the number of crystals required for segmentation and remove beam hardening artifacts along the sample boundaries (explained in Ch. 2). Biotite porphyroblasts from COB3-S1-5 were extracted from the rock in the CT data 


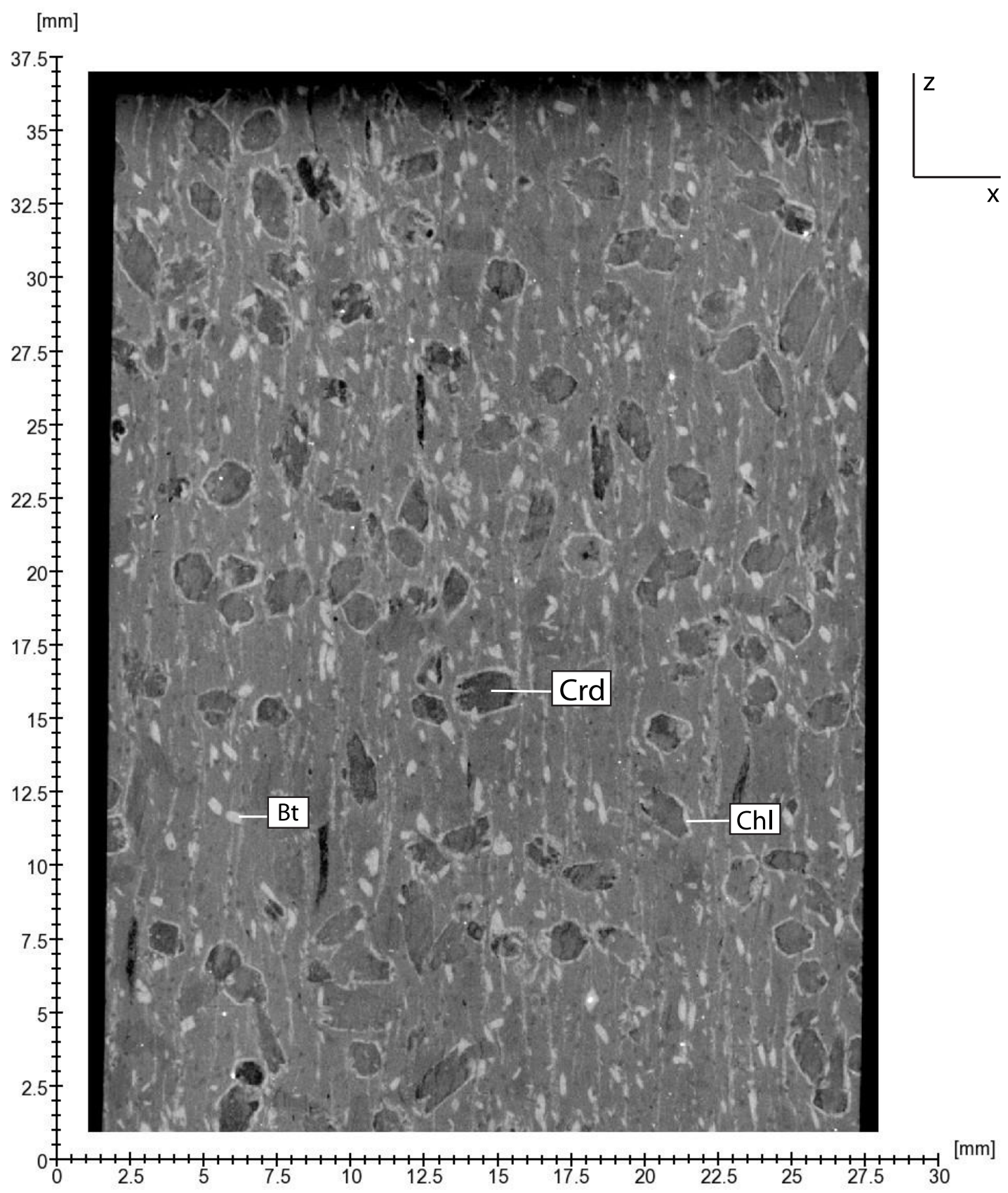

Figure 3-2. Greyscale image of the CT data of COB3-S1-5 produced by NRecon. The image is oriented looking down the $y$-axis of the rock core. Biotite and cordierite porphyroblasts are visible due to their contrasting X-ray attenuation to the matrix phases. Rims of retrograde chlorite are visible surrounding cordierite. See results and discussion for further analysis. Mineral abbreviations after Kretz (1983). 
through the three-dimensional (3D) software Blob3D (Ketcham, 2005). A general threshold was used to isolate the specific greyscale values (corresponding to X-ray attenuation) of biotite. The location, volume and ellipsoidal properties of each biotite crystal were extracted and a primitive ellipsoid was fit onto each crystal based on its surface area, providing the minimum, intermediate and maximum axis lengths as well as aspect ratio and the orientation of each crystal.

Cordierite porphyroblasts were extracted from the CT data through manual segmentation with the 3D software Avizo. Since the porphyroblasts consisted of a range of X-ray attenuation and therefore greyscale values (Fig. 3-2; discussed below), a new method of segmentation was applied (Fig. 3-3). With the segmentation toolbox in Avizo, regions of each cordierite porphyroblast were manually selected that correspond to perpendicular planes in the crystal that are approximately parallel to the minimum, intermediate or maximum crystal axes (Fig. 3-3A). To do this, the cross-hair in Avizo was placed in the center of a crystal, thereby finding each tomography slice $(\mathrm{x}, \mathrm{y}$ and $\mathrm{z})$ that parallels the crystal axis planes. The cordierite planes were then manually segmented with the blow, brush or magic wand tool. The extracted orthogonal slice objects were input into Blob3D so a primitive ellipsoid could be fit and the axis lengths could be obtained for calculation of crystal volume (Fig. 3-3B). To calculate the error introduced by using the "orthogonal slice" method, a number of cordierite porphyroblasts were manually segmented fully to compare their Blob3D volume to the final ellipsoid volume that is fit onto the orthogonal slices (Table 3-2 and Fig. 3-3C, D). The volume obtained through full segmentation is larger than what is obtained by the 
orthogonal slice method by $20-30 \%$. Although this is a substantial amount of error, the relative size between porphyroblasts remains the same and the positioning of porphyroblast centers contains a maximum error of 6\%. Since Reduce3D (discussed below) considers crystal centers and relative crystal sizes, the error introduced here may not have a significant impact on the final textural analysis, but it remains relevant when interpreting the results.
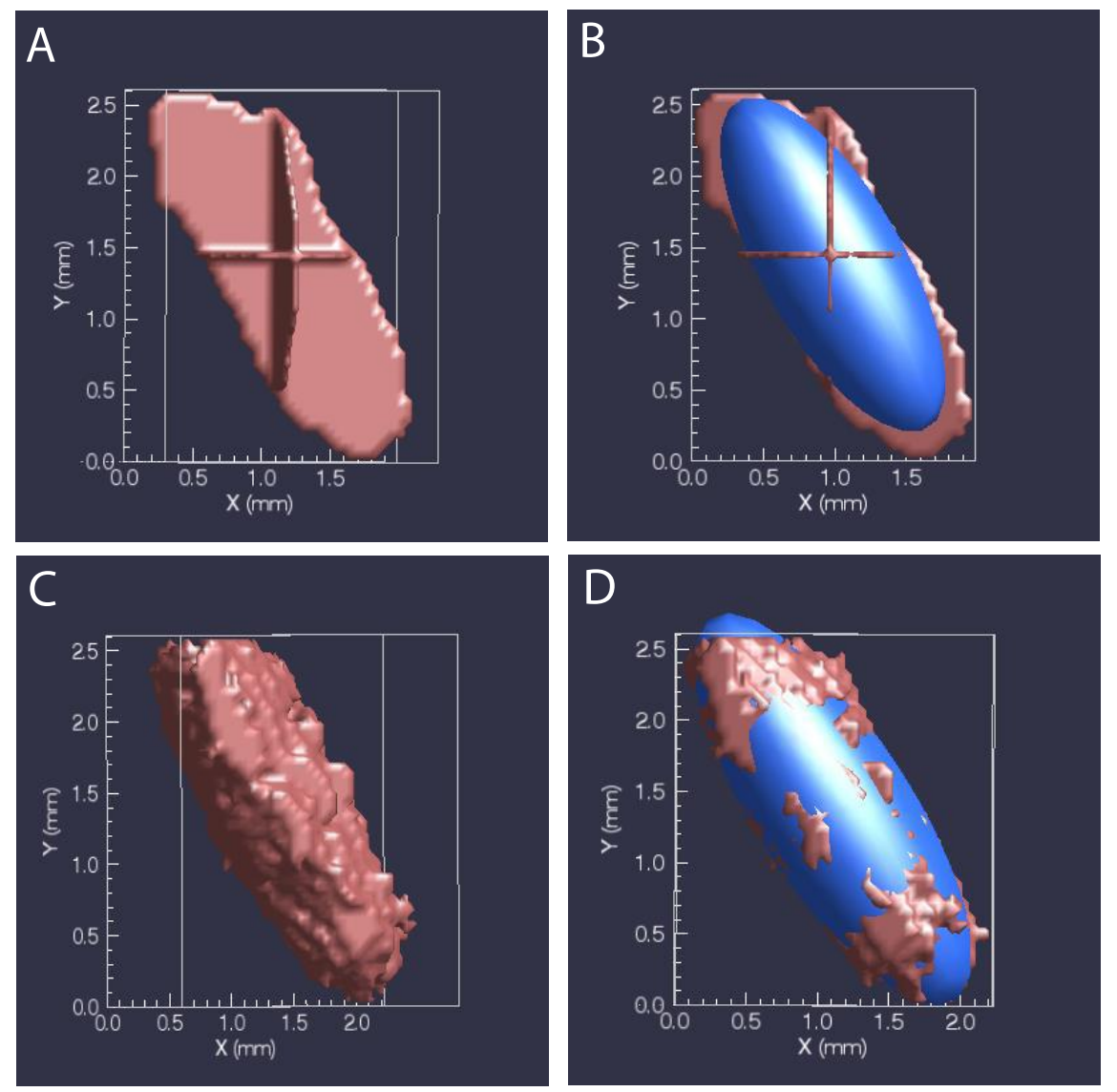

Figure 3-3. Images taken from Blob3D (Ketcham, 2005) that display the "orthogonal slice" segmentation method used to extract cordierite in COB3-S1-5 that contained a variation in X-ray attenuation. (A) Slices segmented in Avizo are perpendicular to one another and approximately correspond to the axes of the crystal. The center of this object was chosen using the cross hair tool in Avizo. (B) An ellipsoidal was fit onto the slices by Blob3D and the minimum, maxmimum and intermediate axes were used to calculate the volume of the porphyroblast. (C) The same porphyroblast segmented fully in Avizo. (D) The ellipsoid fit onto the fully segmented porphyroblast is slightly larger than the ellipsoid in (B) that was fit onto the orthogonal slices. See Table 3-2 for volume calculations. 
Table 3-2. Calculated error of the $x-y-z$ coordinates, crystal volume and ellipsoid volume between cordierites that were fully segmented and those segmented using the orthogonal slice method.

\begin{tabular}{|c|c|c|c|c|c|c|}
\hline & \# & $\mathbf{X}$ & $\mathbf{Y}$ & $\mathbf{Z}$ & $\begin{array}{c}\text { Volume } \\
\left(\mathrm{mm}^{3}\right)\end{array}$ & $\begin{array}{c}\text { Ellipsoid } \\
\text { Volume }\left(\mathrm{mm}^{3}\right)\end{array}$ \\
\hline \multirow{3}{*}{$\begin{array}{c}\text { Full } \\
\text { Segmentation } \\
\text { (Fig. 3-3D) }\end{array}$} & 1 & 1.84 & -3.21 & 5.77 & 1.69 & 2.11 \\
\hline & 2 & -1.65 & 1.02 & 3.17 & 2.14 & 2.34 \\
\hline & 3 & -1.97 & 2.08 & 1.13 & 1.65 & 1.79 \\
\hline \multirow{3}{*}{$\begin{array}{l}\text { Orthogonal } \\
\text { Slice } \\
\text { Segmentation } \\
\text { (Fig. 3-3B) }\end{array}$} & 1 & 1.83 & -3.23 & 5.86 & - & 1.32 \\
\hline & 2 & -1.68 & 1.01 & 3.14 & - & 1.45 \\
\hline & 3 & -1.93 & 2.06 & 1.10 & - & 1.13 \\
\hline \multirow{3}{*}{$\begin{array}{l}\text { Error (\%) } \\
\text { (full vs. } \\
\text { orthogonal } \\
\text { slices) }\end{array}$} & 1 & 0.51 & 0.81 & 1.64 & \multicolumn{2}{|c|}{21.57} \\
\hline & 2 & 2.09 & 0.18 & 0.99 & \multicolumn{2}{|c|}{32.22} \\
\hline & 3 & 1.74 & 0.87 & 2.87 & \multicolumn{2}{|c|}{31.40} \\
\hline
\end{tabular}

\subsubsection{Reduce $3 D$}

A statistical analysis of the 3D distribution of crystal centers and sizes were executed using Reduce3D software (Hirsch et al., 2000; Hirsch, 2000; 2011) in order to shed light on the type of crystal distribution dominating the porphyroblastic texture; random, ordered or clustered. The software calculates scale-independent statistics which obtains an average value across the sample volume as well as scaledependent statistics to correlate texture with distance. By measuring multiple statistics, which consider different crystal features at varying distances, Reduce3D is able to uncover if there is a combination of textures that together dictate the porphyroblast's spatial distribution. The software requires information on each 
crystal center (x-y-z coordinates) and an additional parameter, or mark, which is chosen by the user and typically relates to crystal size (eg; radius, volume).

The statistics are compared to a null hypothesis envelope of $95 \%$ confidence that is created by simulating interface-controlled crystal growth, defined by Kretz (1974), to create a crystal population of the same size distribution and crystal density as the sample volume in question. A homogeneous distribution of nutrients is assumed and the probability of crystal nucleation is everywhere the same except for within a pre-existing crystal. Crystal centers are placed randomly with the largest final crystal sizes placed first as they are expected to have grown earliest under interface-controlled growth (Kretz, 1974; Hirsch, 2000). When a randomly placed crystal impinges upon another a test is run to see if the later placed crystal could have nucleated outside of the earlier placed crystal. This is done by subtracting the radius of the younger crystal from both crystals, if the nucleation site of the younger crystals falls outside of the earlier crystal then the placement is allowed. On top of this basic placement criterion, two additional observability criterions are used to account for highly interpenetrated crystal pairs that, if present in the natural data, would be mistaken for a single crystal, while in the simulation they would be observed as two separate crystals. The observability criterions are explained in depth by Hirsch (2000) and Ketcham et al. (2005), analyses done here have used an observability filter with coefficient $\mathrm{a}_{1}=0.85$ and $\mathrm{a}_{2}=3$, as suggested by Hirsch (2000). The single-scale and correlation statistics are run on 100 simulated populations of interface-controlled growth to obtain results for a random distribution, and then the top and bottom $2.5 \%$ of the envelope are removed. 
The single-scale statistics include the ordering index, clustering index, impingement index and isolation index. The first two indices were introduced to 2D metamorphic texture analysis by Kretz (1966; 1969), while the impingement and isolation indices were contributed by Carlson (1989) and reiterated for 3D by Hirsch (2000). Reduce3D plots all indices except for the isolation index which can be found in the output text file of this software. The scale-dependent correlation functions are the L'-Function (L'F), the Pair Correlation Function (PCF) and the Mark Correlation Function (MCF; Fig. 3-4). These functions, along with the single-scale statistics, have been used in 3D analysis of metamorphic rocks (e.g.; Daniel and Spear, 1999) and were implemented into Reduce3D by Hirsch (2000). When running Reduce3D, a rectangular prism sample shape and the inscribed primitive option were used (see Hirsch, 2011).

\section{Ordering Index}

Also known as the aggregation index " $\mathrm{R}$ " and the nearest-neighbour test (Clark and Evans, 1954; Kretz, 1969; Carlson, 1989; 1991), the ordering index is the ratio between the average observed nearest-neighbour distance in the sample $\left(r_{A}\right)$ and the average expected nearest-neighbour distance in the simulations $\left(\mathrm{r}_{\mathrm{E}}\right): \mathrm{R}=$ $\mathrm{r}_{\mathrm{A}} / \mathrm{r}_{\mathrm{E}}$ (Clark and Evans, 1954; Kretz, 1966; 1969; Jerram et al., 1996; Rudge et al., 2008). When the observed nearest-neighbour distance is greater than what is measured in the random simulation $(\mathrm{R}>1)$, the crystals are more spaced apart and signify an ordered distribution. If the observed crystals are more closely spaced and the average nearest-neighbour distance is less than what is expected $(\mathrm{R}<1)$, a 


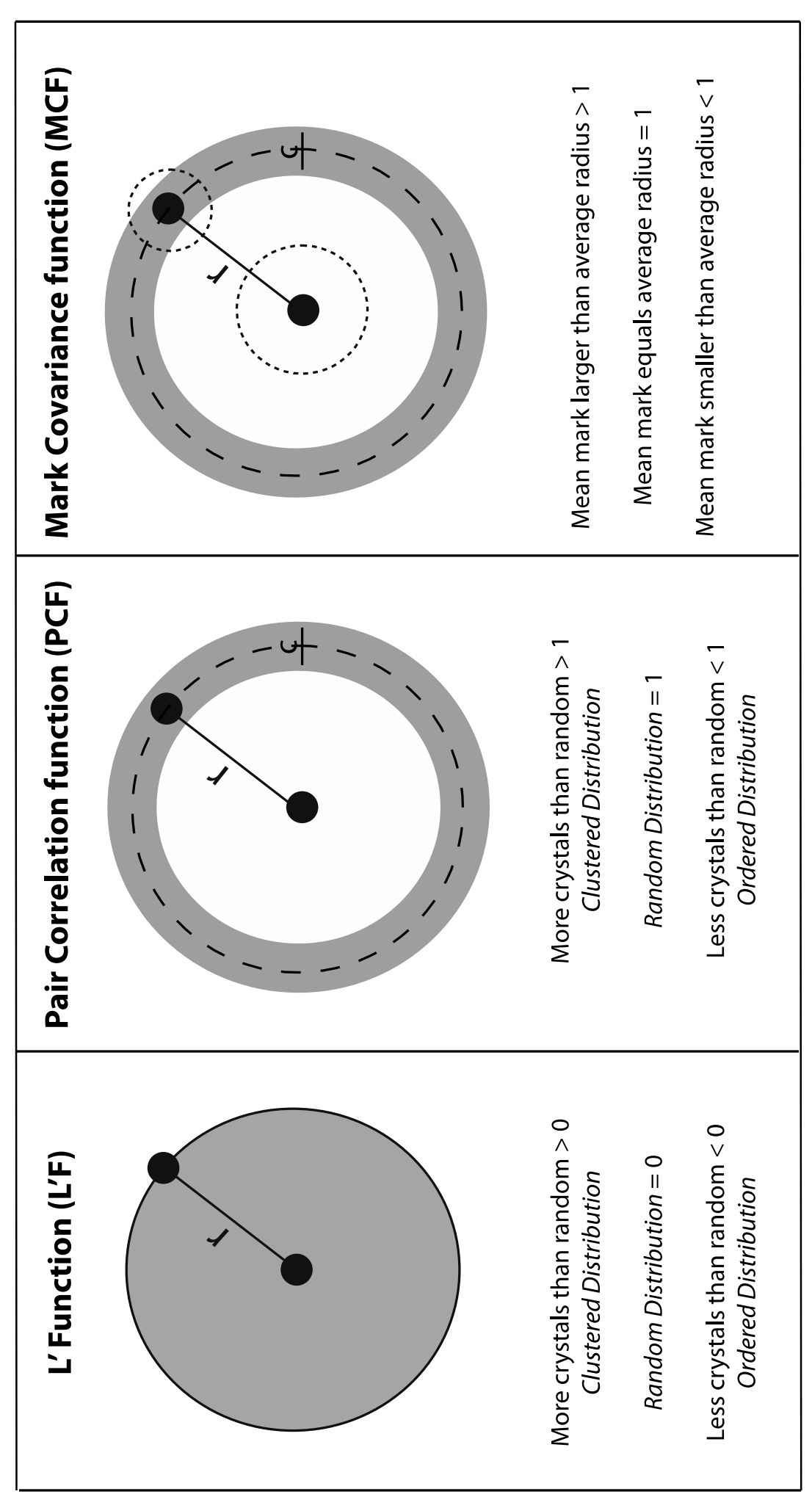

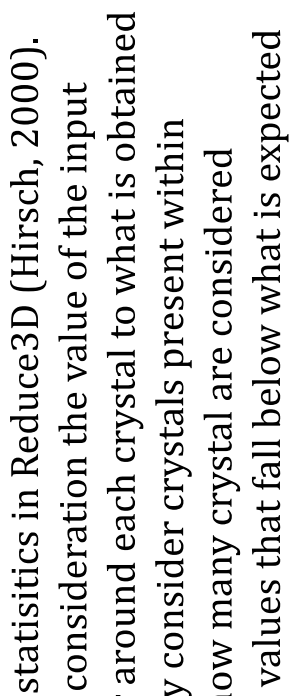

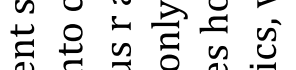

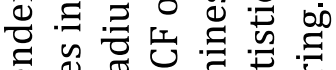

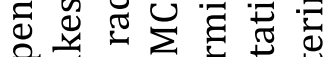

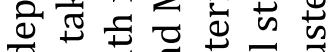

d它

ల్ $\sum_{0}$

थ

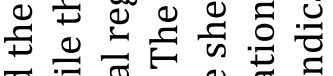

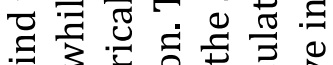

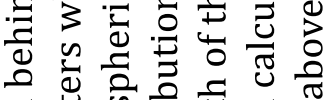

ठ

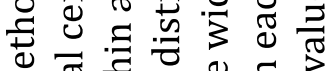

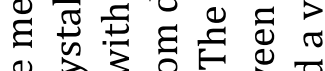

过

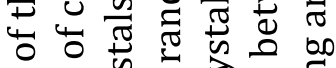

\&

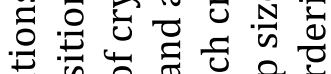

䒕 苛

总过市

引

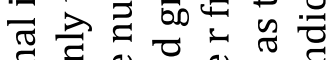

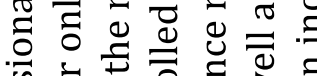

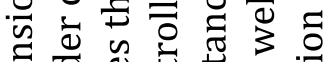

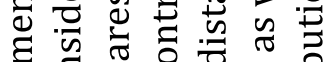

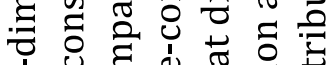

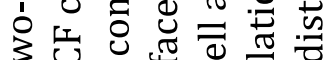

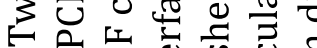

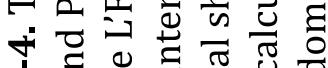
n สิ ข

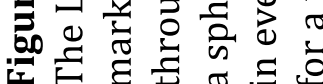


clustered distribution is present. A random distribution gives a value $\mathrm{R}=1$. Reduce3D outputs a value equal to $1 / \mathrm{R}$ and compares it to a $95 \%$ confidence envelope for a random distribution instead of to unity. Values that fall outside the envelope reject the null hypothesis in favour of either clustering or ordering depending on whether they fall above or below the envelope, respectively.

\section{Clustering Index}

First introduced as the random-point method for 2D analysis, the clustering index uses the average distance (d) between a number (n) of crystal centers and randomly located points, along with crystal density $(\lambda)$ to compare the natural sample to a random distribution: $\mathrm{d}^{3} \times \lambda \times 8 / 3 \pi$ n (Denison et al., 1997a). A random array of crystals would result in a $\chi^{2}$ distribution, however to remain consistent, the value is divided by $2 \mathrm{n}$ to compare to unity. A value $<1$ signifies an ordered distribution while a value $>1$ corresponds to clustering. Again for Reduce3D this is compared to a 95\% confidence envelope of interface-controlled crystal growth where values that fall above the envelope suggest clustering and below the envelope suggests ordering.

\section{Impingement Index}

The ordering and clustering indices only take into account the position of crystal centers, whereas the impingement index considers both position and size. Based on the Avrami ratio, this index compares the actual volume of crystals to an extended volume, which is the volume that would be obtained if the crystals grew 
without impingement (Carlson, 1989). The ratio is then tested against the ratio for a random crystal array, which may contain a degree of impinging crystals if the placement and observability criterions are passed. Simply, if the actual and extended volumes are equal then there is zero impingement within the crystal population, indicating an ideal ordered distribution. A random distribution would have an extended volume slightly larger than the actual volume, indicating a small degree of impingement while a clustered distribution, where many crystals may impinge on one another, would contain an extended volume much larger than the actual volume. This ratio is compared to a random distribution in order to consistently compare the value to the null hypothesis envelope as before. A value that falls above the envelope indicates clustering and a value below indicates ordering.

\section{Isolation Index}

The isolation index measures how much the average nearest-neighbour crystal size deviates from the average crystal size. The index is not defined in any literature but is calculated by Reduce3D and found in the output text file of this software. If the average nearest-neighbour size is less than the average size of the entire crystal population then ordering is inferred, due to suppression of growth between neighbours. If the average nearest-neighbour size is greater than the average size then clustering may be present. 


\section{$L^{\prime}$-Function $\left(L^{\prime} F\right)$}

The L'-function originates from Ripley's 2D K-function (Ripley, 1976) which is a measure of the number of crystal centers that are present within a circular region around each crystal (Fig. 3-4). The K-function was transformed to the Lfunction to consider a spherical region for 3D analysis. The test sphere is defined by its radius, also known as the test distance $(r)$, which increases with each test to account for the change in crystal abundance as the spherical volume grows. The Lfunction is normalized to obtain the L'-function in order to compare the final statistic to a random distribution and a value of zero. This is done around every crystal to achieve an average statistic for each test distance. If more crystal centers are present within a volume than what is found in the 100 simulated random arrays (positive statistic, above envelope) then clustering is present within that scale. If less crystal centers are present than what is found for a random distribution (negative statistic, below envelope) then an ordered distribution exists.

\section{Pair Correlation Function (PCF)}

Similarly to the L'-function, the PCF takes into account crystal center positions, but instead of using a spherical test region it uses a spherical shell (Fig. 34). This way, the crystal abundance at every test distance can be determined (instead of within every test volume). The shell is positioned at $r$ and has a thickness that is determined by the bandwidth of an Epanecnikov kernel function (Hirsch, 2000). The idea of the kernel function is to allow all crystal centers within the shell to be considered however crystals closer to the center of the shell (near the actual 
test distance) will be weighted more heavily than those that fall close to the edge of the shell. The thickness of the shell can be adjusted by the user in Reduce3D by changing $c$ ( $c=0.1$ for all statistics done in this study). The PCF is normalized to a random distribution value of unity and compared to the position of the $95 \%$ confidence null hypothesis envelope. An abundance of crystals at a specific test distance will create a value above the envelope indicating clustering, while a scarcity of crystals will indicate ordering and result in a value below the envelope.

\section{Mark Covariance Function (MCF)}

The MCF is unique in that it takes into consideration an additional crystal feature, or mark, such as radius, volume, minimum axis length or maximum axis length. Similar to the PCF, the MCF accounts for crystals present within a spherical shell around each crystal (Fig. 3-4). The arithmetic mean value of the mark for crystals separated by $r$ is compared to the arithmetic mean mark value for the entire population. Accordingly, the MCF does not measure deviations from random but variations in crystal marks which in turn may represent variations in crystal growth, depending on the chosen mark. For example, if radius is used as the mark, and the mean radius of the crystals separated by $r$ is smaller than the mean radius of the population, then a suppression of crystal growth may have taken place at that test distance and an ordered texture is present. If the mean radius of the crystals in question is larger than the mean radius of the population, then an enhancement of crystal growth may have occurred at that length scale which may indicate a cluster of relatively large crystals. The arithmetic mean is used for the MCF instead of the 
geometric mean because the latter has a tendency to reduce the MCF below unity ( $p$. 1-11 in Hirsch, 2000). Accordingly, the results are visually compared to the same statistics for the random distribution simulations, no normalization is done making the MCF a pure correlation between mark and scale.

Previous studies use crystal radius as a mark (Carlson, 1989; Daniel and Spear, 1999; Hirsch et al., 2000; Ketcham et al., 2005; Hirsch and Carlson, 2006; Hirsch, 2008) which is reasonable when quantifying the size distribution of garnet which closely resembles a sphere. When crystals deviate from a spherical geometry another mark, such as volume or axis length may be used, as was done for cordierite and biotite in this study.

Reduce3D automatically assumes the mark to be crystal radius and an option can be chosen by the user to identify crystal volume as the input mark. Inputting minimum or maximum axis length instead will shed light on the distribution of ellipsoid width or length, respectively. It should be noted that when a different mark value is used a few complications may arise for the L'F and PCF because their calculations involve normalization to a randomly distributed array. The randomly placed crystals are simulated to grow spherically under interface-controlled growth to a certain size that is specified by the user in the input file as the mark. If aspect ratio or axis length is used as the mark, the random distribution model will not have the same CSD as the actual crystal population and result in a random distribution that is not a true representation of the population if it were to grow under interfacecontrolled growth. The L'F and PCF will have erroneous results due to normalization 
with a false random distribution simulation. On the other hand, the MCF will be useful in displaying the variation in crystal width or length with distance.

\section{Stereonet}

The orientation of the maximum and minimum axis lengths for cordierite and biotite were obtained by Blob3D and converted into plunge and trend. Stereonet software version 9.1.1 was used to project the lineations onto a stereograph.

\subsection{Results}

\subsubsection{Petrography of COB3-S1-5 (CT_009)}

The rock sample contains porphyroblasts of $\mathrm{Ab}+\mathrm{Bt}+\mathrm{And}+\mathrm{Crd}$ in a schistose matrix defined by Chl $+\mathrm{Ms}+\mathrm{Pl}+\mathrm{Ilm}+$ Qtz (Fig. 3-5). An alignment of albite and biotite porphyroblasts $\mathrm{L}_{1}$ is visible parallel to the matrix foliation $\mathrm{S}_{1}$ while andalusite and cordierite, although slightly elongated, show a decussate texture typical of a hornfels. Cordierite ranges in size from 0.5-1.5 mm and contains rims of alteration to fine grained pinite and is surrounded by an approximately $100 \mu \mathrm{m}$ thick region of $S_{1}$ foliated retrograde chlorite (Fig. 3-5A, B, C). Chlorite is occasionally present in the center of cordierite porphyroblasts as well with no specific orientation (Fig. 3-5B). Idiomorphic andalusites range from 0.4-0.8 mm and have weak chiastolite inclusion textures that display rotation (Fig. 3-5C, D). Biotite fish of 0.1-0.5 mm also contain rotated inclusion trails that merge with the external matrix and occasional hourglass inclusion textures. Inclusions of $\mathrm{Ab}+\mathrm{Bt}+\mathrm{And}$ in 

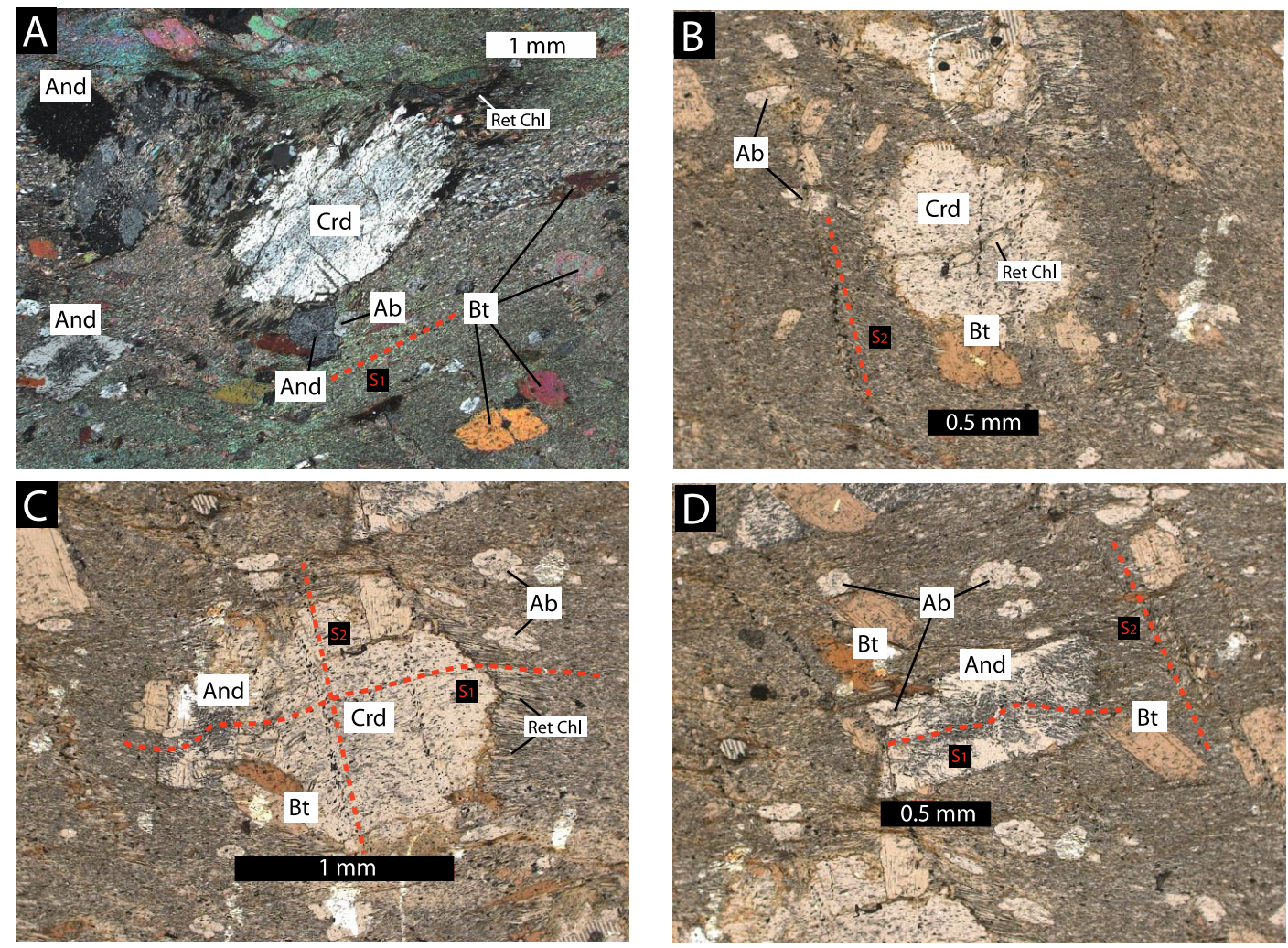

Figure 3-5. Photomicrographs of COB3-S1-5 showing the textural relationships between plagioclase, biotite, andalusite and cordierite porphyroblasts. (A) Cyclic twinning in an elongated Crd with retrograde chlorite (Ret $\mathrm{Chl}$ ) along its rim. The elongation of all porphyroblasts is parallel to the matrix foliation S1. Beneath Crd there is $\mathrm{Ab}+\mathrm{Bt}$ inclusions within the rim of And. (B) Pinitized Crd with Ret Chl in its core and S2 Bt-Ilm crenulations cutting through its structure. (C) Inclusion relationships between porphyroblasts with And+Bt in Crd and a clear Ret Chl rim around Crd. (D) Weak chiastolite inclusion texture in And with merging inclusion trails. Ab inclusion in And. Mineral abbreviations after Kretz (1983).

cordierite suggest cordierite crystal growth after the completion of its included phases, as is the same for $\mathrm{Ab}+\mathrm{Bt}$ inclusions in andalusite, and $\mathrm{Ab}$ inclusions in biotite (Fig. 3-5C, D). This sequence of porphyroblast growth (Ab-Bt-And-Crd) is interpreted to have occurred syn-kinematic to the deformation of the matrix, with the largest crystallized phases having grown more quickly or for longer time than the phases included in their structure. Therefore, in terms of the texture analysis to be done on biotite and cordierite, their nucleation may have been close to simultaneous but crystal growth was dominated by cordierite. 
Perpendicular to $S_{1}$, biotite-ilmenite crenulation cleavages $S_{2}$ cut across the matrix structure as well as through porphyroblasts indicating post-metamorphic deformation (Fig. 3-5B-D). This is relevant to interpreting the position of porphyroblast centers were they repositioned from their original nucleation sites during late-stage deformation. The small size of these crenulations and the observation that they cut through porphyroblasts instead of along their grain boundaries is a good indication that the pre-existing prophyroblasts did not shift positions.

\subsubsection{Phase Equilibria}

The equilibrium phase diagram for COB3-S1-5 is presented in Figure 3-6 with the shaded multi-variant fields that correspond to the metamorphic zones observed in the Bugaboo contact aureole. The presence of primary chlorite and cordierite in sample COB3-S1-5 signifies a univariant line in P-T space at which chlorite breaks down to produce cordierite (Zone 2 in Fig. 3-6). This is predicted to occur at $500^{\circ} \mathrm{C}$ and $1.60 \mathrm{kbar}$. The chlorite-cordierite assemblage is predicted to be stable up to 2.15 kbar, however an isobaric metamorphic path at this $\mathrm{P}$ would experience two episodes of cordierite growth as it would cross the curved cordierite-consuming reaction that bounds the upper $\mathrm{P}$ limit of the mineral assemblage of Zone 3 (Fig. 3-6). Pattison and DeBuhr (2015) observed film-like 


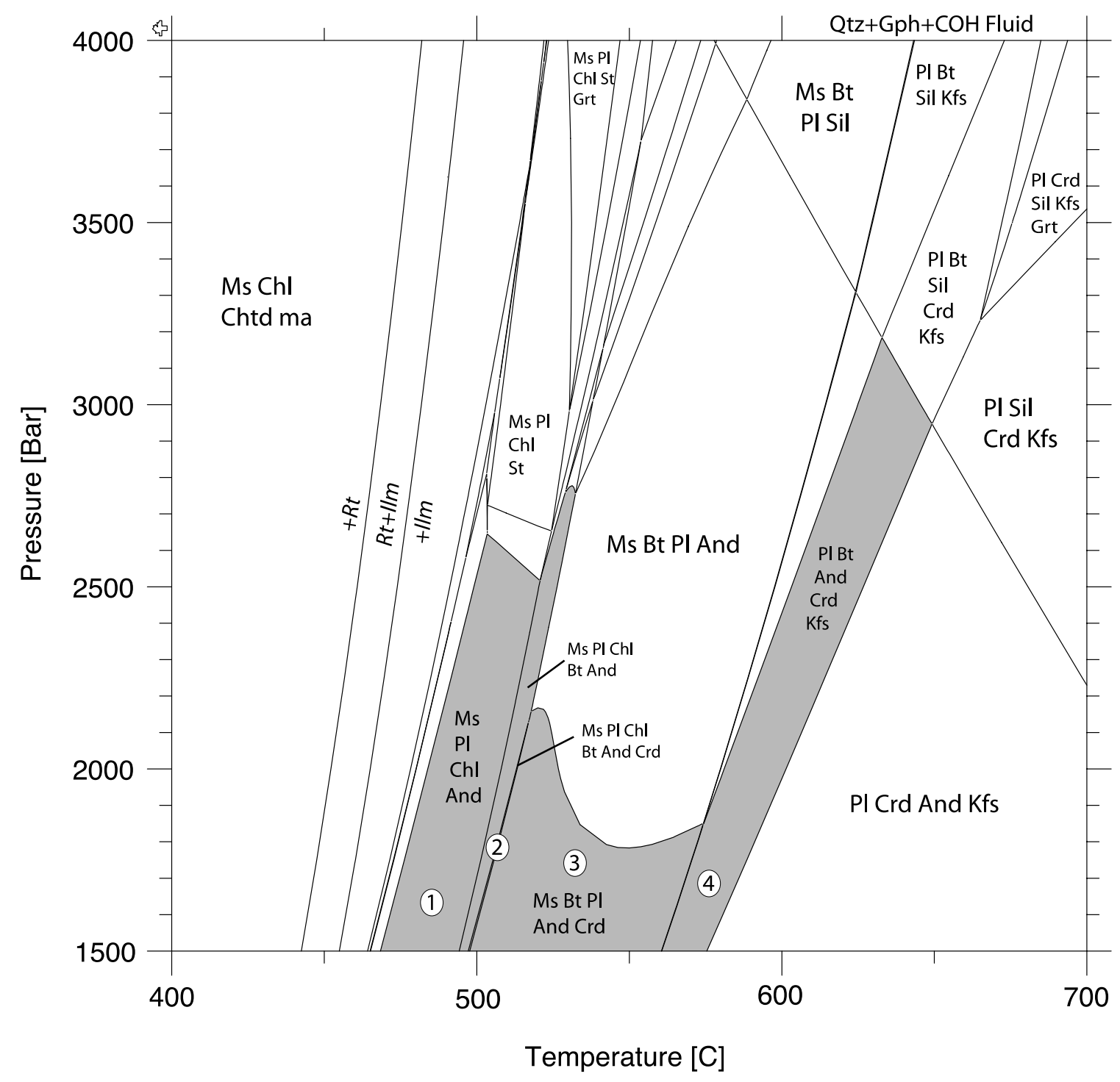

然

Figure 3-6. Phase equilibria for COB3-S1-5 predicted by Theriak/Domino software using the bulk rock composition in Table $3-1$. The shaded regions correspond to the metamorphic zones in Fig. 3-1C and represent the P-T range experienced by the Bugaboo contact aureole. The mineral assemblages of Zone 2 and COB3-S1-5 are predicted to be in equilibrium along the univariant line at which chlorite breaks down and cordierite is produced. Mineral abbreviations after Kretz (1983). 
andalusite within the middle aureole that was present between cordierite porphyroblasts, an indication that this univariant line may have been crossed, although not by a significant amount to fully consume cordierite, or produce a large amount of secondary andalusite. The position of an isobaric P-T path is therefore restricted by the position of the upper univariant line for Zone 3. As concluded in Chapter 2, a $\mathrm{P}$ of $1.60 \mathrm{kbar}$ fits most bulk rock phase equilibria for the contact aureole.

\subsubsection{XR- $\mu$ CT of COB3-S1-5}

Calculations of the linear X-ray attenuation of phases occupying COB3-S1-5 are graphed in Figure 3-7A against X-ray energies up to $1 \mathrm{MeV}$ (1000 keV). For these calculations, the mineral chemistry obtained from DeBuhr (1999) and analyses done by the author were used in combination with mineral densities predicted by Theriak/Domino software. Between 40-130 keV (Fig. 3-7B), the spectrum of X-ray intensity for the scan performed in this study, ilmenite is the highest attenuating phase followed by biotite and chlorite, and the least attenuating phases (cordierite, andalusite, muscovite, albite and quartz) all have similar X-ray attenuation coefficients. Around $80 \mathrm{keV}$, however, the linear attenuation of andalusite, muscovite and cordierite cross so that andalusite becomes a greater attenuating phase than cordierite and muscovite which overlap. The greatest intensity of X-ray energies for the scan performed is $100 \mathrm{keV}$, and the linear attenuation at this energy is the best representation of what the relative greyscale values of the phases will be (Fig. 3-7B). At $100 \mathrm{keV}$, quartz and albite remain the lowest attenuating phases, with 

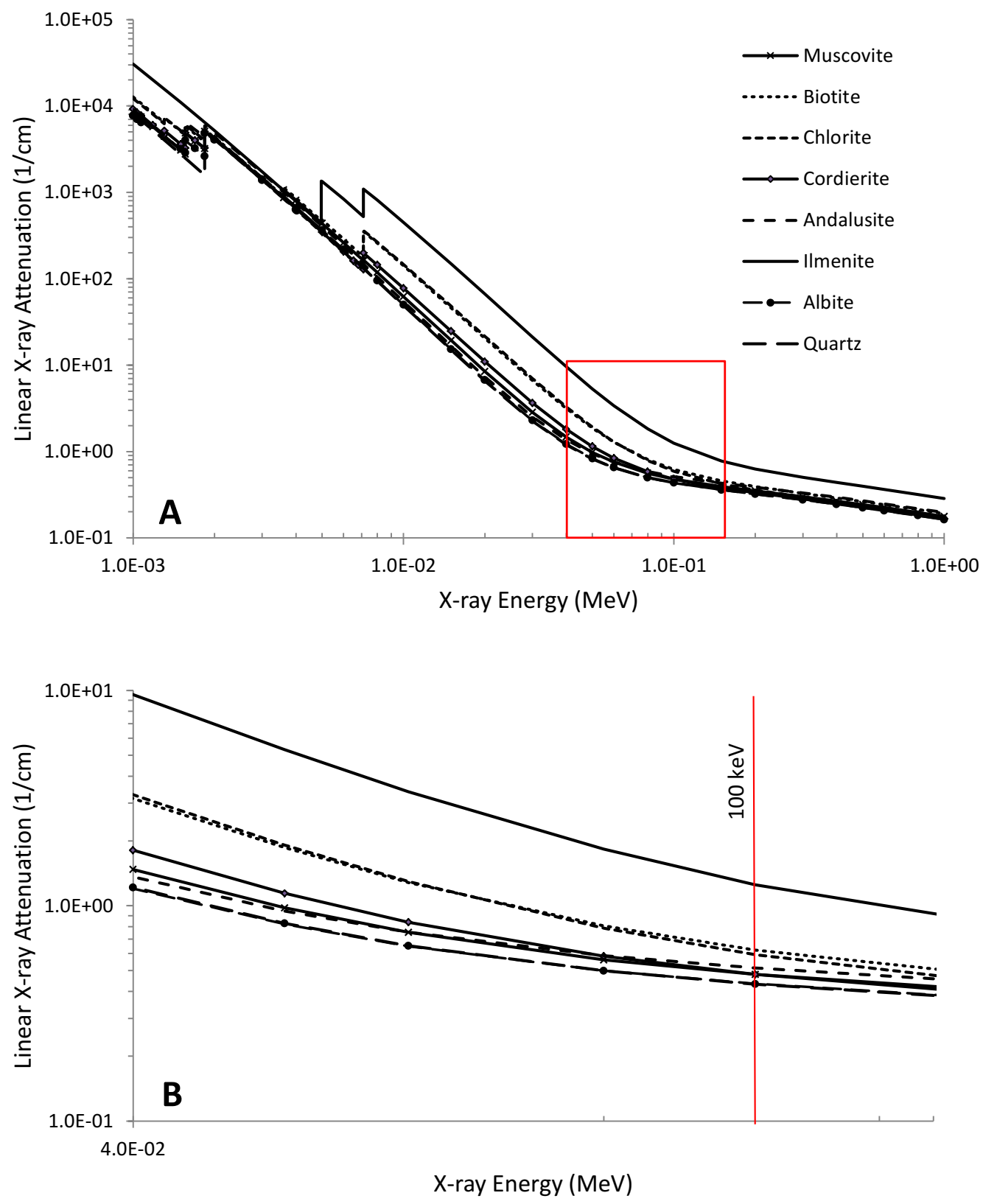

Figure 3-7. The linear $X$-ray attenuation with incoherent scattering for the mineral phases in COB3-S1-5 for (A) an X-ray energy spectrum up to $1 \mathrm{MeV}(1000 \mathrm{keV})$ and (B) the X-ray spectrum of the CT scanner (40-130 keV). The greatest intensity of the X-ray energy lies at $100 \mathrm{keV}$. 
similar cordierite and muscovite values and andalusite now with a greater attenuation. Biotite and chlorite are still relatively the same and ilmenite remains the greatest attenuating phase.

A slice image for sample COB3-S1-5 is displayed in Figure 3-8 alongside a thin section through the rock core at the same location. Andalusite was outlined in the thin section and overlain on the tomography data because its attenuation was very close to that of the rock matrix, even slightly lower, making it technically invisible in the CT data. Biotite is the greatest attenuating porphyroblast phase, appearing the brightest, with cordierite displaying an inhomogeneous distribution of X-ray attenuations within individual porphyroblasts. The greyscale within cordierite ranges from that of the matrix to black, with the black regions matching fractures seen in thin section (Fig. 3-8A, B, D). Cordierite is spatially related to retrograde chlorite, which is visible as a bright highly attenuating rim around each crystal, similar to the attenuation of biotite. Porphyroblasts of albite show a lower Xray attenuation than the matrix and display $L_{1}$ which in turn defines the orientation of $\mathrm{S}_{1}$ in CT (Fig. 3-8C) since the matrix phases are not distinguishable and petrography has shown that albite is lineated parallel to the matrix foliation (Fig. 35). The abundance of biotite-ilmenite $S_{2}$ crenulation cleavages is displayed through CT as fine highly attenuating linear features spaced evenly $0.5-1 \mathrm{~mm}$ apart (Fig. 38C), however, when cutting through cordierite porphyroblasts, $S_{2}$ is not visible (Fig. 3-8A, D). 

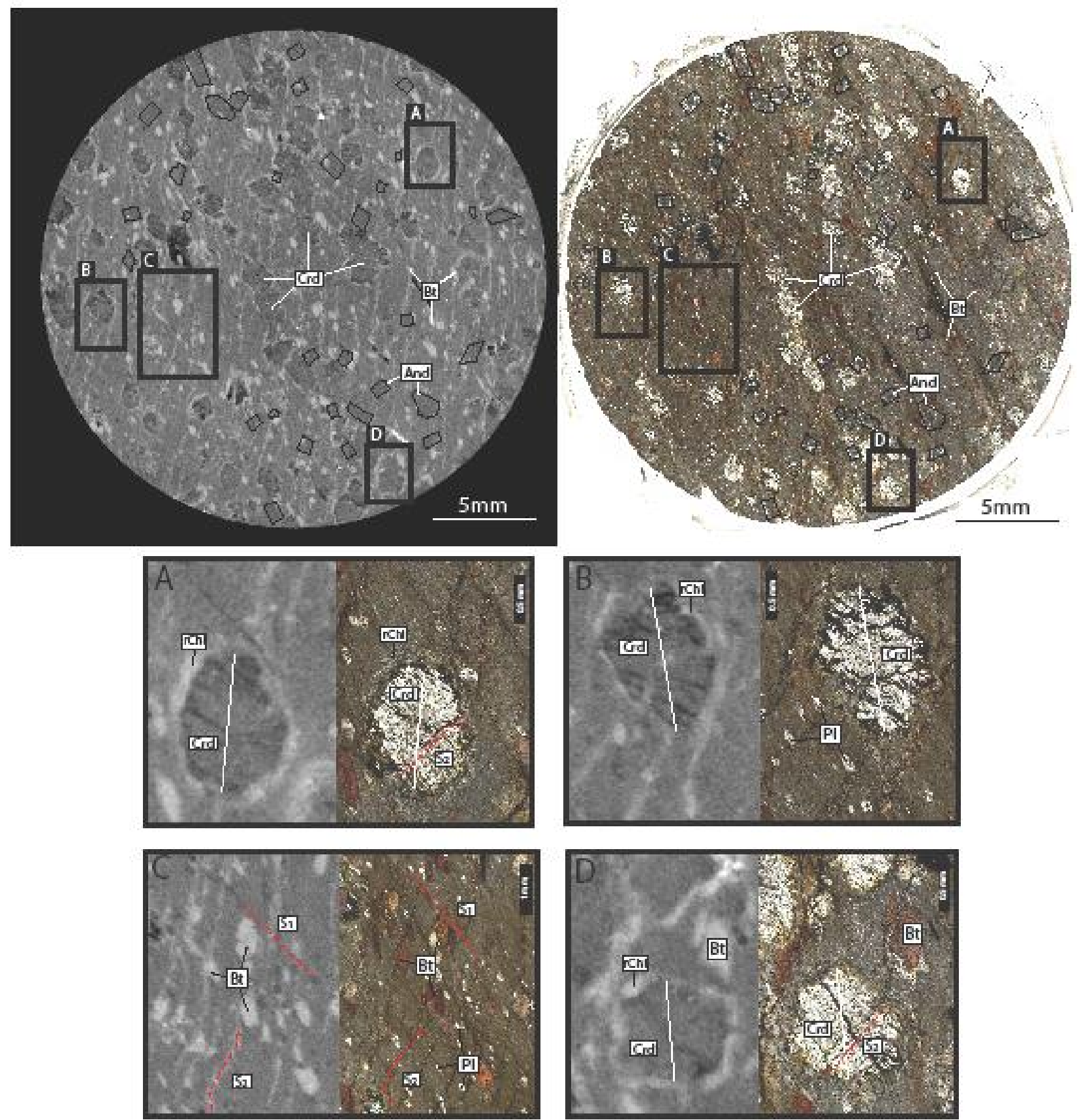

Figure 3-8. Tomography data of COB3-S1-5 with corresponding thin section photos. Crd and $B$ porphyroblasts are visible while And cannot be distinguished from the matrix phases and was therefore outlined. Chemical profiles were done across cordierite A, B and D (see Fig. 2-9). A close-up of the rock structures is shown in C with the matrix foliation $\mathrm{S} 1$ represented by the lineation in $\mathrm{Ab}$ and the $\mathrm{S} 2$ crenulation cleavages identified by highly attenuating Bt+Ilm spaced at $0.5-1 \mathrm{~mm}$. 


\section{Mineral Chemistry}

Profile analyses across cordierite (shown as white lines in Figure 3-8A, B, D) show no heterogeneity with respect to $\mathrm{Na}, \mathrm{Mn}, \mathrm{Fe}$ and $\mathrm{Mg}$, and the chemistry does not change across the low attenuating linear features (Fig. 3-9). The chemistry between crystals is also identical with an average Mg\# of 0.54 (Table 3-3). Biotite is homogeneous with Mg\# of 0.42 from data obtained by DeBuhr (1999). The chemistry of primary and retrograde chlorite is identical, along with the chemistry of retrograde chlorite in the rim and core of cordierite (Table 3-3).

Table 3-3. Average chemical analyses of mineral phases in COB3-S1-5 presented in cation number. Biotite and primary chlorite analyses are after DeBuhr (1999). Cordierite analyses correspond to chemical profiles shown in Figure 3-8A, B and D. Retrograde (Ret) chlorite analyses done by the author.

\begin{tabular}{|c|c|c|c|c|c|c|c|c|c|c|}
\hline Phase & $\mathbf{S i}$ & $\mathbf{A l}$ & $\mathbf{T i}$ & $\mathbf{F e}^{2+}$ & $\mathbf{M n}^{2+}$ & $\mathbf{M g}$ & $\mathbf{C a}$ & $\mathbf{N a}$ & $\mathbf{K}$ & $\mathbf{M g \#}$ \\
\hline \multirow{2}{*}{$\begin{array}{c}\text { Crd A } \\
\mathbf{B}\end{array}$} & 5.230 & 3.709 & 0.002 & 0.791 & 0.027 & 0.948 & 0.005 & 0.341 & 0.062 & 0.54 \\
\cline { 2 - 11 } $\mathbf{D}$ & 5.055 & 3.900 & 0.001 & 0.824 & 0.028 & 0.999 & 0.001 & 0.326 & 0.042 & 0.54 \\
\cline { 2 - 10 } & 5.196 & 3.735 & 0.003 & 0.805 & 0.027 & 0.976 & 0.002 & 0.327 & 0.022 & 0.54 \\
\hline Biotite & 2.657 & 1.760 & 0.088 & 1.327 & 0.005 & 0.991 & 0.000 & 0.040 & 0.868 & 0.42 \\
\hline $\begin{array}{c}\text { Primary } \\
\text { Chlorite }\end{array}$ & 2.702 & 2.917 & 0.006 & 2.282 & 0.016 & 1.803 & 0.157 & 0.057 & 0.001 & 0.44 \\
\hline $\begin{array}{c}\text { Ret } \\
\text { Chlorite } \\
\text { (Core) }\end{array}$ & 2.579 & 2.945 & 0.007 & 2.483 & 0.017 & 1.906 & 0.001 & 0.000 & 0.003 & 0.43 \\
\hline $\begin{array}{c}\text { Ret } \\
\text { Chlorite } \\
\text { (Rim) }\end{array}$ & 2.578 & 2.950 & 0.008 & 2.467 & 0.015 & 1.915 & 0.001 & 0.000 & 0.011 & 0.43 \\
\hline
\end{tabular}



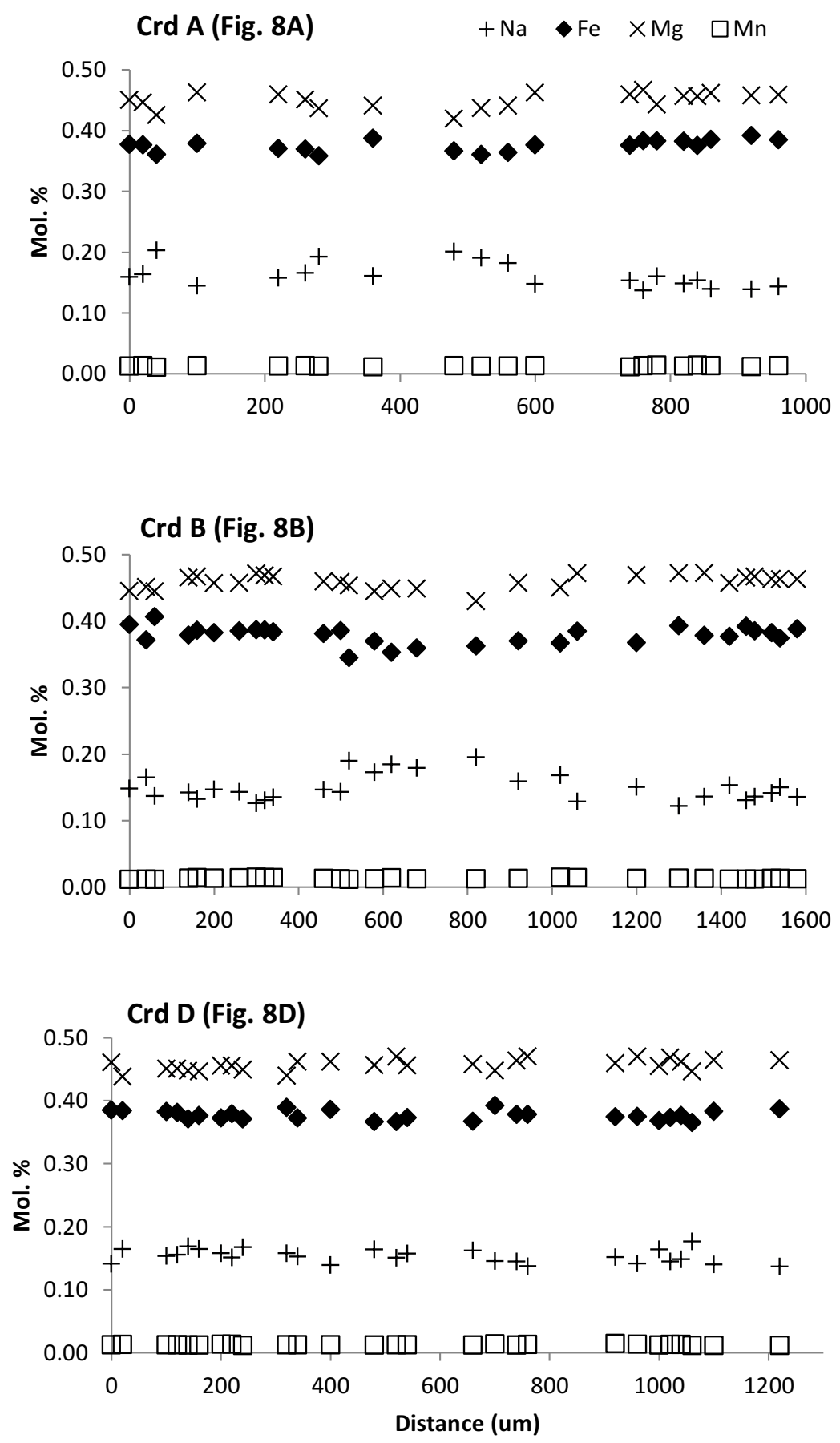

Figure 3-9. Chemical profile analyses across cordierite porphyroblasts shown in Figure 3-8A, B and D. 


\subsubsection{Quantification of the Porphyroblastic Texture Cordierite and Biotite}

Segmentation of cordierite in COB3-S1-5 resulted in the extraction of 840 crystals in $9.29 \mathrm{~cm}^{3}$, of which 300 were intersecting the sample boundaries and the remainder 540 complete crystals were used to quantify the population (Table 3-4). Biotite from the same sample was also segmented and 2306 crystals were used to quantify their texture from $1.41 \mathrm{~cm}^{3}$ (Table 3-5). The crystal size distribution (CSD), aspect ratio distribution (ARD) and volume to aspect ratio plot for the cordierite and biotite populations of sample COB3-S1-5 are displayed in Figures 3-10 and 311. The single scale and scale-dependent statistics calculated by Reduce3D are shown in Figures 3-12 and 3-13 for cordierite and biotite, respectively, using the sphere-normalized radius, volume, minimum and maximum axis lengths as the mark. The statistics are plotted against the test distance and compared to a $95 \%$ confidence envelope for a simulated random distribution, the region shaded in pink. The blue shaded region represents the range of nearest-neighbour $(\mathrm{N}-\mathrm{N})$ distances from the closest to the furthest (data in Tables 3-4 and 3-5). The dark blue bar indicates the mean $\mathrm{N}-\mathrm{N}$ distance with two standard deviations. The minimum and maximum axis orientations are plotted on a stereonet in Figure 3-14 for the two porphyroblast phases. These structures are in relation to the position of the rock core when it was scanned.

It should be noted that when using a parameter other than radius or volume as the mark, the simulated random array is not an accurate representation of the crystal population were it to grow under interface-controlled growth. Because the L'F and PCF are comparisons of the actual crystal population to the simulation, the 
resulting statistical values are erroneous and should not be examined. This can be seen in the calculated volume fraction of biotite and cordierite when their axis lengths were used as the mark (Tables 3-4 and 3-5) because the simulation is growing the crystals as spheres to a radius the size of their minimum or maximum length. Nonetheless, it is clear that the L'F and PCF statistics produced from using axis lengths are very similar to what is obtained when using radius or volume (Fig. 3-12 and 3-13). The MCF results for these mark parameters are of primary focus.

Table 3-4. Extracted data for the analyzed cordierite population in COB3-S1-5.

\begin{tabular}{|c|c|c|c|}
\hline Measure & Radius & Max Axis Length & Min Axis Length \\
\hline Vol. \% & 9.11 & 41.39 & 3.50 \\
\hline Xl Density (\#/cm3) & 7.47 & 7.27 & 7.52 \\
\hline Min Size & 0.026 & 0.041 & 0.018 \\
Avg. Size (cm) & $\mathbf{0 . 0 6 5}$ & $\mathbf{0 . 1 1 0}$ & $\mathbf{0 . 0 4 6}$ \\
Max Size & 0.086 & 0.185 & 0.067 \\
\hline Min N-N Distance & 0.074 & 0.084 & 0.074 \\
Avg. N-N Dist. (cm) & $\mathbf{0 . 1 3 1}$ & $\mathbf{0 . 1 4 0}$ & $\mathbf{0 . 1 3 2}$ \\
Max N-N Distance & 0.261 & 0.261 & 0.261 \\
\hline Isolation Index & 1.43 & 5.81 & 3.74 \\
\hline
\end{tabular}

Table 3-5. Extracted data for the analyzed biotite population in COB3-S1-5.

\begin{tabular}{|c|c|c|c|}
\hline Measure & Radius & Max Axis Length & Min Axis Length \\
\hline Vol. \% & 3.43 & 83.9 & 7.56 \\
\hline Xl Density (\#/cm3) & 14.3 & 83.2 & 14.3 \\
\hline Min Size & 0.005 & 0.027 & 0.007 \\
Avg. Size (cm) & $\mathbf{0 . 0 1 6}$ & $\mathbf{0 . 0 6 3}$ & $\mathbf{0 . 0 2 0}$ \\
Max Size & 0.035 & 0.149 & 0.056 \\
\hline Min N-N Distance & 0.011 & 0.0280 & 0.011 \\
Avg. N-N Dist. (cm) & $\mathbf{0 . 0 4 8}$ & $\mathbf{0 . 0 6 9}$ & $\mathbf{0 . 0 4 8}$ \\
Max N-N Distance & 0.107 & 0.116 & 0.107 \\
\hline Isolation Index & 2.69 & 7.19 & 3.21 \\
\hline
\end{tabular}



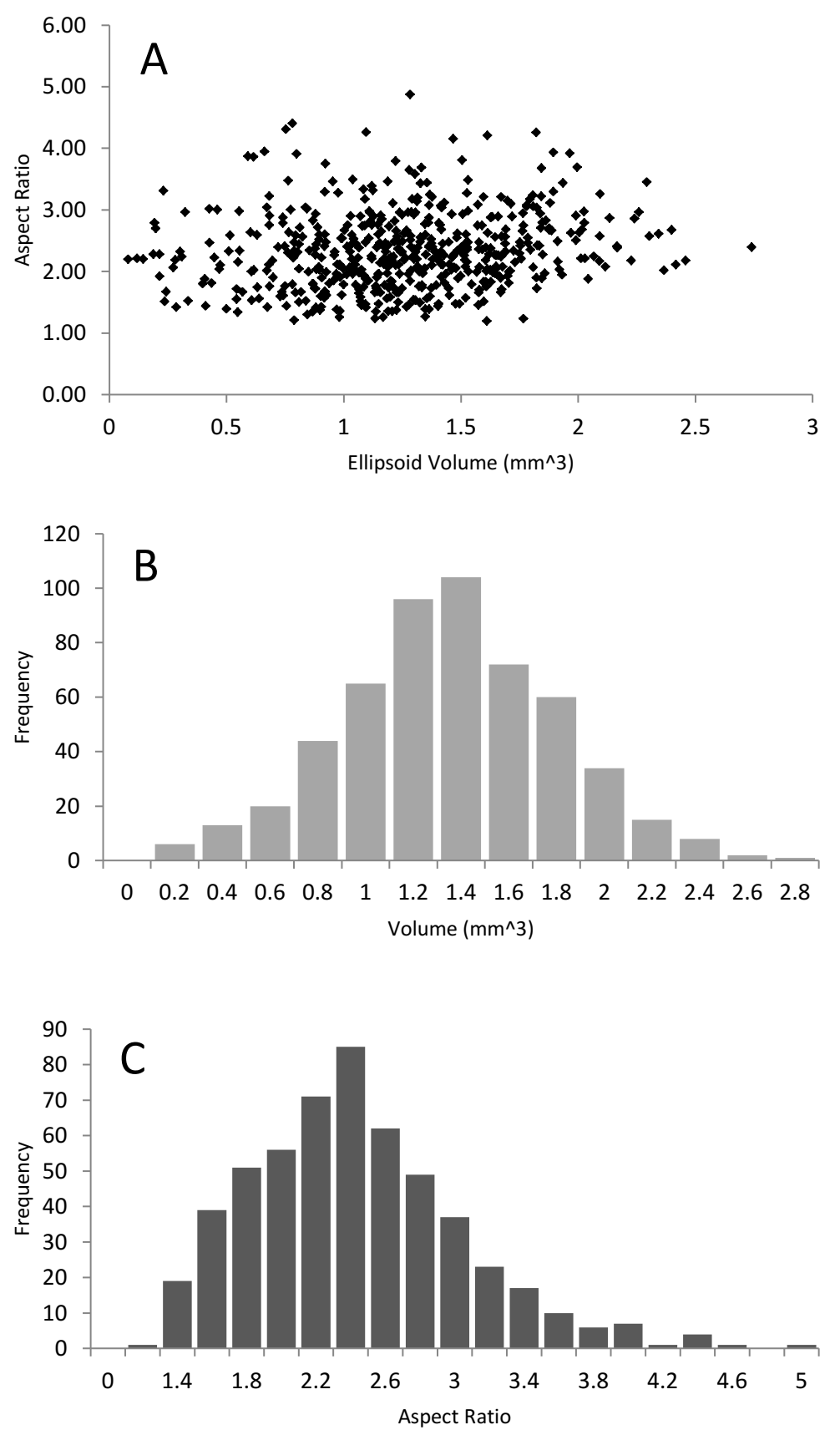

Figure 3-10. Quantification of cordierite from COB3-S1-5 using volume and aspect ratio. 

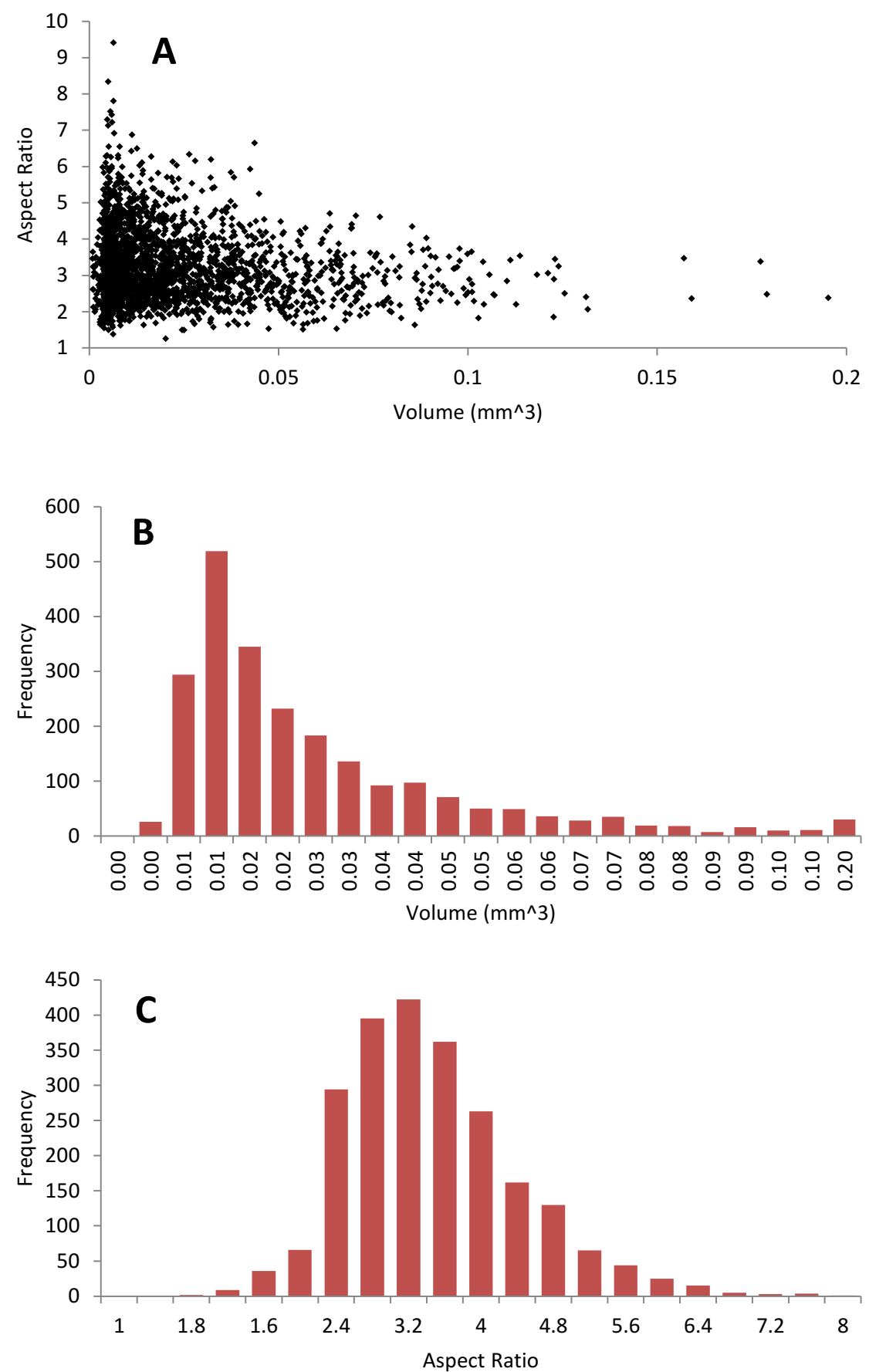

Figure 3-11. Quantification of the biotite population in COB3-S1-5 using volume and aspect ratio. 

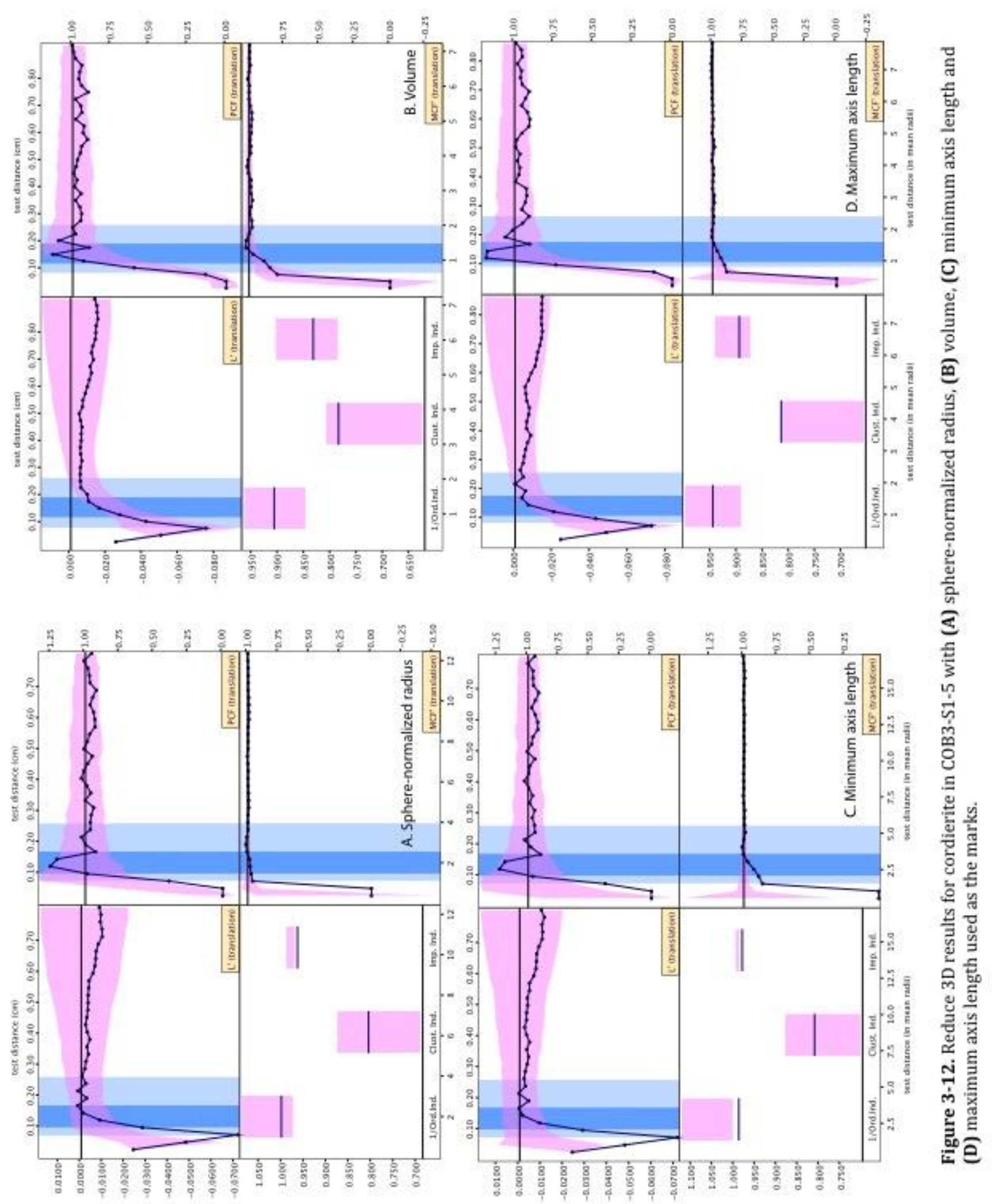

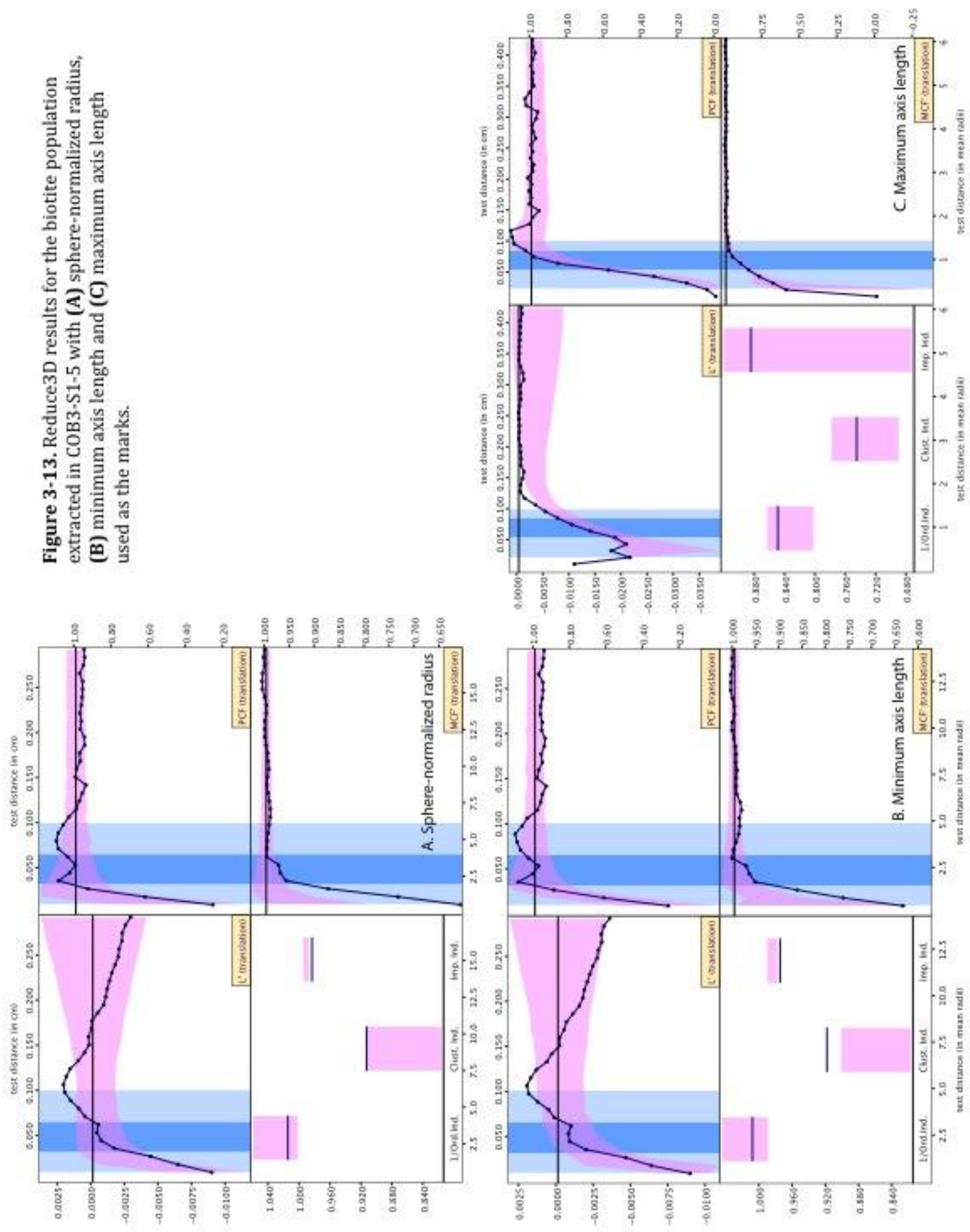


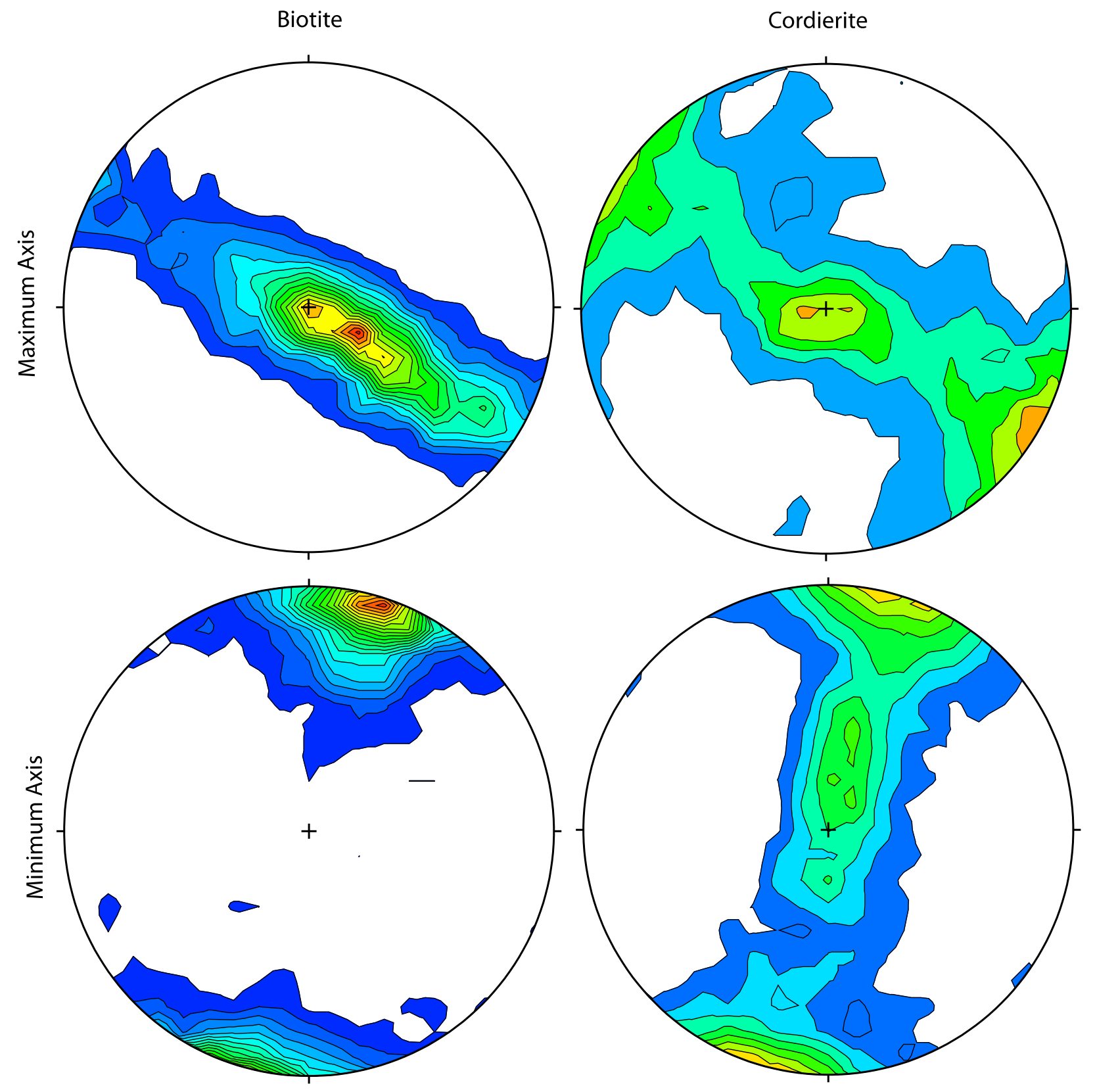

Figure 3-14. Stereonet plots for the maximum and minimum axis lengths obtained by Blob3D of biotite and cordierite in COB3-S1-5 using Stereonet software. The plots are relative to the orientation of the rock core in the CT scanner. The maximum axes of both biotite and cordierite lie within S1and their minimum axes are perpendicular to S1. 


\section{Biotite}

Porphyroblasts of biotite are elongated with an inverse logarithmic relationship between size and aspect ratio; the smallest crystals have larger aspect ratios than the largest crystals (Fig. 3-11A). Both the CSD and ARD are skewed to the right (Fig. 3-11B, C). The maximum axis is oriented in the plane $120 / 88$ while the minimum axis creates a perpendicular lineation at 08/012 (Fig. 3-14). Through petrography, biotite was observed to align parallel to the matrix foliation (Fig. 3-5) therefore this planar structure of the maximum axis length is approximately parallel to the foliation in the rock matrix.

With the sphere-normalized radius used as the mark (Fig. 3-13A) the ordering and clustering index fall within the $95 \%$ confidence envelope while the impingement index falls below, an indication that there is less impingement than expected. The L'F and PCF display a clustering signal at length scales around the greatest $\mathrm{N}-\mathrm{N}$ distance with all other scales falling within the null hypothesis envelope. At the smallest length scales, the statistical values fall below the envelope in the MCF, indicating an ordered texture from the minimum to the mean $\mathrm{N}-\mathrm{N}$ distance. Very similar statistical patterns are produced when the minimum axis length is used as the mark (Fig. 3-13B) with reinforcement of clustering in the L'F, PCF and clustering index, as well as ordering below the mean N-N distance in the MCF.

The maximum axis length resulted in different statistical patterns that more strongly indicate a random distribution, but with the same clustering peaks in the L'F and PCF (Fig. 3-13C). Further evidence for the suppression of crystal growth 
between neighbouring crystals is provided with the isolation index (Table 3-5) which shows that the average size between nearest-neighbours is smaller than the average size of the entire population.

\section{Cordierite}

The mean aspect ratio of the extracted cordierite porphyroblasts is 2.33 . The CSD shows a normal distribution of cordierite volumes (Fig. 3-10B) and the ARD is weakly skewed to the right (Fig. 3-10C). There is no relationship between volume and aspect ratio (Fig. 3-10A). The orientation of the maximum axis lies in the plane 303/87, approximately parallel the foliation of biotite and therefore the rock matrix, and the minimum axis creates a planar feature at 014/86 (Fig. 3-14).

With a sphere-normalized radius used as the mark (Fig. 3-12A), the ordering and clustering index fall within the null hypothesis envelope of a random distribution while the impingement index falls below the envelope, an indication that there is less impingement in the actual sample than for the random array. The L'F and PCF exhibit a random distribution at most scales, with values falling inside the $95 \%$ confidence envelope. At the mean $\mathrm{N}-\mathrm{N}$ distance, which happens to also be the mean diameter of cordierite assuming a spherical geometry (Table 3-4), a clustering signal is obtained in the PCF with values falling slightly above the envelope. An almost perfect random distribution of crystal size (based on radius) is seen through the MCF with the exception of scales at and below the mean N-N distance. At these smallest scales, the values for the MCF fall below unity but remain just within the envelope. The two smallest values that equal zero in the PCF and 
MCF, and anomalous in the L'F, represent the absence of any crystals spaced at the distance of $0.07 \mathrm{~cm}$.

When volume is used as the mark instead of radius the results are slightly different (Fig. 3-12B). All the single-scale statistics fall within the $95 \%$ confidence envelope. The scale-dependent statistics also fall within the envelope, but the values obtained are different from when radius is used as the mark. The peak in the PCF at the mean nearest-neighbour distance is observed again, along with the weak correlation between size and distance at the smallest scales in the MCF, however these values remain within the null hypothesis envelope. The correlation between size (based on volume) and distance is not as consistent around unity as it was with radius but remains within the envelope.

When the value for the mark is the minimum or the maximum axis length (Fig. 3-12C, D), the values at the smallest scales in the MCF that showed weak ordering for the radius mark are now illustrating a stronger signal towards ordering. The MCF for the minimum axis length results in the most significant ordering signal at scales less than the mean $\mathrm{N}-\mathrm{N}$ distance as well as in the singlescale ordering and impingement indices. Using axis length as the mark instead of radius or volume produces extremely similar statistical patterns. In all Reduce3D results, the values greater than the maximum $\mathrm{N}-\mathrm{N}$ distance, outside the shaded blue envelope, show a gradual decrease in the L'F, variation in the PCF and a perfect random distribution in the MCF. Important repetitive patterns are the clustering peak in the PCF at the mean N-N distance and the ordering signal below the mean N$\mathrm{N}$ distance in the MCF. 


\subsection{Discussion}

The extraction of cordierite from COB3-S1-5 was favourable due to the heterogeneous distribution of X-ray attenuation within the crystals and the contrast with their highly attenuating chlorite rim. The variation in X-ray attenuation was found to not be a result of chemical heterogeneities (Fig. 3-9) but instead changes in density due to fracturing based on comparison of the tomography and thin section data (Fig. 3-8). For the linear attenuation calculated in Figure 3-7, the density of cordierite predicted by Theriak/Domino of $2.64 \mathrm{~g} / \mathrm{cm}^{3}$ was used, but a reduction in density due to fracturing and the production of fine grained material would change the overall linear attenuation. Figure 3-15 displays the linear attenuation of the $\mathrm{Mg}$ and Fe end members of cordierite at $2.64 \mathrm{~g} / \mathrm{cm}^{3}$, along with reductions in density to 2.0, 1.5 and $1.0 \mathrm{~g} / \mathrm{cm}^{3}$. A change in Mg-Fe content greatly impacts the attenuation of cordierite, as well as a change in the density of its crystal structure, which is the dominant reason for cordierite visibility through CT in COB3-S1-5. The fractures are not parallel to the $S_{2}$ crenulation cleavages and are not filled with alteration minerals (Fig. 3-5 and 3-8), an indication of late deformation that may be related to exhumation.

Biotite and cordierite show unique volume distributions (Fig. 3-10B, 11B) which may reflect their sequential growth and their competitive consumption for the same chemical elements (i.e.; Fe and Mg). Petrography and phase equilibria suggest biotite nucleation prior to cordierite, therefore the first increment of its growth most likely occurred free of Fe-Mg competition with another phase. Once cordierite began to nucleate and consume $\mathrm{Fe}$ and $\mathrm{Mg}$, biotite nucleation declined 
rapidly as illustrated by its rightly skewed volume distribution in Figure 3-11B. Cordierite's normal volume distribution (Fig. 3-10B) shows a more gradual decrease in nucleation site frequency near the end of its crystallization and less competition for nutrients.

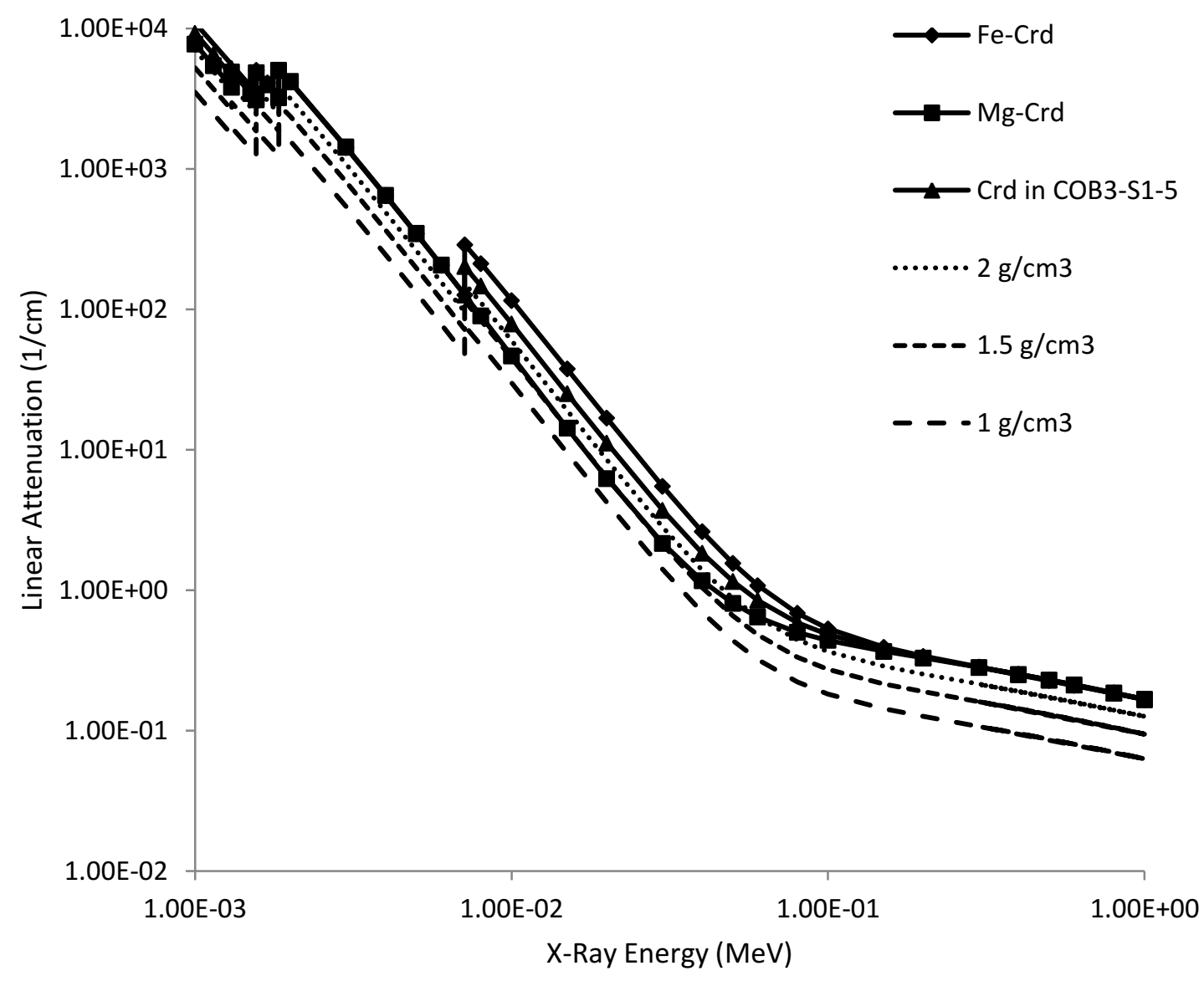

Figure 3-15. The linear X-ray attenuation of the Fe and Mg end members of cordierite compared to the observed chemistry of cordierite in COB3-S1-5 with a predicted density of $2.64 \mathrm{~g} / \mathrm{cm}^{3}$. Mg-pure cordierite will have a lower X-ray attenuation than one whose composition is purely $\mathrm{Fe}$. A decrease in density also causes a decrease in X-ray attenuation and is a dominant reason for the visibility of cordierite in COB3-S1-5. 
The statistical results from Reduce3D provide a substantial amount of information on both nucleation and crystal growth. The spatial positioning of crystal centers (L'F and PCF), assuming this is also the location of the original nuclei, gives information on the distribution of nucleation sites. The spatial size distribution of crystal centers (MCF) uncovers the relative competition for chemical nutrients between neighbouring crystals, and is therefore most important within the range of N-N distances (light blue shaded region).

\subsubsection{Clustering of Porphyroblast Centers}

Relating the textural analyses of biotite and cordierite to their petrographic partnership in thin section reveals some interesting aspects of performing a 3D analysis on porphyroblasts that share the same rock volume. Petrography, phase equilibria and volume distributions have all suggested biotite growth prior to the majority of cordierite growth. Segmentation of biotite through Blob3D lead to the extraction of individual porphyroblasts as well as inclusions in andalusite and cordierite porphyroblasts, while the manual segmentation of cordierite would not have subtracted the volume biotite occupied as an inclusion. Due to the presence of biotite inclusions, cordierite and andalusite may not have consumed a significant amount of the original biotite volume upon their crystallization, leaving the spatial distribution of biotite porphyroblast centers relatively untouched. With this being said, the incipient distribution of both porphyroblasts' center coordinates should have been accurately extracted from the rock volume, assuming the postcrystallization deformation $\mathrm{D}_{2}$ did not alter this feature. Were biotite consumed by 
the growth of cordierite or andalusite, its incipient texture upon nucleation and crystallization would not be preserved and this may be reflected in the statistical analysis.

Clustering of biotite from $0.08-0.12 \mathrm{~cm}$ in the L'F and $0.07-0.10 \mathrm{~cm}$ in the PCF (Fig. 3-13A, B) approximately matches clustering in cordierite at $0.11-0.13 \mathrm{~cm}$ in the PCF (Fig. 3-12A, C, D). This scale is also the average cordierite diameter, assuming a spherical geometry, and cordierite's average maximum axis length (Table 3-4). If cordierite did not consume biotite during crystal growth, securing its incipient position as inclusions, then this clustering may be explained by the presence of chemical heterogeneities in the protolith and an inhomogeneous distribution of biotite nucleation site probabilities (Denison et al., 1997; Daniel and Spear, 1999; Ketcham et al., 2005). From phase equilibria (Fig. 3-6) and KFMASH Reactions (I) and (II), it is evident that biotite and cordierite grew at the expense of chlorite. Therefore, the distribution of chlorite in the protolith may be mirrored in the distribution of the porphyroblasts that preferred to nucleate on its crystal structure. The presence of chlorite within the cores of cordierite may be evidence for this clustering mechanism, as primary cordierite growth may have preserved an inclusion of the remnant chlorite on which it nucleated. During retrogression, the chlorite inclusion may have resumed growth consuming cordierite from the inside out, if mass transfer across cordierite was efficient.

Daniel and Spear (1999) interpreted clustering of regional garnet prophyroblasts to possibly be a result of strain partitioning that drives nucleation within certain areas. The syn-kinematic growth of cordierite and biotite, interpreted 
through petrography (Fig. 3-5A-C) and their planar alignment (Fig. 3-14), may provide an alternative explanation for their clustered nucleation as deformation may have reorganized the distribution of interfacial energy required to drive porphyroblastic nucleus formation. However, this explanation is not as likely in a contact metamorphic setting where energy input from strain is minimal, compared to regional metamorphic settings.

Since biotite nucleation occurred prior to complete chlorite destabilization (Fig. 3-6), biotite clustering may instead be the result of cordierite overprinting the original biotite texture and resulting in a false clustering signal at the scale of the mean diameter of cordierite $(\sim 0.12 \mathrm{~cm})$. Since the presence of cordierite was not taken into account when analyzing biotite, the simulated random distribution done by Reduce3D would have filled the entire sample volume with growing biotite, while the actual volume was mainly restricted to areas in which cordierite was not present, other than the occasional inclusion. Reduce3D is able to account for a dualporphyroblastic rock volume by prompting the user to create a "holes" file, which for this study would contain the position and size of cordierite to be subtracted from the rock volume when analyzing biotite, creating holes. This type of analysis requires the extraction of both porphyroblasts from the same rock volume as well as the consideration of biotite inclusions in cordierite which was not possible with the orthogonal slice segmentation method. Although using a "holes" file would shed light on the true distribution of biotite in the rock matrix, the effect of one's porphyroblasts' growth on another could not be examined, as was done here. The presence of cordierite, or biotite-free regions, resulted in "clusters" of biotite 
between cordierite when normalized to the null hypothesis random array. A textural relationship such as this would explain the partial consumption of an already crystallized phase by a second, or the superior growth of one phase over another if nucleation were simultaneous. Although biotite was not fully consumed by cordierite, the growth of cordierite around a biotite crystal would have stopped it from growing to its desired size as well as restricting future nucleation of biotite to a region outside cordierite. The clustering of biotite centers was likely enhanced as a result of secondary and dominant cordierite as well as andalusite growth creating biotite-poor areas in the rock.

Another reason for biotite clustering observed in the CT dataset may be from the formation of planar biotite-rich crenulation cleavages $S_{2}$ spaced evenly at distances of approximately $0.5-1.0 \mathrm{~mm}$ (Fig. 3-8C). Defined by smaller biotite than the porphyroblasts, this post-metamorphic layering may boost the clustering signal seen through the L'F and PCF (Fig. 3-13). The inverse logarithmic relationship between biotite's aspect ratio and volume may also be explained by $S_{2}$ which contain smaller more elongated crystals than the large equant porphyroblasts.

\subsubsection{Ordering of Porphyroblasts}

Statistical values falling below the random distribution envelope in the MCF (Fig. 3-12A, C, D and Fig. 3-13A, B) implies that cordierite and biotite porphyroblasts spaced by these distances have an average mark value that is less than the average mark value of the entire population. For biotite, this occurs at $0.03-0.06 \mathrm{~cm}$, twice the mean mark value or the crystal diameter assuming it's a sphere in Figure 3-13A 
and the short axes diameter in Figure 3-13B. For cordierite, ordering occurs up to $0.15 \mathrm{~cm}$, less than the mean diameter assuming a spherical geometry in Figure 3$12 \mathrm{~A}$ but greater than the mean diameter of the short axis in Figure 3-12C. Noting the distance of an ordering signal in relation to the diameter of the crystal (depending on the mark used) is important for distinguishing false ordering due to the assumption that a crystal center may not nucleate inside another crystal. This is called the volume effect (Hirsch, 2000) or the Strauss hard core effect (Rudge et al., 2008). It has also been noted in single-scale statistics as a weak deviation from unity towards ordering for interface-controlled simulations of spatially random crystal distributions (Denison et al., 1997a). Therefore, this effect is present in the simulated random distribution as the decrease of statistical values for the $95 \%$ confidence envelope at scales below the average $\mathrm{N}-\mathrm{N}$ distance, and the calculated values falling below the envelope represent true ordering of cordierite and biotite.

Re-enforcement of this ordered texture is most significant for the minimum axis length in biotite (Fig. 3-13B) and for both axis lengths in cordierite (Fig. 3-12C, D). The rate of Reactions (I) and (II) were therefore controlled by the diffusion of elements through the rock matrix, creating regions depleted in nutrients and with lower chemical affinities for porphyroblast crystallization around the growing crystals (Carlson, 1989; 1991), although no petrographic evidence for these zones, such as prograde reaction rims, was observed in thin section.

A combination of clustering and ordering has been observed in previous studies on garnet porphyroblasts (Carlson, 1989; Denison and Carlson, 1997; Daniel and Spear, 1999). Ordering of cordierite in this study lies within the scale of its 
clustering and may be explained by solely diffusion-controlled growth without the heterogeneous distribution of chlorite in the protolith. Whereas the formation of critical clusters of cordierite molecules would result in cordierite nucleation and subsequent growth, subcritical clusters of cordierite molecules are unstable, shrink and release their nutrients to the rock matrix (Gaidies et al., 2011). During diffusioncontrolled nucleation, the chemical nutrients released will not transport far, thus creating regions in the rock matrix enriched in the elements required for future cordierite growth (Kelton, 2000). If cordierite continues to be part of the stable phase assemblage, nucleation of cordierite will have a greater probability of occurring within these enriched regions and an abundance of crystals may begin to grow in close proximity to each other.

\subsubsection{Considering Elongation of Porphyroblasts}

The assumption of Reduce3D that crystal growth is spherical is a simplification and can create misleading statistical results if used on porphyroblasts that are not spherical. The enhancement of the ordering signal when the axis lengths are used is evidence that a spherical assumption balances out such signals, causing them to be less noticeable. When converting a spherical crystal population to one in which the crystals are elongated new parameters are introduced, such as orientation of the long axis, and textural features adjust, such as the degree of impingement. Consider two spherical crystals with minimal impingement, there is no specific orientation to them and the amount of impingement is directly related to the distance between their centers. However, if the centers of two elongate crystals 
were spaced at the same distance, the amount of impingement is related to their orientation instead. Reduce3D does not take into account elongation or orientation therefore it is difficult to quantify the degree of impingement, making the impingement index irrelevant for the analysis of elongated crystals.

The distribution of both porphyroblasts' aspect ratios is skewed to the right (Fig. 3-10C and 3-11C), indicating few crystals were able to maximize their growth in the long direction. Whether these large aspect ratios represent crystals that began growth first is a question as to how an elongate crystal grows. Chemical profiles show no heterogeneity across either direction (Fig. 3-9 and Appendix II), which may indicate that the rate of the addition of new chemical nutrients was equal in all directions, assuming the prograde chemistry in cordierite is still preserved. If chemical attachment on the long axis continued after attachment ceased on the short axis then one might expect to see varying chemistry across the crystal that indicates high T equilibration towards the ends of the long axis.

The enhanced ordering signal observed in the MCF with the minimum axis lengths (Fig. 3-12C and 3-13B) expresses dominant growth suppression in the direction perpendicular to the porphyroblasts' maximum elongation and therefore perpendicular to the matrix foliation. Evidently, although the reaction rate was diffusion-controlled, the orientation of elongate cordierite and biotite porphyroblasts was a result of syn-kinematic growth during deformation induced by the batholith intrusion. The ordering signal observed in the MCF that uses the maximum axis length of cordierite (Fig. 3-12D) shows that diffusion was also the rate-limiting step for crystal growth parallel to the matrix foliation. 
The elongation of cordierite is the dominant reason for any error introduced into the data during orthogonal slice segmentation (Fig. 3-3). If an elongated porphyroblast lies at a high angle to the $\mathrm{x}, \mathrm{y}$ and $\mathrm{z}$ directions of the CT data, the segmented orthogonal slices will be further from the true long, intermediate and short axes of the crystal. In other words, if the segmented orthogonal selections are perfectly aligned with the true axes of the crystal, then the best fit ellipsoid should fit the crystal with minimal error. However, if the true axes of the crystal are not parallel to the orthogonal views then more error is created. The introduction of 20$30 \%$ error into the calculated volume of the cordierite porphyroblasts, specifically shrinking of the actual crystal size, would result in a random array simulated by Reduce3D that consists of more closely spaced crystals than a random array where the true, larger, crystal sizes are used. Based on the observability criterions used, the placement of crystals for interface-controlled simulation depends on their final crystal size. A population of smaller crystals (i.e.; the extracted cordierite size) would therefore be more closely spaced than a population of larger crystals (i.e.; the actual cordierite size). Since the L'F and PCF measurements are normalized to the simulated random distribution, statistical results may deviate towards ordering, where the distance between crystals is greater. The L'F and PCF results for cordierite (Fig. 3-12) occasionally show weak ordering at the smallest length scales but overall fall within the lower half of the $95 \%$ confidence envelope for the majority of length scales, possibly a result of the reduced sizes that were extracted through the orthogonal segmentation method. A consistent reduction in crystal volume should not have a significant impact on the MCF since the relative sizes of 
crystals is preserved. Nevertheless, the measured cordierite volume fraction obtained through Reduce3D (Table 3-4) and their average volume (Fig. 3-10) would be lower than the actual value.

\subsection{Conclusions}

This study presents textural data on cordierite porphyroblasts and relates its texture to biotite porphyroblasts in the same rock to explain the effects of sequential porphyroblast growth. The growth of cordierite after biotite had an impact on its texture by creating biotite-poor regions in the rock and thus a false clustering signal. The correlation between size and distance at the smallest length scales for cordierite and biotite indicates diffusion-controlled crystal growth of both phases. Further analysis using the "holes" files in Reduce3D would provide more evidence for the kinetics of Reaction I and the growth of biotite. Clustering in cordierite may either reflect a heterogeneous distribution of chemical nutrients in the protolith, possibly chlorite, or diffusion-controlled nucleation of cordierite by Reaction II. Taking into consideration the elongation of the porphyroblasts has proven useful in deciphering their true texture and brings forward the limitations associated with the general assumption of spherical crystal geometries.

In conclusion, the rate of metamorphic crystallization of cordierite and biotite within the outer portion (Zone 2) of the Bugaboo contact aureole was controlled by the rate of intergranular diffusion of chemical elements. However, the homogeneous chemistry of both porphyroblasts does not correspond with diffusion-controlled growth, which is expected to create chemical heterogeneity 
across the rock volume. This contradiction suggests chemical equilibration after final crystallization, either rapidly at peak metamorphic conditions or during retrograde metamorphism. The presence of prograde chlorite with biotite and cordierite in the assemblage is a strong indication that equilibration could not have occurred ca. $50^{\circ} \mathrm{C}$ above the stability field of Chl-bearing assemblages. In addition to the similar observed chemistries between retrograde and prograde chlorite, equilibration during retrograde metamorphism is a better explanation. Even if the thermodynamic data and bulk rock compositions used in this study are accurate representations of the observed rock samples, the observed mineral chemistries remain inadequate for quantifying the degrees of overstep. The analysis of texture is proven here to be more reliable than mineral chemistry in terms of understanding nucleation and crystal growth mechanisms. 


\section{CHAPTER 4}

Concluding Thesis Remarks

The purpose of this thesis was to unravel the metamorphic history of a suite of hornfelses from the Bugaboo contact aureole by completing a textural analysis of the rock-forming porphyroblasts. Petrography allowed for primary textural interpretations with regards to the relative kinematics of porphyroblast crystallization. Syn-kinematic porphyroblast growth indicates deformation and heating induced by the batholith intrusion were simultaneous, with both factors strengthening towards the contact creating pre-kinematic porphyroblast textures at high grades. Phase equilibria predicts $500-590^{\circ} \mathrm{C}$ at $1.60 \mathrm{kbar}$ to fit the majority of bulk rock compositions, assuming the thermodynamic database is accurate and the specific bulk rock compositions attained are representative of the collected samples. These are new P estimates compared to previous results by Pattison and DeBuhr (2015) who obtained a P of 3.0-3.3 kbar due to the use of a different thermodynamic database that does not consider a $\mathrm{COH}$-bearing fluid and the use of the average bulk rock composition of the Bugaboo samples. The wide variation in the positioning of Crd-bearing equilibrium assemblages shows the sensitivity of cordierite stability to minor chemical changes, most significantly the composition of the intergranular fluid, and the uncertainties with predicting equilibrium mineral assemblages at low P.

Through XR- $\mu \mathrm{CT}$ done on the Bugaboo samples, it has been shown that the chemistry of a mineral phase is not the only factor that determines its resultant 
greyscale X-ray attenuation value. Density changes through fracturing and reduction in grain size, or alteration to fine grained mineral aggregates, are other factors that can drastically affect the X-ray attenuation of a mineral. The volume effect adds to this by limiting the size of visible features in the CT data, making fine matrix phases indistinguishable from each other. However, the volume effect was also observed to help the visibility of inclusion-rich phases by decreasing their average X-ray attenuation. The spatial relationship between phases was additionally proven to be a significant factor in the visibility of certain minerals in the Bugaboo samples. If two minerals of different X-ray attenuations are closely related to each other spatially then this may aid in viewing and extracting the minerals in CT. The contrasting Xray attenuation between the dominant matrix phases with porphyroblasts may also enhance visibility and ease segmentation. These results and interpretations present a significant conclusion to the observation of rocks in CT that not only mineralogy and chemistry play a role but texture is additionally relevant when choosing a desirable sample to scan.

The 3D distribution of biotite and cordierite was extracted from the outer aureole, their size and spatial distribution was quantified and interpreted as evidence for diffusion-controlled crystallization. The biotite- and cordieriteproducing reaction occurred simultaneously with deformation of the rock matrix and a weak amount of strain induced by the batholith intrusion resulting in parallel planar alignment of the porphyroblasts. Clustering of cordierite porphyroblasts may be a result of diffusion-controlled nucleation and the formation of enriched regions around sub-critical cordierite clusters, or the nucleation of cordierite on pre- 
existing clustered chlorite porphyroclasts. The growth of cordierite dominantly after biotite crystallization created biotite-poor regions in the rock, resulting in a false clustering signature of biotite porphyroblasts. Post-metamorphic deformation and the formation of biotite-rich crenulation cleavages additionally contributed to this clustering signal. Further analysis of the biotite population that would consider the presence of cordierite would provide evidence for the primitive distribution of nucleation sites. The textural analysis of multiple porphyroblasts adds crucial information on the nucleation and crystal growth of minerals during the same metamorphic event that compete for chemical nutrients from the same rock volume.

The homogeneous chemistry across biotite and cordierite porphyroblasts, and between prograde and retrograde chlorite, is an indication of efficient diffusion throughout the rock volume and chemical equilibration during retrograde metamorphism. Therefore, comparisons between prograde isopleth predictions and the observed chemical analyses are not valid for estimating P-T conditions of cordierite and biotite crystallization. Despite the unreliable chemistry obtained, the mechanism in control of the rate of the biotite- and cordierite-producing reactions was deciphered instead by analyzing the distribution of porphyroblast size. The position and size of porphyroblasts remain relatively untouched since nucleation and crystal growth, particularly for low P metamorphic settings, and is therefore a more dependable feature when interpreting the kinetics of metamorphic reactions. 


\section{References}

Archibald, D.A., Glover, J.K., Price, R.A. Ferrar, E. and Carmichael, D.M. 1983. Geochronology and tectonic implications of magmatism and metamorphism, southern Kootenay Arc and neighbouring regions, southeastern British Columbia. Part I: Jurassic to mid-Cretaceous. Can J Earth Sci, 20: 1891-1913.

Archibald, D.A., Krogh, T.E., Armstrong, R.L. and Ferrar, E. 1984. Geochronology and tectonic implications of magmatism and metamorphism, southern Kootenay Arc and neighbouring regions, southeastern British Columbia. Part II: Mid-Cretaceous to Eocene. Can J Earth Sci, 21: 567-583.

Brandon, A.D. and Lambert, R.StJ. 1992. Rb-Sr geochronology of Mesozoic granitoids in the southern Canadian Cordillera. In Project Lithoprobe southern Cordillera Transect, Report 24, pp. 95-104.

Brandon, A.D. and Lambert, R.StJ. 1993. Geochemical characterization of midCretaceous granitoids of the Kootenay Arc in the southern Canadian Cordillera. Can J Earth Sci, 30: 1076-1090.

de Capitani, C. and Petrakakis, K. 2010. The computation of equilibrium assemblage diagrams with Theriak/Domino software. Am Miner, 95: 1006-1016.

Carlson, W.D. 1989. The significance of intergranular diffusion to the mechanisms and kinetics of porphyroblast crystallization. Contrib Mineral Petrol, 103: $1-24$.

Carlson, W.D. 1991. Competitive diffusion-controlled growth of porphyroblasts. Mineral Mag, 55: 317-330. 
Clark, P.J. and Evans, F.C. 1954. Distance to nearest neighbour as a measure of spatial relationships in populations. Ecology, 35:445-452.

Connolly, J.A.D. and Cesare, B. 1993. C-O-H-S fluid composition and oxygen fugacity in graphitic metapelites. J Metamorph Geol, 11: 379-388.

Cook, F.A. and Van der Velden, A.J. 1995. Three-dimensional crustal structure of the Purcell anticlinorium in the Cordillera of southwestern Canada. GSA Bulletin, 107: $642-664$.

Daniel, C.G. and Spear, F.S. 1999. The clustered nucleation and growth processes of garnet in regional metamorphic rocks from north-west Connecticut, USA. $J$ Metamorph Geol, 17: 503-520.

DeBuhr, C. 1999. Metamorphic petrology and mass balance analysis in the Bugaboo contact aureole [Ph.D. thesis]: Calgary, Alberta, The University of Calgary, $321 \mathrm{p}$.

Dension, C., Carlson, W.D. and Ketcham, R.A. 1997. Three-dimensional quantitative textural analysis of metamorphic rocks using high-resolution computed X-ray tomography: Part I. Methods and techniques.J Metamorph Geol, 15: 29-44.

Fisher, G.W. 1978. Rate laws in metamorphism. Geochimica et Cosmochimica Acta, 42: 1035-1050.

Gaidies, F., Pattison, D.R.M. and de Capitani, C. 2011. Toward a quantitative model of metamorphic nucleation and growth. Contrib Mineral Petrol, 162: 975-993.

Gaidies, F., Petley-Ragan, A., Chakraborty, S., Dasgupta, S. and Jones, P. 2014. Constraining the conditions of Barrovian metamorphism in Sikkim, India: P-T-t 
paths of garnet crystallization in the Lesser Himalayan Belt. J Metamorph Geol, 33: 23-44.

Galwey, A.K. and Jones, K.A. 1963. An attempt to determine the mechanism of a natural mineral-forming reaction from examination of the products. $J$ Chem Soc, $5681-5686$.

Hirsch, D.M. 2000. Quantitative studies of porphyroblastic textures [Ph.D. thesis]: Austin, Texas, The University of Texas, $184 \mathrm{p}$.

Hirsch, D.M. 2008. Controls on porphyroblast size along a regional metamorphic field gradient. Contrib Mineral Petrol, 155: 401-415.

Hirsch, D.M. 2011. Reduce3D: A tool for three-dimensional spatial statistical analysis of crystals. Geosphere, 7: 724-732.

Hirsch, D.M. and Carlson, W.D. 2006. Variations in rates of nucleation and growth of biotite porphyroblasts. J Metamorph Geol, 24: 763-777.

Hirsch, D.M., Ketcham, R.A. and Carlson, W.D. 2000. An evaluation of spatial correlation functions in textural analysis of metamorphic rocks. Geol Mater Res, 2: 142.

Holland, T.J.B. and Powell, R. 1998. An internally consistent thermodynamic data set for phases of petrological interest. J Metamorph Geol, 16: 309-343.

Jamieson, R.A., Hart, G.G., Chapman, G.G. and Tobey, N.W. 2012. The geology of the South Mountain Batholith in Halifax, Nova Scotia: geology, mineral assemblages, and isograds. Can J Earth Sci, 49: 1280-1296.

Jerram, D.A., Cheadle, M.J., Hunter, R.H. and Elliott, M.T. 1996. The spatial distribution of grains and crystals in rocks. Contrib Mineral Petrol, 125: 60-74. 
Jerram, D.A. and Cheadle, M.J. 2000. On the cluster analysis of grains and crystals in rocks. Am Miner, 85: 47-97.

Jerram, D.A. and Higgins, M.D. 2007. 3D Analysis of Rock Textures: Quantifying Igneous Microstructures. Elements, 3: 239-245.

Kelton, K.F. 2000. Kinetic model for nucleation in partitioning systems. J Non Cryst Solids, 274: 147-154.

Ketcham, R.A. 2005. Computational methods for quantitative analysis of threedimensional features in geological specimens. Geosphere, 1: 32-41.

Ketcham, R.A. and Carlson, W.D. 2001. Acquisition, optimization and interpretation of X-ray computed tomographic imagery: applications to the geosciences. Comput Geosci, 27: 381-400.

Ketcham, R.A., Meth, C., Hirsch, D.M. and Carlson, W.D. 2005. Improved methods for quantitative analysis of three-dimensional porphyroblastic textures. Geosphere, 1: $42-59$.

Kretz, R. 1966. Interpretation of the shape of mineral grains in metamorphic rocks. J Petrol, 7: 68-94.

Kretz, R. 1969. On the spatial distribution of crystals in rocks. Lithos, 2: 39-66.

Kretz, R. 1974. Some models for the rate of crystallization of garnet in metamorphic rocks. Lithos, 7: 123-131.

Kretz, R. 1983. Symbols for rock-forming minerals. Am Miner, 68: 277-279.

Kretz, R. 1993. A garnet population in Yellowknife schist, Canada. J Metamorph Geol, 11: 101-120. 
Kretz, R. 2006. Shape, size, spatial distribution and composition of garnet crystals in highly deformed gneiss of the Otter Lake area, Quebec, and a model for garnet crystallization. J Metamorph Geol, 24: 431-449.

Lasaga, A.C. 1998. Kinetic theory in the earth sciences. Princeton University Press, Princeton.

Mahar, E.M., Baker, J.M., Powell, R., Holland, T.J.B. and Howell, N. 1997. The effect of Mn on mineral stability in metapelites. J Metamorph Geol, 15: 223-238.

Muller, T., Baumgartner, L.P., Foster, C.T. and Bowman, J.R. 2009. Crystal size distribution of periclase in contact metamorphic dolomite marbles from the Southern Adamello Massif, Italy. J Petrol, 00: 1-15.

Ohmoto, H. and Kerrick, D. 1977. Devolatilization equilibria in graphitic systems. Am J Sci, 277: 1013-1044.

Pattison, D.R.M. and DeBuhr, C. 2015. Petrology of metapelites in the Bugaboo aureole, British Columbia, Canada. J Metamorph Geol, DOI: 10.1111.

Pattison, D.R.M., de Capitani, C. and Gaidies, F. 2011. Petrological consequences of variations in metamorphic reaction affinity J Metamorph Geol, 29: 953-977.

Pattison, D.R.M., Spear, F., DeBuhr, C.L., Cheney, J.T. and Guidotti, C.V. 2002. Thermodynamic modelling of the reaction muscovite + cordierite $\rightarrow \mathrm{Al}_{2} \mathrm{SiO}_{5}+$ biotite + quartz $+\mathrm{H}_{2} \mathrm{O}$ : constraints from natural assemblages and implications for the metapelitic petrogenetic grid. J Metamorph Geol, 20: 99-118.

Pattison, D.R.M. and Vogl, J.J. 2005. Contrasting sequences of metapelitic mineral-assemblages in the aureole of the tilted Nelson Batholith, British Columbia: 
Implications for phase equilibria and pressure determination in andalusitesillimanite-type settings. Can Miner, 43: 51-88.

Pownall, J.M., Waters, D.J., Searle, M.P., Shail, R.K. and Robb, L.J. 2012. Shallow laccolithic emplacement of the Land's End and Tregonning granites, Cornwall, UK: Evidence from aureole field relations and P-T modeling of cordierite-anthophyllite hornfels. Geosphere, 8: 1467-1504.

Reesor, J.E. 1973. Geology of the Lardeau map-area, east-half, British Columbia. Memoir 369, Geological Survey of Canada, Department of Energy, Mines and Resources.

Ripley, B.D. 1976. The second-order analysis of stationary point processes. J Appl Probab, 13: 255-266.

Rudge, J.F., Holness, M.B. and Smith, G.C. 2008. Quantitative textural analysis of packings of elongate crystals. Contrib Mineral Petrol, 156: 413-429.

Symmes, G.H. and Ferry, J.M. 1992. The effect of whole-rock MnO content on the stability of garnet in pelitic schists during metamorphism. J Metamorph Geol, 10: 221-237.

Threlfall, T. 2003. Structural and Thermodynamic Explanations of Ostwald's Rule. Org Proc Res Develop, 7: 1017-1027.

Waters, D.J. and Lovegrove, D.P. 2002. Assessing the extent of disequilibrium and overstepping of prograde metamorphic reactions in metapelites from the Bushveld Complex aureole, South Africa. J Metamorph Geol, 20: 135-149. 


\section{$\underline{\text { APPENDIX I }}$}

Thermodynamic Database

After Holland and Powell (1998)

Tcdb55c2_COH_prltbi2 


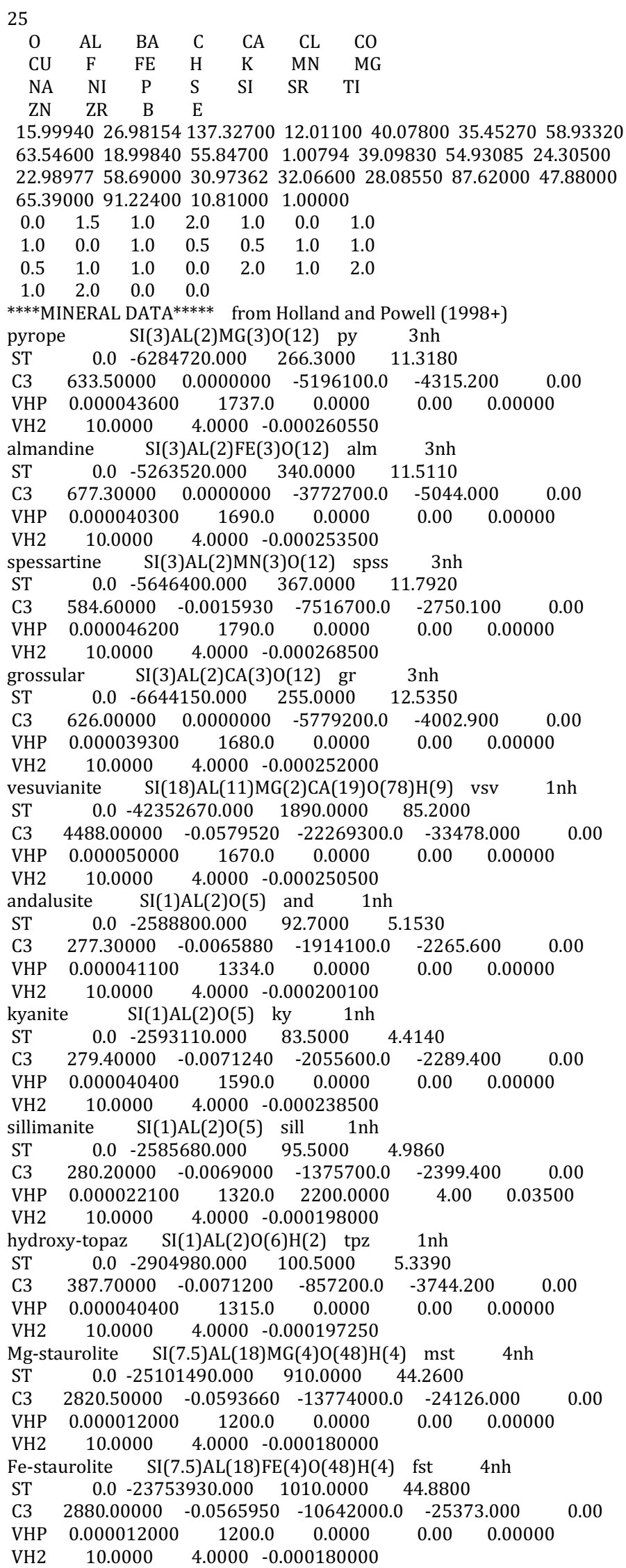




\begin{tabular}{|c|c|c|c|c|c|c|}
\hline \multicolumn{2}{|c|}{ Mn-staurolite } & \multicolumn{5}{|c|}{ SI(7.5)AL(18)MN(4)O(48)H(4) mnst $4 \mathrm{nh}$} \\
\hline ST & \multicolumn{2}{|c|}{$0.0-24203880.000$} & 1024.0000 & \multicolumn{3}{|c|}{45.4600} \\
\hline C3 & 2873.30000 & -0.0890640 & -12688000.0 & \multicolumn{2}{|c|}{-24749.000} & \multirow[t]{3}{*}{0.00} \\
\hline VHP & 0.000012000 & $\quad 1200.0$ & 0.0000 & \multirow[t]{2}{*}{0.00} & 0.00000 & \\
\hline VH2 & 10.0000 & \multicolumn{3}{|c|}{$4.0000-0.000180000$} & & \\
\hline \multicolumn{7}{|c|}{ Mg-chloritoid $\quad$ SI(1)AL(2)MG(1)O(7)H(2) } \\
\hline ST & $0.0-3551$ & 1420.000 & 140.0000 & \multicolumn{3}{|l|}{$\begin{array}{l}\text { metd } \\
6.8750\end{array}$} \\
\hline C3 & \multirow{2}{*}{$\begin{array}{l}464.40000- \\
0.000054200\end{array}$} & -0.0126540 & -1147200.0 & -4341.000 & & .00 \\
\hline VHP & & $\quad 1465.0$ & 0.0000 & $0.00 \quad 0$. & 0.00000 & \\
\hline VH2 & 10.0000 & $4.0000-0$ & .000219750 & & & \\
\hline $\mathrm{Fe}-\mathrm{ch}$ & oritoid $\quad$ SI $(1$ & 1)AL(2)FE(1 & ) $\mathrm{O}(7) \mathrm{H}(2)$ fctd & $1 \mathrm{nh}$ & & \\
\hline ST & $0.0-3215$ & 5380.000 & 155.0000 & 5.9800 & & \\
\hline $\mathrm{C} 3$ & 484.60000 & -0.0138080 & -198900.0 & -4762.200 & 0.0 & 00 \\
\hline VHP & 0.000054200 & $\quad 1465.0$ & 0.0000 & $0.00 \quad 0$. & 0.00000 & \\
\hline VH2 & 10.0000 & $4.0000-0$ & .000219750 & & & \\
\hline $\mathrm{Mn}-\mathrm{c}$ & loritoid $\quad$ SIC & (1)AL(2)MN & (1)O(7)H(2) & nnctd & nh & \\
\hline ST & $\begin{array}{ll}0.0 & -3329\end{array}$ & 9280.000 & $166.0000 \quad 7$ & 7.1750 & & \\
\hline C3 & 464.40000 & -0.0126540 & -1147200.0 & -4341.000 & & .00 \\
\hline VHP & 0.000054200 & $\quad 1465.0$ & 0.0000 & $0.00 \quad 0$. & 0.00000 & \\
\hline VH2 & 10.0000 & $4.0000-0$ & .000219750 & & & \\
\hline clino & oisite $\quad \operatorname{SI}(3)$ & )AL(3)CA(2) & $\mathrm{O}(13) \mathrm{H}(1) \quad \mathrm{cz}$ & $1 \mathrm{nh}$ & & \\
\hline ST & $\begin{array}{lll}0.0 & -6898\end{array}$ & 3150.000 & 301.0000 & 3.6300 & & \\
\hline $\mathrm{C} 3$ & 567.00000 & 0.0180630 & -7034000.0 & -2603.000 & & .00 \\
\hline VHP & 0.000046000 & $\quad 1120.0$ & 0.0000 & $0.00 \quad 0$. & 0.00000 & \\
\hline VH2 & 10.0000 & $4.0000-0$ & .000168000 & & & \\
\hline Fe-ep & idote $\quad$ SI(3) & ) AL(1)FE(2) & $\mathrm{CA}(2) \mathrm{O}(13) \mathrm{H}(1$ & fep & $2 \mathrm{nh}$ & \\
\hline ST & $\begin{array}{ll}0.0 & -6002\end{array}$ & 2180.000 & $357.0000 \quad 14$ & 4.1900 & & \\
\hline C3 & 520.10000 & 0.0314990 & -15426000.0 & 218.800 & & 00 \\
\hline VHP & 0.000050500 & $\quad 1294.0$ & 0.0000 & 0.00 & 0.00000 & \\
\hline VH2 & 10.0000 & $4.0000-0$ & .000199280 & & & \\
\hline epidc & SI(3)A & $\mathrm{AL}(2) \mathrm{FE}(1) \mathrm{C}$ & $\mathrm{A}(2) \mathrm{O}(13) \mathrm{H}(1)$ & ep & $2 \mathrm{nh}$ & \\
\hline ST & $0.0-6463$ & 3210.000 & 328.0000 & 3.9100 & & \\
\hline C3 & 544.60000 & 0.0247810 & -11230000.0 & -1192.100 & & 0.00 \\
\hline VHP & 0.000050500 & $\quad 1233.0$ & 0.0000 & $0.00 \quad 0$. & 0.00000 & \\
\hline VH2 & 10.0000 & $4.0000-0$ & 0.000184950 & & & \\
\hline Mg-c & rdierite & $\mathrm{I}(5) \mathrm{AL}(4) \mathrm{MC}$ & $\mathrm{G}(2) \mathrm{O}(18) \mathrm{crd}$ & $1 \mathrm{nh}$ & & \\
\hline ST & $0.0-9163$ & 3370.000 & 407.5000 & 3.3220 & & \\
\hline C3 & 821.30000 & 0.0433390 & -8211200.0 & -5000.000 & & .00 \\
\hline VHP & 0.000007600 & 810.0 & 1800.0000 & 20.00 & 0.2000 & \\
\hline $\begin{array}{l}\text { VH2 } \\
\text { (in: }\end{array}$ & $\begin{array}{c}10.0000 \\
\text { aldwin et al. } 20\end{array}$ & $\begin{array}{r}4.0000-0 \\
005: \text { no hydr }\end{array}$ & $\begin{array}{l}.000121500 \\
\text { ro-cord!!!!!!!!!!) }\end{array}$ & & & \\
\hline hydr. & ordierite $\operatorname{SI}($ & (5)AL(4)MG & $(2) \mathrm{O}(19) \mathrm{H}(2)$ & hord & Inh & \\
\hline ST & $0.0-9446$ & 5980.000 & 487.3000 & 3.3220 & & \\
\hline C3 & 869.70000 & 0.0519950 & -7723700.0 & -5251.200 & & .00 \\
\hline VHP & 0.000007600 & 810.0 & 1800.0000 & 20.00 & 0.2000 & \\
\hline VH2 & 10.0000 & $4.0000-0$ & 0.000121500 & & & \\
\hline $\mathrm{Fe}-\mathrm{cc}$ & cdierite $\quad$ SI 5 & 5) $\mathrm{AL}(4) \mathrm{FE}(2$ & $\mathrm{O}(18)$ fcrd & $2 \mathrm{nh}$ & & \\
\hline ST & $0.0 \quad-8436$ & 6070.000 & $475.0000 \quad 23$ & 3.7100 & & \\
\hline C3 & 851.50000 & 0.0447240 & -6645000.0 & -5623.400 & & .00 \\
\hline VHP & 0.000007600 & 0 & 1800.0000 & 20.00 & 0.2000 & \\
\hline VH2 & 10.0000 & $4.0000-0$ & 0.000121500 & & & \\
\hline Mn-c & rdierite $\mathrm{SI}$ & (5)AL(4)MN & $(2) \mathrm{O}(18) \mathrm{mncr}$ & $1 \mathrm{nh}$ & & \\
\hline ST & $\begin{array}{ll}0.0 & -8681\end{array}$ & 1180.000 & 475.0000 & 4.0270 & & \\
\hline C3 & 847.70000 & 0.0284900 & -7668200.0 & -5311.400 & & .00 \\
\hline VHP & 0.000007600 & 810.0 & 1800.0000 & 20.00 & 0.2000 & \\
\hline VH2 & 10.0000 & $4.0000-0$ & 0.000121500 & & & \\
\hline phas & $-A \quad S I(2) N$ & MG(7)O(14) & $\mathrm{H}(6) \quad \mathrm{phA}$ & $7 \mathrm{nh}$ & & \\
\hline ST & $0.0-7130$ & 0410.000 & 350.0000 & 5.4420 & & \\
\hline C3 & 964.00000 & -0.0115210 & -4517800.0 & -7724.700 & & .00 \\
\hline VHP & 0.000082600 & $\quad 1450.0$ & 0.0000 & 0.00 & 0.00000 & \\
\hline VH2 & 10.0000 & $4.0000-0$ & 0.000217500 & & & \\
\hline Mg-c & rpholite $\quad$ SI & (2)AL(2)MG & $(1) \mathrm{O}(10) \mathrm{H}(4)$ & mcar & $1 \mathrm{nh}$ & \\
\hline ST & $\begin{array}{lll}0.0 & -4781\end{array}$ & 1240.000 & 210.0000 & 0.5900 & & \\
\hline C3 & 667.80000 & -0.0125590 & -1167100.0 & -6440.000 & & .00 \\
\hline VHP & 0.000050000 & 525.0 & 0.0000 & $0.00 \quad 0.0$ & .00000 & \\
\hline VH2 & 10.0000 & $4.0000-0$ & 0.000078750 & & & \\
\hline $\mathrm{Fe}-\mathrm{ca}$ & pholite $\quad$ SI $(2$ & 2)AL(2)FE(1 & 1) $\mathrm{O}(10) \mathrm{H}(4)$ & $1 \mathrm{nh}$ & & \\
\hline ST & $0.0-4413$ & 3200.000 & 255.0000 & 0.6900 & & \\
\hline C3 & 674.80000 & -0.0100920 & -715800.0 & -6554.500 & & 00 \\
\hline
\end{tabular}




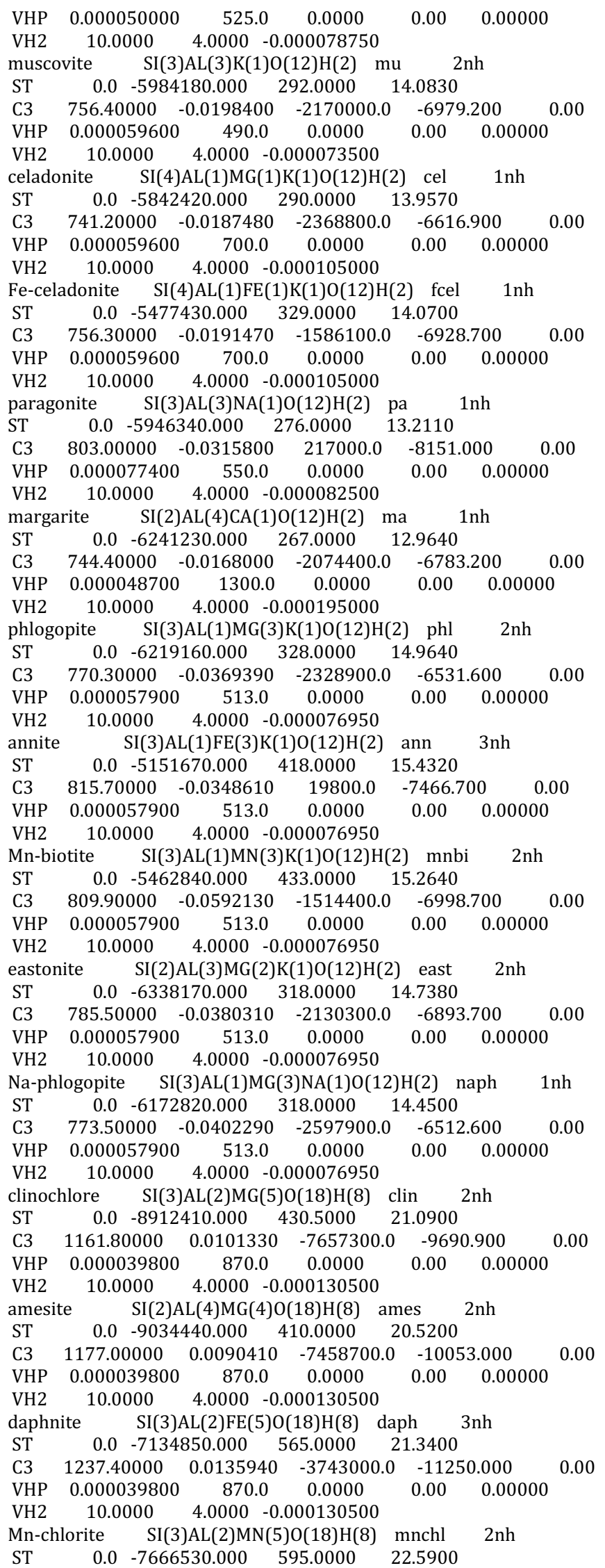




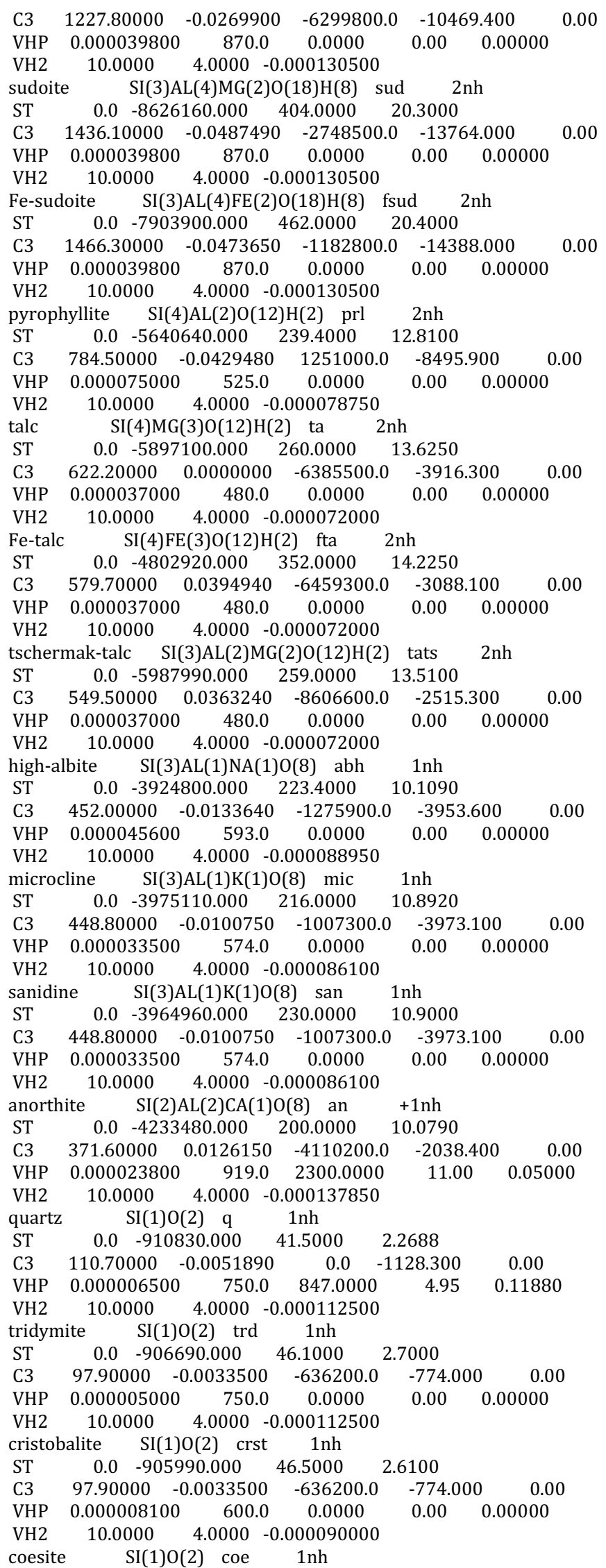




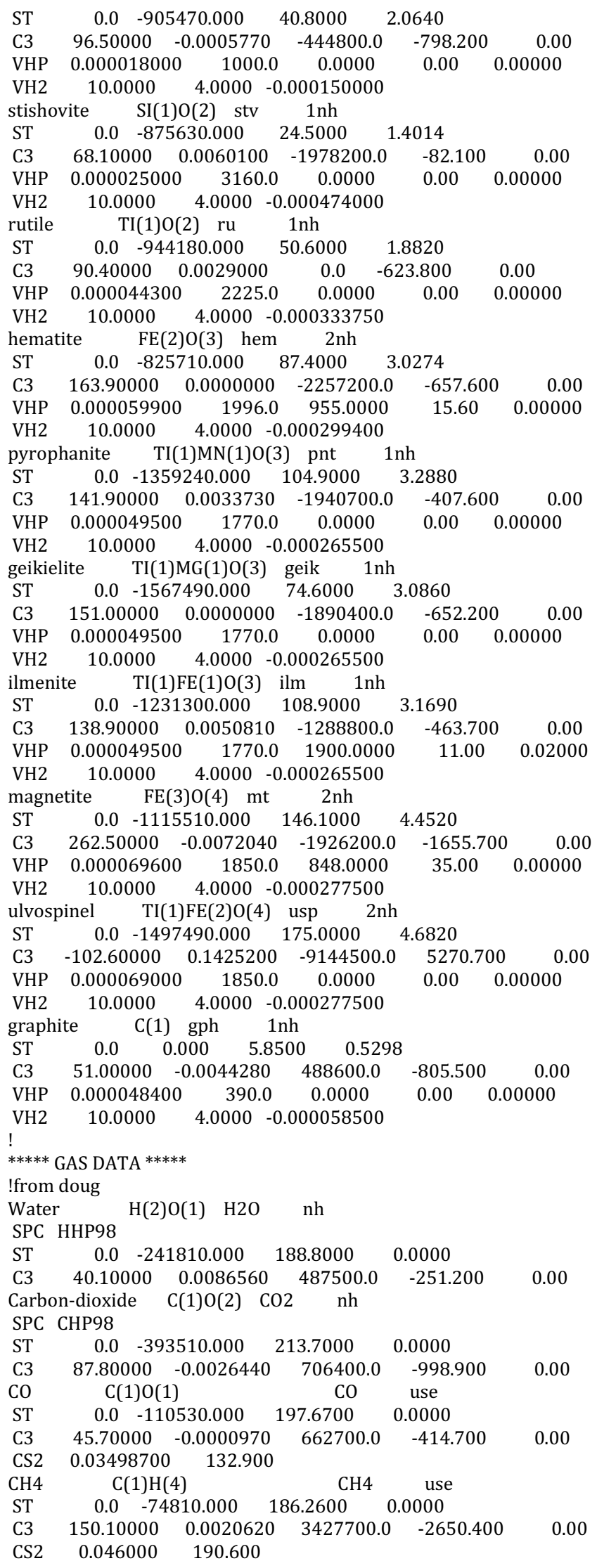




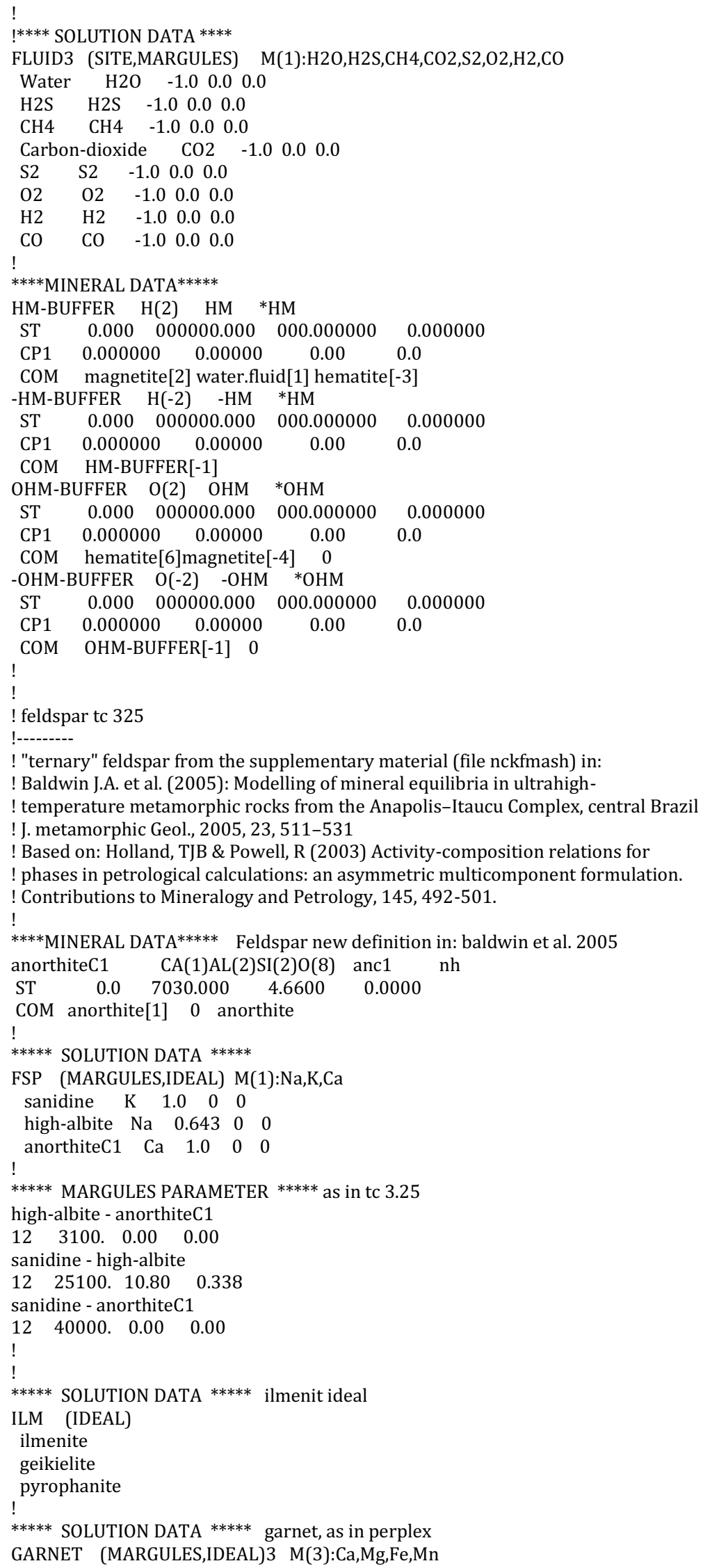




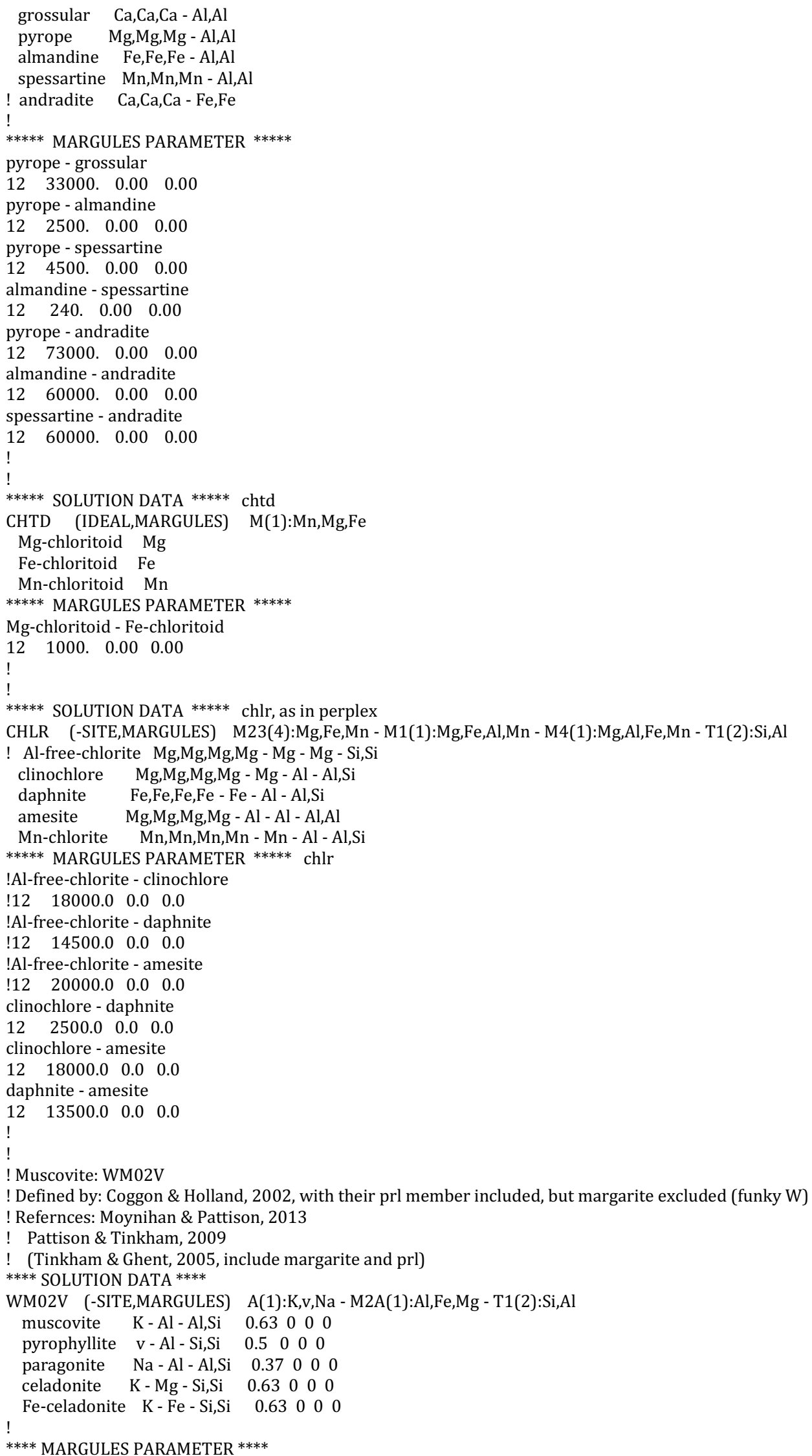




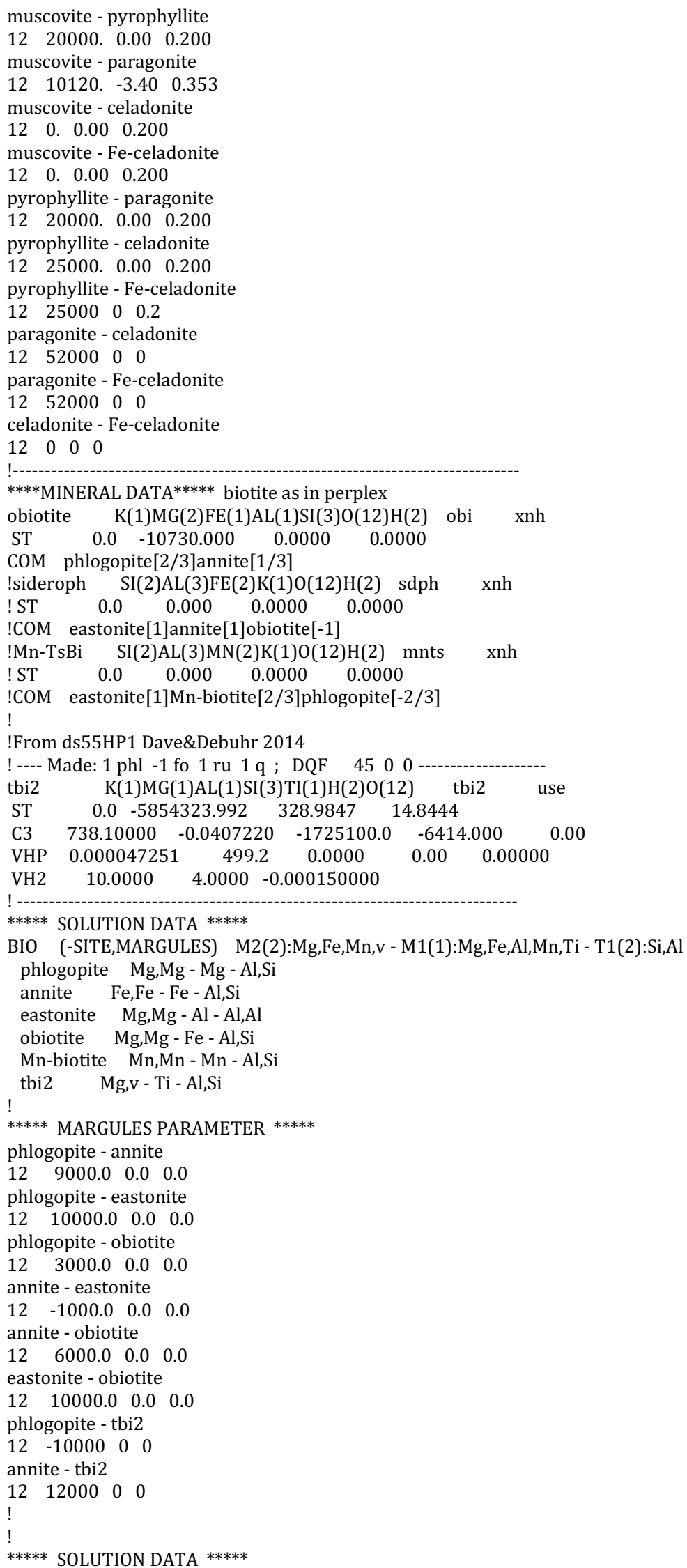


STAU (IDEAL,MARGULES) 4 M(4):Fe,Mg,Mn

Mg-staurolite $\mathrm{Mg}, \mathrm{Mg}, \mathrm{Mg}, \mathrm{Mg}$

Fe-staurolite $\mathrm{Fe}, \mathrm{Fe}, \mathrm{Fe}, \mathrm{Fe}$

Mn-staurolite $\mathrm{Mn}, \mathrm{Mn}, \mathrm{Mn}, \mathrm{Mn}$

***** MARGULES PARAMETER *****

Mg-staurolite - Fe-staurolite

$\begin{array}{llll}12 & -8000.0 & 0.0 & 0.0\end{array}$

!

***** SOLUTION DATA *****

! (in: baldwin et al. 2005: no hydro-cord!!!!!!!!!!)

CORD (SITE) M(2):Fe,Mg,Mn - B(1):n,h

Mg-cordierite $\mathrm{Mg}, \mathrm{Mg}-\mathrm{n}$

Fe-cordierite $\mathrm{Fe}, \mathrm{Fe}-\mathrm{n}$

Mn-cordierite $\mathrm{Mn}, \mathrm{Mn}-\mathrm{n}$

hydr.cordierite $\mathrm{Mg}, \mathrm{Mg}-\mathrm{h}$

***** SOLUTION DATA *****

SPIN (IDEAL)

spinel

hercynite 


\section{$\underline{\text { APPENDIX II }}$}

Chemical Profiles of Cordierite from Zone 2

$\begin{array}{lr}\text { COB3-S1-5 } & 147-152 \\ \text { COB3-S1-7 } & 153-156 \\ \text { COB-6 } & 157-159\end{array}$


COB3-S1-5 Crd 01
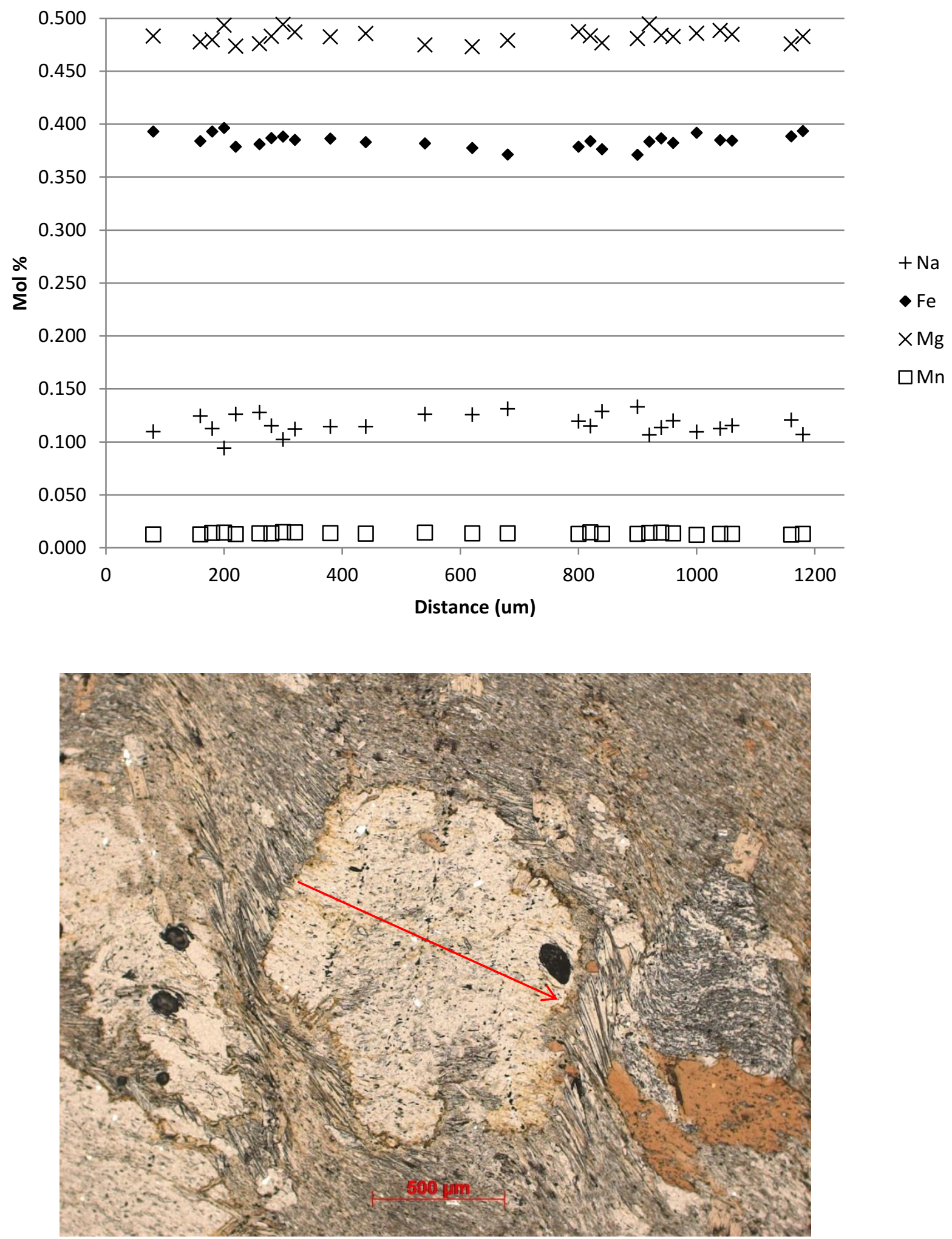
COB3-S1-5 Crd 02
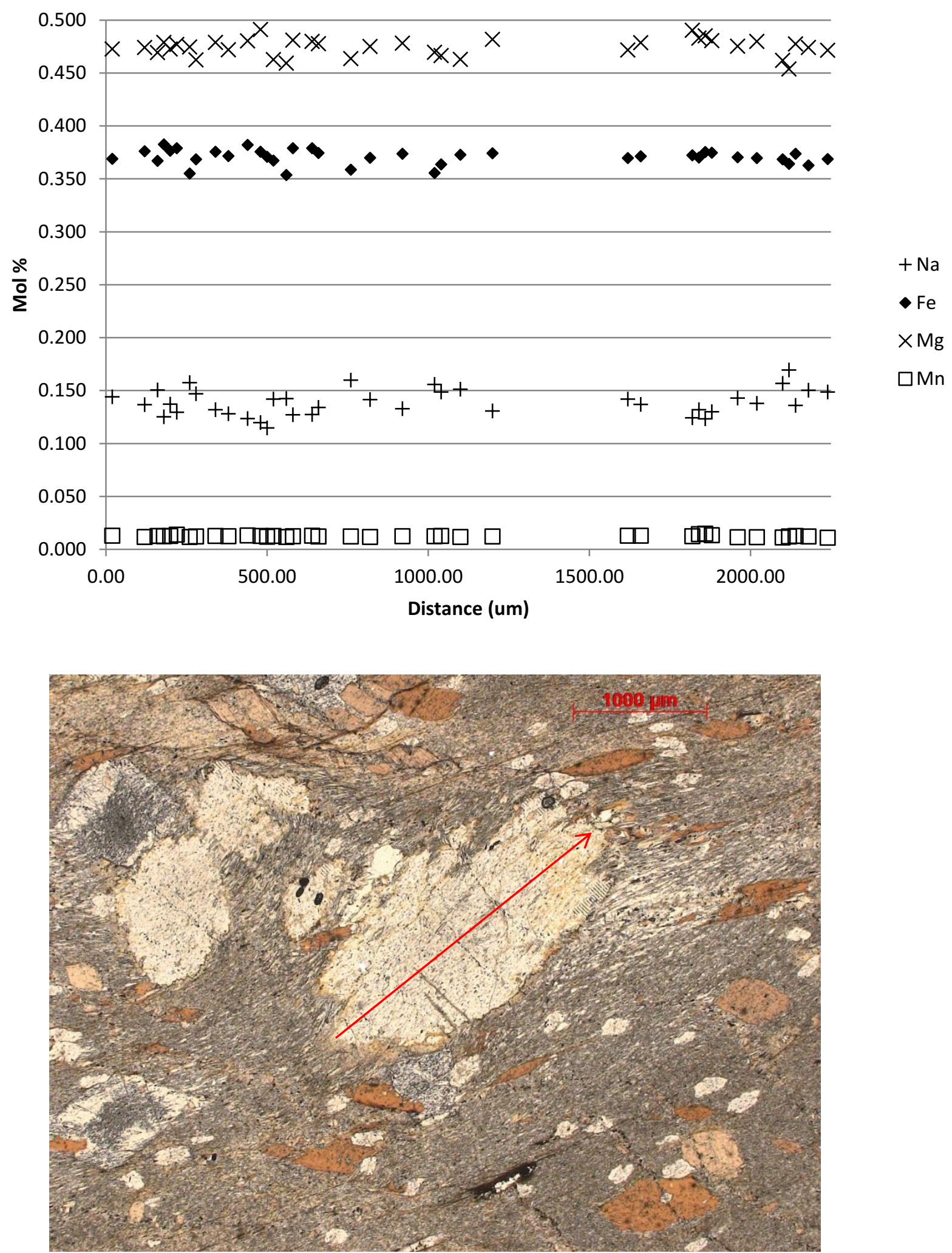


\section{COB3-S1-5 Crd 03}
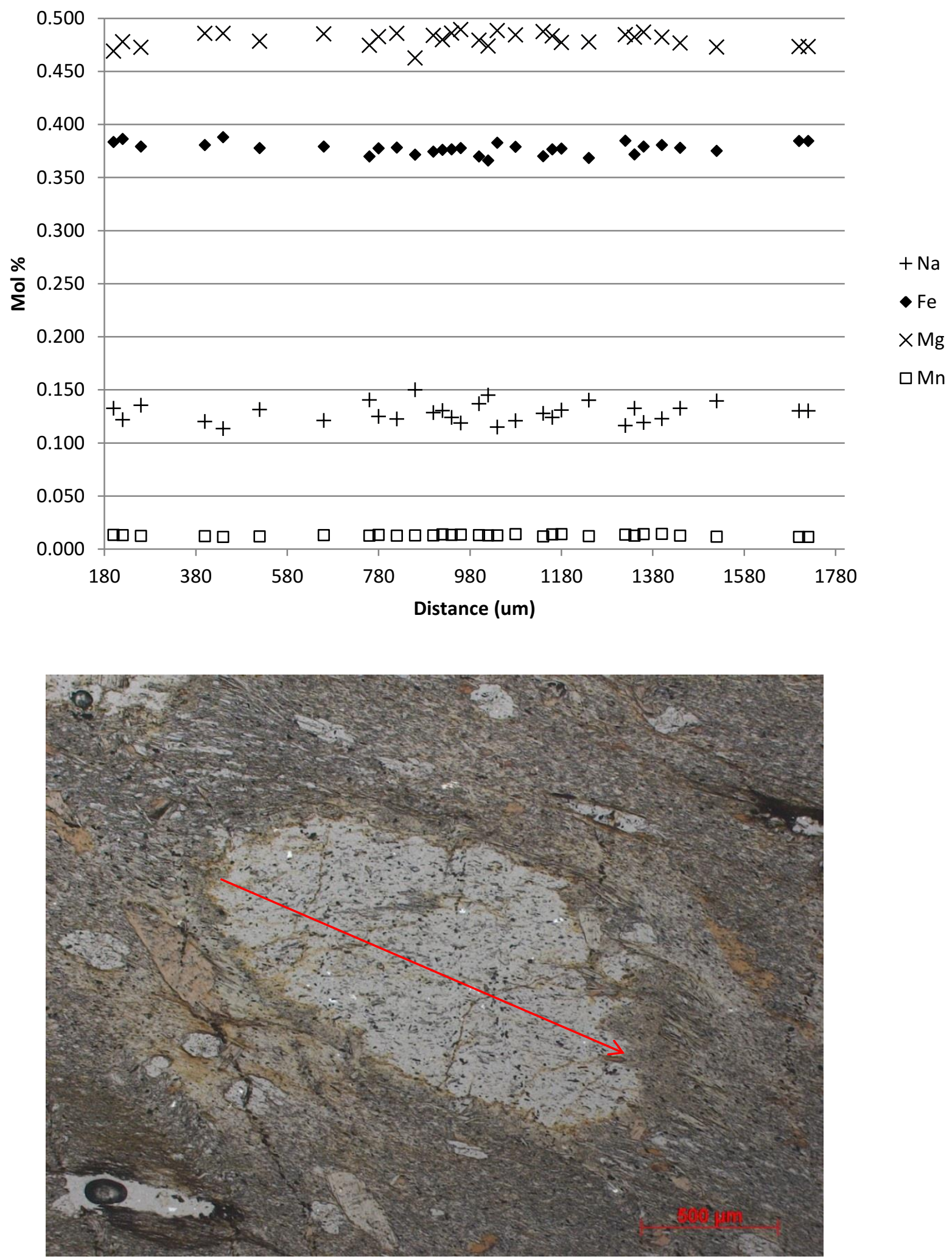
COB3-S1-5 Crd 04
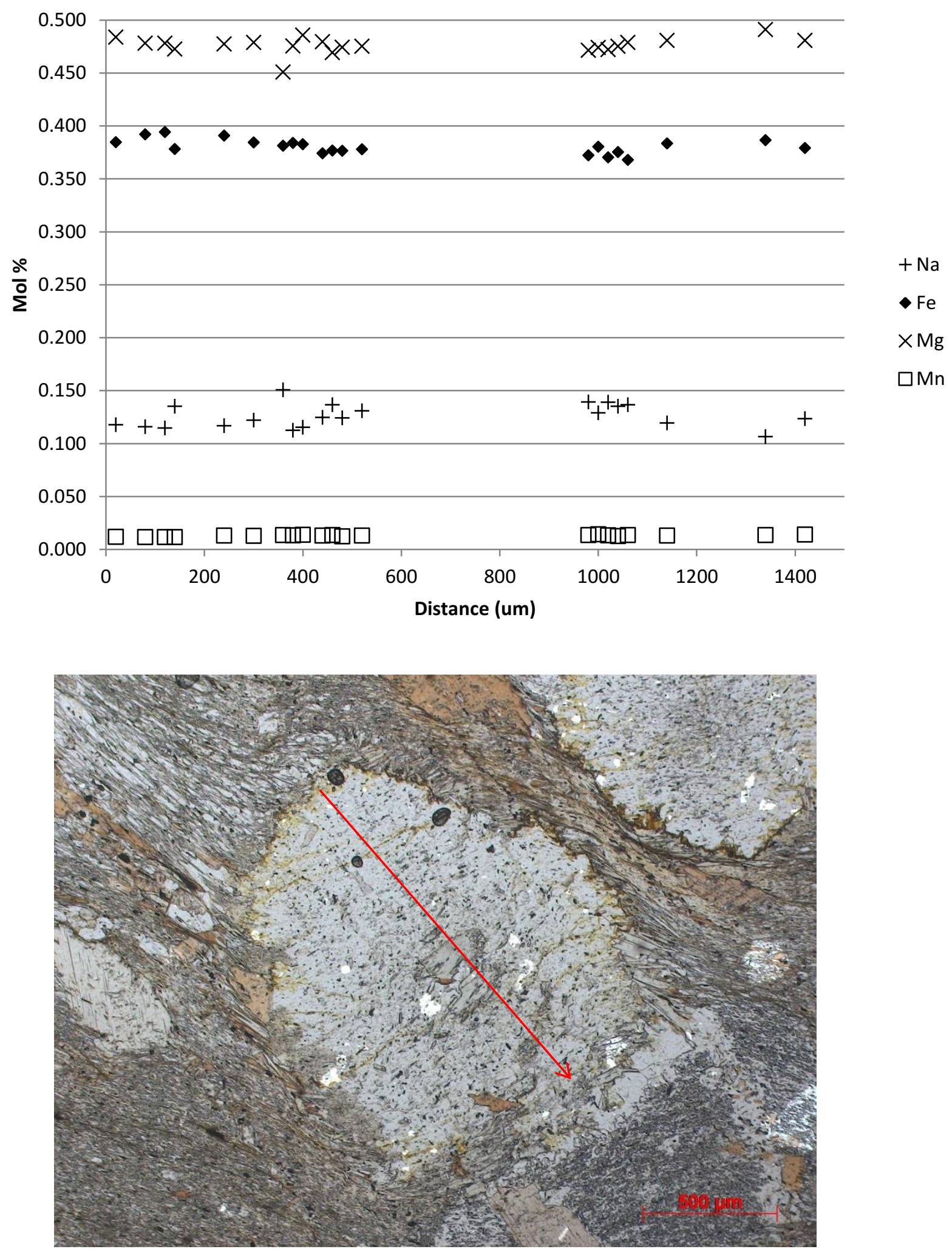


\section{COB3-S1_5 Crd 05}
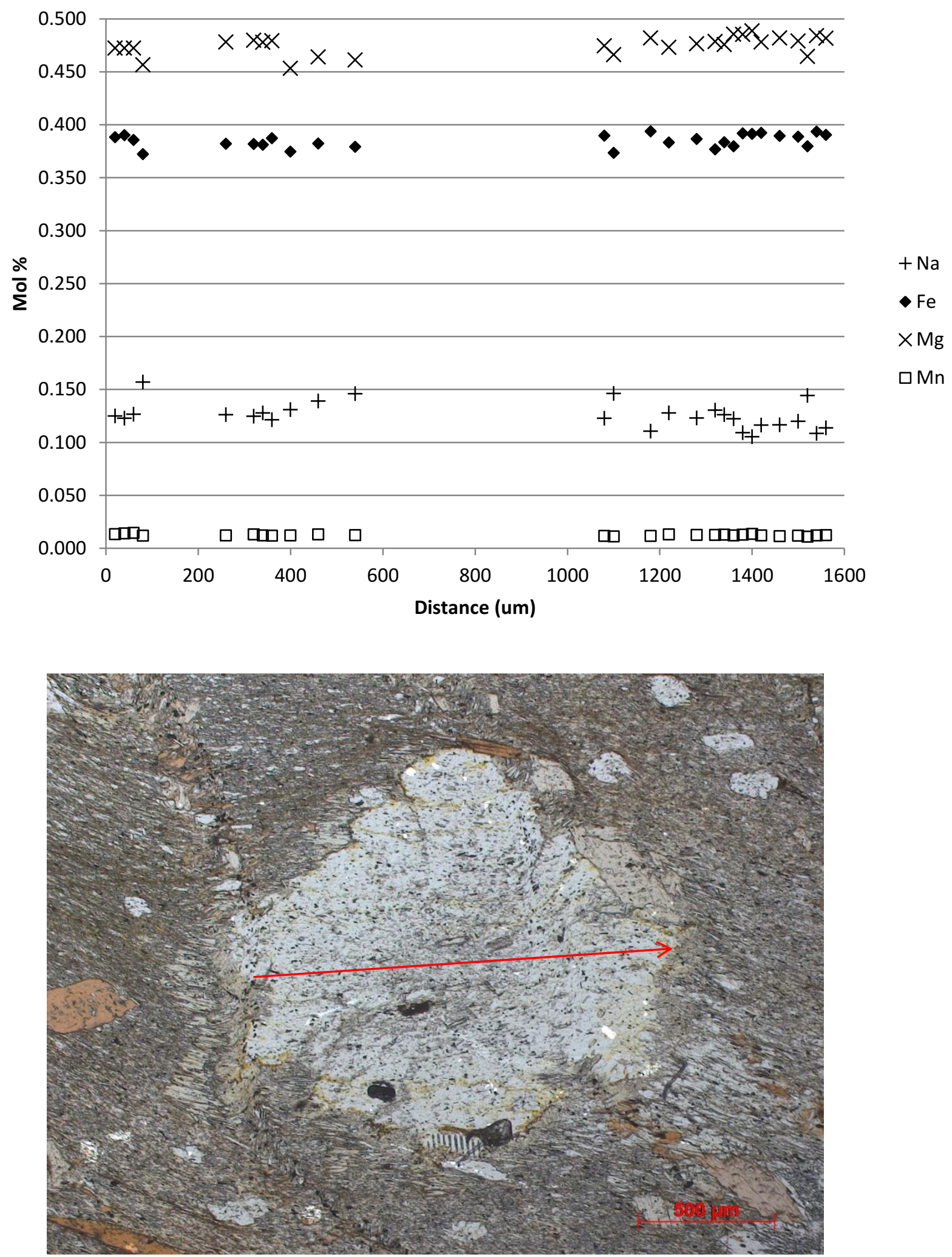
COB3-S1-5 Crd 06
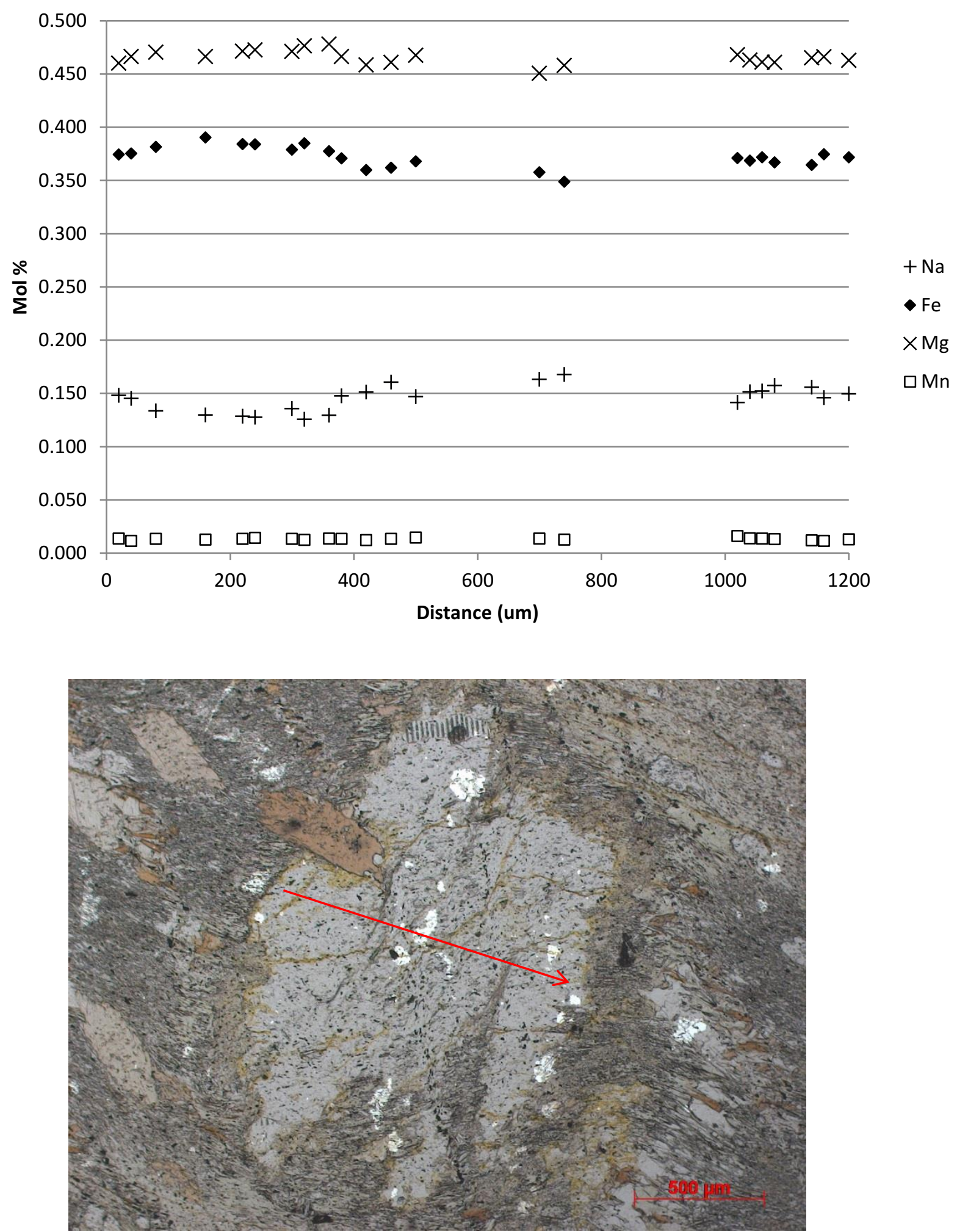


\section{COB3-S1-7 Crd 01}
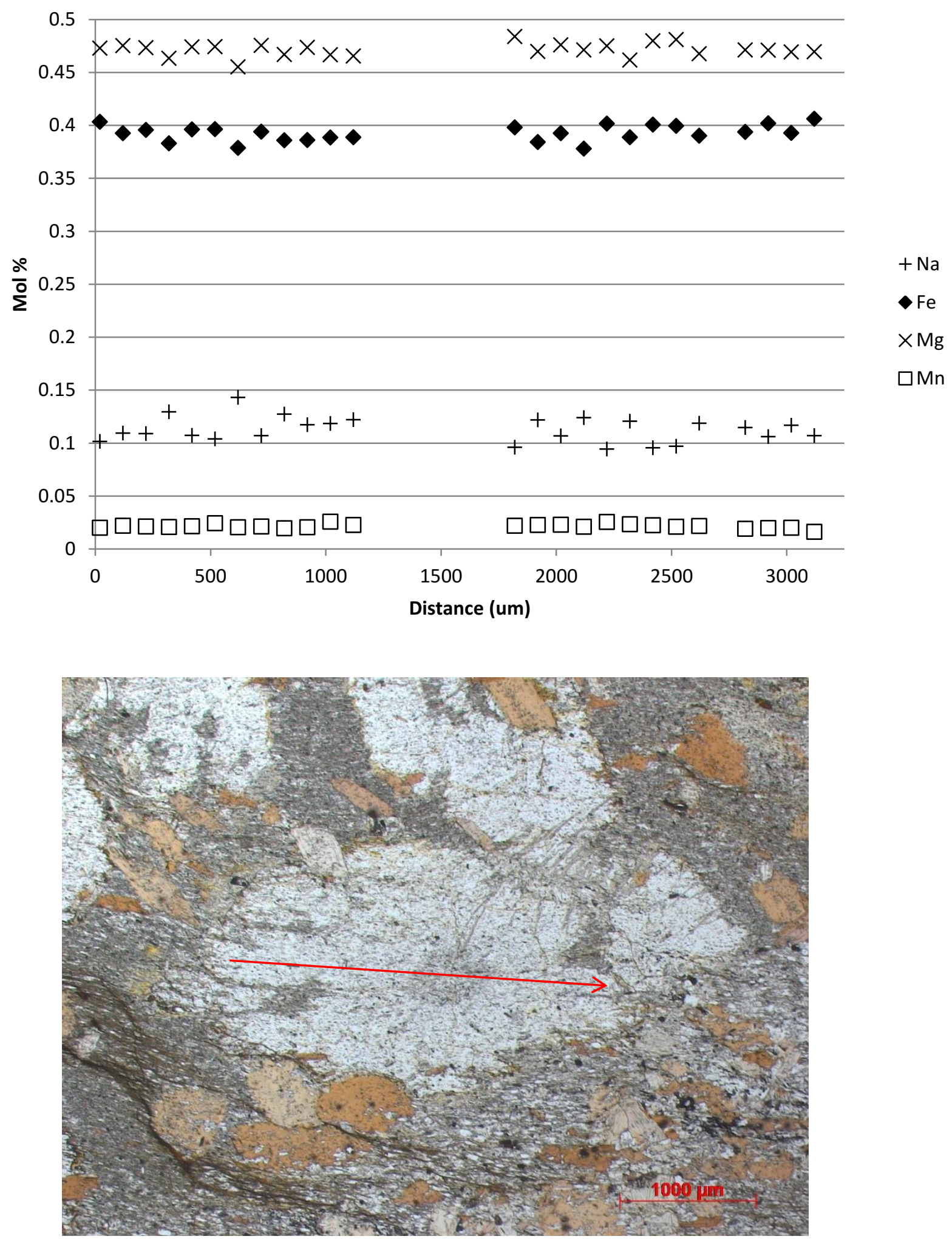
COB3-S1-7 Crd 02
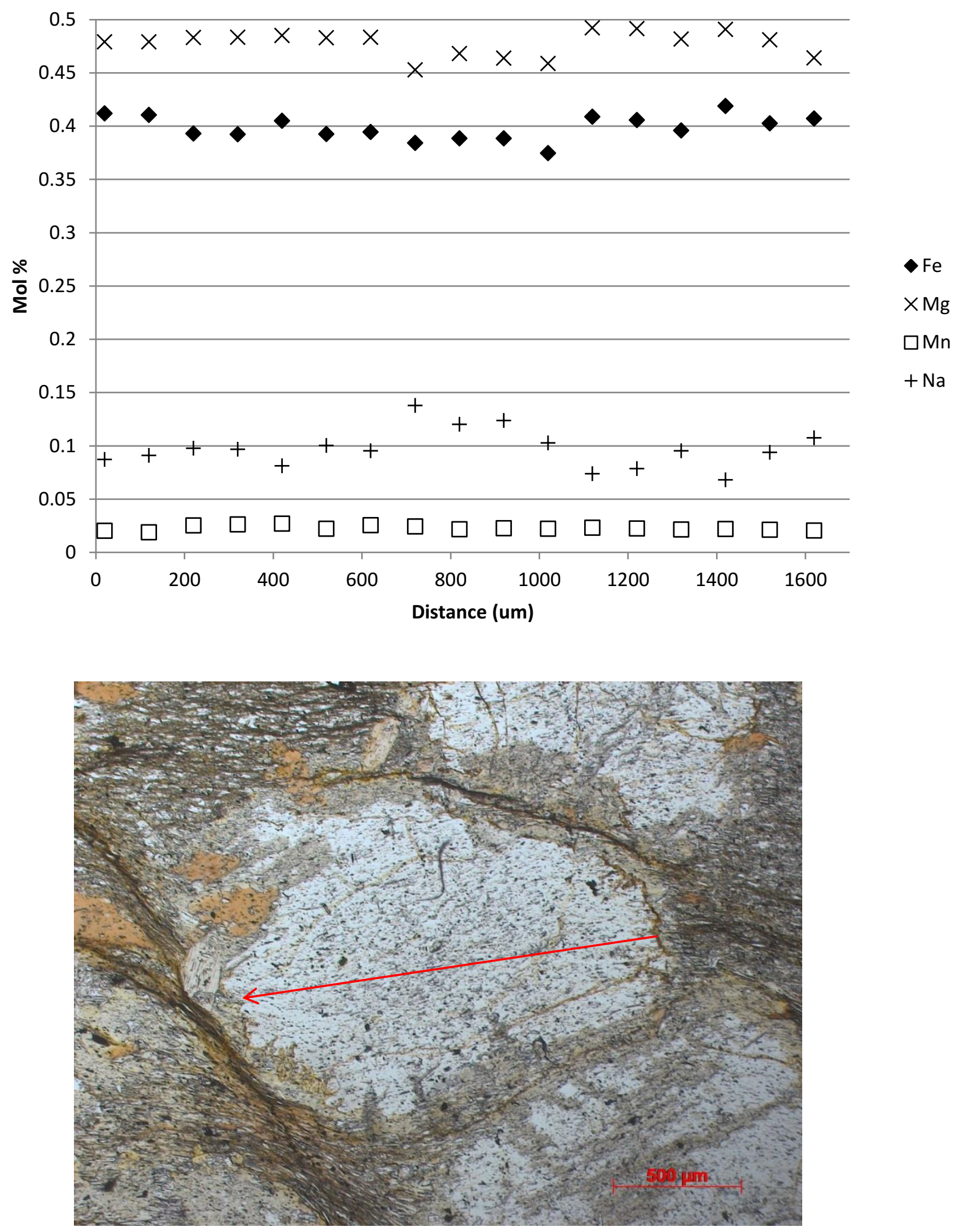
COB3-S1-7 Crd 03
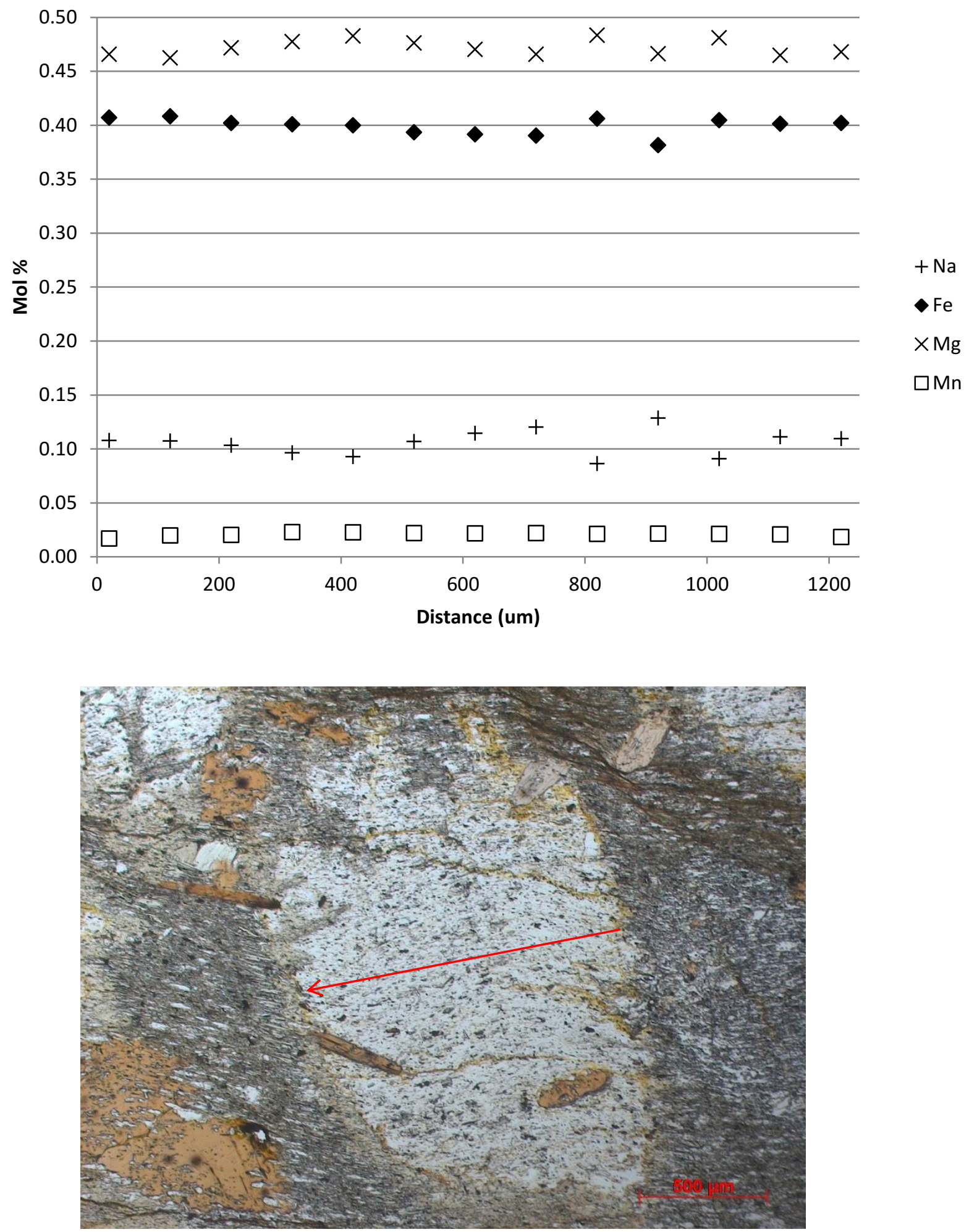
COB3-S1-7 Crd 04
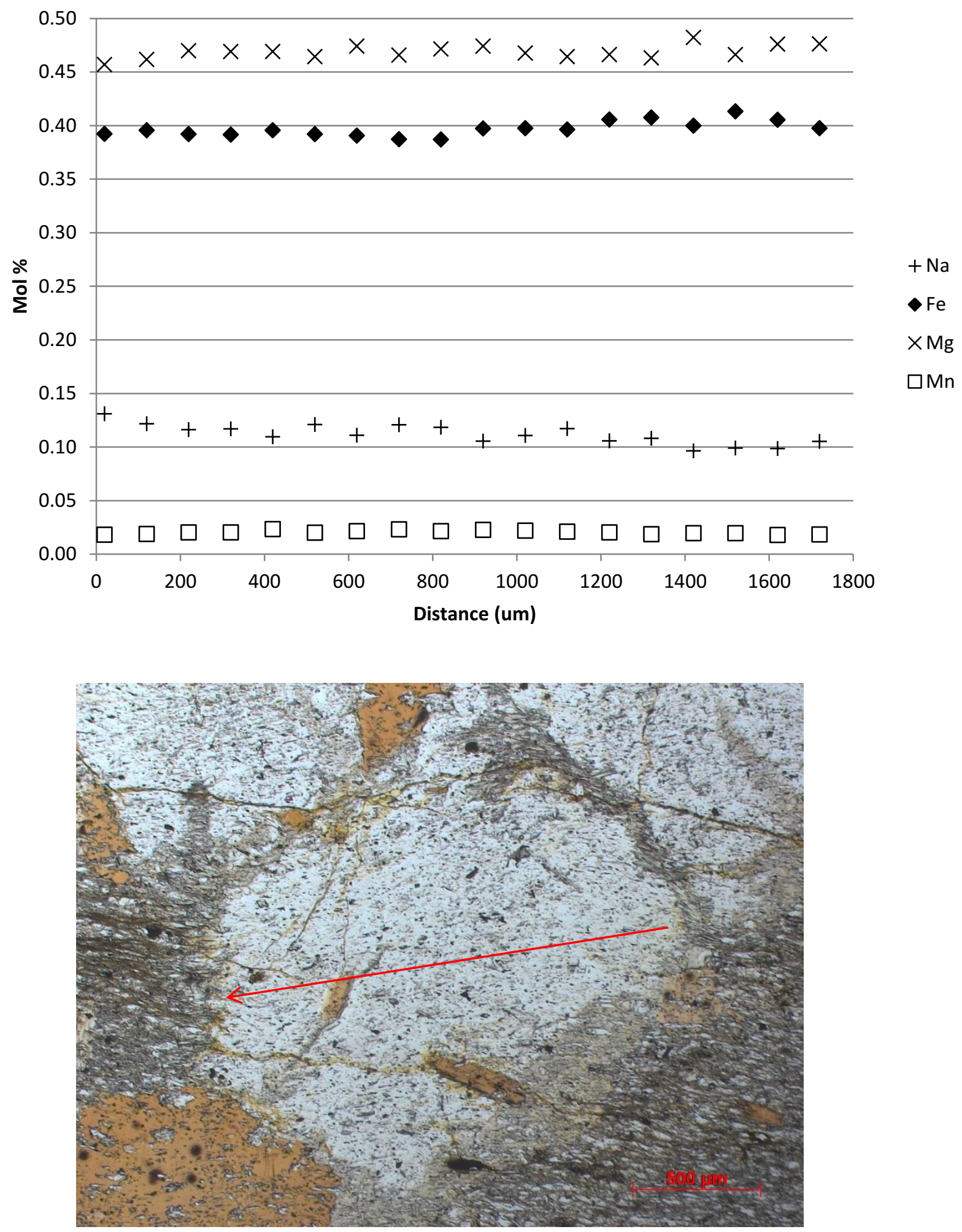


\section{COB-6 Crd 01}
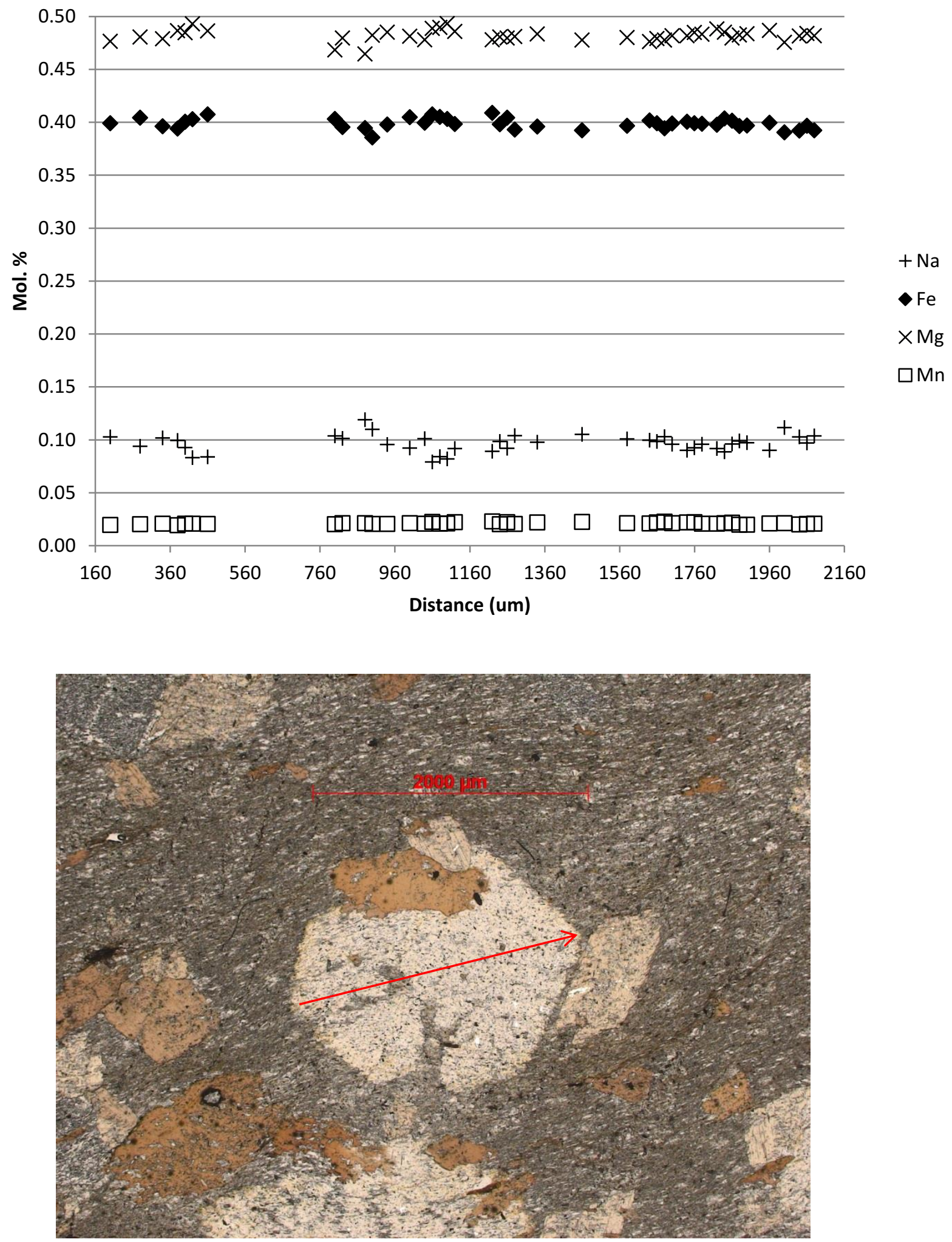


\section{COB-6 Crd 02}
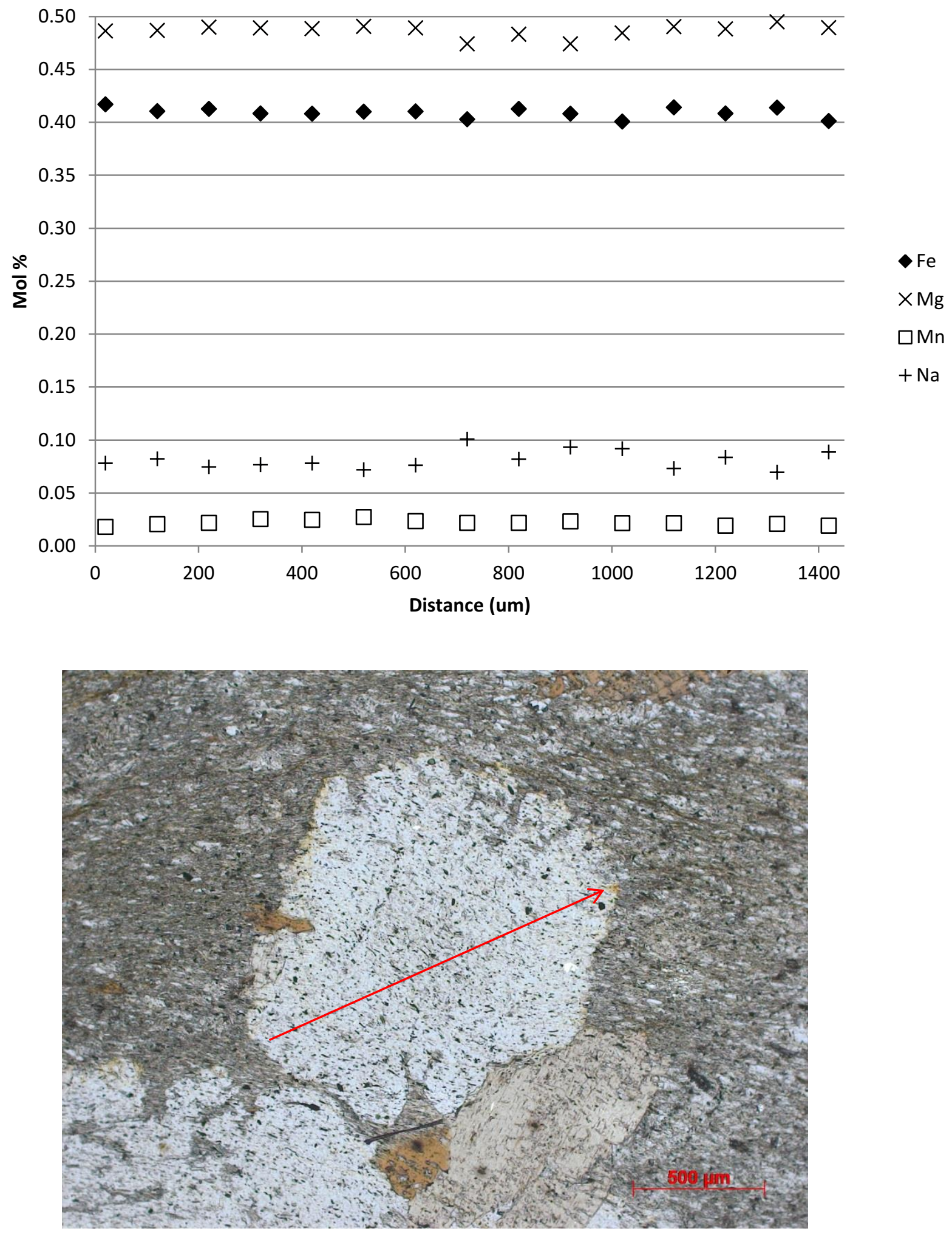


\section{COB-6 Crd 03}
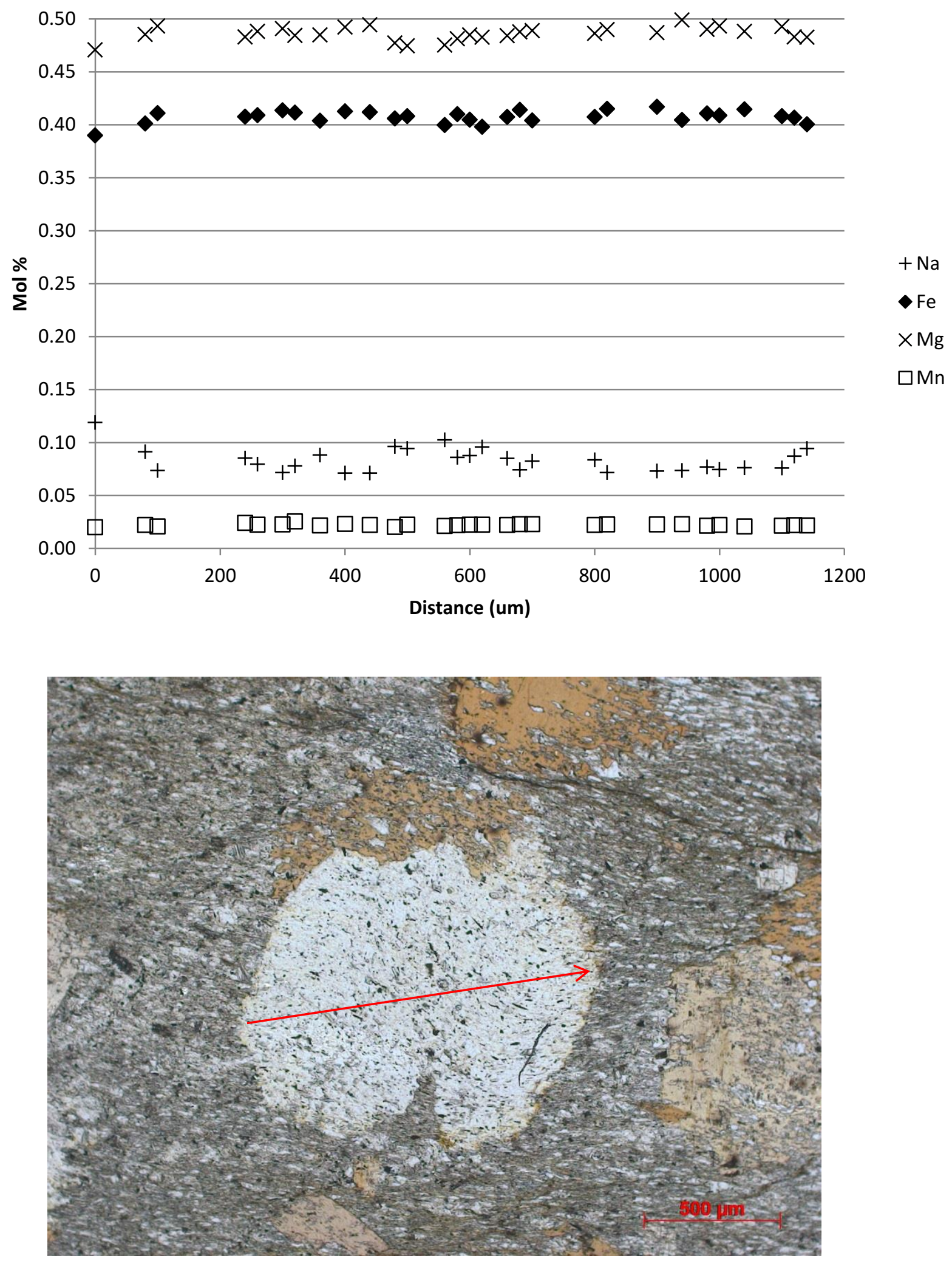


\section{APPENDIX III}

Rock Specific Phase Equilibria

\begin{tabular}{|c|c|}
\hline COB-14 & 161 \\
\hline COB3-S1-1 & 162 \\
\hline COB3-S1-2 & 163 \\
\hline COB3-S1-5 & 164 \\
\hline COB3-S1-7 & 165 \\
\hline COB3-S1-8 & 166 \\
\hline COB3-S1-10 & 167 \\
\hline COB3-S1-12 & 168 \\
\hline COB3-S1-15 & 169 \\
\hline COB-6 & 170 \\
\hline COB-9 & 171 \\
\hline COB-10 & 172 \\
\hline COB-12 & 173 \\
\hline COB-25 & 174 \\
\hline COB-27 & 175 \\
\hline COB-29 & 176 \\
\hline COB-31 & 177 \\
\hline COB2-S2-1 & 178 \\
\hline COB2-S2-2 & 179 \\
\hline COB2-S2-4 & 180 \\
\hline COB2-S2-6 & 181 \\
\hline COB2-S2-7 & 182 \\
\hline COB2-S2-9 & 183 \\
\hline
\end{tabular}




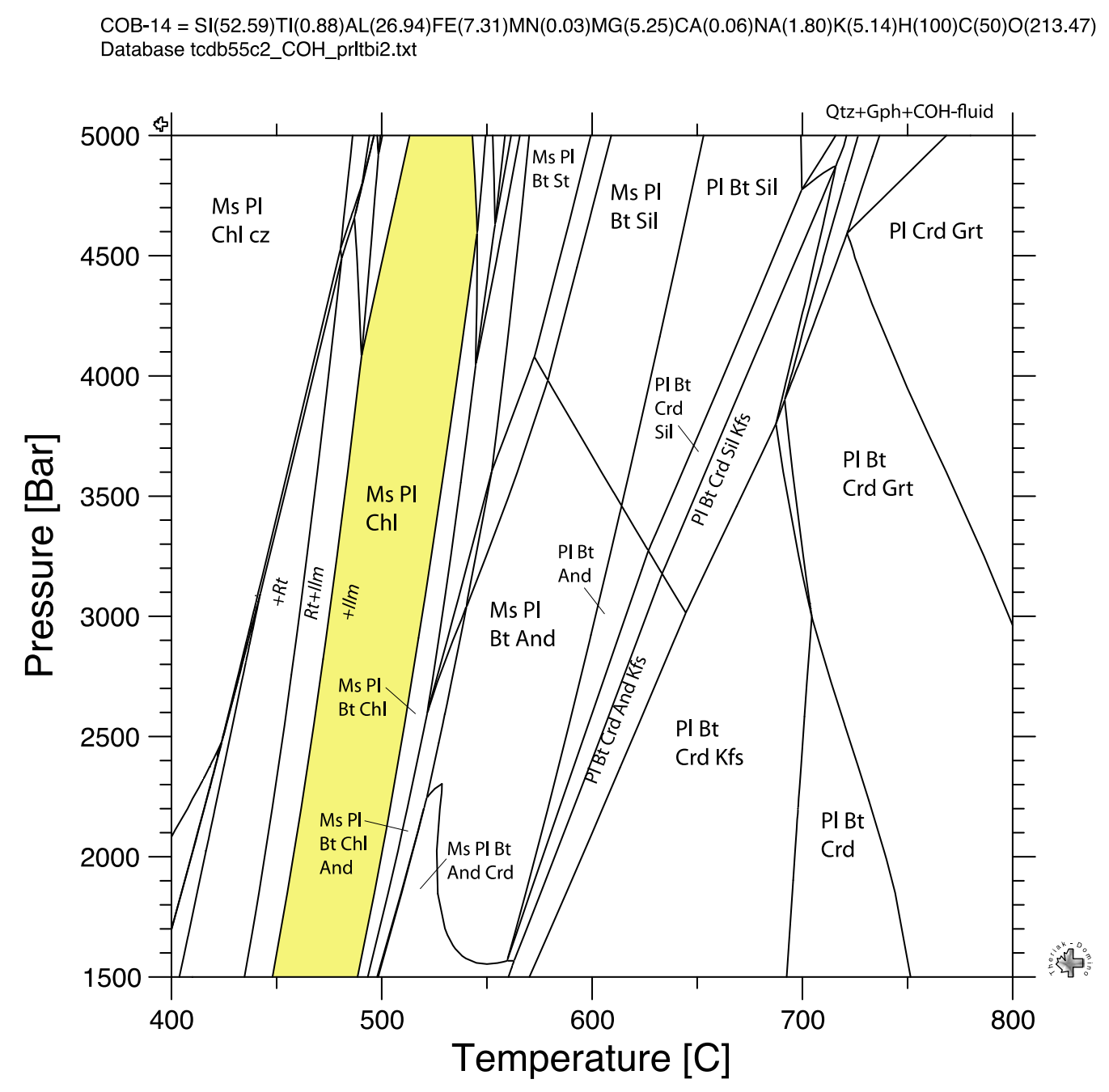




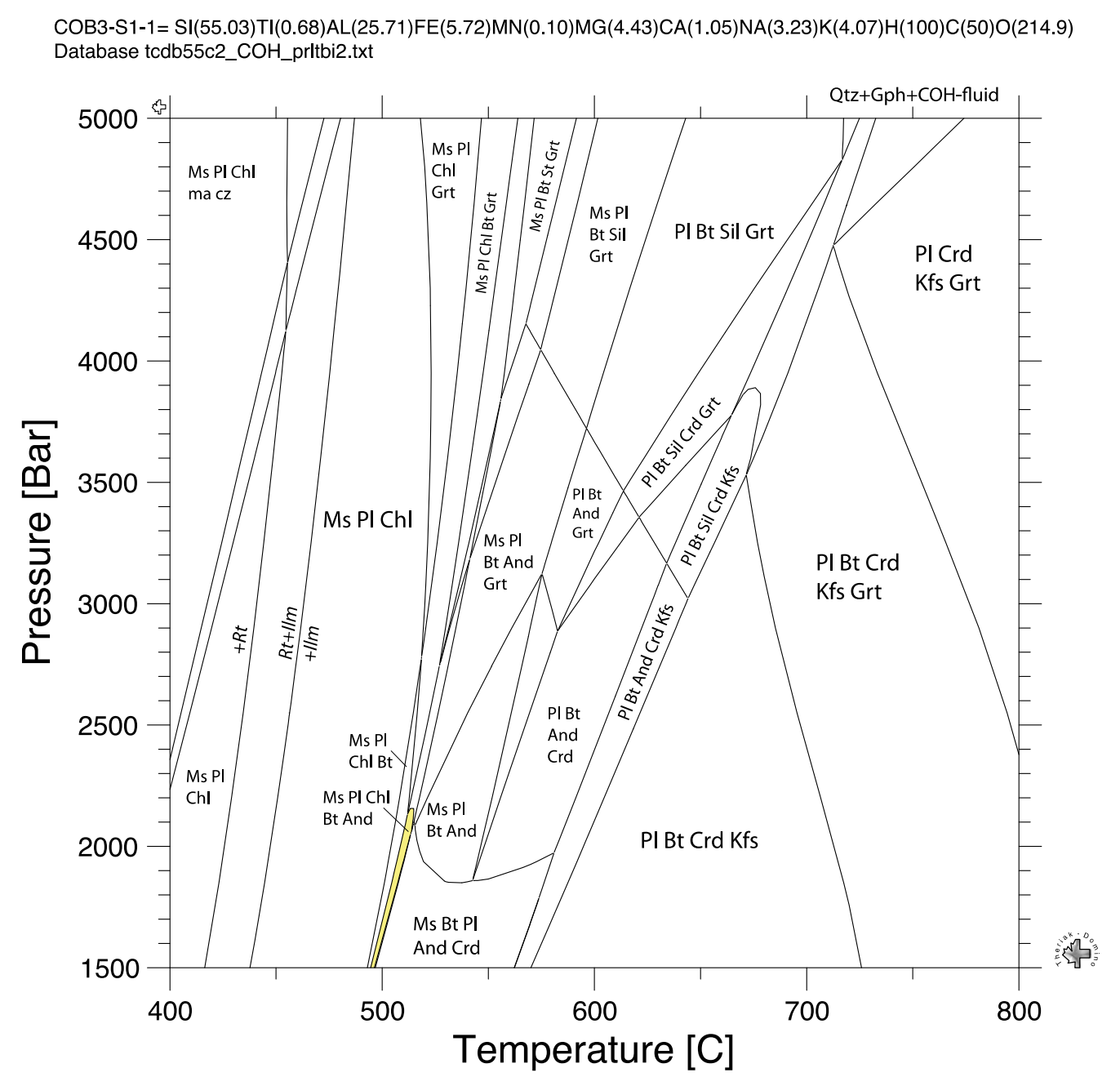


COB3-S1-2= SI(56.27) TI(0.65)AL(25.69)FE(5.81)MN(0.06)MG(4.64)CA(0.43)NA(1.77)K(4.68)H(100)C(50)O(216.54) Database tcdb55c2_COH_prltbi2.txt

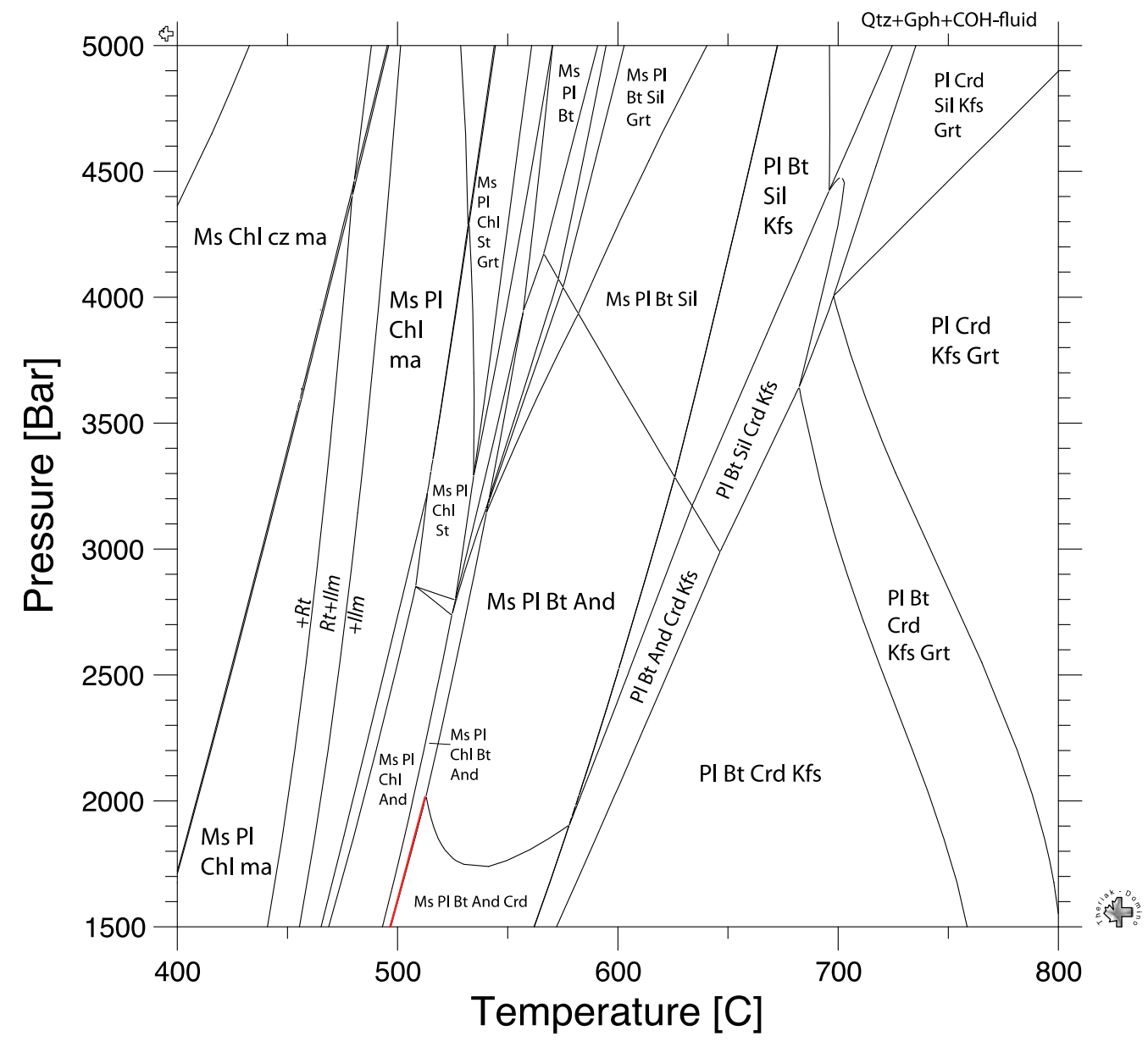


COB3-S1-5 = SI(50.34) TI(0.60)AL(31.21)FE(5.55)MN(0.06)MG(4.00)CA(0.15)NA(2.59)K(5.50)H(100)C(50)O(212.49) Database tcdb55c2_COH_prltbi2.txt

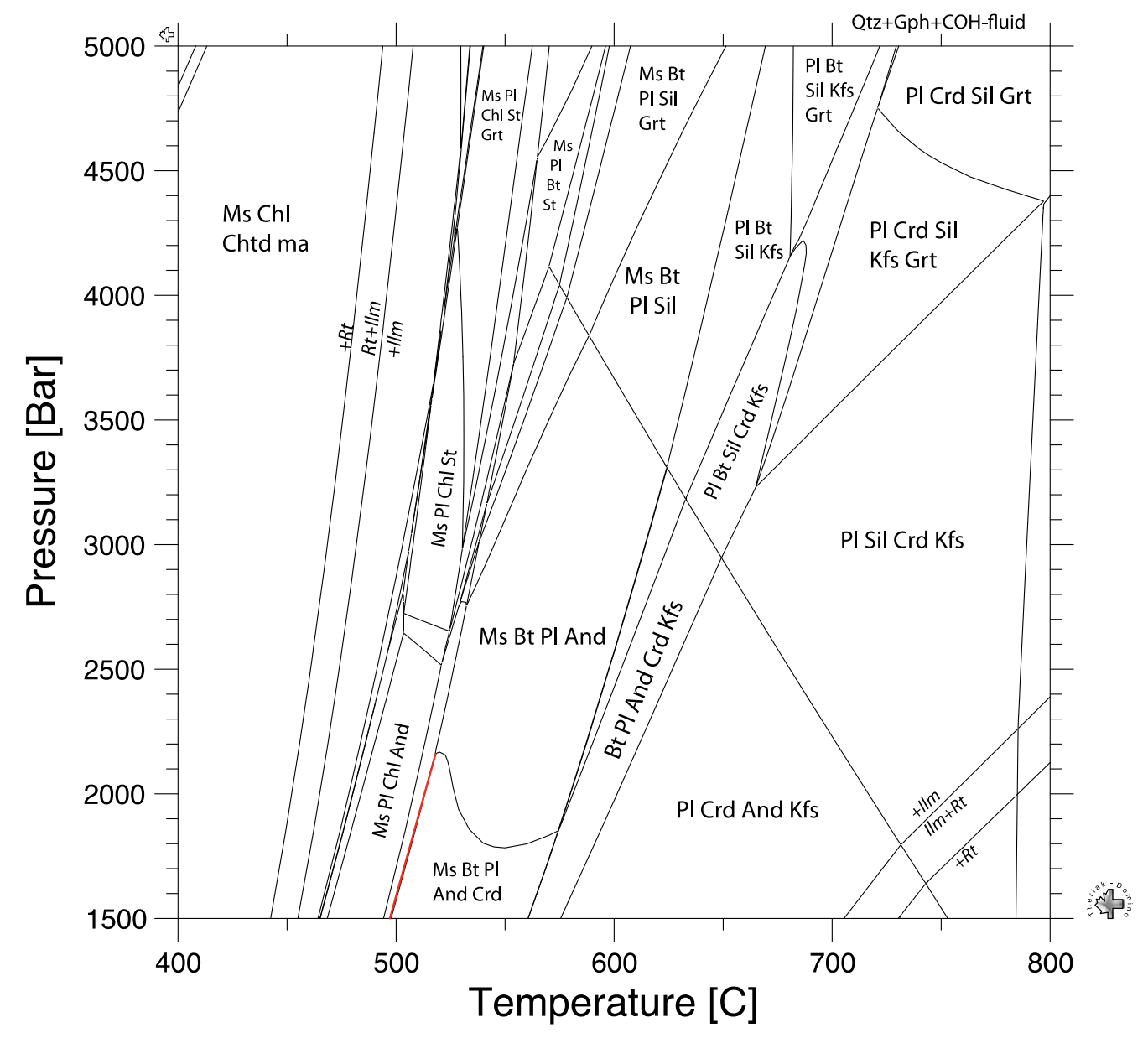


COB3-S1-7= SI(51.07) $\mathrm{TI}(0.67) \mathrm{AL}(27.45) \mathrm{FE}(7.52) \mathrm{MN}(0.16) \mathrm{MG}(5.73) \mathrm{CA}(0.86) \mathrm{NA}(2.72) \mathrm{K}(3.83) \mathrm{H}(100) \mathrm{C}(50) \mathrm{O}(212.19)$ Database tcdb55c2_COH_prltbi2.txt

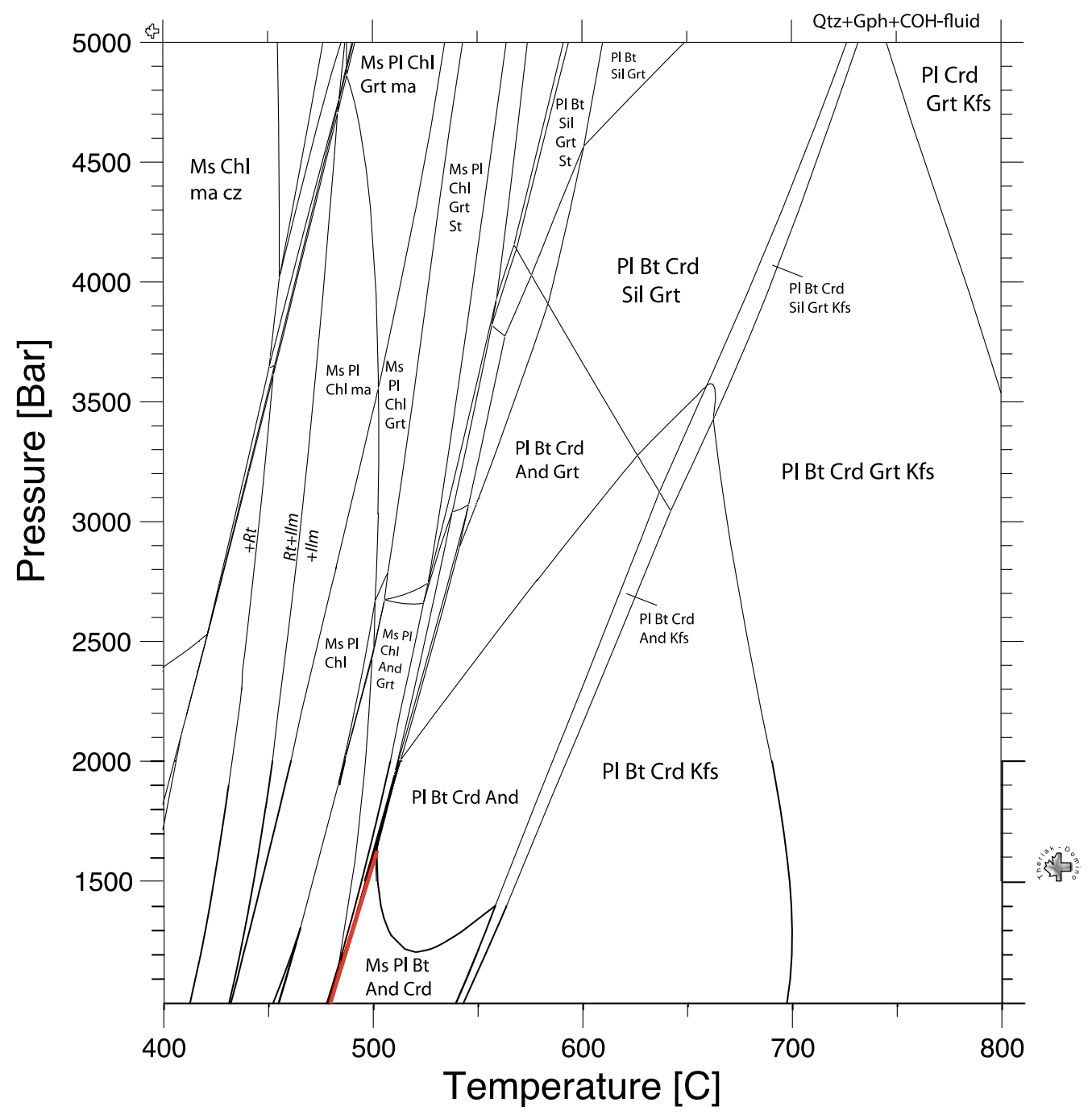




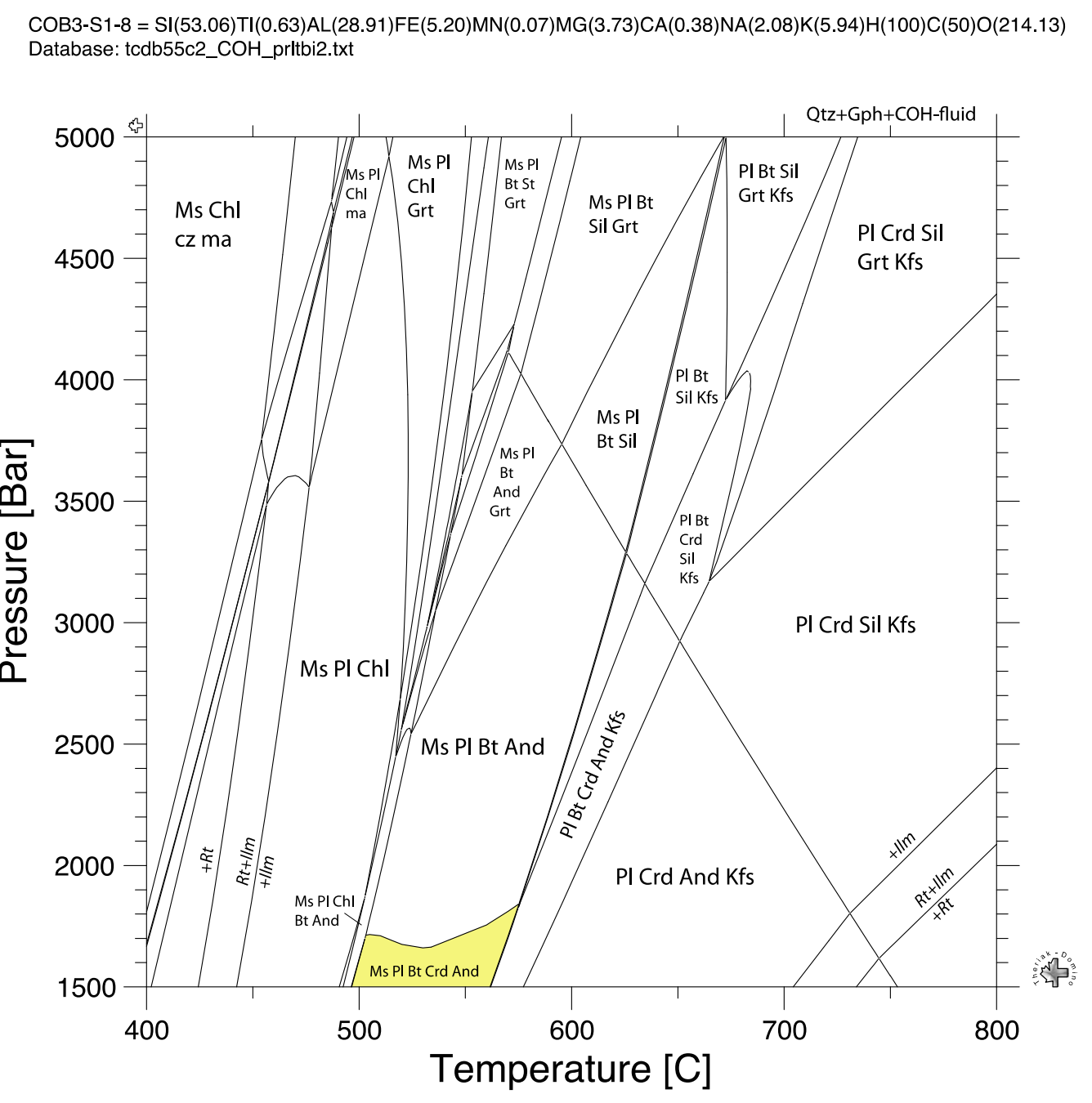




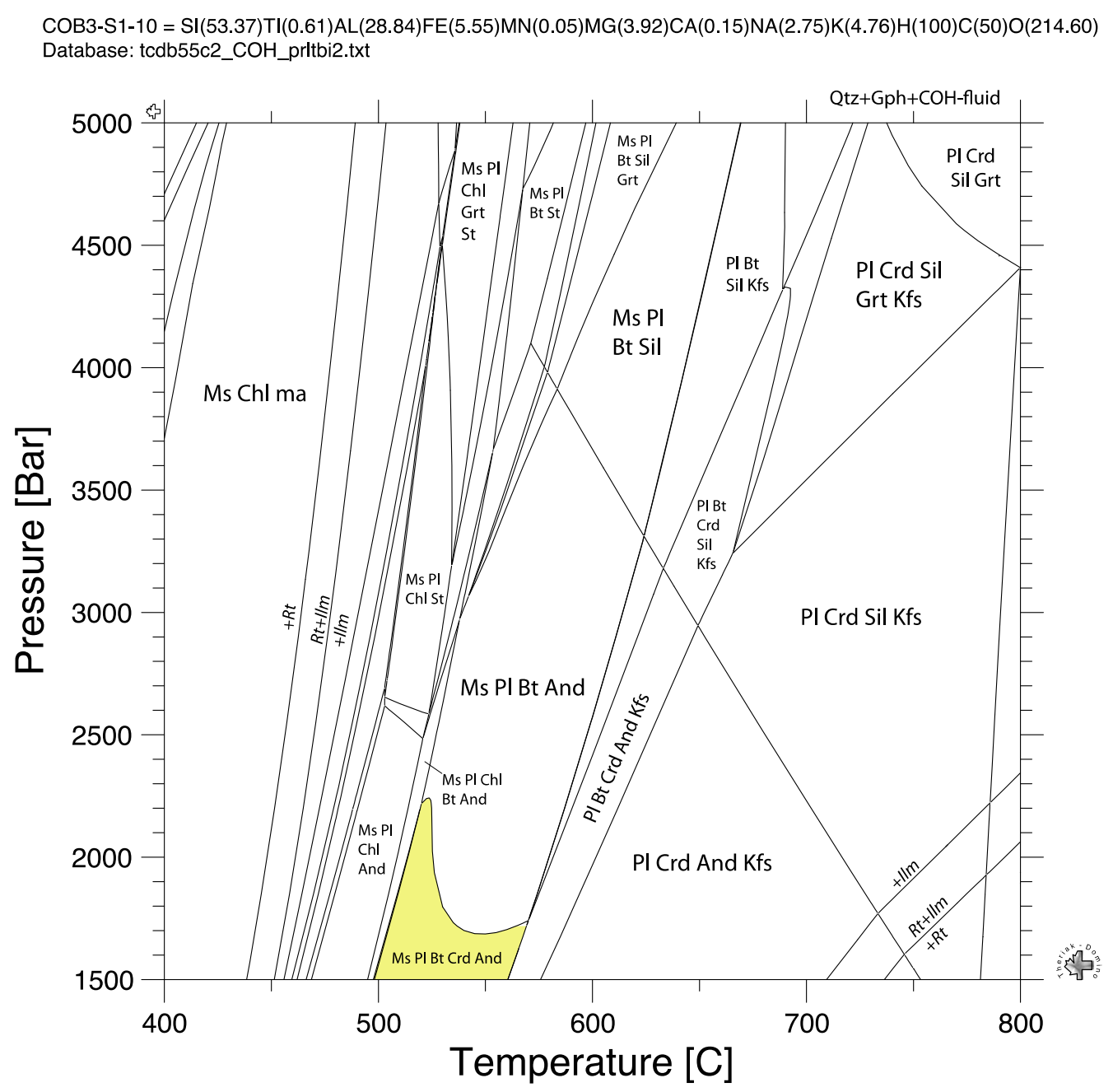




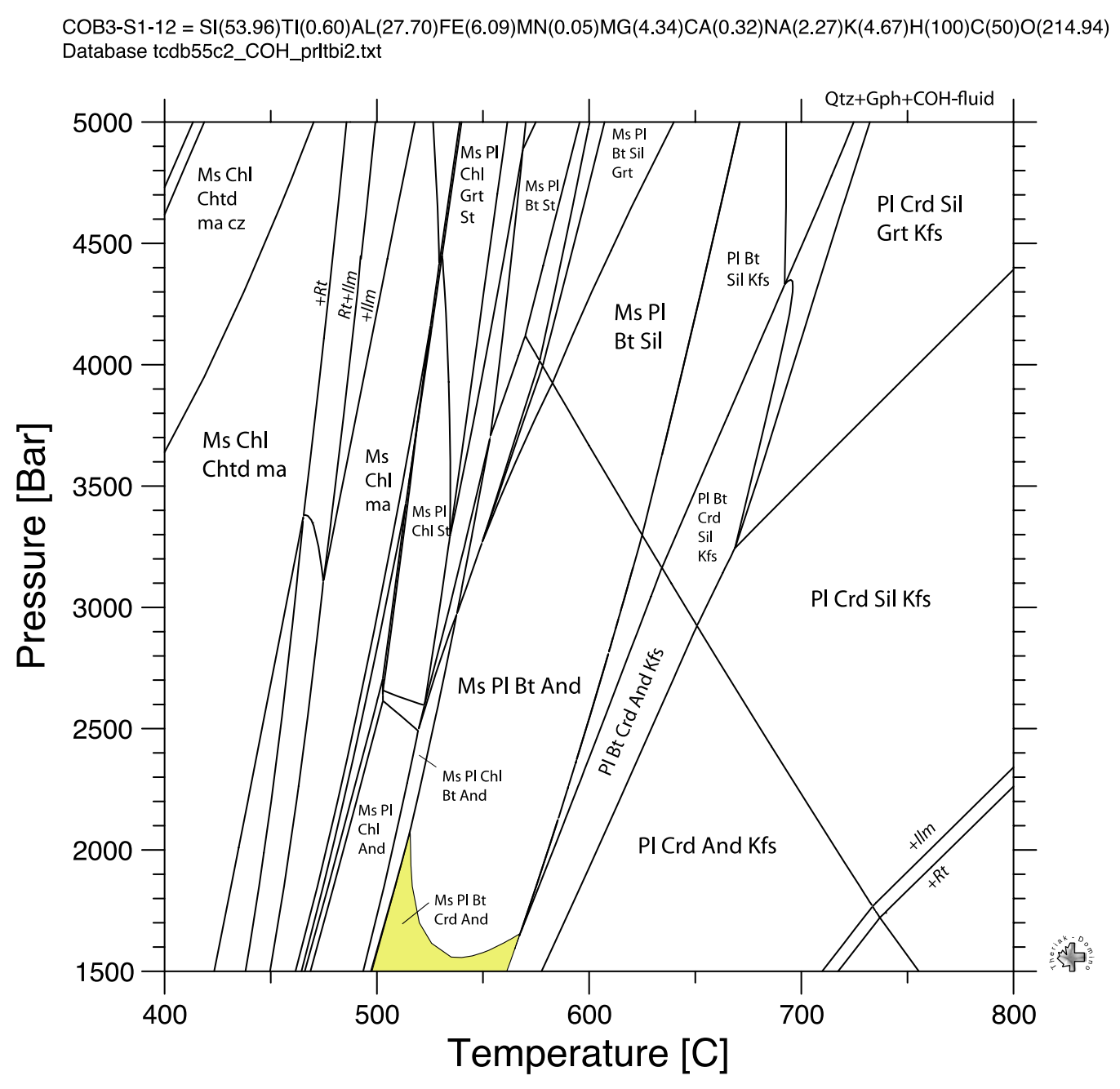


COB3-S1-15 = SI(52.49) $\mathrm{TI}(0.68) \mathrm{AL}(27.40) \mathrm{FE}(6.54) \mathrm{MN}(0.13) \mathrm{MG}(4.98) \mathrm{CA}(0.52) \mathrm{NA}(2.25) \mathrm{K}(4.00) \mathrm{H}(100) \mathrm{C}(50) \mathrm{O}(214.24)$ Database tcdb55c2_COH_prltbi2.txt

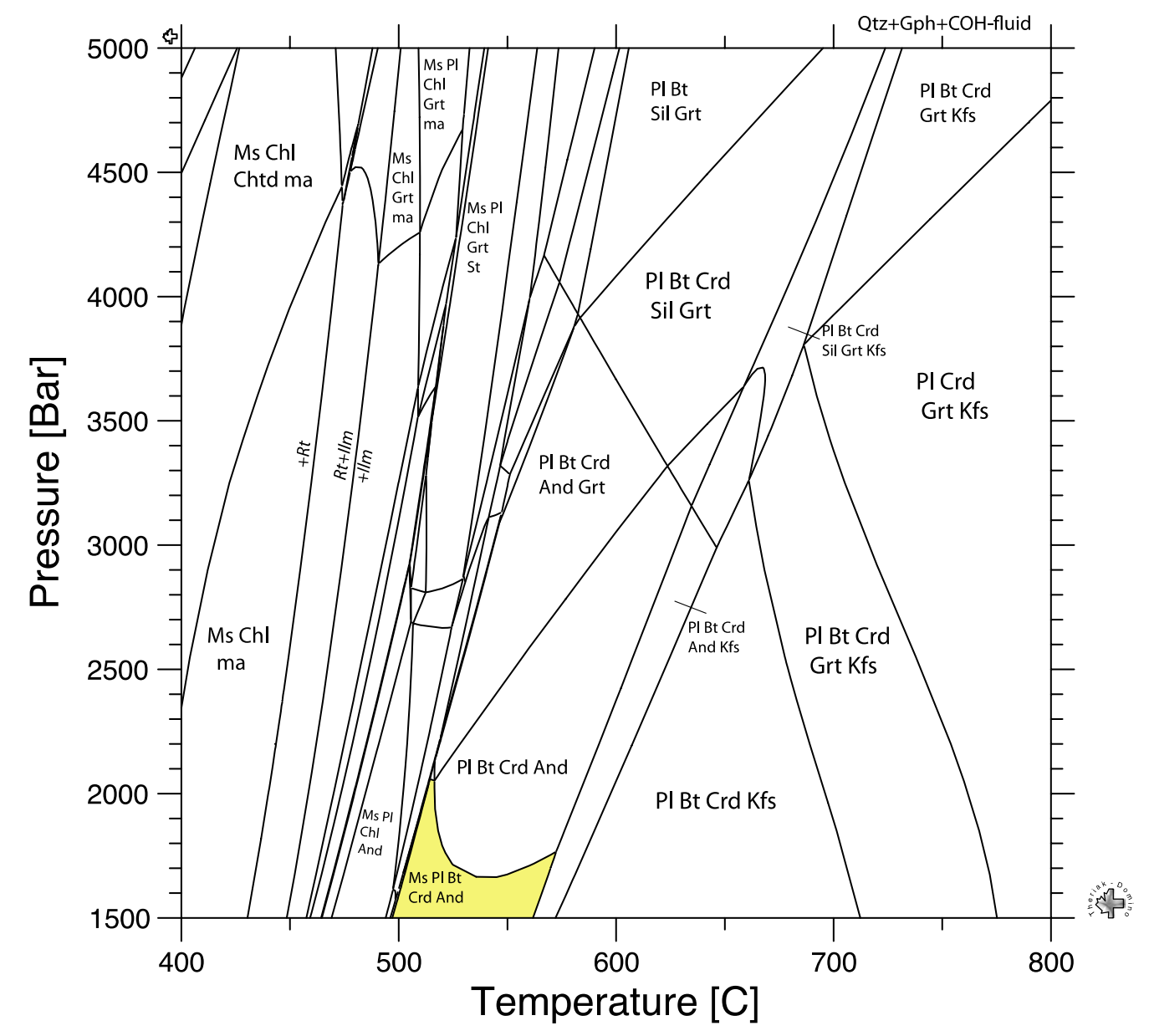




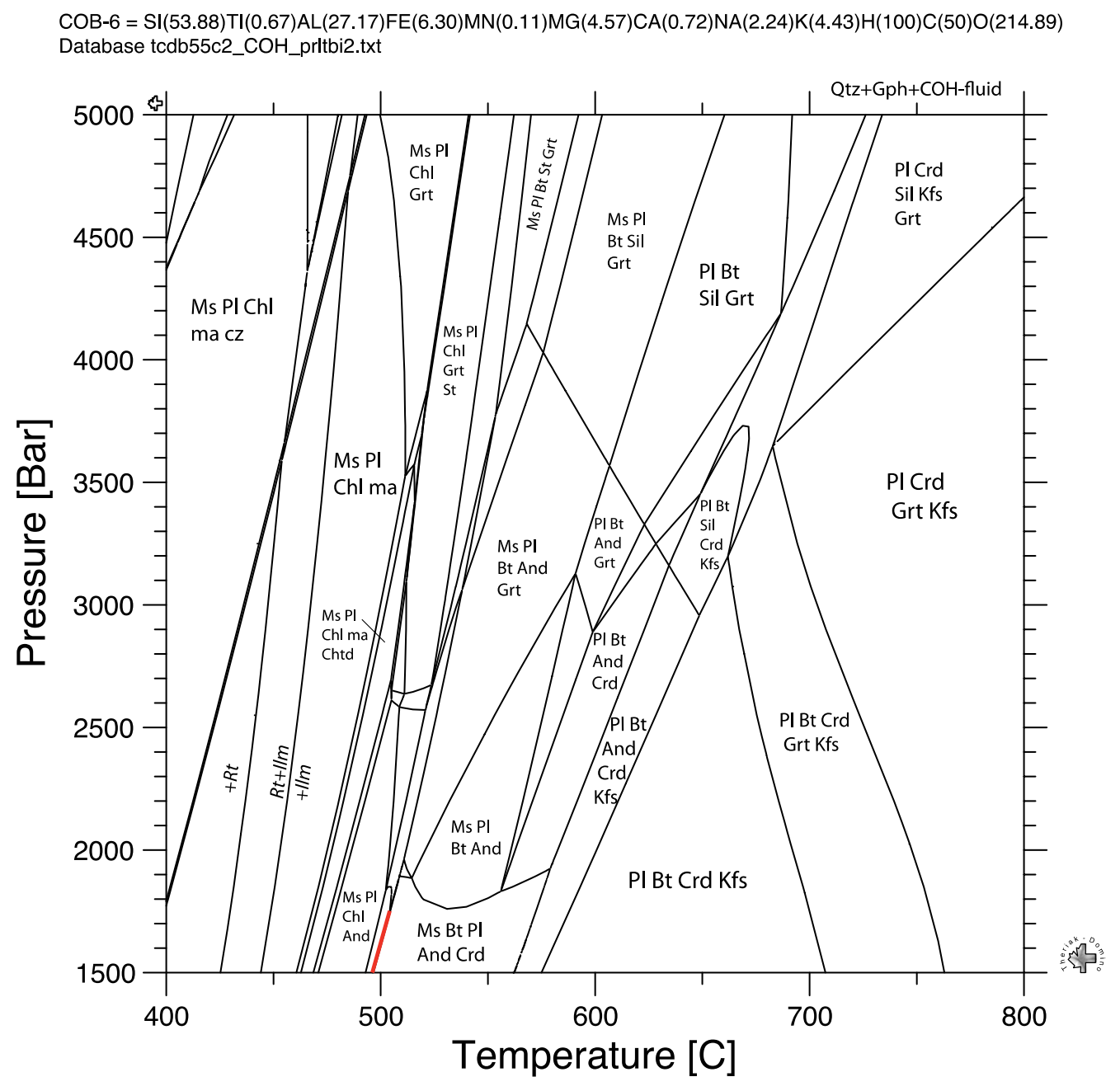



COB-9 = SI(56.84)TI(0.69)AL(23.72)FE(5.67)MN(0.06)MG(4.57)CA(2.10)NA(2.75) $\mathrm{K}(3.60) \mathrm{H}(100) \mathrm{C}(50) \mathrm{O}(216.22)$
Database tcdb55c2_COH_prltbi2.txt

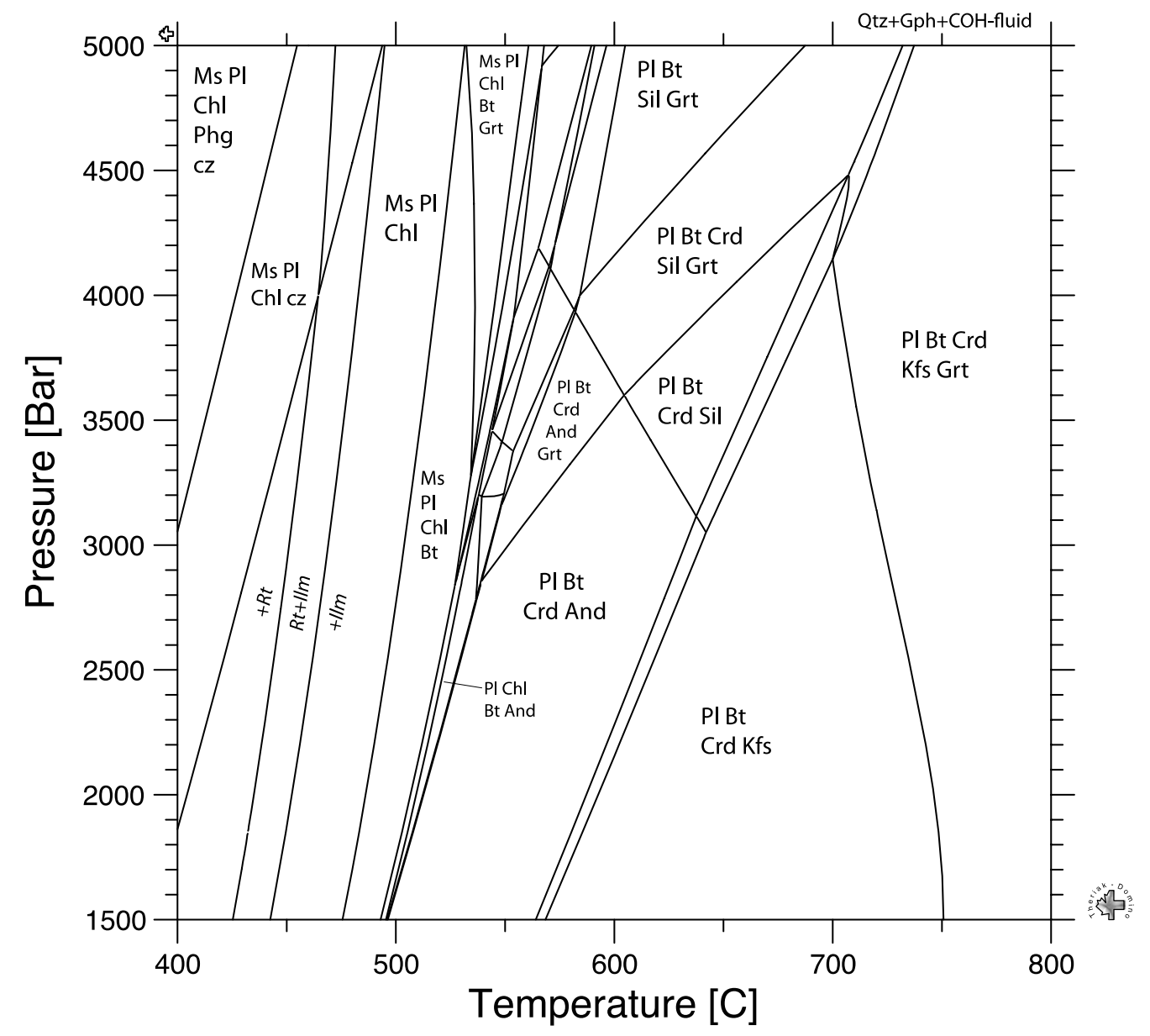




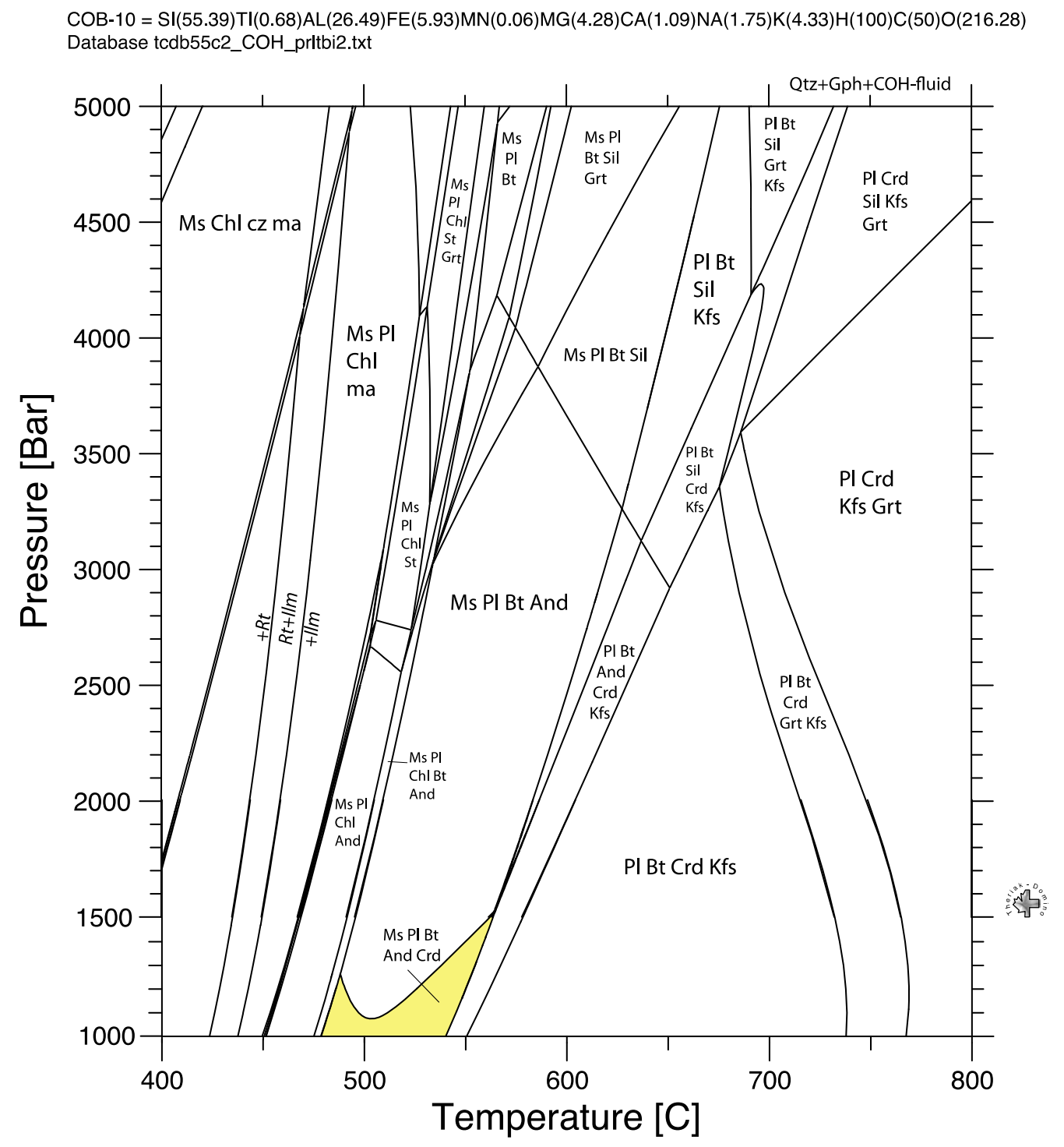




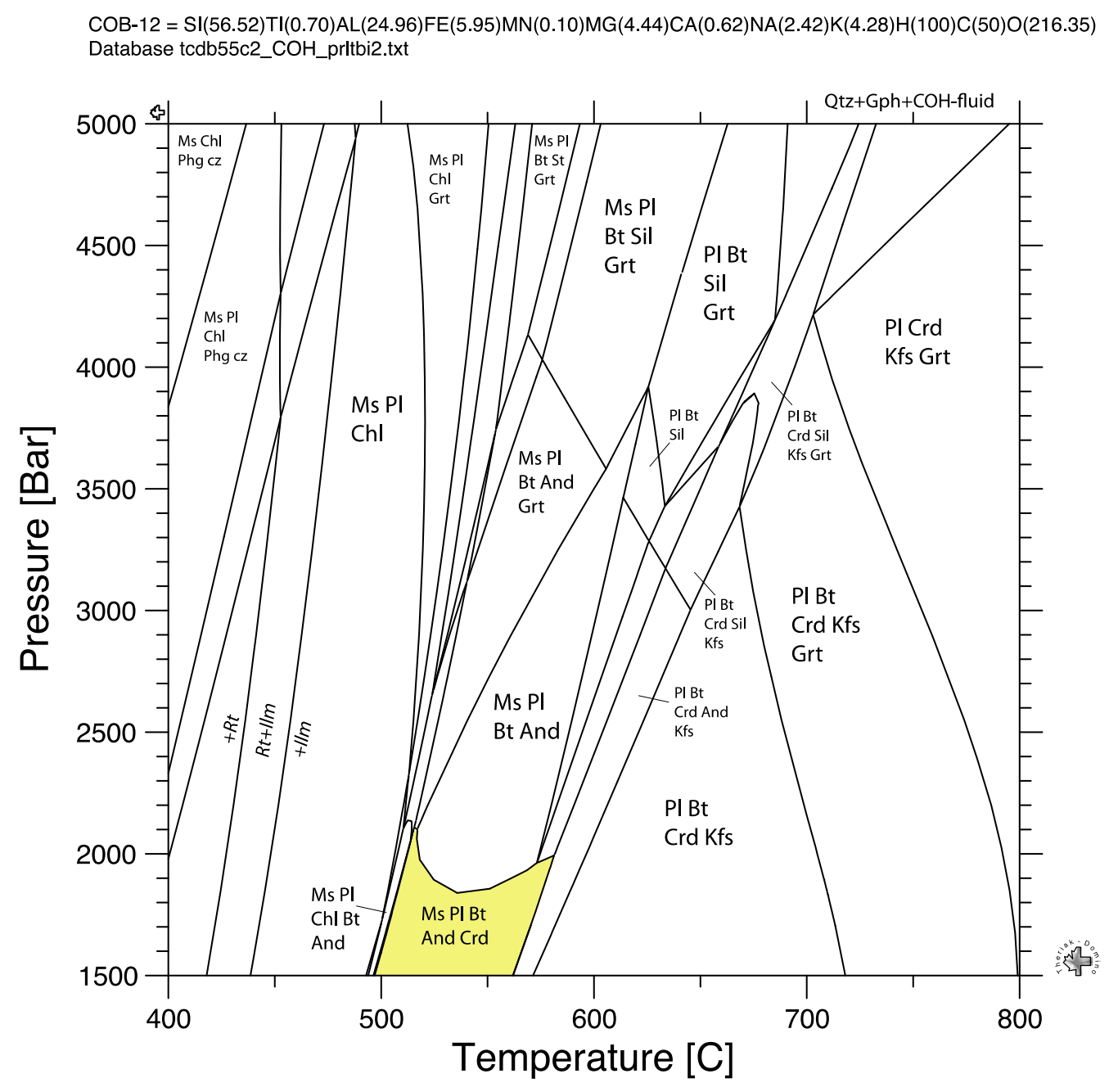




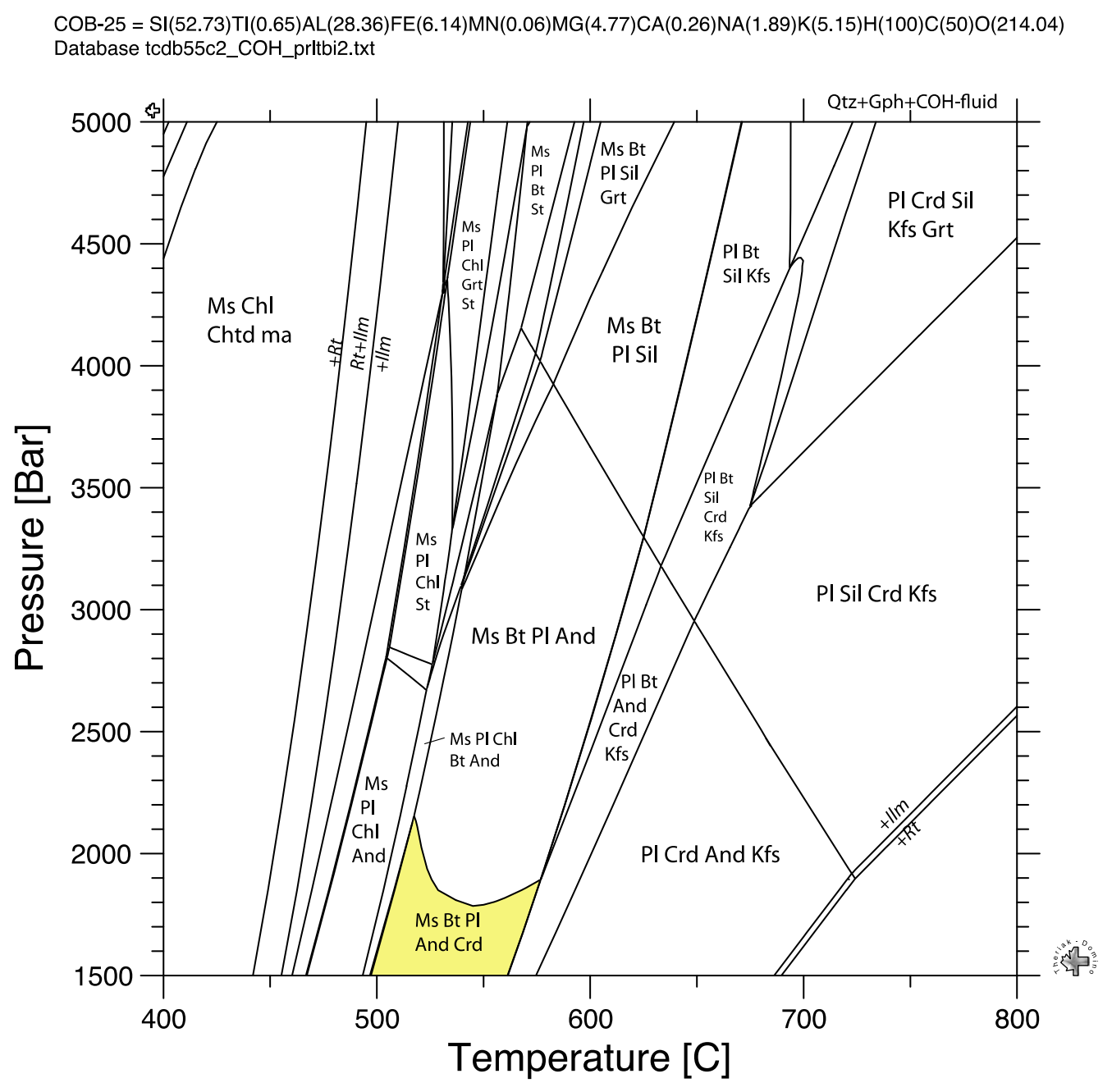




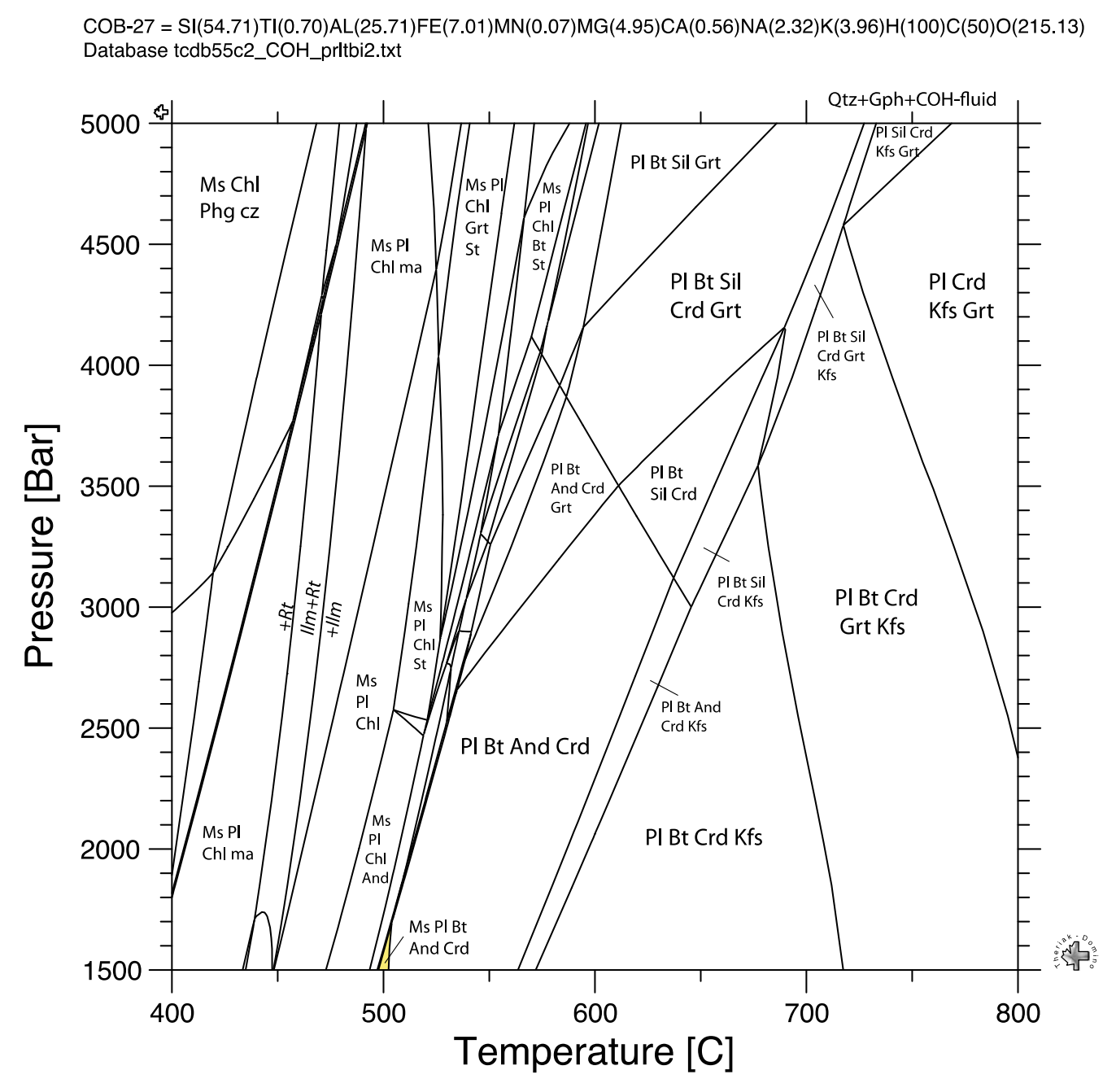




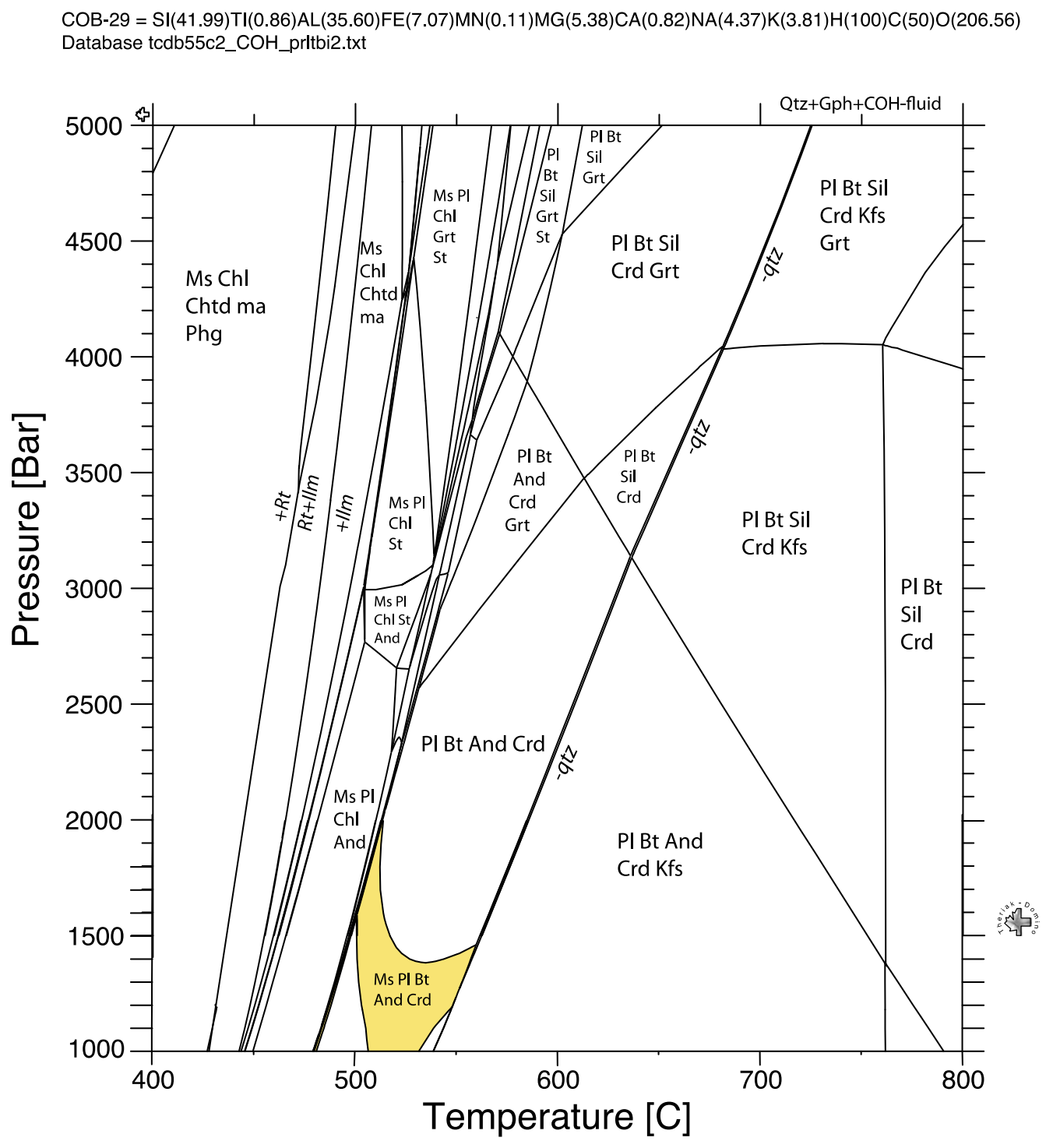




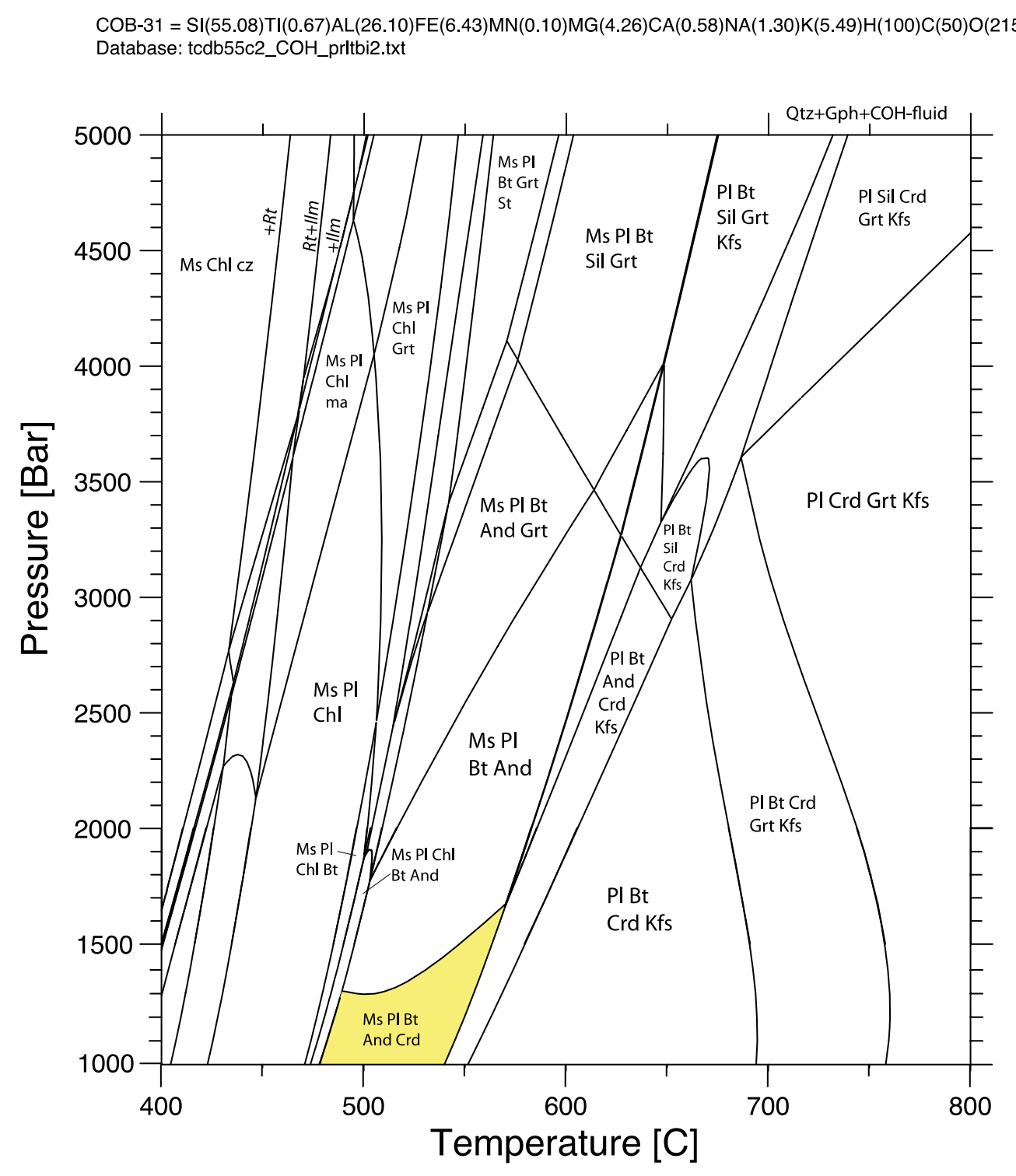




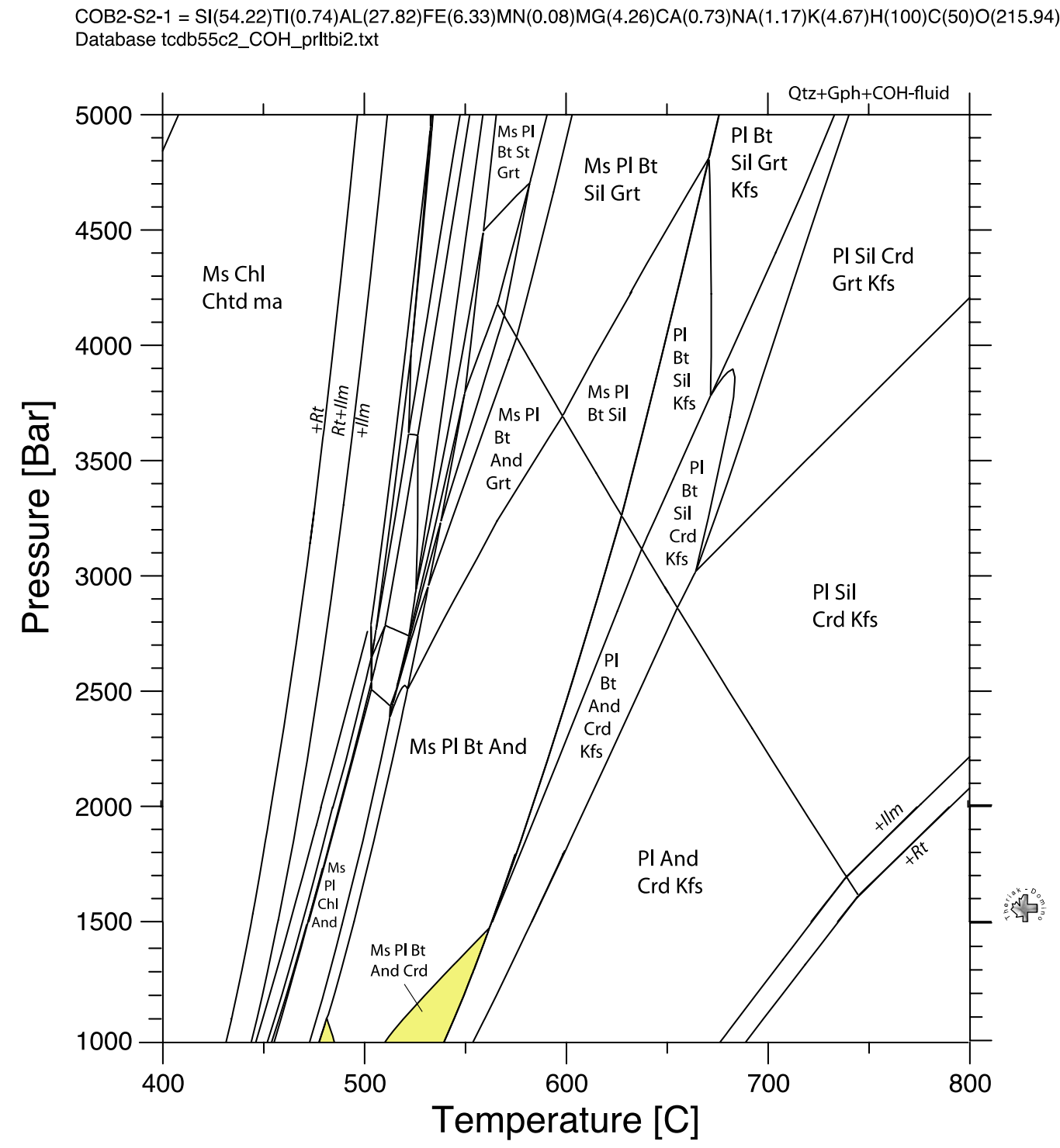


COB2-S2-2 = SI(56.74) $\mathrm{TI}(0.73) \mathrm{AL}(24.10) \mathrm{FE}(7.19) \mathrm{MN}(0.08) \mathrm{MG}(4.82) \mathrm{CA}(0.77) \mathrm{NA}(1.23) \mathrm{K}(4.33) \mathrm{H}(100) \mathrm{C}(50) \mathrm{O}(216.74)$ Database tcdb55c2_COH_prltbi2.txt

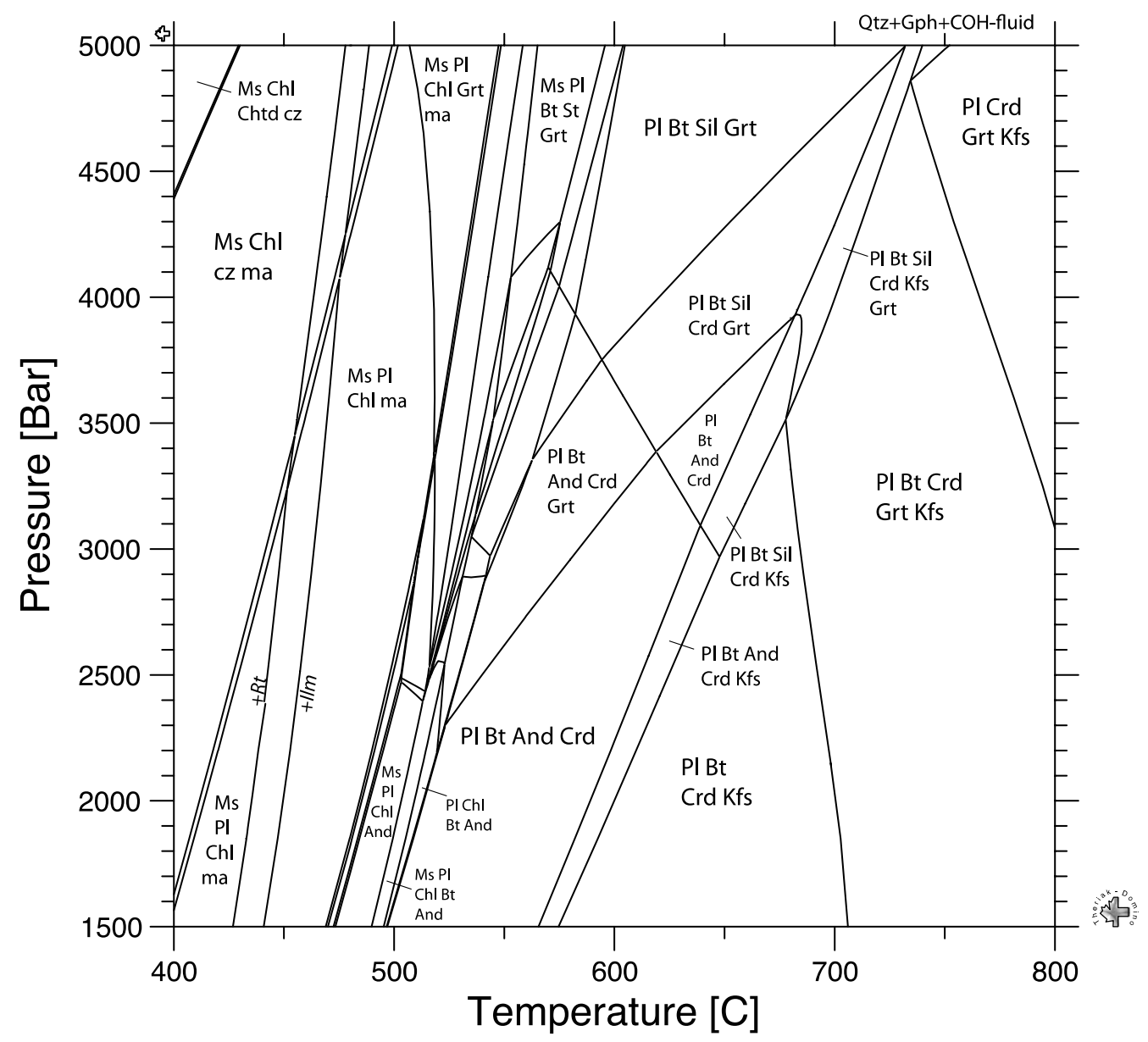




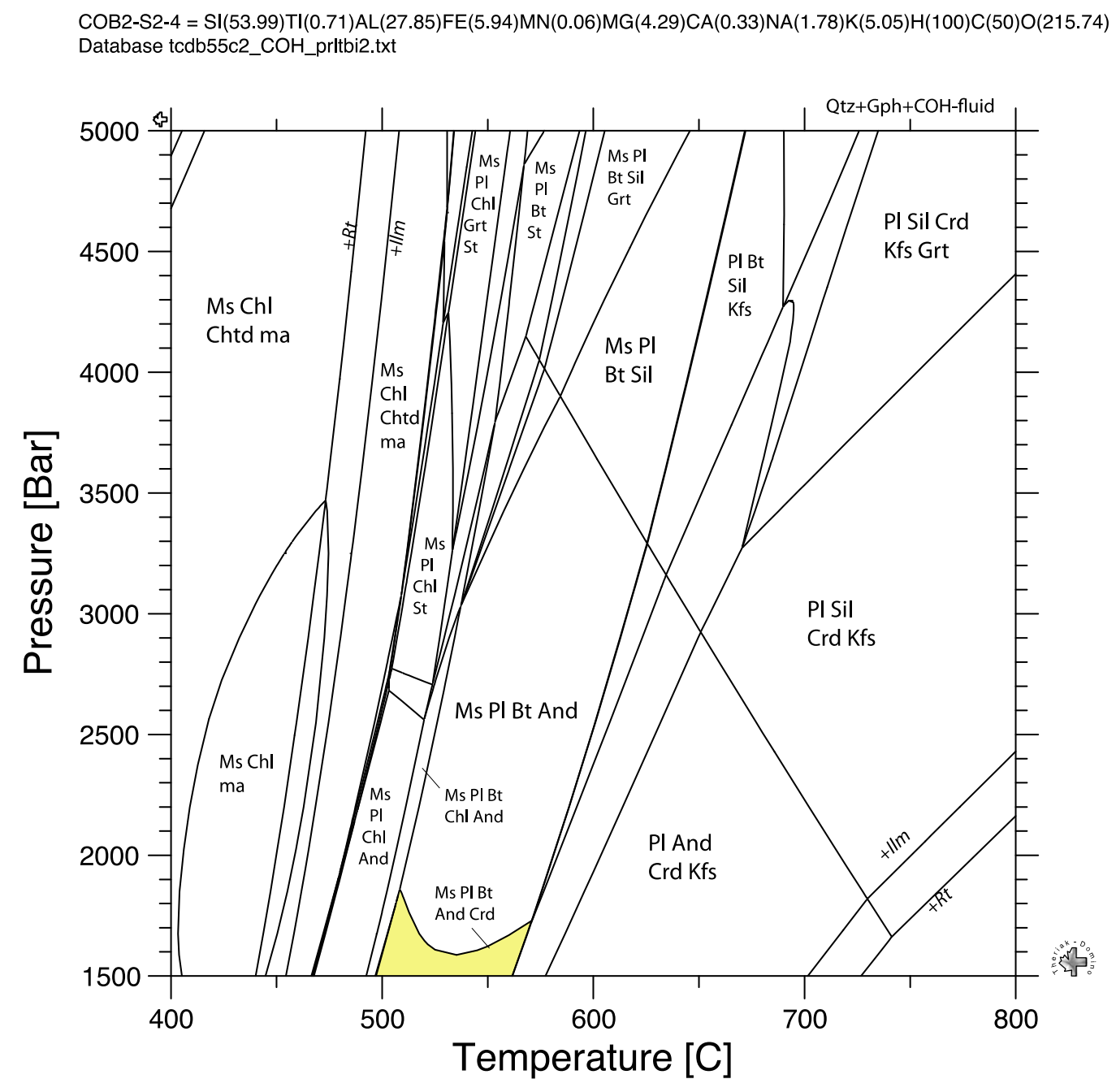




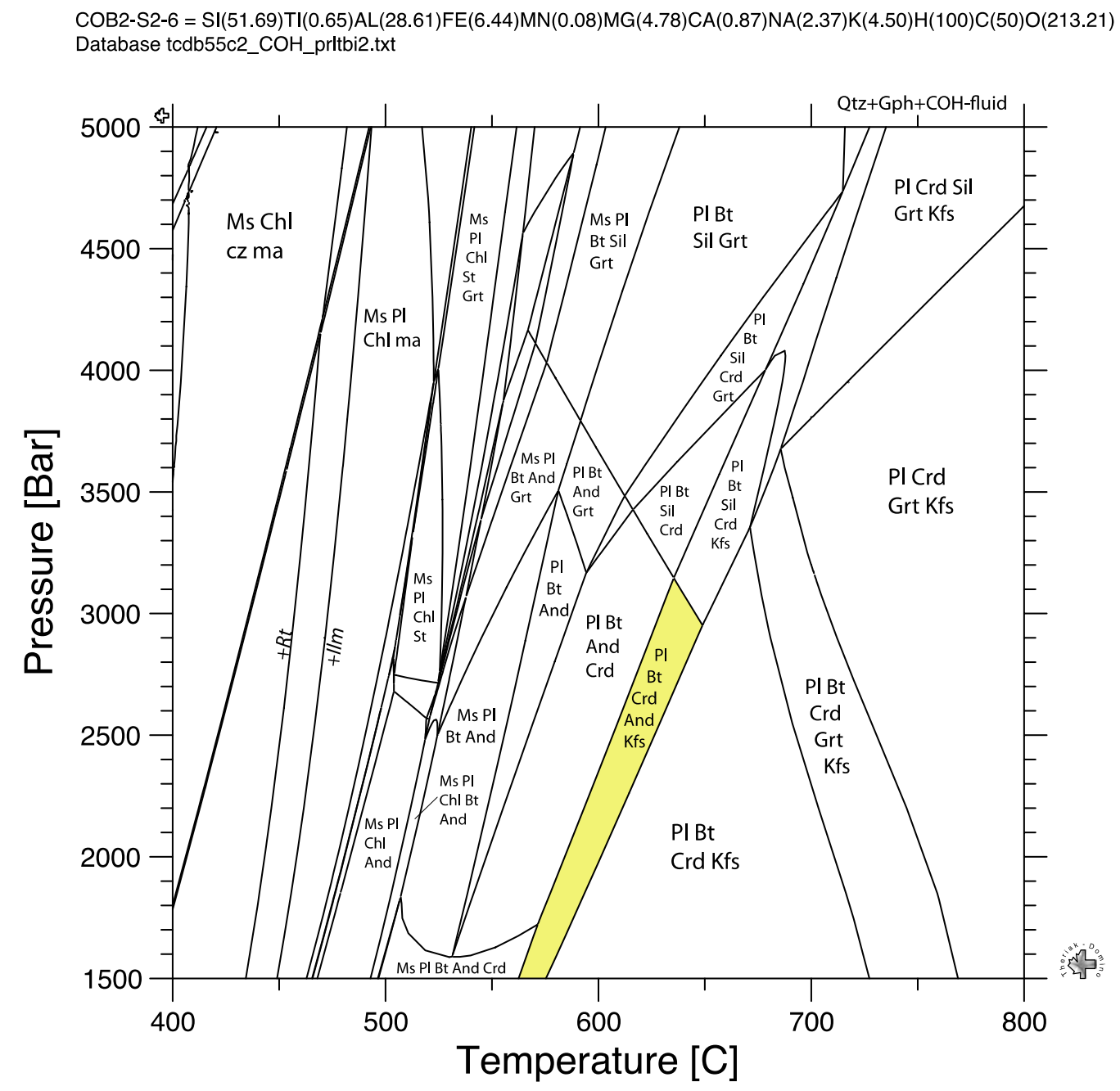


COB2-S2-7 = SI(56.15) TI(0.52)AL(28.35)FE(3.31)MN(0.06)MG(2.72)CA(0.35)NA(2.37)K(6.18)H(100)C(50)O(216.57) Database tcdb55c2_COH_prltbi2.txt

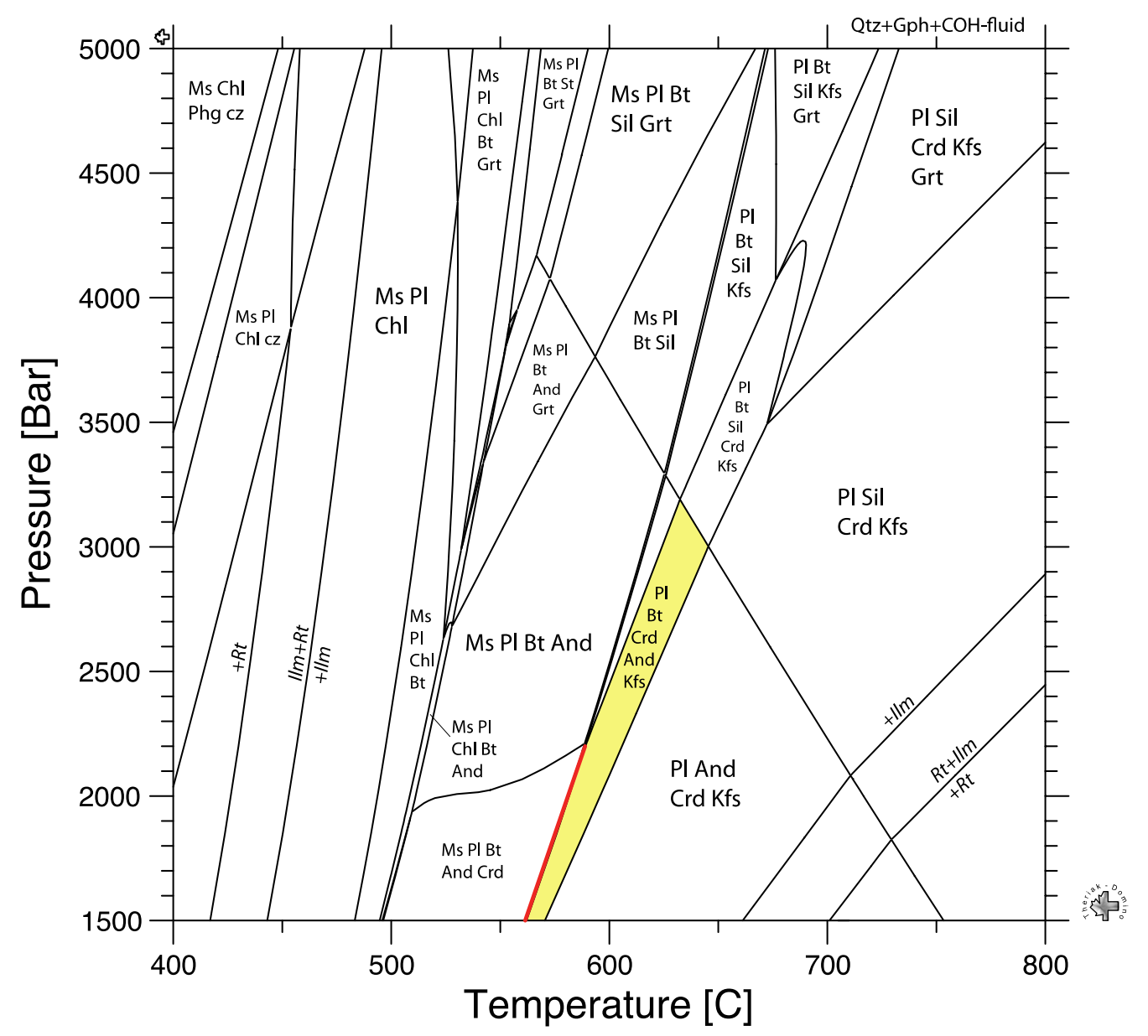




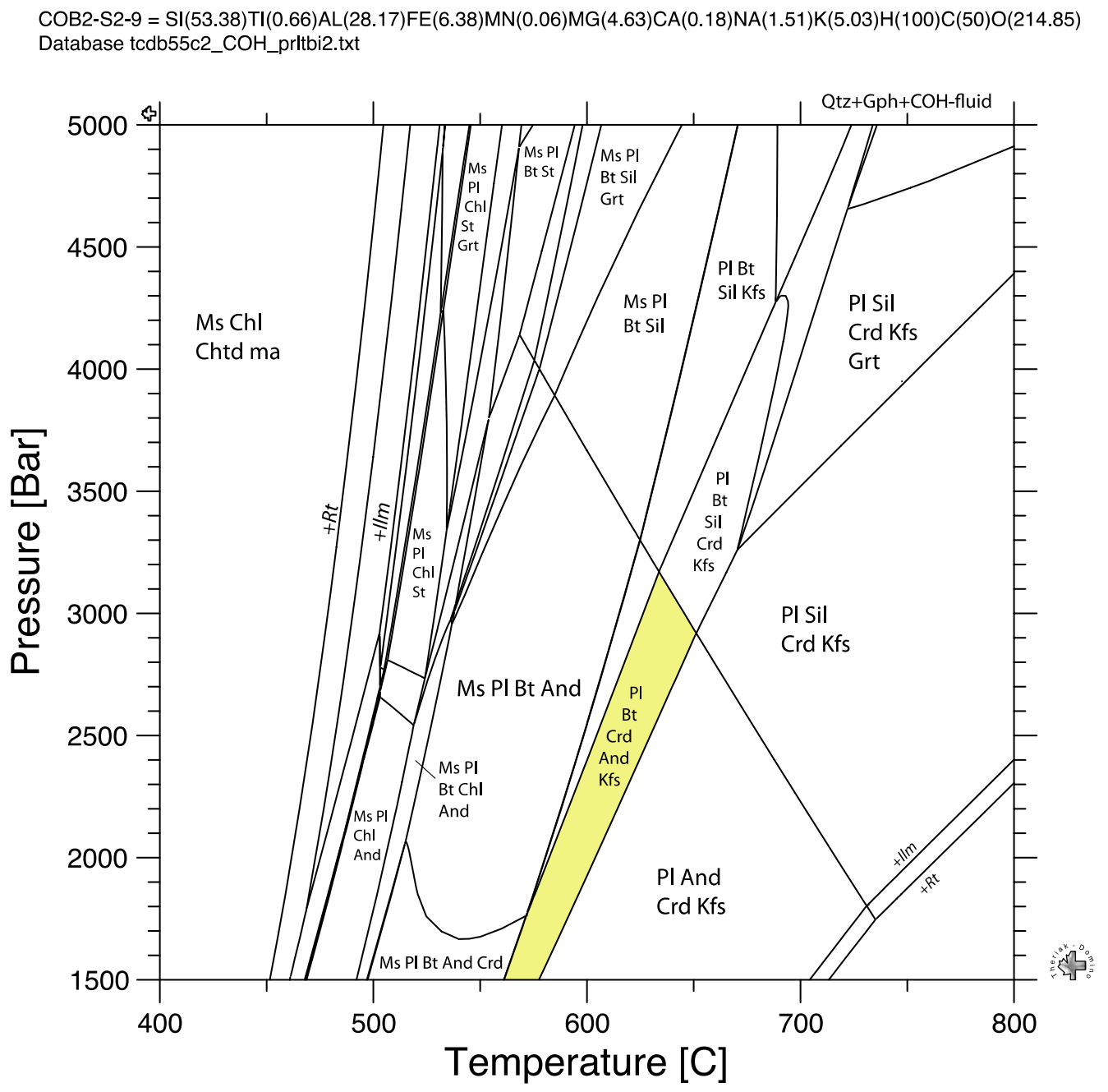

